AUTARQUIA ASSOCIADA À UNIVERSIDADE DE SÃO PAULO

Cálculo da fração de vazio em escoamentos bifásicos (gás/líquido) a partir da identificação de bolhas em imagens digitais

Pedro Luiz Santos Serra

Tese apresentada como parte dos requisitos para obtenção do Grau de Doutor em Ciências na Área de Tecnologia Nuclear - Reatores

Orientador:

Prof. Dr. Roberto Navarro de Mesquita 


\section{INSTITUTO DE PESQUISAS ENERGÉTICAS E NUCLEARES}

Autarquia associada à Universidade de São Paulo

Cálculo da fração de vazio em escoamentos bifásicos (gás/líquido) a partir da identificação de bolhas em imagens digitais

\section{Pedro Luiz Santos Serra}

Tese apresentada como parte dos requisitos para obtenção do Grau de Doutor em Ciências na Área de Tecnologia Nuclear - Reatores

Orientador:

Prof. Dr. Roberto Navarro de Mesquita

Versão Corrigida

Versão Original disponível no IPEN

São Paulo 


\section{Lúcia e Caio,}

a vocês, pelo carinho, amor e compreensão em todas as fases desta tese de doutorado mas,em especial, pelo apoio recebido nos momentos mais críticos de sua realização. 


\section{AGRADECIMENTOS}

Pessoas especiais foram marcantes nessa jornada. Algumas me indicaram o caminho e como abrir portas, outras transformaram momentos de angústia em incentivo, motivação possibilitando realizações e, por fim, aquelas que não economizaram esforços em suas orientações convertendo situações difíceis, impasses e condições obscuras em soluções.

Ao Dr. Régis Cortez Bueno por mostrar e me indicar o caminho a seguir. Através dela foi possível a realização destes estudos no Centro de Engenharia Nuclear CEN do Instituto de Pesquisas Energéticas e Nucleares - IPEN e pela parceria, companheirismo e amizade.

Ao Dr. Paulo Henrique Mazotti pela abertura aos debates que resultaram na solução de muitos problemas. Pela ajuda na construção do módulo gerador de escoamento bifásico para aplicação no reator e, principalmente, no incentivo e motivação nos momentos de desânimo e ausência de resultados justificáveis.

Em especial ao Dr. Roberto Navarro de Mesquita na condução deste trabalho, apontando caminhos em situações difíceis, mostrando opções em ocasiões de resultados não convincentes, fomentando com dados e revertendo situações que se apresentavam sem possibilidades de evolução. Uma pessoa visionária que ao longo desses anos demonstrou uma invejável capacidade de mostrar que a ciência não tem limites e a humanidade evolui ao buscar avançar superando barreiras.

A todos vocês, muito obrigado e que a luz do Grande Arquiteto do Universo ilumine vossas jornadas. 
"No fundo não sou literato, sou pintor. Nasci pintor, mas como nunca peguei nos pincéis a sério, arranjei, sem nenhuma premeditação, este derivativo de literatura, e nada mais tenho feito senão pintar com palavras."

Carta a Godofredo Rangel, Areias, 6/7/1909. 


\title{
CÁLCULO DA FRAÇÃO DE VAZIO EM ESCOAMENTOS BIFÁSICOS (GÁS/LÍQUIDO) A PARTIR DA IDENTIFICAÇÃO DE BOLHAS EM IMAGENS DIGITAIS
}

\author{
Pedro Luiz Santos Serra
}

RESUMO

\begin{abstract}
A Agência Internacional de Energia Atômica (IAEA - "International Atomic Energy Agency") vem incentivando o desenvolvimento de sistemas passivos de refrigeração em plantas nucleares visando a simplificação e o incremento da confiabilidade em funções essenciais de segurança nos projetos de uma próxima geração de reatores nucleares refrigerados a água. O principal fundamento desses sistemas é o emprego da circulação natural como sistema de segurança aplicável em operações de desligamento do reator para manutenção ou na ocorrência de acidentes. A circulação natural é um fenômeno que surge em virtude do gradiente de temperatura em pontos diferentes do circuito de refrigeração. Em condições extremas de estabilidade têm-se o estabelecimento do escoamento bifásico gás/líquido podendo configurar-se segundo diferentes regimes. A fração de vazio é reconhecida como um dos parâmetros chave na predição da ocorrência de instabilidades do escoamento bifásico.
\end{abstract}

Apresenta-se neste trabalho uma inovadora metodologia para estimativa da fração de vazio a partir de imagens digitais capturadas diretamente de circuitos experimentais que geram o escoamento bifásico. O método é baseado na aquisição de imagens, com controle da profundidade de campo, de uma seção do Circuito de Circulação Natural (CCN) presente no IPEN/CNEN-SP. A imagem é segmentada com base na inferência fuzzy de diferentes parâmetros de segmentação e ajustada ao foco utilizado na sua aquisição. Ela é varrida de um modo inédito e iterativo, utilizando máscaras de diferentes tamanhos integrando um conjunto de redes neurais com a Transformada Randomizada de Hough. Cada diferente tamanho de máscara é escolhido de acordo com os tamanhos das bolhas que são os objetos de interesse. $\mathrm{O}$ volume da bolha é estimado baseado em sua projeção plana capturada nas imagens digitais. O cálculo da fração de vazio considera o volume da seção geométrica do escoamento no tubo de vidro cilíndrico e a profundidade de campo utilizada e nos parâmetros geométricos inferidos para cada bolha detectada.

Os resultados mostraram que a integração entre o conjunto de redes neurais e a Transformada Randomizada de Hough aumentaram a robustez das estimativas do sistema. 


\title{
TWO-PHASE FLOW VOID FRACTION ESTIMATION BASED ON BUBBLE SEGMENTATION AND DIMENSIONING USING NEURAL NETS AND MODIFIED RANDOMIZED HOUGH TRANSFORM
}

\author{
Pedro Luiz Santos Serra
}

\begin{abstract}
The International Atomic Energy Agency (IAEA) has been encouraging the use of passive cooling systems in new designs of nuclear power plants. Next nuclear reactor generations are intended to possess simpler and robust safety functions. Natural circulation based systems hold an undoubtedly prominent position among these. Natural circulation phenomenon occurrence depends only on the existence of refrigerant liquid temperature gradient in different sections of the plant refrigerator circuit. The study of limit conditions for these systems has led to instability behavior analysis where many different two-phase flow patterns are present. Void fraction is a key parameter in thermal transfer analysis of theses flow instability conditions.

This works presents a new method to estimate void fraction from digital images captured at an experimental two-phase flow circuit. The method is primarily based on depth-of-field controlled image acquisition of a section of a closed loop of natural circulating water through cylindrical glass tubes. This loop is called Natural Circulation Facility (NCF) and is located at Nuclear and Engineering Research Institute in Brazil (IPEN/CNEN-SP). Image is segmented based on fuzzy inference of different segmentation parameters and adjusted to image acquisition focus. The image is then scanned in an inedited way using different-sized masks integrating a set of different artificial neural networks with a modified Randomized Hough Transform. Each different mask size is chosen in accordance to bubble sizes which are objects of interest. The bubble volume is estimated based on two-dimensional projection sizing based on digitally acquired images. Void fraction calculation takes into account the volume of the geometrical section of flow inside cylindrical glass tube considering used depth-of-field. It is also based on the summed bubble geometrical parameters inferred for each detected bubble.

The results have shown that integration between artificial-neural-net sets and Randomized Hough Transforms increase system estimations robustness.
\end{abstract}




\section{SUMÁRIO}

Página

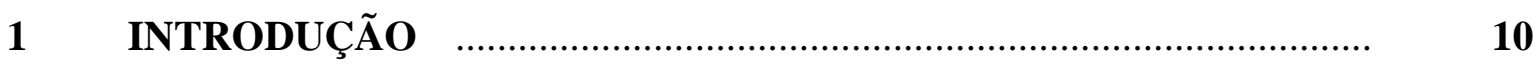

2 OBJETIVO

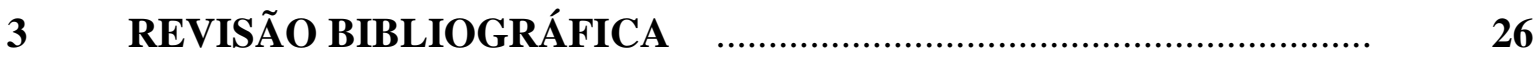

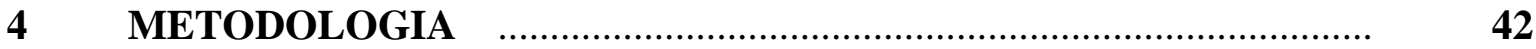

4.1 Concepção e descrição do sistema ....................................................... 42

4.1.1 Seleção da amostra do escoamento ...................................................... 44

4.1.2 Cálculo do volume total das bolhas na amostra do escoamento $\quad$.......... $\quad 47$

4.1.3 Cálculo da fração de vazio da amostra do escoamento $\quad$........................ $\quad 54$

4.2 Fundamentação teórica das principais aplicações $\quad$................................ $\quad 54$

4.2.1 Método fuzzy para a seleção da profundidade da imagem da amostra do escoamento

4.2.2 As redes neurais artificiais (RNA's) no processo de identificação das bolhas $\quad$.............................................. $\quad \mathbf{6 5}$

Configuração inicial da rede neural $\quad$................................................... $\quad \mathbf{7 2}$

Treinamento da rede neural $\quad$................................................................ 74

Execução da rede neural ................................................................. $\quad 77$

4.2.3 Identificação dos parâmetros geométricos das interfaces gás-líquido $\quad$............................................... $\quad 78$

4.2.4 Cálculo da fração de vazio da amostra do escoamento $\quad$.......................... 87

4.3 Calibração e ajustes do sistema computacional $\quad$................................... 91 Método gravimétrico para cálculo da fração de vazio $\quad$......................... $\quad 94$

4.4 Descrição do Circuito de Circulação Natural $\quad$.......................................... 97

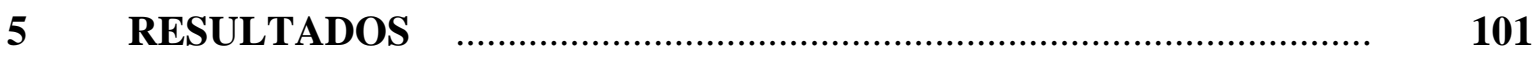

5.1 Condições gerais e de contorno dos experimentos $\quad$.............................. 102

5.2 Análise estatística dos perfís das bordas das bolhas (aplicação lapsob) 
Página

5.3 Sistema de inferência focal fuzzy $\quad$.......................................................... 109

5.4 Ferramenta de seleção da amostra - selecTool $\quad$...................................... 112

5.5 Ferramenta construtora das amostras de treinamento $\quad$........................ $\quad 114$

5.6 Configuração final do conjunto de redes neurais $\quad$............................... 119

5.7 Eliminação das bolhas detectadas na amostra da imagem do escoamento e identificação geométrica via transformada randomizada de Hough (TRH) $\quad$............................. 122

Identificação da bolha por votação - parte I $\quad$....................................... $\quad \mathbf{1 2 3}$

Identificação do centro de outra

elipse por votação - parte II e III $\quad$....................................................... $\quad \mathbf{1 2 4}$

Resultados da integração da transformada randomizada de

Hough com outros algoritmos na detecção de bolhas em foco $\quad$........... $\quad 127$

$\begin{array}{lll}\text { 5.8 Cálculo da estimativa da fração de vazio } & 132\end{array}$

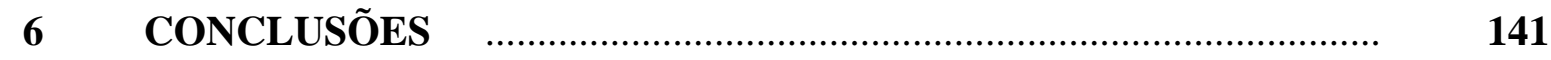

REFERÊNCIAS BIBLIOGRÁFICAS $\quad$ _........................................ 147

APÊNDICE A - Base de dados de imagens digitais do escoamento bifásico $\quad$.......................................... 153

APÊNDICE B - Análise estatística dos perfís de bordas $\quad \ldots \ldots \ldots \ldots \ldots \ldots . . . . . . . . .158$

APÊNDICE C - Código computacional

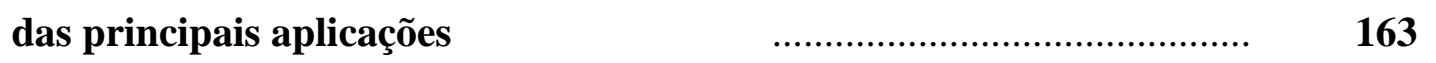




\section{INTRODUÇÃO}

A produção de energia elétrica a partir de fontes nucleares tem como princípio a conversão do calor liberado de reações nucleares em energia mecânica, responsável pela indução de energia elétrica. O fundamento desta forma de produção energética é a ocorrência de uma reação em cadeia controlada denominada fissão nuclear, obtida a partir da quebra de partículas de Urânio pelo bombardeamento de nêutrons, figura 1.

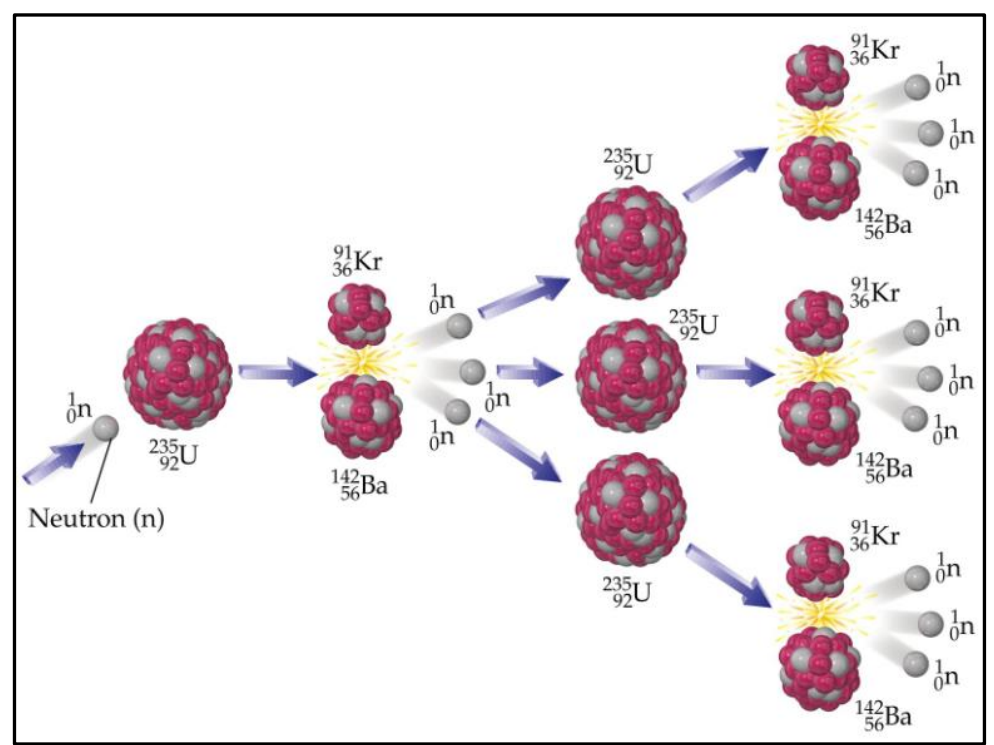

FIGURA 1 - Representação da fissão nuclear

FONTE: <http:// parquedaciencia.blogspot.com.br/2013/09/

fissao-ou-fusao-nuclear-qual-diferenca.html>

A quebra destas partículas resulta na liberação de outras partículas e de uma impressionante quantidade de energia sob a forma de calor, capaz de aquecer um fluido a temperaturas que permitem a geração de energia mecânica suficiente para a indução de energia elétrica com boa eficiência, TERREMOTO (2012). Tudo isto sem depositar um grama de gás carbônico na atmosfera.

A figura 2 ilustra um diagrama esquemático de uma usina termonuclear ou, simplesmente usina nuclear, com um reator nuclear de potência refrigerado a água pressurizada (PWR- Pressurized Water Reactor). Nela pode-se identificar as principais partes integrantes deste tipo de usina. 


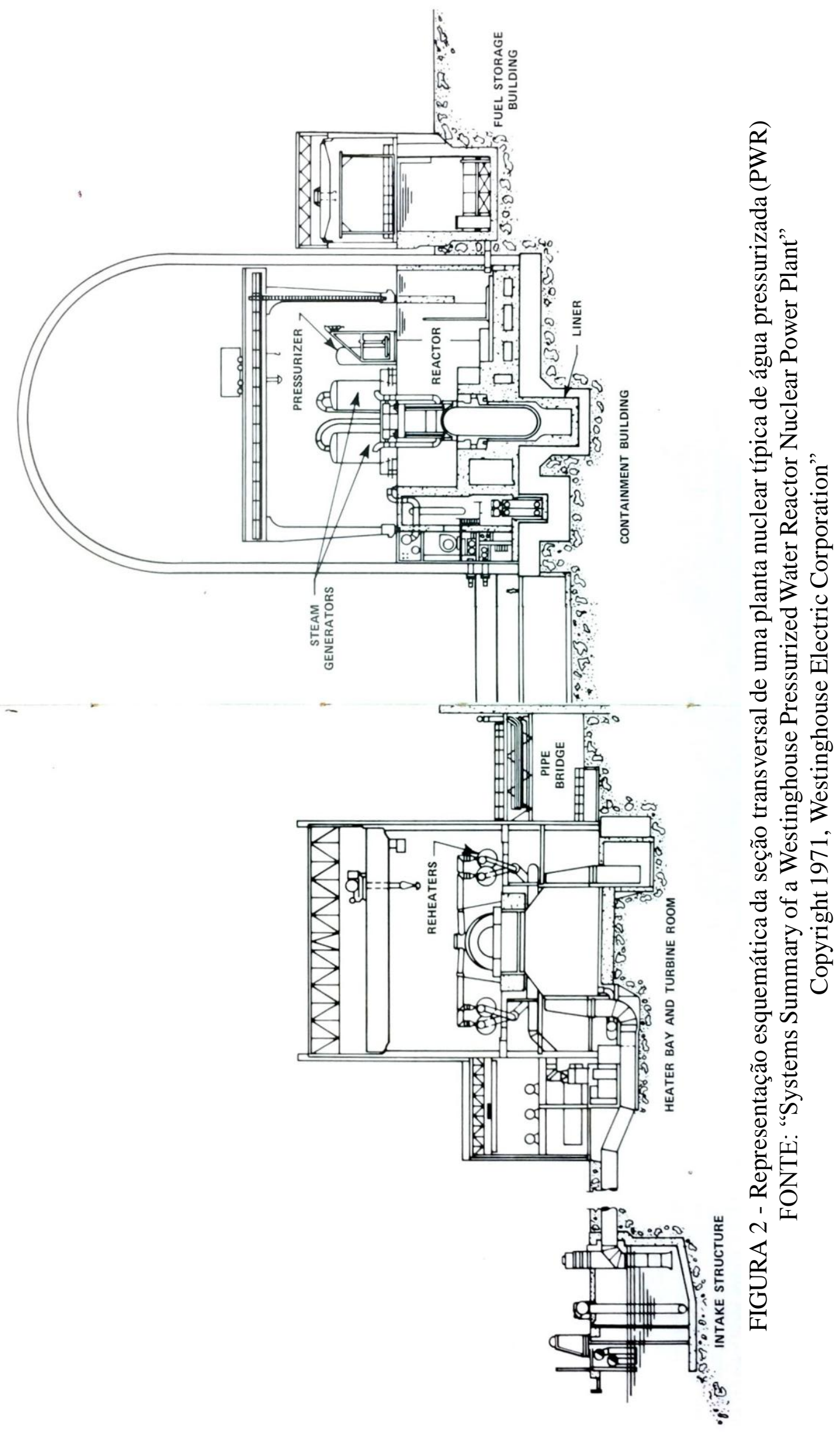


O núcleo do reator é a parte onde ocorre a fissão nuclear que é responsável pela geração de energia sob a forma de calor. Além do combustível (Urânio enriquecido), o núcleo do reator é preenchido com água como fluído refrigerante que constituí o circuito primário de refrigeração. A água é também empregada como moderador dos nêutrons resultantes da fissão nuclear neste tipo de reator.

O processo de moderação consiste na redução da velocidade de propagação dos nêutrons a fim de possibilitar a ocorrência de novas reações pela sua incidência em outros núcleos de Urânio constituindo a reação em cadeia. Varetas de Cádmio ou Boro são empregadas para controle do fluxo de nêutrons no reator. Elas também são utilizadas para desligamento ("shutdown") do reator para sua manutenção ou devido a ocorrência de acidentes.

O fluído refrigerante a alta pressão é bombeado ao longo do circuito primário para troca de calor com um circuito secundário, responsável pela produção do vapor para movimento das turbinas e consequente geração de energia elétrica. O núcleo do reator, circuito primário de refrigeração e parte do circuito secundário da usina estão confinados em uma blindagem especial denominada blindagem biológica, formada por uma espessa e compacta parede de concreto.

Segundo a Agência Internacional de Energia Atômica - IAEA (CLEVELAND e CHOI, 2009) a energia produzida a partir de fontes nucleares representa $15 \%$ de toda energia elétrica produzida no mundo. Diversos países já incluem em sua política energética a introdução da energia nuclear ou o aumento de sua capacidade de geração. Para sua viabilização, diversas organizações e instituições investem na busca da simplificação dos modelos de plantas nucleares tendo como principal objetivo a redução de custo partindo do desenvolvimento e da implantação de sistemas mais simples, sem prejuízo de sua confiabilidade. A proposta de desenvolvimento e implantação de sistemas passivos de segurança aplicada a reatores refrigerados a água (WCR - "Water Cooled Reactors") está em plena concordância com tais objetivos e foi indicada como um método desejável de simplificação e incremento da confiabilidade em funções essenciais de segurança em plantas nucleares (IAEA, 1991). A criação de um projeto de pesquisa coordenado ("Coordinated Research Project - CRP") pela IAEA em 2004, intitulado Fenômeno de Circulação Natural, Modelamento e Confiabilidade de Sistemas Passivos de Segurança que Utilizam Circulação Natural ("Natural Circulation Phenomena, Modeling and 
Reliability of Passive System that Utilize Natural Circulation") visa o estudo de sistemas passivos de segurança utilizando a circulação natural como um modelo econômico e seguro, aplicável em plantas nucleares. Tais indicações estão fundamentadas na eliminação dos custos de instalação, manutenção e operação dos sistemas ativos que requerem múltiplas bombas com geradores independentes e redundantes de energia elétrica.

Uma representação esquemática de um modelo de resfriamento baseado nos princípios da circulação natural é ilustrada na figura 3. Dentre as principais situações para aplicação deste sistema releva-se a ocorrência de panes no sistema ativo de refrigeração, denominados "Loss of Collant Accident" - LOCA, resultando no desligamento da planta nuclear.

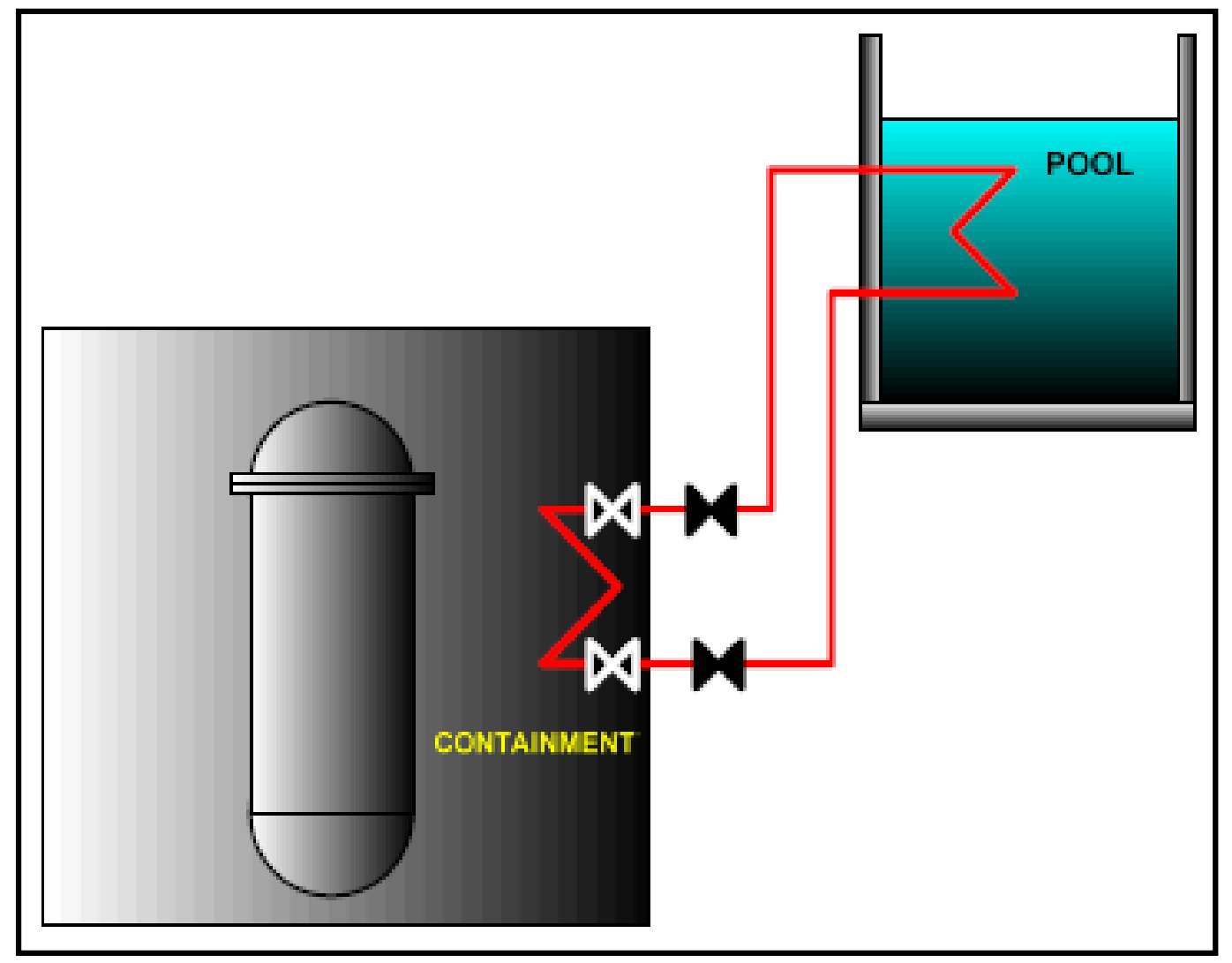

FIGURA 3 - Esquema da aplicação de um circuito de refrigeração natural com um dissipador passivo de calor em uma planta nuclear.

FONTE: CLEVELAND e CHOI (2009)

CLEVELAND E CHOI (2009) evidenciaram ainda a criação, pela "CRP", de um plano integrado de pesquisa com uma descrição de tarefas direcionadas, tais como:

- estabelecimento do estado de arte em circulação natural;

- identificação e descrição de sistemas de referência; 
- identificação e caracterização dos fenômenos que influenciam a circulação natural;

- exame da aplicação de dados e códigos para projetos e segurança e

- exame da confiabilidade de sistemas passivos de segurança que utilizam circulação natural.

Estas diretrizes requerem a realização de análises detalhadas com a finalidade de assegurar o desempenho destes sistemas sob as mais diversas condições. Extensos estudos e análises no sentido de avaliar valores que influenciam este desempenho são realizados com o propósito da obtenção de modelos representativos das condições e na descoberta e avaliação dos parâmetros relacionados ao fenômeno.

KUMAR et al. (2015) revelaram que uma das consequências do acidente de Fukushima foi a realização de revisões detalhadas nas características de segurança das plantas nucleares mais recentes. Constataram, no projeto do reator avançado de água pesada (AHWR - Advanced Heavy Water Reactor) em desenvolvimento no Bhabha Atomic Research Center - India, a possibilidade da transferência de uma pequena fração do calor de decaimento total do sistema principal de transporte de calor para o moderador por radiação. Isto levaria, em operações prolongadas de desligamento ("station black-out"), o aumento da temperatura e pressão do moderador. Para lidar com este problema mantendo as condições do moderador dentro dos limites de segurança por ao menos sete dias, um novo sistema passivo de segurança empregando circulação natural foi incorporado ao projeto do reator.

Alguns reatores da geração atual fazem uso da circulação natural como fundamento para desenvolvimento de sistemas passivos de segurança empregados na remoção de calor em caso de desligamento do sistema ("shutdown") para fins de manutenção, ou na ocorrência de falhas das bombas de circulação do sistema principal de refrigeração. Eles são aplicados em reatores de potência refrigerados a água (PWR) e a água pesada (PHWR), KUDARIYAWAR et al. (2016). A aplicação desses sistemas mostrou-se eficaz na remoção de até $20 \%$ da potência nominal do reator. KUDARIYAWAR et al. (2016) realizaram simulações empregando Fluido Dinâmica Computacional (CFD - Computer Fluid Dynamics) com o objetivo de geração de dados do campo de escoamento em diversas condições transientes em um circuito experimental de circulação natural. Tais dados seriam úteis no conhecimento completo da evolução do escoamento e dos campos de temperatura no circuito em situações que resultariam em 
diversos tipos de instabilidades. A principal contribuição de seu trabalho foi a confirmação da teoria de transporte de "hot plugs" empregada para explanar os vários tipos de instabilidade (como pulsação unidirecional ou bi-direcional). A validação do modelo CFD foi realizada com dados obtidos de um circuito experimental de circulação natural. A instabilidade da circulação natural foi calculada e, em um primeiro instante, a relação entre o padrão de escoamento instável e o transporte de "plugs" quente/frio foram estudados detalhadamente. KUDARIYAWAR et al. (2016) evidenciaram a abrangência de tais estudos visto que circuitos de refrigeração com circulação natural são utilizados em diversas outras aplicações de engenharia como, sistemas de aquecimento solar, resfriamento de motores de combustão interna, lâminas de turbina a gás, extração de potência geotérmica e sistemas de refrigeração de computadores.

ZHANG et al. (2015) apresentaram estudos experimentais pela aplicação de um circuito de circulação natural para resfriamento do reator de pesquisa da universidade de Kyoto (KUR - Kyoto University Research Reactor) em condições térmicas de operação (10 a $100 \mathrm{~kW})$ e de desligamento ("shutdown"). Foram realizadas tomadas de temperatura em diversos pontos do circuito que é empregado para resfriamento do núcleo do reator. Também foram analisadas as velocidades do escoamento ao longo do núcleo do reator. ZANGH et al. (2015) constataram que as condições mais críticas para o circuito de circulação natural ocorreram na condição de operação de $100 \mathrm{~kW}$, no entanto, consideradas dentro dos critérios de segurança estabelecidos para operação do reator.

Ressalta-se que praticamente todas as análises e estudos sobre o comportamento do fluído em circuitos de circulação natural envolvem o desenvolvimento e a aplicação de diversos modelos teóricos, ou semi-empíricos, aliados ao desenvolvimento de circuitos experimentais. Além das publicações já mencionadas GOUDARZI e TALEBI (2015) retrataram esta interação ao empregar um modelo matemático analítico de equações governantes da geração de entropia aplicado a diversas configurações geométricas e condições de operação de um circuito experimental de circulação natural.

A circulação natural surge como consequência da ocorrência de forças direcionais (denominadas "driving forces") proveniente da variação da densidade do fluido em função do gradiente de temperatura em diferentes localizações de um circuito, (MESQUITA et al. 2009). Ela apresenta, em situações limites de transferência de calor, características particulares que incluem o escoamento bifásico com a presença de gás e 
líquido. O padrão deste escoamento pode ser determinante na identificação destas situações e, por conseguinte, na eficiência de um circuito refrigerador concebido com base neste fenômeno natural. Tais padrões são normalmente classificados como: "em bolhas" ("bubble flow"), pistonados ("plugs" ou "slugs"), agitados ("churn") e anulares (BARBOSA JR.,2012), figura 4.

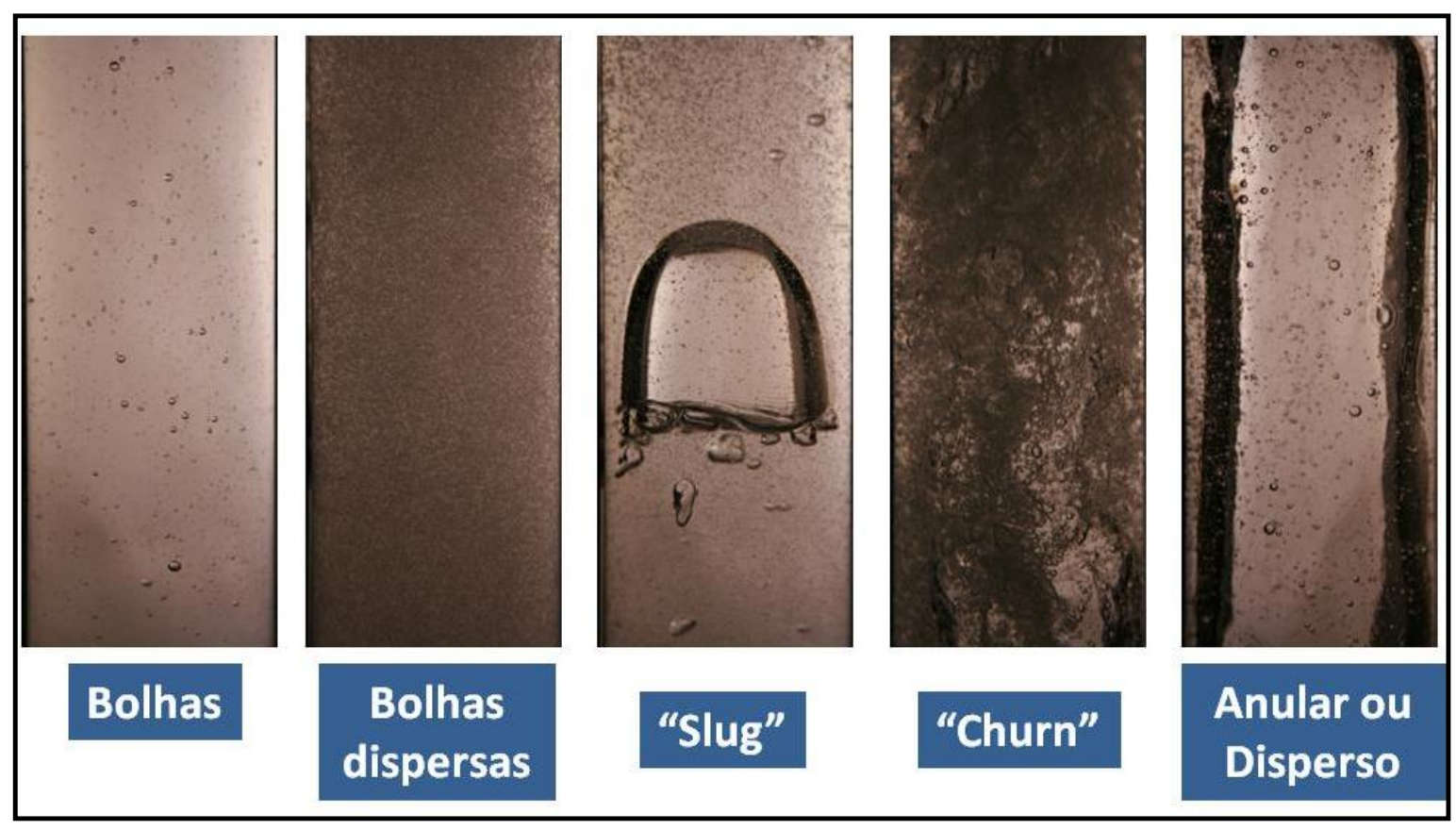

FIGURA 4 - Padrões de escoamento gás-líquido em tubos verticais segundo classificação apresentada por BARBOSA JR. (2012). FONTE: Elaborada pelo próprio autor /

\section{IMAGENS: CCN/CEN}

NAYAK, et al. (2007, p. 387) em seu estudo sobre estabilidade em sistemas bifásicos de circulação natural, menciona que a taxa de escoamento é dependente do vazio gerado no sistema devido a adição de calor e perda de carga. Acrescenta ainda que estimativas precisas da fração de vazio, bem como a queda de pressão devido ao atrito (“frictional pressure drop"), são parâmetros chaves para predição do limiar de instabilidade.

A fração de vazio consiste na relação entre o volume de gases e o volume total do escoamento (gases e líquido) e exerce grande influência sobre os limites de estabilidade do sistema. Trata-se de um parâmetro em destaque nos estudos relacionados ao comportamento do escoamento bifásico. Seu valor está presente na maioria das correlações que tratam deste comportamento assim como nos diversos parâmetros envolvidos com o regime de escoamento. Sua variação temporal é indicativa de situações de transição entre os regimes de escoamento e de condições de instabilidade. 
SCHLEGEL et al. (2009) mencionam a inexistência de escoamento pistonado ("slugs") em sistemas com escoamento bifásico com grandes diâmetros e os classifica nos tipos: "em bolhas", bolhas capilares ("cap-bubbles") e agitado ("churn"). Partindo de medições da fração de vazio em um circuito vertical e empregando uma função cumulativa de densidade de probabilidade (para fins de representação da variação temporal da fração de vazio) com um mapa auto-organizável de Kohonen obtém como resultado, o regime de escoamento no circuito. Eles associaram a fração de vazio e o regime de escoamento como os parâmetros principais na predição do escoamento. Vale ressaltar que SCHLEGEL et al. (2009) fizeram uso de um circuito com circulação forçada, ou seja, empregando bombas de centrifugação para circulação do fluído no circuito. Algumas de suas conclusões não devem ser estendidas para escoamentos bifásicos em circuitos com circulação natural.

BARBOSA, CRIVELARO e SELEGHIM JR. (2010) também fizeram uso do Mapa Auto Organizável para identificação e classificação do escoamento bifásico em um complexo circuito experimental empregando circulação forçada, desenvolvido e localizado nas dependências do Laboratório de Engenharia Termo fluído da Universidade de São Paulo localizado no Campus de São Carlos (NETeF-USP). Os valores da fração de vazio, obtidos através de um sensor capacitivo, associado a queda e o gradiente de pressão extraídos do circuito foram empregados para treinamento, testes e aplicação do mapa auto-organizável. Os resultados representavam a classificação do escoamento no circuito experimental segundo seis tipos diferentes de regimes.

SMITH et al. (2012) mencionam a ocorrência de uma fase transitória entre um escoamento com bolhas e um agitado. Ambos referenciam a fração de vazio como parâmetro essencial e identificador do regime de escoamento ao longo do circuito.

Tais estudos estão concentrados na identificação e caracterização das formas possíveis de escoamento dentro de um sistema com circulação natural.

A tecnologia empregada para aquisição das imagens de escoamento é dependente do tipo de sistema e do fluído utilizado. UCHIMURA et al. (1998) emprega um sistema de imageamento por radiografia de nêutrons em tempo real (RTNR - Real Time Neutron Radiography) na aquisição das imagens em um circuito de circulação natural que emprega metal líquido como refrigerante. SAITO et al. (2011) aplica esta 
mesma tecnologia na visualização do escoamento em um circuito com escoamento bifásico empregando água como refrigerante. Esta tecnologia é empregada em circuitos com tubulação metálica. Ela consiste, basicamente, na exposição do escoamento a um feixe de nêutrons incidente sobre um anteparo (cintilador granular de nêutrons - $\mathrm{LiF}_{6} \mathrm{Zns}$ ). A passagem do feixe de nêutrons térmicos por regiões com presença de gás no escoamento produzirá uma atenuação energética menor, resultando na geração de uma imagem com maior intensidade de luz resultante da reação do feixe de nêutrons com o cintilador posicionado atrás da tubulação com o escoamento. A imagem produzida pela reação desses feixes de nêutrons incidentes com o cintilador é capturada por uma câmera de alta resolução através de uma adequada combinação de lentes e espelhos, figura 5.

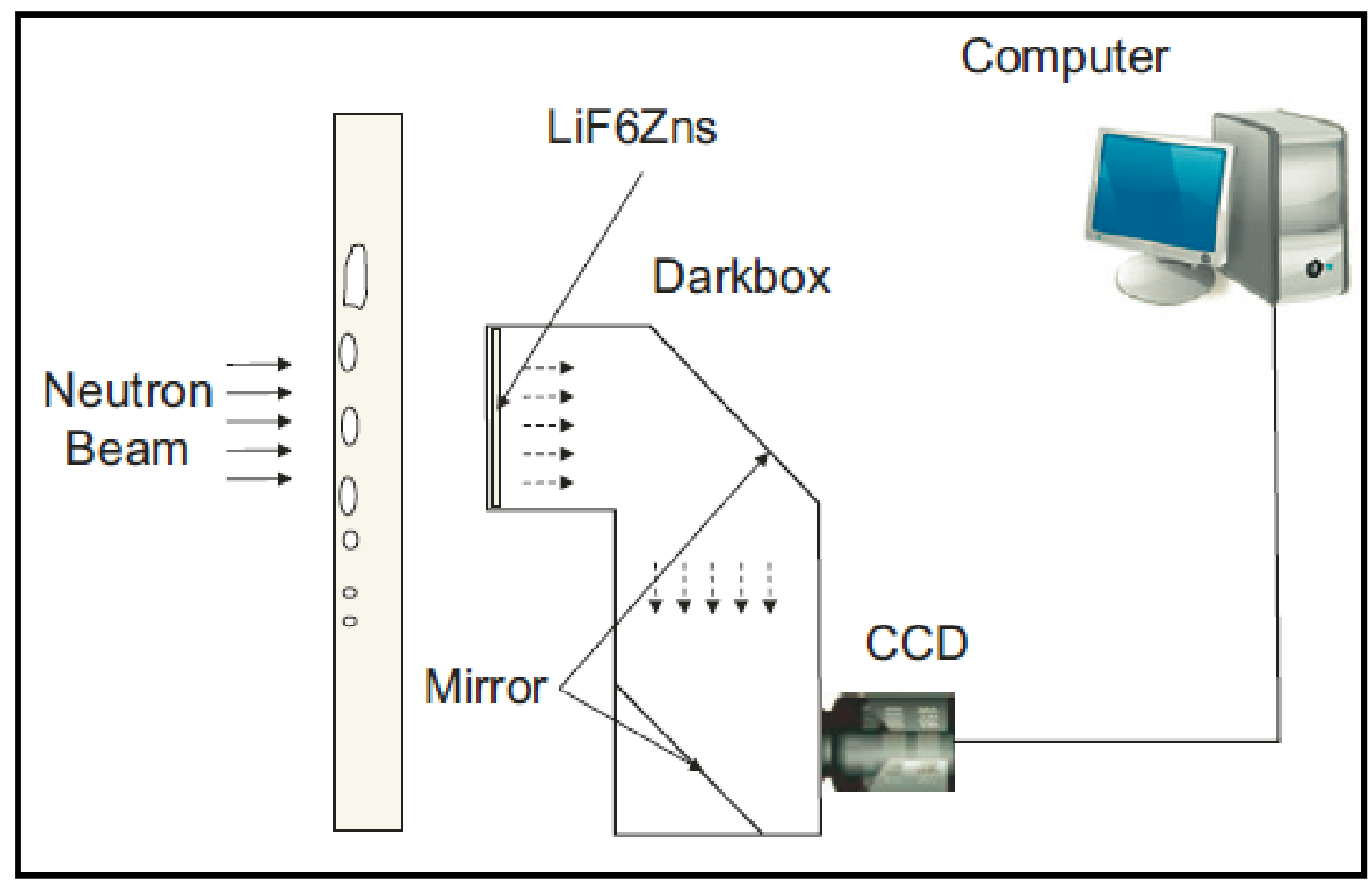

FIGURA 5 - Representação esquemática do sistema de imageamento por radiografia de nêutrons. FONTE: SAITO et al.(2011)

SUNDE, AVDIC e PÁZSIT (2005) apresentaram um método de identificação e classificação de escoamento bifásico também baseado em dados de imagens capturadas via imageamento por nêutrons. Eles empregaram um modelo que consiste na aplicação de redes neurais para classificação do tipo de escoamento a partir destas imagens. Elas foram pré-processadas utilizando o método de subtração de sombras e filtro Wavelet. Concluíram que o emprego de Wavelet pouco contribuiu na melhoria da precisão dos resultados, porém, resultou em um impacto positivo na fase de treinamento da rede neural. 
Circuitos experimentais com tubulações de vidro permitem a extração das imagens pelo emprego direto de câmeras de alta resolução e definição. Esta tecnologia, conhecida por imageamento direto, visa o aumento da velocidade de exposição, resultando na melhoria da qualidade no processo de aquisição das imagens e a redução do custo na obtenção experimental de parâmetros de escoamento (por exemplo: regime e velocidade de escoamento, fração de vazio estática e temporal, etc.) sem o comprometimento da precisão dos resultados. Para tanto as mais diversas técnicas de reconhecimento de padrões em imagens são aplicadas com a finalidade de buscar um aprimoramento das análises subsequentes.

O modelo adotado por WANG e DONG (2009) tem como base a variação da escala de cinza (Gray Level Co-occurence Matrix - GLCM) e do gradiente (Gray Level Gradient Co-occurence Matrix - GLGCM) de imagens capturadas experimentalmente via imageamento direto, figuras 6 e 7.

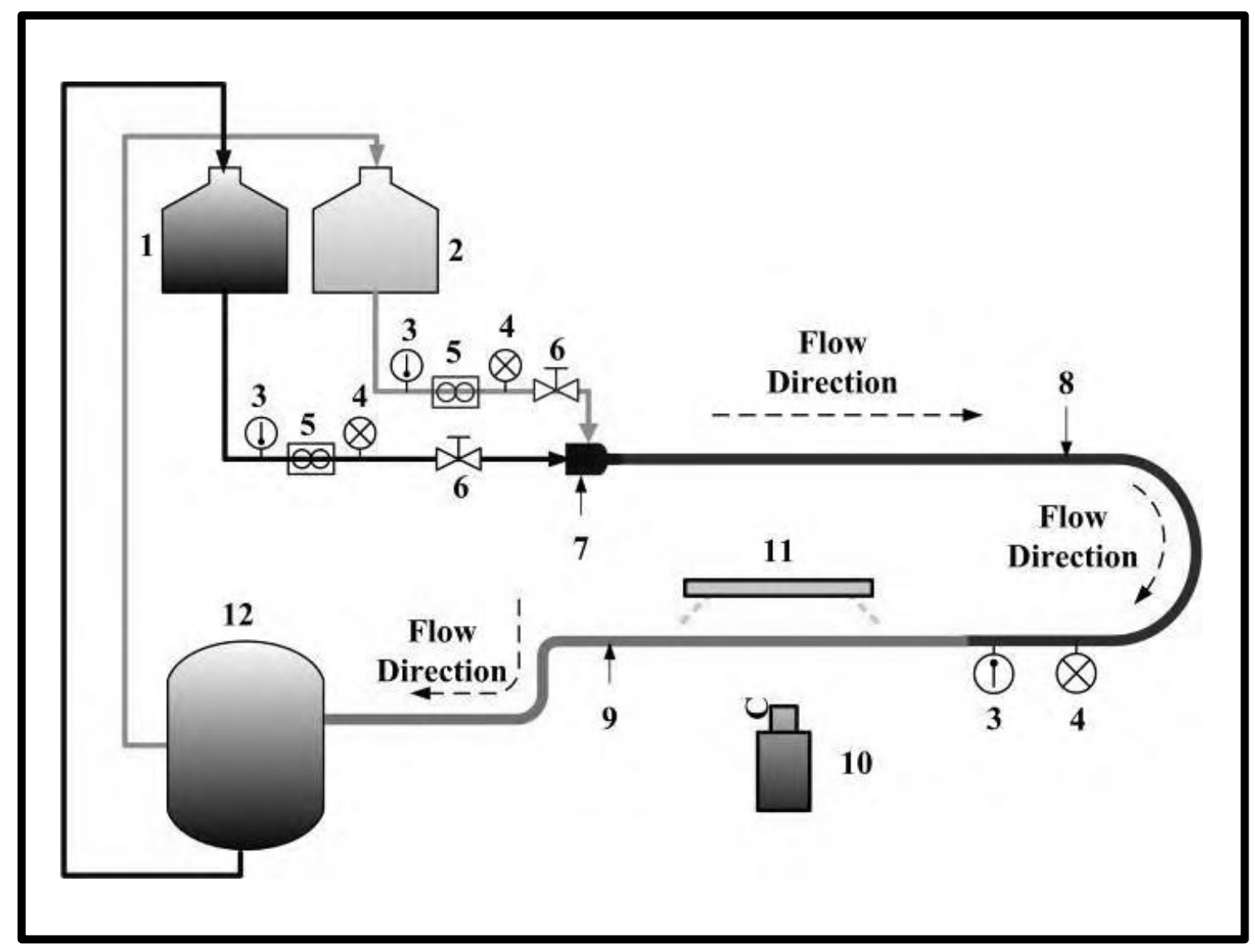

FIGURA 6 - Vista esquemática do experimento.

FONTE: WANG e DONG (2009)

WANG e DONG (2009) limitaram-se às informações baseadas em um método de extração de características relacionadas à textura das imagens (energia, homogeneidade, 
entropia, protuberância, assimetria de cinza, inércia e média de graduação de cinza). A partir das matrizes de níveis de coocorrência de cinza (GLCM e GLGCM), das faixas de variação de tais características e da dinâmica do escoamento (velocidade do fluido e dos gases em função do tempo) foi possível o reconhecimento, com boa precisão, do tipo de escoamento bifásico dentro das quatro opções ilustradas e propostas pelo autor.

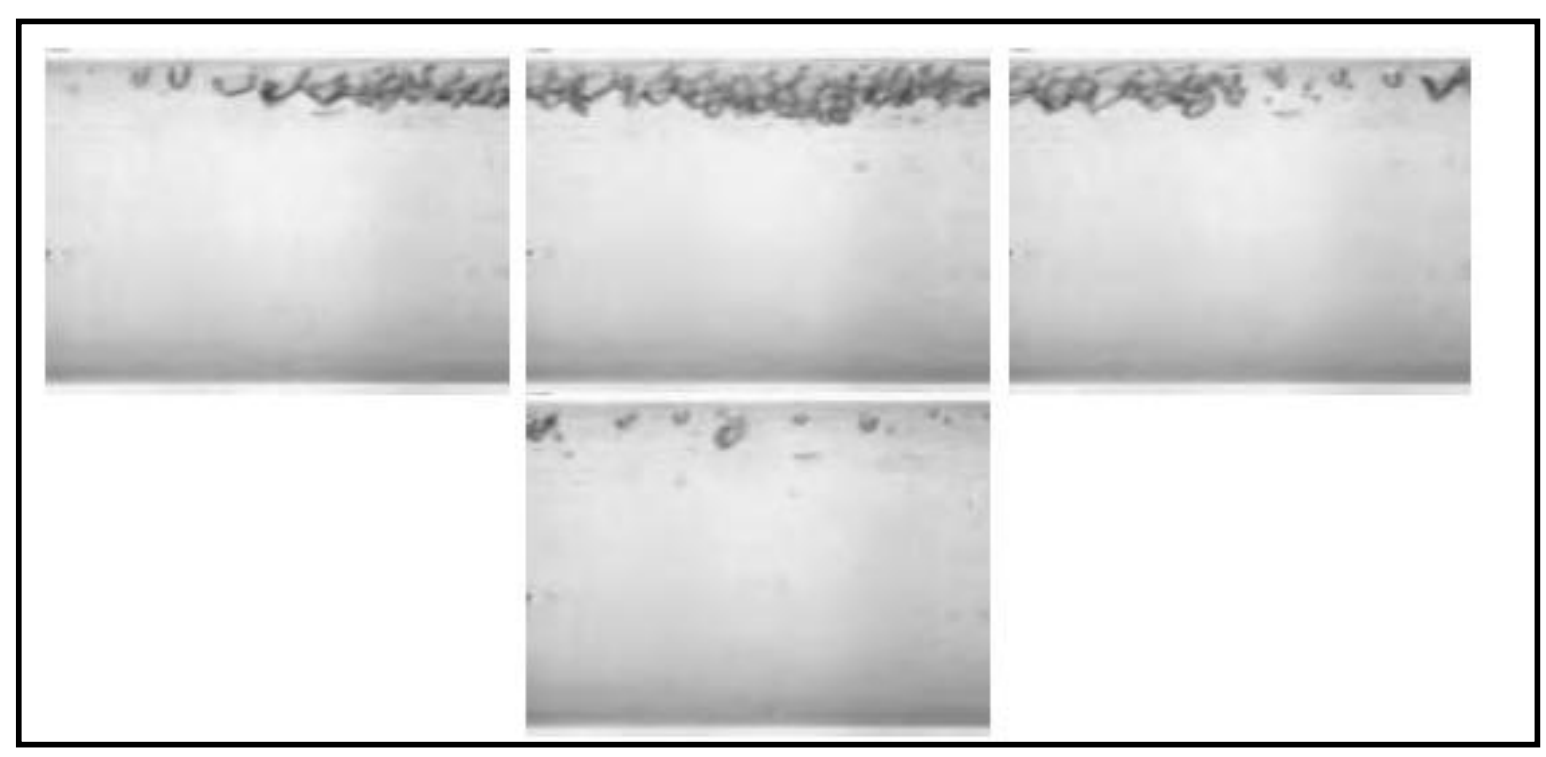

FIGURA 7 - Imagens do escoamento bifásico (gás-líquido) FONTE: WANG e DONG (2009)

WANG e DONG (2009) alegaram ainda que o emprego deste modelo pode permitir a medida da fração de volume de gás (fração de vazio) em circuitos experimentais horizontais.

Existem muitas publicações voltadas à determinação do padrão de escoamento através de técnicas de reconhecimento de padrões aplicados a imagens de escoamento bifásico, cada qual empregando uma particularidade no sentido de obter resultados de forma mais eficiente, com redução de custo e com alta confiabilidade, DE MESQUITA et al.(2012), SUNDE, AVDIC e PÁZSIT (2005), WANG e DONG (2009), FICHERA et al.(2000) e CRIVELARO e SELEGHIM JR.(2002).

WOLDESEMAYAT e GHAJAR (2007) realizaram uma análise sobre 68 correlações empíricas de fração de vazio baseadas em um conjunto imparcial de dados ( 2845 pontos) cobrindo uma grande margem de parâmetros. Um total de 403 pontos foram selecionados da literatura e confrontados com quatro modelos de correlações da fração de vazio consideradas as mais adequadas para aplicação em circuitos verticais. Embora a comparação dos resultados entre duas correlações específicas terem apresentado uma 
diferença da ordem de $5 \%$, os casos mais gerais e que continham a grande maioria dos dados pesquisados na literatura apresentavam erros da ordem de $\pm 15 \%$, figura 8 .

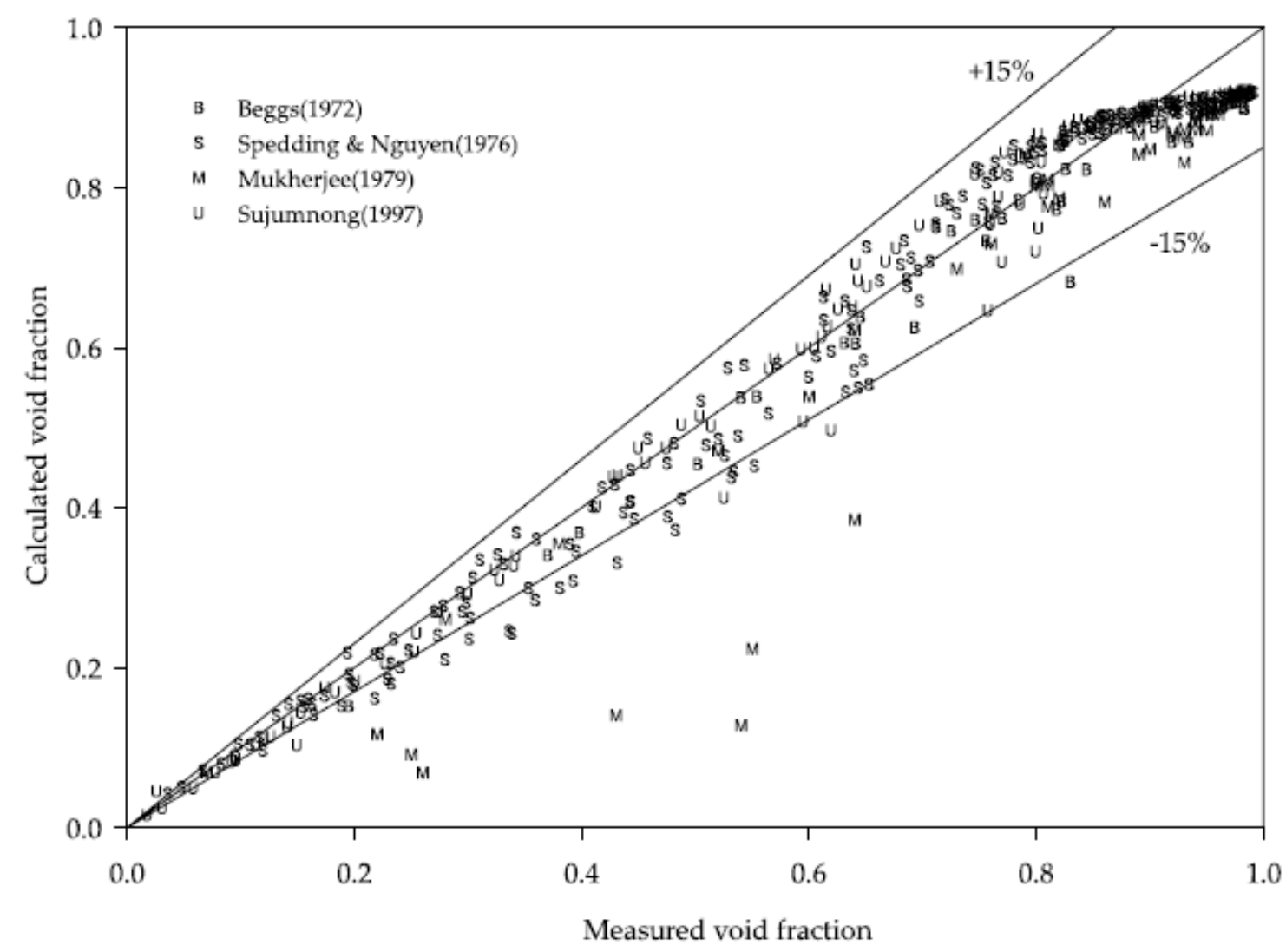

FIGURA 8 - Comparação entre a fração de vazio obtida das correlações e medidas para circuitos verticais. FONTE: WOLDESEMAYAT e GHAJAR (2007).

A ocorrência dessas discrepâncias torna evidente a necessidade de interações cada vez mais frequentes no sentido de alimentar e municiar tanto os estudos teóricos para obtenção de modelos mais representativos e das mais diversas condições do modelo físico, como pela aquisição experimental dos parâmetros essenciais na elaboração e avaliação desses modelos.

Novas propostas de métodos que fazem integração entre estes dois tipos de abordagem têm surgido em outras áreas de aplicação, como na área médica ou biológica.

ELSALAMONY (2016) faz uso da integração de técnicas de processamento de imagens e algoritmos inteligentes para identificação e diagnóstico de anemia a partir de imagens digitais microscópicas de amostras (esfregaços) de sangue. Esta integração de diferentes técnicas está ilustrada na figura 9 tendo como primeira fase os processos de coloração das imagens das células sanguíneas, a aplicação de uma variante da transformada de Hough, denominada transformada circular de Hough (CHT - Circular Hough Transform) em conjunto com funções de segmentação para detecção e contagem de 
células sanguíneas saudáveis ou não. A transformada circular de Hough é empregada na detecção das células vermelhas e sua contagem.

A técnica "watershed" e um conjunto de funções morfológicas foram empregadas na melhoria das imagens e separação de células oclusas. Muitas operações são realizadas pela transformada circular de Hough como a identificação da polaridade da célula e estimativa dos centros das células nas imagens. Uma rede neural multicamada é aplicada para classificação do tipo de anemia permitindo um diagnóstico preciso e eficiente.

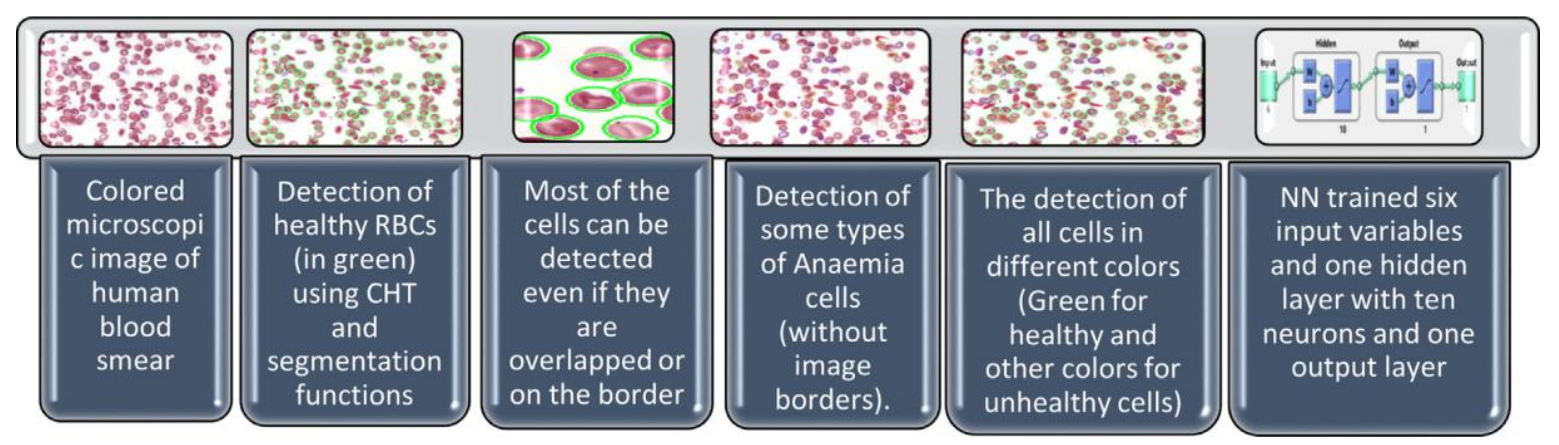

FIGURA 9 - Principais fases do algoritmo. FONTE: ELSALAMONY (2016)

A metodologia proposta por ELSALAMONY (2016) apresentou resultados satisfatórios na identificação e precisão dos diversos tipos de anemia. Seus resultados indicaram uma eficiência de 100\%, 98\%, $100 \%$ e 99,3\% para identificação de quatro classes representativas dos tipos de formas anêmicas como: foice, eliptocitose, microcitose e nenhuma.

Embora represente um menor custo, a obtenção da fração de vazio a partir de imagens extraídas experimentalmente resulta em imprecisões relacionadas às suas próprias características.

A identificação dos fatores que contribuem para estas imprecisões aliada ao estudo e desenvolvimento de técnicas integradas de processamento de imagens e algoritmos inteligentes prestam uma importante contribuição na pesquisa atual envolvendo escoamentos bifásicos e, por conseguinte, a compreensão e entendimento do fenômeno da circulação natural e de todas as suas particularidades.

Com base nos estudos previamente apresentados constata-se que a pesquisa do comportamento dos padrões bifásicos em circulação natural necessita do desenvolvimento de modelos integrados envolvendo técnicas de processamento de imagem, técnicas experimentais de medida de parâmetros e técnicas de varredura iterativa. 
Este trabalho surge dentro deste contexto, propondo o desenvolvimento de programas computacionais integrados para cálculo da fração de vazio volumétrica a partir de imagens digitais bidimensionais capturadas de circuitos experimentais. Estes algoritmos representam uma solução de parte importante do problema de obtenção confiável de parâmetros necessários para a compreensão, a mensuração e a consequente predição do escoamento bifásico e, por conseguinte, do próprio fenômeno da circulação natural.

Os cálculos partem de uma amostra volumétrica do escoamento bifásico selecionada de uma imagem capturada por imageamento direto em um circuito experimental de vidro. Este processo utiliza inferência fuzzy para eliminação de pixels fora da profundidade de campo previamente selecionada nas câmeras de alta resolução utilizadas na aquisição. Executa-se, sobre esta amostra volumétrica de escoamento, um inédito processo de sucessivas varreduras integradas de redes neurais artificiais associadas à aplicação de um modelo modificado da transformada randomizada de Hough. Esta inédita metodologia, que utiliza esta sequência de operações, permite a inferência precisa da quantidade de gás na amostra volumétrica do escoamento no instante da captura da imagem, permitindo a determinação da razão entre este volume de gases e o da amostra do escoamento, parâmetro usualmente conhecido como fração de vazio volumétrico.

Os modelos de cálculo tem como principal suporte a confiabilidade obtida pela integração entre os algoritmos inteligentes, as técnicas de segmentação e a transformada randomizada de Hough. Uma estimativa da precisão e confiabilidade da estimação é obtida pela comparação com resultados obtidos de experimentos específicos que fazem a medida direta deste parâmetro. 
O objetivo geral deste trabalho é o desenvolvimento de um sistema computacional para cálculo da fração de vazio a partir do imageamento direto do escoamento bifásico em circuitos de circulação natural.

A composição de diversos modelos integrados com diferentes tecnologias são tratados como metas que visam a realização dos objetivos específicos conforme descrição abaixo:

- o estabelecimento de dimensões de uma amostra tridimensional, ou volumétrica, da imagem do escoamento para minimização da distorção ótica devida à concavidade da tubulação do experimento;

- a associação da profundidade de campo selecionada na câmera de alta resolução na aquisição direta da imagem do escoamento a valores de parâmetros de segmentação associados ao foco da imagem;

- o reconhecimento da imagem de cada uma das bolhas dentro das dimensões da amostra da imagem do escoamento e

- a associação de circunferências ou elipses representadas analiticamente por seus parâmetros e propriedades com a forma das interfaces gás-líquido capturadas de bolhas em imagens digitais do escoamento bifásico de circuitos experimentais de circulação natural.

Trata-se de uma pesquisa e desenvolvimento tecnológico necessário para suprir importante lacuna na pesquisa atual relativa à obtenção confiável, por imageamento, de parâmetros para modelamento de escoamento bifásico. Esta confiabilidade é aperfeiçoada pela integração de técnicas de processamento de imagens com algoritmos inteligentes.

O ineditismo desta iniciativa está fundamentado nos seguintes itens:

- o desenvolvimento de uma metodologia que associa os parâmetros de aquisição de imagem relativos à profundidade de campo (com foco pré-estabelecido) com os parâmetros de segmentação da imagem analisada, utilizando inferência fuzzy e métricas de foco; 
- a utilização de um conjunto de redes neurais artificiais treinadas para subimagens com dimensões diferentes e de acordo com as buscadas dos objetos de interesse na imagem (neste trabalho, bolhas). Estas subimagens são geradas por uma varredura da imagem da amostra volumétrica do escoamento utilizando máscaras virtuais;

- a integração deste conjunto de redes neurais com a transformada de Hough para a otimização e robustez na detecção e classificação dos objetos de interesse e

- o refinamento da metodologia de votação na transformada randomizada de Hough (TRH) para incremento da robustez na identificação dos parâmetros geométricos das formas elípticas.

O desenvolvimento do sistema computacional tem como objeto de aplicação o cálculo da fração de vazio de imagens digitais capturadas do Circuito de Circulação Natural (CCN) do Centro de Engenharia Nuclear do IPEN (DE MESQUITA et al., 2012) visando sua aplicação em futuras análises e estudos deste fenômeno. A aquisição das imagens do escoamento deste circuito experimental é realizada por imageamento direto.

O ajuste e a calibração da metodologia de cálculo e das aplicações é baseado em uma bancada experimental de medida de fração de vazio via método gravimétrico. 
Em TERREMOTO (2012) é apresentado o processo de geração de energia elétrica a partir de fontes nucleares. Esta forma de geração está fundamentada na ocorrência de uma reação em cadeia controlada, denominada fissão nuclear. Ela consiste na quebra de partículas de Urânio pelo bombardeamento de nêutrons resultando na liberação de outras partículas e de uma impressionante quantidade de energia sob a forma de calor. Esta última capaz de aquecer um fluido a temperaturas que permitem a geração de energia mecânica suficiente para a indução de energia elétrica com boa eficiência. Trata-se de uma das principais fontes energéticas mundiais visto que, segundo CLEVELAND E CHOI (2009), representa $15 \%$ da geração da energia elétrica mundial.

CLEVELAND E CHOI (2009) apresentaram um quadro resumido de diversos modelos de sistemas nucleares refrigerados a água que fazem uso da circulação natural como sistemas passivos de segurança. Eles mencionaram ainda que estudos para a simplificação dos futuros projetos de plantas nucleares são motivados pela Agência Internacional de Energia Atômica (AIEA) para implementação de novas tecnologias direcionadas à redução de custo sem o comprometimento da segurança.

O impactante cenário do acidente de Fukushima conduziu a um emergente questionamento dos sistemas de segurança convencionais devido a sua dependência de componentes ativos. A composição desses dois fatores associado ao incentivo dado pela Agência Internacional de Energia Atômica para o desenvolvimento e implementação de projetos que fazem uso da circulação natural como sistema passivo de segurança induziram, segundo KUMAR et al. (2015), a necessidade de revisão dos mais recentes projetos e instalações de reatores nucleares. No projeto do Reator Avançado de Água Pesada (AHWR - "Advanced Heavy Water Reactor") em desenvolvimento no Bhabha Atomic Research Center, na Índia, KUMAR et al. (2015) constataram a possibilidade da transferência de uma pequena fração do decaimento de calor total do sistema principal de transporte de calor para o moderador por radiação. Isto levaria, em operações prolongadas de desligamento ("station black-out"), ao aumento da temperatura e pressão do moderador. Para manter as condições do moderador dentro dos limites de segurança por ao menos sete 
dias, um novo sistema passivo de segurança empregando a circulação natural foi incorporado ao projeto do reator.

A aplicação de circuitos de circulação natural monofásicos surge como uma proposta viável para os futuros projetos de reatores nucleares a água pressurizada (PWR Pressurized Water Reactor) e a água pesada pressurizada (PHWR - Pressurized Heavy Water Reactor). Elas seriam efetivas na remoção de até vinte por cento da potência nominal do núcleo em reatores a água pressurizada quando acionadas em casos de falhas de potência nas bombas de circulação. O emprego deste fenômeno não se restringe apenas à tecnologia nuclear. KUDARIYAWAR et al. (2016) relataram a aplicação da circulação natural em diversos outros segmentos da engenharia como aquecedores solares, resfriamento de transformadores, extração geotérmica de potência, resfriamento de motores de combustão interna, resfriamento de computadores e resfriamento de lâminas de turbinas em virtude da expressiva confiabilidade desses sistemas. Seus estudos foram baseados na utilização de um circuito experimental de circulação natural (NCL - Natural Circulation Loop) com quatro configurações representativas de diferentes tipos de reatores nucleares. Eles consistem em simulações de fases de transição do escoamento neste circuito pela aplicação da técnica de fluído dinâmica computacional em três dimensões (3D CFD - Tree Dimensional Computer Fluid Dynamics). O modelo é validado com os dados experimentais extraídos do circuito. Em um primeiro caso de cálculo de instabilidade no circuito foi estudada, em detalhes, a relação entre padrões de escoamento instáveis e o transporte de slugs frios/quentes.

KUDARIYAWAR et al. (2016) mencionaram que projetos avançados, como o CAREM (Central Argentina de Elementos Modulares) consideram o emprego da circulação natural monofásico como um modo normal de resfriamento do núcleo do reator. Eles também demonstraram a necessidade de integração e confronto dos resultados obtidos por modelos teóricos com os extraídos de circuitos experimentais para análises deste fenômeno. Os resultados experimentais de seus estudos foram observados em um circuito de circulação natural retangular com quatro configurações diferentes, cada qual representativa de uma das formas de aplicação da circulação natural em sistemas nucleares.

Ainda que experimentalmente, o emprego de reatores de pesquisa mostraram-se uma importante e realística ferramenta no estudo da circulação natural aplicada em sistemas de refrigeração. ZHANG et al. (2015) avaliaram a capacidade de refrigeração e segurança a partir de investigações experimentais realizadas no Reator de 
Pesquisa da Universidade de Kyoto (KUR - Kyoto University Research Reactor). O Reator de Pesquisa da Universidade de Kyoto consiste de um reator de pesquisa moderado a água com potência máxima possível de 5MW. Concluíram que a operação com circulação natural em potência térmica de $100 \mathrm{~kW}$ representou a condição mais severa de operação do reator. Nesta condição, todos os parâmetros estimados estavam dentro dos critérios de segurança do reator de pesquisa.

ZHANG et al. (2015) mencionaram ainda que a circulação natural é efetiva para fins de remoção do calor do núcleo em operações de desligamento ("shutdown").

O principal objetivo dos circuitos de circulação natural é a obtenção simultânea de alta eficiência termodinâmica e operação estável. GOUDARZI e TALEBI (2015) mencionaram que o circuito de circulação natural rejeita passivamente calor das fontes para dissipadores de calor sem o emprego de bombas mecânicas. A ocorrência de instabilidades como, oscilação da pressão, potência removida, temperatura, taxa de fluxo de massa e densidade do fluído podem causar problemas na operações desses sistemas. GOUDARZI e TALEBI (2015) realizaram estudos para otimização dos parâmetros geométricos e condições operacionais em circuitos de circulação natural visando a minimização da geração de entropia resultando em um melhor desempenho e, consequentemente, maior eficiência do circuito.

A instabilidade em circuitos experimentais de circulação natural se manifesta pela ocorrência mútua do escoamento bifásico (gás-líquido). O escoamento bifásico se estabelece segundo um padrão de classificação que foi apresentado por BARBOSA Jr. (2012) como: "em bolhas" ("bubble flow"), pistonados ("plugs" ou "slugs"), agitados ("churn") e anulares. MESQUITA et al. (2009) empregaram algoritmos inteligentes para aprimoramento na detecção de bordas e reconhecimento de padrões durante fases de transições nos regimes de escoamento a partir de imagens digitais capturadas do Circuito de Circulação Natural (CCN) desenvolvido e instalado no Centro de Engenharia Nuclear (CEN) nas dependências do Instituto de Pesquisas Energéticas e Nucleares (IPEN). Eles descrevem a circulação natural como um fenômeno natural resultante de forças direcionais que surgem da diferença de densidade do fluído devido ao gradiente de temperatura em pontos diferentes do circuito.

BOURE et al. (1973) e RUPINI et al. (2014) afirmam que a instabilidade em escoamentos bifásicos pode ser avaliada a partir de uma complexa composição entre diversas variáveis. Destacam-se a variação da queda de pressão e do fluxo de massa do 
escoamento, sendo que esta última pode ser estimada a partir de correlações envolvendo a fração de vazio.

A instabilidade em sistemas de escoamento bifásico deve ser exaustivamente analisada em função da sua associação à perda de eficiência do circuito na remoção de calor.

Segundo NAYAK et al.( 2007, p. 386 - 398), estimativas precisas da fração de vazio e da perda de pressão por atrito são parâmetros chaves para a predição de um limiar de instabilidade. Eles desenvolveram um modelo linearizado baseado no modelo de deriva de fluxo com quatro equações para estudo do efeito de diferentes modelos de escoamentos bifásicos como fator multiplicador bifásico de atrito, velocidade de deriva e do parâmetro de distribuição de vazio na estabilidade do escoamento em sistemas de circulação natural. Concluíram que o uso de modelos de escoamentos homogêneos para fator de fricção como para fração de vazio prevê uma grande taxa de escoamento de circulação natural comparado com outros modelos. Em circulação natural, a taxa de escoamento depende do vazio gerado no sistema devido a adição de calor e a perda de pressão no sistema.

Os circuitos experimentais buscam a reprodução fiel do escoamento bifásico em todo o circuito projetado para implementação do sistema de refrigeração. Alguns modelos de circuito tem por finalidade a aquisição direta de imagens do escoamento por imageamento direto ou por imageamento por nêutrons para identificação, análise e estudos dos parâmetros que regem o escoamento em suas mais diversas configurações. Diversos outros parâmetros são mensuráveis nestes circuitos habilitando-os para ajustes, configuração e calibração de sistemas computacionais que são executados interativamente. A validação via confronto dos resultados obtidos por correlações teóricas e resultados experimentais bem como no aperfeiçoamento e atualização das correlações teóricas já existentes, são também objetos de aplicação desses circuitos.

SCHLEGEL et al. (2009) empregaram um modelo denominado medidor de vazio por impedância elétrica, que na realidade mede a admitância da mistura bifásica sobre uma área estabelecida de um complexo circuito experimental gerador de escoamento bifásico. As medições são armazenadas sob a forma de tensão de saída de um circuito medidor. A identificação do regime de escoamento é realizada pelo uso de um Mapa AutoOrganizado de Kohonen (SOM - Self Organized Map) empregando a Função de Densidade de Probabilidade Acumulada (CPDF - Cumulative Probability Density Function) da área média do sinal da fração de vazio, representada pela conversão do sinal de saída do 
circuito medidor. Eles relacionaram a inexistência de escoamento pistonado ("slugs bubbles") a circuitos com tubulações com grandes diâmetros. Classificaram o escoamento bifásico nos tipos: "em bolhas", bolhas capilares ("cap-bubbles") e agitado ("churn") e atribuíram à fração de vazio e ao regime de escoamento como os dois parâmetros relevantes para predição do escoamento.

Um complexo sistema experimental foi apresentado por BARBOSA, CRIVELARO e SELEGHIM JR. (2010) que permite a simulação do escoamento bifásico gás-líquido e gás sólido. A aplicação de um modelo de rede neural, denominado mapa auto organizável, apresentaram resultados precisos na avaliação e análise do modelo gás-líquido do escoamento bifásico. Seus dados de entrada do escoamento são extraídos de sensores posicionados ao longo do circuito experimental.

SMITH et al. (2012) também fizeram uso do medidor de fração de vazio por impedância elétrica para validação e confronto dos resultados de seus estudos com a aplicação do modelo de dois fluídos para cálculo do comportamento do escoamento bifásico por tratar-se do modelo mais prático disponível, embora com certa complexidade no que diz respeito aos termos de transferência interfacial.

O circuito experimental utilizado por SMITH et al. (2012) inclui uma seção de visualização do escoamento para imageamento direto empregando câmeras filmadoras com velocidade de 10000 quadros por segundo para captura das imagens aplicadas ao estudo do movimento das partículas no escoamento. Com o emprego da equação de transporte de área interfacial aliado aos resultados adquiridos experimentalmente, SMITH et al. (2012) confirmaram um critério para um regime de transição do escoamento para circuitos com tubulações com grandes diâmetros. Eles também identificaram as condições de entrada que podem induzir mudanças no padrão do escoamento.

A potencialidade do imageamento por nêutrons foi constatada por SAITO et al. (2011) na visualização do escoamento bifásico em tubulações metálicas a partir da implementação e instalação de um sistema de imageamento por nêutrons no buraco B4 do reator de pesquisa da universidade de Kyoto (KUR - Kyoto University Reactor). Eles apresentaram exemplos de imagens estáticas e dinâmicas do escoamento bifásico capturadas via imageamento por nêutrons. SAITO et al. (2011) demonstraram que a tecnologia de imageamento por nêutrons permite a visualização de escoamentos em tubulações metálicas e são mais apropriados para aplicações em que o escoamento ocorre em sistemas com alta pressão. 
UCHIMURA, et al. (1998) também fizeram uso do imageamento por nêutrons em tempo real (RTNR - Real Time Neutron Radiography) para visualização do escoamento bifásico (gás-líquido) em circuitos que empregam metal líquido. Seu principal objetivo foi a observação do movimento das bolhas em um escoamento bifásico em circuitos com metal líquido buscando extrair valores da fração de vazio e velocidade do escoamento.

SUNDE, AVDIC e PÁZSIT (2005) fazem uso do imageamento por nêutrons em circuitos com tubulação metálica. Suas análises são baseadas na integração da transformada "Wavelet" (análise de multi resolução) com uma rede neural artificial e consistem na classificação do escoamento bifásico dentre os quatro tipos de regime conhecidos. Seus resultados mostraram-se bons na identificação dos regimes em bolhas e anular, porém confusos na identificação dos regimes "churn" e "slug" em função da ocorrência simultânea desses dois tipos de regimes de escoamento.

Os estudos realizados por WANG e DONG (2009) partiram de imagens digitais capturadas por imageamento direto de um circuito experimental horizontal. Suas análises eram baseadas na construção de dois modelos matriciais (matriz de co-ocorrência de nível de cinza - GLCM e gradiente da matriz de co-ocorrência de nível de cinza GLGCM) com base nas características de texturas das imagens. Eles constataram a existência de uma relação efetiva entre estas características com a razão de densidade gás-líquido do escoamento. Esta relação não ocorre quando se trata da velocidade superficial do gás ou do líquido.

DE MESQUITA et al.(2012), KUDARIYAWAR et al.(2016), ZHANG et al.(2015), SCHLEGEL et al.(2009), SMITH et al.(2012), SAITO et al. (2011), UCHIMURA et al.(1998), SUNDE, AVDIC e PÁZSIT(2005), WANG e DONG(2009), FICHERA et al.(2000) e CRIVELARO e SELEGHIM JR.(2002) fizeram uso de circuitos experimentais para fins de reprodução dos modelos de escoamento em análise ou da similaridade do sistema a ser estudado com o projeto a ser implementado em modelos reais. O principal objetivo destes circuitos é sua representatividade para desenvolvimento de códigos matemáticos com a reprodução das principais características do escoamento permitindo sua predição em aplicações reais. A grande maioria dos estudos relatados mostraram uma convergência na identificação dos possíveis regimes de escoamento através das diversas técnicas apresentadas, muitos deles apontaram a fração de vazio como um dos principais parâmetros nesta predição e, consequentemente, na avaliação da estabilidade do sistema. 
A fração de vazio é um dos parâmetros críticos e está diretamente envolvida na predição da perda de pressão e da transferência de calor em sistemas gás-líquido, relataram WOLDESEMAYAT e GHAJAR (2007). Eles realizaram uma análise comparativa de 68 correlações de fração de vazio sobre um conjunto de dados, a partir da coleta e triagem de 2845 dados. Estas análises consideraram diferentes configurações de circuitos experimentais com diâmetro, ângulo de inclinação e regime de escoamento. Seus resultados mostraram discrepâncias de até $15 \%$ entre valores obtidos pela aplicação das correlações selecionadas e os resultados obtidos experimentalmente. Com isto fica evidente a necessidade de interações cada vez mais frequentes no sentido de alimentar e municiar tanto os estudos teóricos para obtenção de modelos mais representativos e das mais diversas condições do modelo físico, como pela aquisição experimental de parâmetros empregando as mais diversas tecnologias com o objetivo de assegurar medições dentro de precisões aceitáveis.

Em imageamento direto as imagens do escoamento devem ser controladas, ou seja, os estudos são realizados a partir da seleção de uma parcela volumétrica do escoamento. Esta seleção deve ser criteriosa, a fim de minimizar considerações sobre os efeitos óticos causadores de distorções nas imagens, bem como na compatibilização entre a configuração do equipamento empregado para a captura das imagens digitais e de parâmetros de segmentação da imagem para determinação e controle da profundidade da amostra.

KROTKOV (1987) elaborou um estudo para medição automática da qualidade do foco de uma imagem ("sharpness of focus") para formulação ou elaboração de uma métrica ou critério de "sharpness". O principal objetivo dos estudos de KROTKOV (1987) era de estabelecer um critério de distância de um objeto associado à qualidade do foco de uma imagem. Ele apresentou alguns modelos apropriados para estabelecimento do critério de "sharpness" associado à uma distância focal. O primeiro deles, denominado "Tenegrad" consiste na estimativa do gradiente da intensidade de cinza $\nabla I(x, y)$ para cada ponto da imagem e somar todas as magnitudes maiores que um limiar. As derivadas parciais para composição do gradiente são obtidas pela aplicação do operador Sobel com a convolução de kernel. O segundo modelo trata da aplicação do operador Laplaciano, $\nabla^{2} I(x, y)$, associada a convolução de kernel para cada pixel da imagem. Um terceiro modelo foi a variância do nível de cinza da imagem onde ele associou altas variâncias de nível de cinza 
a imagens com alta estrutura "sharp", ou seja, imagens bem definidas e com alta qualidade de foco.

O desenvolvimento de um modelo que associasse estes parâmetros à profundidade de campo de imagens digitais permitiria a seleção de amostra de escoamento com três dimensões e com profundidade controlada. Em função das pequenas variações ambientais passíveis de ocorrência em experimentos com captura de imagens digitais, os modelos de inferência Fuzzy mostram-se adequados à este tipo de aplicação.

MENDEL (1995) apresenta um tutorial para construção de modelos nebulosos ("fuzzy") aplicado a sistemas de engenharia. A compatibilização dos parâmetros sugeridos por KROTKOV (1987) para avaliação da qualidade de foco de imagens ("sharpness") segundo um modelo nebuloso e com base em uma análise estatística sobre imagens obtidas experimentalmente, sugere a inédita proposta de associação da profundidade de campo selecionada pela câmera de alta resolução empregada na captura de imagens digitais (ou distância focal) com um modelo lógico nebuloso que estabelece a qualidade de foco.

A integração entre algoritmos inteligentes e técnicas de processamento de imagens digitais vem contribuindo cada vez mais com a robustez e eficiência de várias aplicações nas mais diversas áreas.

DAVE e BHASWAN(1992) fazem uso da integração da lógica fuzzy com uma técnica de "clustering" para detecção parcial de formas. Concluíram que a eficiência de seus algoritmos na detecção de círculos e elipses tem desempenho comparado ao da transformada de Hough.

HAN et al.(1994) emprega a lógica nebulosa, ou lógica "fuzzy", integrada com a transformada de Hough para fins de ajuste das formas segundo um modelo geométrico bem definido.

SURAL e DAS (1999) fazem uso de um modelo denominado neuro-fuzzy no reconhecimento de caracteres em documentos digitalizados. Trata-se de um problema ótico de reconhecimento de caractere (OCR - Optical Character Recognition). As duas abordagens fundamentais para este problema são o reconhecimento de caracteres e "template matching" (comparação de modelos). Também mencionaram que o perceptron de múltiplas camadas ("MLP - Multi Layer Perceptron") e outras e outras redes neurais são frequentemente utilizadas no reconhecimento de caracteres após terem sido treinadas com um conjunto de padrões pelo treinamento supervisionado. 
BASAK e PAL (2005) apresentam uma generalização da transformada de Hough clássica pela aplicação de um modelo "Fuzzy" (denominado transformada Fuzzy Hough, ou "FHT - Fuzzy Hough Transform" ) para fins de captura de figuras com formas descritas como imprecisas, mal definidas, ou até distorcidas.

Este conjunto de citações sugerem que a integração entre algoritmos inteligentes com detectores de borda aliados à modelos de identificação e/ou associação de interfaces gás-líquido à figuras analiticamente definidas contribuiriam com uma maior robustez na identificação e mensuração da quantidade de gases em uma amostra volumétrica de escoamento bifásico.

Na medicina, ELSALAMONY (2016) faz uso de um sistema integrado na apresentação de um algoritmo para diagnóstico da ocorrência de anemia a partir de imagens microscópicas de amostras sanguíneas. A identificação e contagem de células anêmicas é realizada por uma combinação de técnicas de identificação da forma da célula, empregando transformada circular de Hough, separação de células oclusas pelo emprego da técnica Watershead e contagem final e classificação das células doentes da amostra pelo emprego de uma rede neural alimentada adiante. Seu algoritmo apresentou resultados bastante promissores, da ordem de 97 a 100\% de precisão ocasionando diagnósticos altamente precisos e eficientes.

Seguindo um modelo mais adequado na integração de técnicas para detecção de bolhas em amostras volumétricas selecionadas de imagens digitais de escoamento bifásico optou-se, neste trabalho, por uma original integração entre redes neurais artificiais multicamadas (Multilayer Perceptrons) com um exclusivo modelo de votação implementado na transformada randomizada de Hough (TRH). A esta rede neural artificial é atribuída a função de identificação e seleção da imagem contendo uma única bolha. Esta imagem selecionada possui dimensões quadradas, ou seja largura e altura, aproximadamente iguais à duas vezes as dimensões dos semi-eixos maior e menor da bolha.

HAYKIN (2001) menciona que as arquiteturas de redes neurais artificiais mais adequadas para aplicações com reconhecimento de padrões são os Perceptron de Múltiplas Camadas ( $M L P$ - Multilayer Perceptrons) e a rede de Função Base Radial $(R B F)$. Ele define formalmente o reconhecimento de padrões como o processo pelo qual um padrão/sinal recebido é atribuído a uma classe dentre um número predeterminado de classes (categorias). 
Justifica-se, portanto, a integração de um modelo de rede neural artificial multicamadas como um dos mais adequados ao reconhecimento de padrão dentre os estudados e apresentados por HAYKIN (2001). O emprego desta rede teria como proposta o reconhecimento de cada bolha em um processo inédito, iterativo e dinâmico de varredura sobre uma amostra volumétrica da imagem do escoamento bifásico. O cálculo do volume de gases de cada bolha requer o uso de um detector de borda que evidencie sua interface gás-líquido.

BHARDWAJ e MITTAL (2012) apresentam uma comparação entre diversos detectores de borda para fins de identificação daquele que proporcionou melhor performance. Concluíram que a declividade modificada apresentou melhores resultados, inclusive quando comparados com o detector Canny até então considerado o mais promissor dentre os avaliados.

MICHÉ e DEBRIE (1995) apresentam um novo operador de segmentação de imagens auto adaptativo para aplicações em tempo real. Ele é baseado em um modelo estendido de declividade para detecção de bordas em imagens com baixo contraste e sem qualquer pré-processamento.

BUENO (2016) apresenta resultados promissores para o cálculo da fração de vazio de escoamentos bifásicos a partir de imagens digitais pela aplicação de um interessante modelo integrando lógica fuzzy e declividade na detecção de bordas.

BENSHAIR, MICHÉ e DEBRIE (1996) fazem uso deste modelo de declividade em um modelo de programação dinâmica para aplicação em algoritmos de correspondência de visão binocular estéreo ("binocular stereo vision"), ou seja, a reconstituição de uma estrutura tridimensional a partir de um par de cenas tomadas de posições próximas. A opção pelo seu emprego deve-se ao melhor desempenho na varredura da imagem para detecção das bordas sem o comprometimento da complexidade de tempo do algoritmo.

A declividade tanto na sua versão básica, como na estendida, requer análise da intensidade de cinza de uma certa quantidade de pixels anterior, durante e posteriormente a formação da borda. Isto inviabiliza sua aplicação em imagens quadradas com dimensões aproximadas as das bolhas com que foram reconhecidas e selecionadas pela rede neural artificial. Estas dimensões foram estabelecidas visando evitar a extração dos parâmetros geométricos de duas ou mais bolhas próximas uma das outras considerando-as como uma 
única bolha. Recomenda-se portanto, a aplicação do operador Canny visto que, segundo BHARDWAJ e MITTAL (2012), é assumidamente uma segunda e eficiente opção para o processo de detecção de bordas.

WENYING et al. (2008) apresentam um algoritmo de segmentação de imagem baseado em um modelo aperfeiçoado do operador Canny. Aplicado em escoamento bifásico em tubulação de pequenos diâmetros, WENYING et al. (2008) concluíram que o modelo desenvolvido é efetivo para análise e reconhecimento de bolhas em escoamentos multifásicos, no entanto o algoritmo necessita ser melhorado para obtenção de resultados melhores.

A transformada de Hough tanto em sua aplicação convencional, como em seus modelos avançados, fazem uso das coordenadas dos "supostos" pixels das bordas das bolhas detectadas pela aplicação do operador Canny. Estas coordenadas seriam utilizadas na identificação dos parâmetros geométricos descritivos das figuras analíticas (elipses ou circunferências) que melhor se ajustem à este conjunto de pixels.

A complexidade de tempo e espaço de algoritmos que aplicam a transformada de Hough em sua forma convencional cresce exponencialmente em função do acréscimo dos parâmetros considerados nas dimensões de uma matriz acumuladora. Esta última, representada pela variação de cada parâmetro geométrico da figura analítica a ser detectada. Um grande número de alternativas foram resultantes da busca de vários autores para a solução desta indesejável situação. Muitas delas foram eficazes na redução da complexidade de tempo e espaço, porém, pouco efetivas na robustez dos resultados.

TSUJI e MATSUMOTO (1978) relataram que a aplicação direta da transformada de Hough para detecção de objetos elípticos em imagens digitalizadas requer uma matriz acumuladora de dimensão cinco para indexação de parâmetros especificando sua localização, forma e orientação. Seu uso torna-se impraticável em função do longo tempo computacional e grande necessidade de memória. Eles propuseram a ideia de contornar este problema a partir da avaliação de clusters em um espaço de parâmetros bidimensional e unidimensional empregando uma propriedade conhecida das elipses para seleção de um número menor de pontos candidatos à borda de uma elipse. Os cinco parâmetros que melhor ajustam a elipse a partir destes candidatos são avaliados pelo método dos mínimos quadrados. Suas conclusões e discussões foram realizadas sobre imagens digitalizadas e sintetizadas (com 128 x 128 pixels). Embora o algoritmo tivesse 
apresentado resultados satisfatórios para estas condições identificaram a deficiência na detecção de elipses parcialmente obstruídas.

BALLARD (1981) apresenta a transformada generalizada de Hough como uma composição de mapeamentos de formas simples para construção de mapeamentos de formas complexas. Ele associa esta propriedade da transformada generalizada de Hough a um tipo universal de transformada que pode ser usada para encontrar formas complexas. Embora não faça nenhuma menção à complexidade de tempo e espaço, ele propõe a realização de estudos para melhoria de desempenho de seu algoritmo.

DAVIES (1987) apresenta um novo algoritmo, baseado na transformada de Hough, para detecção de objetos circulares em imagens digitais. Embora admita a boa robustez do algoritmo na supressão de imagens com ruído, DAVIES (1987) reconhece um melhor desempenho do modelo original da transformada de Hough em imagens com oclusões ou quebra de objetos superior a um quarto da circunferência de um objeto.

NIXON (1989) apresenta uma versão estendida da transformada de Hough com a proposta de construção de um algoritmo mais eficiente em termos de tempo de execução e ocupação de memória que sua versão original. Seu algoritmo é baseado nas informações do gradiente residual nos pontos de intersecção local da forma verdadeira e da forma estimada do objeto para ajuste na imagem. Análises do resíduo entre a tangente local da forma e a direção prevista revelaram uma relação analítica para a discrepância na presente estimativa. Concluiu que a técnica estendida é não linear e nem sempre resulta em valores exatos para cada parâmetro.

YUEN, ILLINGWORTH e KITTLER (1989) apresentaram uma alternativa para contornar os problemas de armazenagem e desempenho da transformada de Hough em seu modelo original. Eles realizaram a decomposição da transformada de Hough em duas fases. O método mostrou-se eficiente em diversas situações tendo como relevância a detecção de elipses parcialmente oclusas.

XU, OJA e KULTANEN (1990) propuseram um método que captura aleatoriamente " $\boldsymbol{n}$ " pixels e os mapeia sobre um ponto no espaço de parâmetros. Seus resultados mostraram um novo e efetivo método no que diz respeito a necessidade de espaço para armazenamento, velocidade de processamento e alta resolução.

YIP, TAM e LEUNG (1992) indicam o emprego da transformada de Hough para extração das propriedades geométricas de figuras analíticas por se tratar de uma 
técnica reconhecidamente robusta para detecção de formas definidas analiticamente. Eles apresentaram um modelo modificado da transformada de Hough com a redução da necessidade de espaço de memória, sem o comprometimento de sua eficiência e robustez. Tal modelo está fundamentado na redução da matriz acumuladora para uma matriz bidimensional.

XU e OJA (1993) expõe as vantagens da transformada randomizada de Hough em relação a original e suas variantes. Eles apresentam detalhadamente os fundamentos da transformada randomizada de Hough demonstrando, com base em conceitos teóricos e experimentais, as vantagens desta promissora técnica de extração de características de formas geométricas.

YOO e ISHWAR(1993) apresentam uma variação da transformada de Hough para detecção de formas elípticas baseadas na definição polar e de polos das cônicas. A principal vantagem desta definição é evitar a propagação dos erros na estimação de parâmetros sobre os sucessivos estágios da transformada de Hough original. O método proposto mostrou ser preciso, mesmo com reduzido número de pares de pontos, permitindo a detecção de elipses oclusas e concêntricas com precisão.

MCLAUGHLIN (1998) descreve um algoritmo para detecção de formas elípticas com base na transformada randomizada de Hough. Seu método é comparado com três outros métodos, também baseados na transformada de Hough. O modelo apresentado por MCLAUGHLIN(1998) mostrou-se mais preciso na redução do número de pontos das imagens originais e detecção de falsas elipses.

INVERSO (2002) apresenta em seu algoritmo uma particularização da transformada randomizada de Hough para detecção de elipses com ângulos com semi-eixo maior ortogonal e paralelo ao eixo das abscissas. Evidencia que o maior desgaste no desenvolvimento de seu projeto foi na derivação das equações da elipse. Segundo INVERSO (2002) a transformada randomizada de Hough não reduz significantemente o tempo de processamento e os requisitos de memória necessários para captura das elipses.

YU, LIU e HE (2008) apresentam uma variação da transformada randomizada de Hough empregando um ponto de controle de cônicas e um vínculo entre as normais nos pontos finais das cordas da elipse. Isto tem como consequência uma grande redução da amostragem e acumulação. Outro fator de grande importância é o emprego de um modelo empregando lógica fuzzy para seleção entre as diversas elipses candidatas que surgem 
devido ao reduzido número de pontos nas bordas detectadas nas imagens. A aplicação da lógica fuzzy tem como base o uso do "status" de distribuição dos pontos da borda da elipse candidata em relação a área do polígono inscrito. Este modelo está fundamentado na visão perceptual de agrupamento. Isto contribui para a confiança nos resultados extraídos e, portanto, na precisão do cálculo da fração de vazio.

CHENG, GUO e ZHANG (2009) desenvolveram um interessante algoritmo com integração da transformada randomizada de Hough com um algoritmo genético para seleção aleatória dos pares de pontos mais promissores selecionados a partir de uma função de ajuste. Concluíram um melhor desempenho do algoritmo na detecção de curvas claras e com ruídos.

ZHANG, JIANG E LIU (2012) mencionaram que a injeção de gás acima de $1 \%$ em circuitos verticais simuladores de escoamento bifásico resulta na ocorrência de bolhas oclusas na ordem de $40 \%$. Existem dois reconhecidos métodos para tratar com bolhas oclusas em imagens digitais e estimativas da distribuição do tamanho das bolhas (BSD - Bubble Size Distribution). O método apresentado é baseado em dois passos fundamentais. O primeiro deles, denominado segmentação de contorno, assume que "pontos côncavos" em uma sequência dominante de pontos estão sempre conectados. O agrupamento de segmentos, segundo passo, é principalmente baseado no critério do desvio da distância média entre a curva ajustada e uma dimensão correspondente, por exemplo, uma estimativa da área da figura correspondente. Segundo os autores, os resultados mostraram-se bastante precisos quando comparado com outros dois métodos, porém, podese avaliar ainda a ocorrência de falsas estimativas em função do agrupamento de duas bolhas como se fossem uma única.

TENG, KIM e KANG (2012) apresentam uma metodologia baseada na transformada randomizada de Hough com aperfeiçoamento no esquema de votação. Os cinco parâmetros da elipse são votados separadamente em dois passos: o primeiro voto é para identificação das coordenadas do centro e o segundo é para os demais parâmetros (comprimento do semi-eixo maior e semi-eixo menor e ângulo entre o semi-eixo maior e o eixo das abscissas. A principal contribuição de TENG, KIM e KANG (2012) consiste na análise da variação dos ângulos das linhas tangentes nos pontos da borda para diferenciá-los entre ruído e pontos do padrão da elipse e a derivação das equações para extração dos cinco parâmetros da elipse por um esquema de votação em dois níveis. Seus resultados mostraram-se bastante promissores no que diz respeito ao desempenho do 
algoritmo e sua precisão mesmo em casos de imagens com objetos elípticos parcialmente representados.

MUKHOPADHYAY e CHAUDHURI (2015) apresentam uma síntese dos últimos cinquenta e um anos de pesquisa e desenvolvimento da transformada de Hough e se surpreenderam em relação ao ainda grande número de atualizações desta metodologia nos últimos cinco anos. Mencionam a existência de escopo para desenvolvimento da transformada de Hough com os mais diversos objetivos como, velocidade, precisão e resolução especialmente na detecção parcial de formas e perspectivamente curvas complexas e distorcidas bi e tri dimensionais.

STROKINA et al. (2016) apresentaram uma metodologia para detecção de bolhas circulares concêntricas empregando a transformada circular de Hough. Eles relataram a ocorrência da formação de bolhas em dispersões de óleo e relacionaram a formação de círculos concêntricos à ocorrência de uma grande quantidade de efeitos óticos distintos como reflexão, refração, interferência e outros. Embora satisfatórios, seus resultados apresentaram um erro relativo médio de $28 \%$ no volume de gás em uma aplicação industrial de bomba de suspensão.

RICCA, BELTRAMETTI e MASSONE (2016) apresentaram minuciosamente todos os fundamentos matemáticos da transformada de Hough como sua principal ferramenta para identificação de imagens com simetria. O alvo de aplicação desta tecnologia é a identificação de anomalias em imagens médicas, mais especificamente, tomografia computadorizada por raio $\mathrm{X}$.

O emprego da transformada randomizada de Hough (TRH) mostra-se uma eficiente ferramenta no desenvolvimento de aplicações para identificação dos parâmetros geométricos de figuras que melhor se ajustem às bordas de interesse das bolhas (interface gás-líquido) reconhecidas na amostra volumétrica da imagem do escoamento através da seleção pela rede neural artificial multicamada e alimentada adiante (Feedforward Multilayer Perceptron). Este modelo apresenta-se como o mais adequado para aplicação em imagens com poucas bolhas conforme avaliação de MC LAUGHLIN (2002). Sua integração com a rede neural artificial em um processo dinâmico de sucessivas varreduras da amostra volumétrica da imagem digital do escoamento bifásico representa um processo original na pesquisa e desenvolvimento de ferramentas aplicadas aos estudos do escoamento bifásico. A meta desta parte do processo é o cálculo do volume de gás em uma amostra volumétrica selecionada de uma imagem digital de escoamento bifásico. A razão 
entre este volume de gás e o da amostra resulta na estimativa da fração de vazio que, baseada em um conjunto de ajustes, medições e confrontos com resultados experimentais, permitem a estimativa deste parâmetro para todo um circuito de circulação natural. 


\subsection{Concepção e descrição do sistema}

O sistema computacional foi concebido para operar em três fases distintas recebendo as imagens digitais do escoamento capturadas de um circuito experimental como principal entrada. Informações adicionais sobre o experimento como a resolução da câmera utilizada na captura das imagens, seu posicionamento em relação ao circuito, o diâmetro e o comprimento da secção do tubo de vidro do circuito experimental enquadrado pela câmera são necessárias para calibração, ajuste e configuração final do sistema.

A concepção do sistema computacional para cálculo da fração de vazio é representada pelas fases de operação apresentadas na figura 10. Elas são ilustradas pelos blocos no centro da figura. As entradas de cada fase estão à esquerda de cada bloco e suas respectivas saídas, à direita. Cada fase foi concebida em função de seu objetivo específico. A primeira delas consiste na seleção de uma amostra do escoamento bifásico e recebe como entrada uma imagem digital obtida de seção da tubulação do circuito experimental. A imagem é capturada com a câmera posicionada de modo a utilizar todo o sensor ótico, alinhando a maior dimensão do sensor com a maior seção longitudinal capturada do tubo cilíndrico. O sentido do escoamento é da direita para a esquerda nas imagens representadas neste trabalho. Este sentido corresponde ao escoamento ascendente no circuito experimental. O sistema realiza a conversão da imagem, originalmente colorida, em escala de cinza normalizada com posterior rotação de noventa graus no sentido horário. A seleção das dimensões da amostra do escoamento considera a ocorrência de distorções devido aos efeitos óticos na aquisição da imagem e compatibilização da profundidade de campo selecionada na câmera com seu foco. Na fase seguinte, a amostra do escoamento será sucessivamente varrida por máscaras virtuais para reconhecimento das bolhas no escoamento e cálculo do volume de cada uma delas. O somatório desses volumes atribuído a uma variável acumuladora representa, ao final desta segunda fase, o volume total de gás contido dentro dos limites da amostra. A terceira e última fase do sistema calcula a razão entre o volume de gases e o volume total da amostra resultando na estimativa da fração de vazio da amostra da imagem capturada do escoamento bifásico.A partir de uma adequada calibração, pode-se assumir o resultado desta saída do sistema como uma medida extensiva 
da fração de vazio média relativa a todo o volume de interesse do circuito experimental. Este conjunto de algoritmos são integrados visando a obtenção de uma estimativa da fração de vazio local após calibração e comparação com a medida direta, supondo que a amostra seja representativa de um grau de homogeneidade deste parâmetro de escoamento ao longo do circuito.

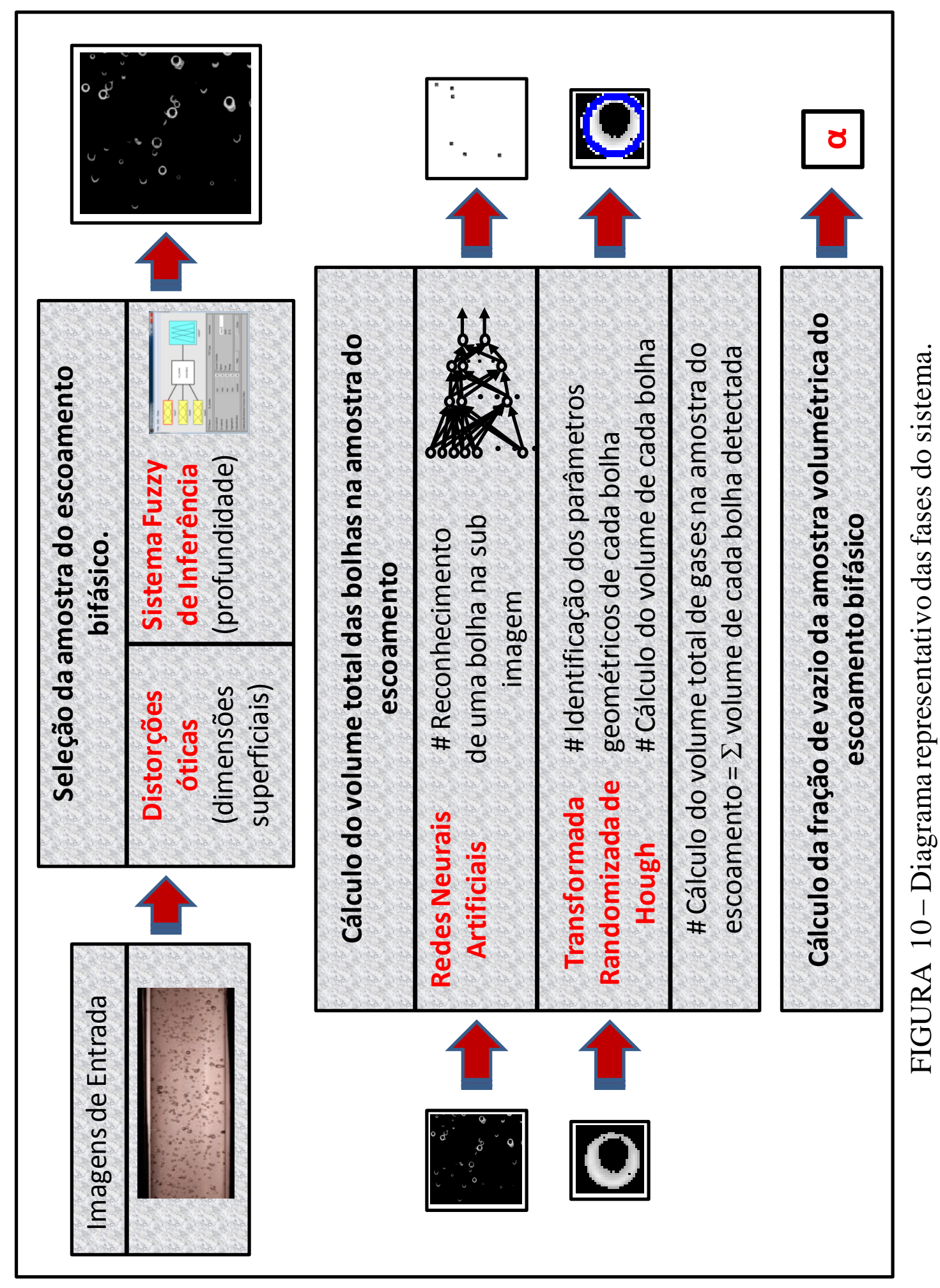




\subsubsection{Seleção da amostra do escoamento}

Trata-se da primeira fase do sistema e consiste na execução de uma sequência de operações digitais sobre a imagem do escoamento finalizando na seleção de uma amostra da imagem do escoamento capturada do circuito experimental, figura 11.

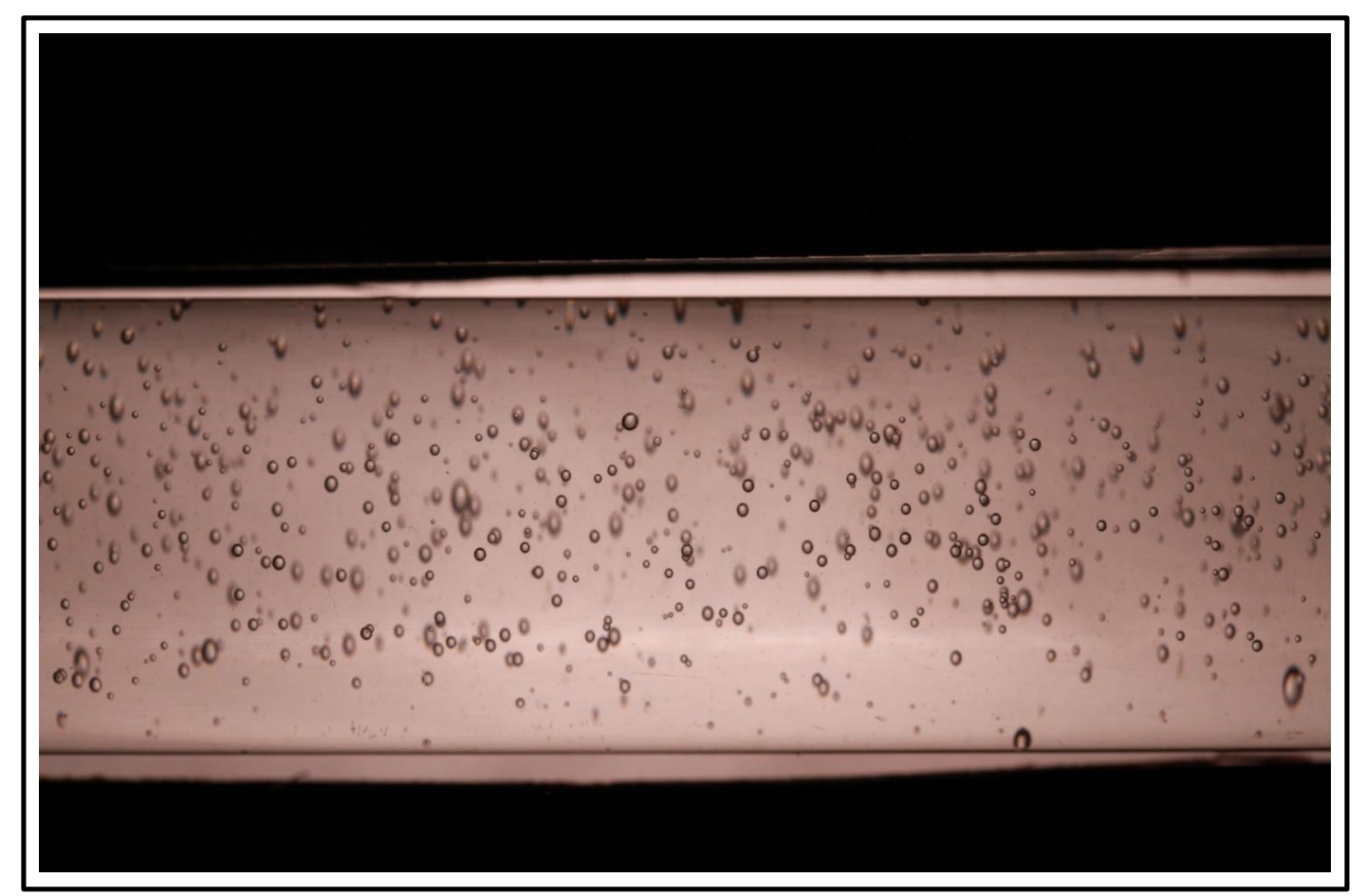

FIGURA 11 - Exemplo de uma imagem digital capturada do circuito gerador de escoamento bifásico. ARQUIVO: IMG_0805.JPG

FONTE: Bancada de calibração da fração de vazio - CEN/IPEN.

Inicialmente a imagem é convertida para uma representação em escala de cinzas normalizada, ou seja, com variação na intensidade de grau de cinza entre zero (preto) e um (branco). Além de estabelecer uma normalização para todas as imagens, a conversão em níveis de cinza torna o desenvolvimento e a execução das demais aplicações mais simples e econômicas em termos de ocupação de memória e tempo de processamento.

As dimensões frontais da amostra visam a minimização da inclusão na amostra da imagem de partes dela que incluem distorções da imagem devidas aos efeitos óticos que ocorrem. O principal deles está relacionado ao desvio dos feixes de luz advindos da amostra em direção à câmera fotográfica ocasionado pela refração por duas interfaces, a primeira entre a água e o vidro do tubo e a segunda entre o vidro do tubo e o ar. Alguns estudos sobre o foco na aquisição de imagens neste tipo de experimentos foram publicados recentemente pelo grupo do CEN que estuda o CCN (MASOTTI E DE MESQUITA 2015, p. 175-205) que descrevem parte do problema das distorções causadas por este fenômeno em tubos cilíndricos de vidro. 
Outros efeitos óticos podem ser observados que estão relacionados à reflexão interna da luz e à interferência entre feixes advindos destas reflexões internas e feixes advindos do exterior do tubo. Eles estão diretamente relacionados a formação de sombras sobre as interfaces gás/líquido dificultando sua identificação.

A profundidade da amostra é obtida por uma inovadora aplicação envolvendo um modelo fuzzy de inferência para mapeamento da profundidade de campo selecionada na câmera aos parâmetros de segmentação de imagens, indicados por KROTKOV (1987) como representativos do seu foco. A aplicação deste modelo sobre cada pixel da imagem realiza este mapeamento fundamentado na combinação desses três parâmetros:

- a intensidade de cinza normalizada;

- a soma da intensidade negativa de cinza, ou seja, do inverso da intensidade de cinza, "1-I(x,y)", ao operador Sobel. Este último representando a primeira derivada da variação da intensidade de cinza do pixel. Esta composição é normalizada de forma a ajustar seus valores ao domínio $[0,1]$ e

- adição da intensidade negativa de cinza com o resultado da aplicação do operador Laplaciano. Este último representando a segunda derivada sobre a variação da intensidade de cinza. Esta composição também é normalizada para fins de ajuste dos seus valores no domínio $[0,1]$.

A associação da intensidade negativa de cinza aos operadores Sobel e Laplaciano normalizados, para cada pixel da imagem, tem o propósito de relacionar este parâmetro a uma função crescente em concordância a como normalmente são apresentados os valores dos operadores Sobel e Laplaciano. O modelo da inferência focal fuzzy aplicado sobre uma imagem do escoamento está esquematizado na figura 12.

As entradas do modelo de inferência fuzzy são extraídas da imagem após sua conversão em intensidade de cinza normalizada, rotação de noventa graus no sentido antihorário e seleção das dimensões frontais conforme os critérios adotados para limitação da percepção dos efeitos de distorção ótica. Após este processo são aplicados os operadores Sobel e Laplaciano sobre cada pixel desta imagem resultando em mais duas novas imagens, também normalizadas, com as mesmas dimensões da original. Realiza-se a soma da imagem com intensidade negativa de cinza normalizada à estas duas resultantes, compondo assim a entradas do modelo fuzzy. A aplicação do modelo de inferência focal fuzzy se faz sobre cada pixel nas mesmas posições dessas imagens. Eles são "fuzzificados" 
segundo funções de pertinência previamente elaboradas e com base em um estudo sobre as bordas das bolhas consideradas "em foco" e "fora de foco" apresentado no apêndice A.

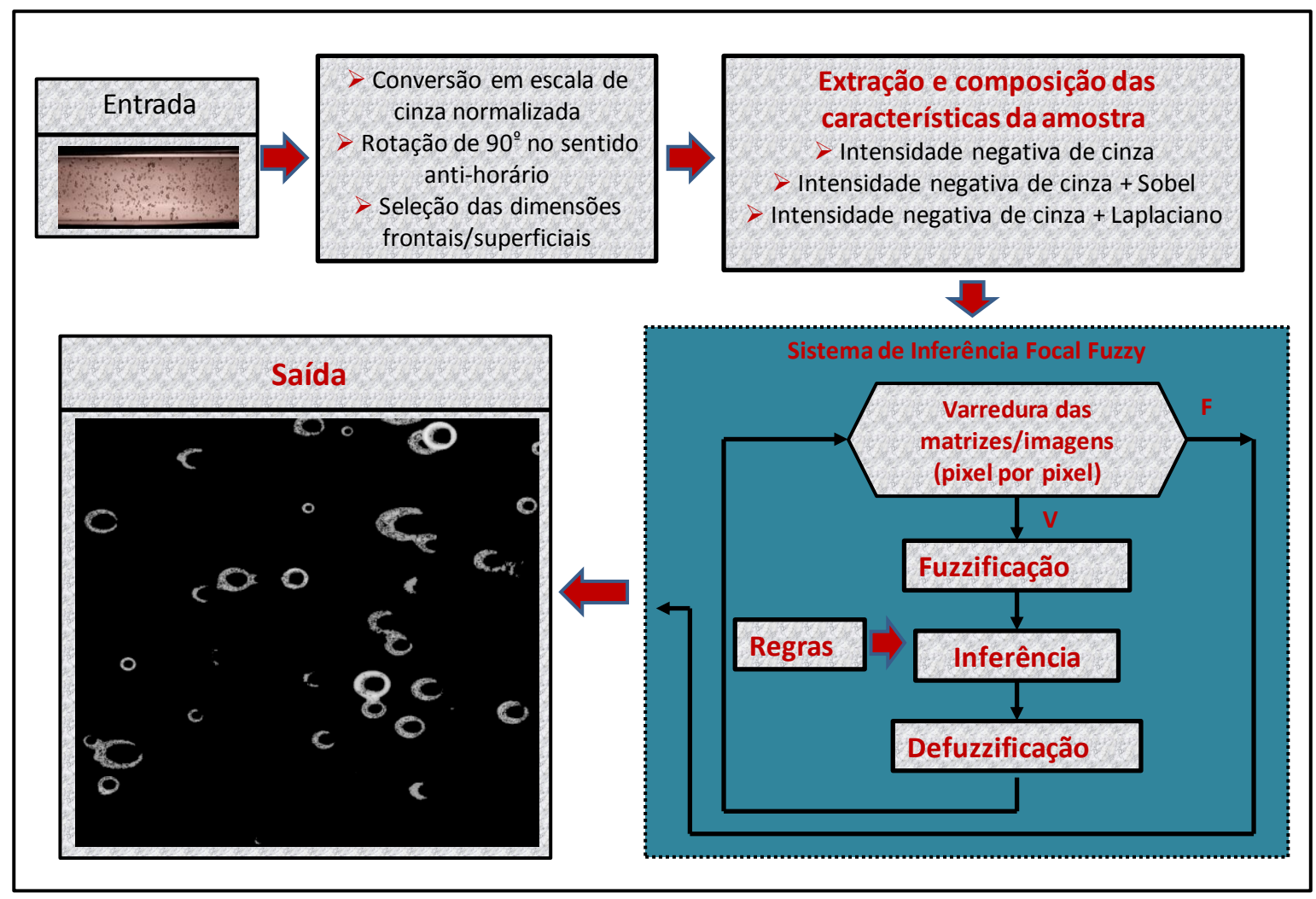

FIGURA 12 - Representação esquemática da fase de seleção da amostra sobre uma imagem digital do escoamento bifásico

Após a inferência das regras sobre estas variáveis e aplicação do processo de "defuzzificação", os pixels "em foco" são preservados com seus valores de intensidade negativa de cinza normalizados. Os pixels "fora de foco" são eliminados por serem considerados fora da profundidade de campo selecionada na câmera utilizada no experimento. Assim como as funções de pertinência do processo de "fuzzificação" as empregadas na "defuzzificação" consideram a associação dos resultados do experimento de medida direta da fração de vazio comparando com a profundidade de campo utilizada na aquisição.A profundidade de campo utilizada na aquisição da imagem é aferida segundo uma escala de nível posicionada na lateral da tubulação do circuito experimental.

Este modelo de inferência focal fuzzy tem como fundamento a aplicação de lógica matemática voltada a aplicações envolvendo variações de seus elementos e que podem produzir resultados dentro de certa faixa de variações predeterminadas. Estas faixas de variação são viabilizadas por variáveis linguísticas, que contém uma descrição intuitiva e prática do conceito envolvido em cada variável. Estes modelos são conhecidos como lógica fuzzy ou lógica nebulosa. A iniciativa de desenvolver um modelo empregando esta 
tecnologia deve-se a possibilidade da variação dos parâmetros de segmentação da imagem como consequência das variações na luminosidade do ambiente em que os experimentos são realizados. A estrutura de um sistema fuzzy de inferência, seus processos, elementos e sua fundamentação, são apresentados em detalhes na seção 4.2.1.

A figura 13 ilustra um modelo representativo de todas as métricas mencionadas e utilizadas para o estabelecimento das dimensões frontais e de profundidade da amostra do escoamento bifásico. O volume desta amostra representa um importante valor para o cálculo da estimativa final da fração de vazio.

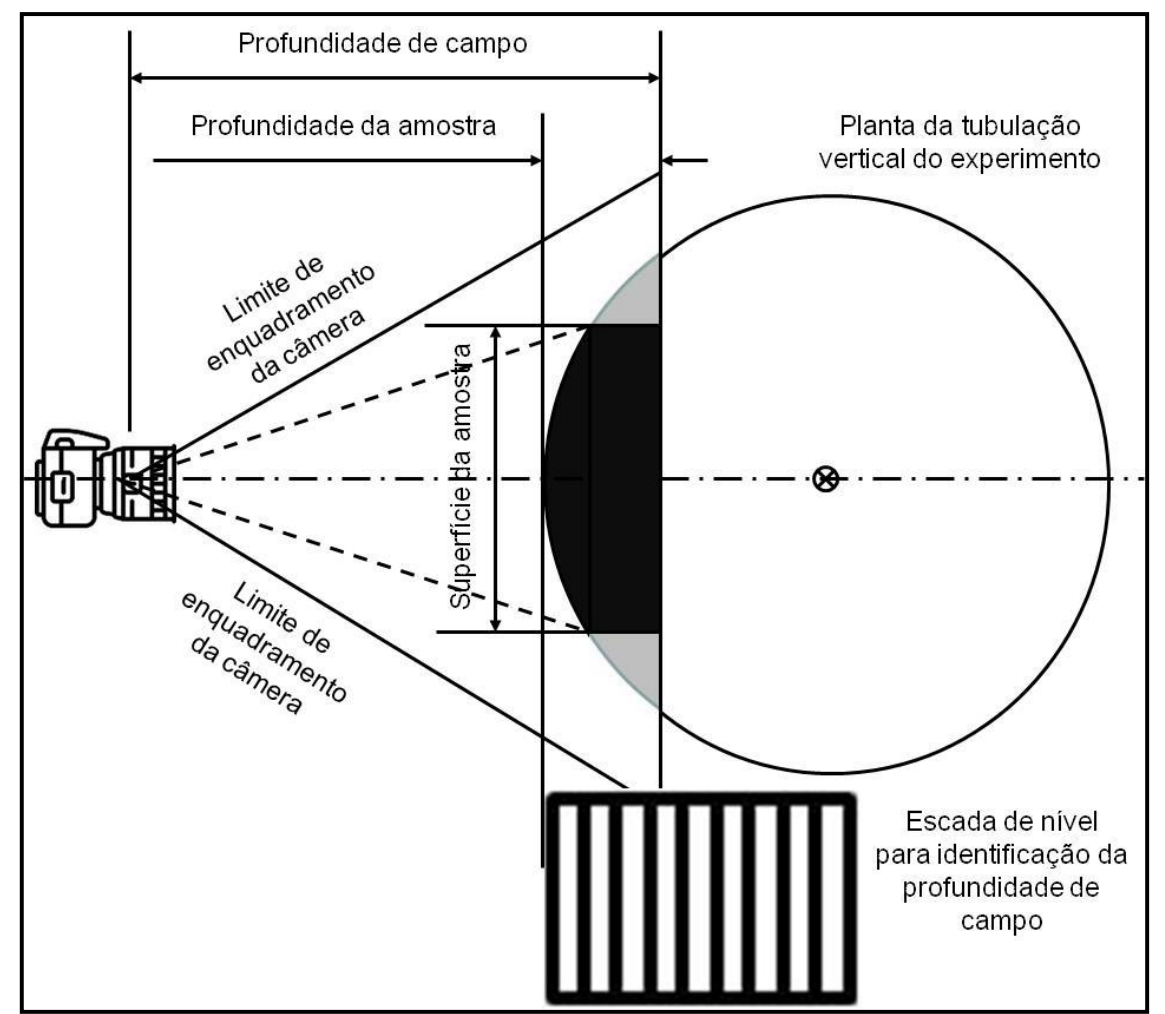

FIGURA 13 - Representação esquemática das métricas adotadas para definição da amostra do escoamento bifásico

\subsubsection{Cálculo do volume total das bolhas na amostra do escoamento}

Esta segunda fase do sistema recebe a amostra da imagem do escoamento como entrada que doravante será denominada amostra do escoamento ou simplesmente amostra. Trata-se da imagem resultante da execução da primeira fase do sistema que é considerada ser representativa do escoamento bifásico ao longo do circuito experimental no instante de sua captura. O somatório do volume estimado de todas as bolhas nos limites desta amostra deverá representar o volume total de gás dentro das suas dimensões e trata-se de um importante parâmetro para o cálculo da fração de vazio. 
O cálculo do volume de cada bolha é realizado mediante sua detecção (ou reconhecimento) e na identificação dos parâmetros geométricos da figura analítica (elipse ou circunferência) que melhor se ajusta à borda externa (interface gás/líquido) da projeção ortogonal da elipse bidimensional capturada na imagem fotográfica. Este volume supõe que a elipse bidimensional represente sua projeção com seus eixos maior e menor paralelos ao plano do sensor da câmera. Supõe-se ainda que as bolhas com projeção elíptica sejam homogêneas e regulares. Também fica implícito a ocorrência de erros nos casos em que bolhas elípticas que projetem uma circunferência no sensor. A descrição do cálculo simplificado está contida na seção 4.2.4. O volume de cada bolha detectada é adicionado a uma variável acumuladora que tem seu valor atualizado sempre que uma nova bolha é detectada. A imagem da bolha é eliminada da amostra após a execução desta sequência de procedimentos. A variável acumuladora conterá, ao final da detecção de todas as bolhas, a estimativa do volume total de gases da amostra.

Esta metodologia é original em todas as suas características pois envolve o emprego de máscaras virtuais para convolução da imagem da amostra. Estas máscaras quadradas, ou seja, com altura e largura iguais, iniciam o processo com dimensões equivalentes às das menores bolhas observadas em todas as imagens de escoamento. Elas varrem toda a imagem da amostra do escoamento pixel por pixel. Ao finalizar a varredura da amostra, a dimensão da máscara é aumentada para início de uma nova varredura. Este processo se repete até a dimensão da máscara atingir valores equivalentes aos das maiores bolhas observadas no escoamento. As máscaras virtuais operam como selecionadoras de subimagens. Elas são deslocadas sobre a imagem da amostra do escoamento fazendo a seleção de subimagens de acordo com suas dimensões. Este deslocamento ocorre pixel a pixel, ou seja, coluna por coluna e linha por linha. Em cada seleção é executada uma rede neural artificial previamente configurada e treinada para as dimensões da máscara virtual. Ela tem a finalidade de reconhecimento da imagem de uma bolha dentro dos limites da máscara virtual, ou subimagem. Caso não seja identificada nenhuma bolha, a máscara virtual é deslocada de um pixel segundo a metodologia adotada para a varredura da amostra e inicia um novo processo para a detecção de uma bolha sobre uma nova subimagem. Na ocorrência do reconhecimento de uma bolha na subimagem, executa-se um processo para associação da figura geométrica formada pela borda da bolha a uma definida analiticamente podendo ser uma elipse ou circunferência (caso especial de uma elipse com semieixos maior e menor iguais). Este processo foi desenvolvido com base na 
transformada randomizada de Hough (RHT - Randomized Hough Transform) que tem como principal fundamento a associação de figuras geométricas analiticamente bem definidas a conjuntos de pontos selecionados aleatoriamente e, no caso deste trabalho, supostamente localizados nas bordas das bolhas em imagens digitais.

Uma vez associada as propriedades geométricas de uma figura analítica aos pixels que descrevem sua borda (pixels de borda), é realizado o cálculo do volume da bolha adicionando este valor em uma variável acumuladora do volume de todas as bolhas anteriormente detectadas. Após a atualização desta variável, a bolha é eliminada da amostra da imagem de escoamento para evitar uma segunda identificação em outra varredura com uma máscara virtual com dimensões maiores. A máscara virtual é então deslocada de um pixel segundo a metodologia de varredura estabelecida dando continuidade ao processo.

A figura 14 retrata este conjunto de processos e nela descreve-se o procedimento inédito e original da varredura da imagem de cada amostra de escoamento empregando com a aplicação integrada de máscaras virtuais com uma rede neural artificial com múltiplas camadas e alimentada adiante ("Feedforward Multilayer Perceptron") para detecção das bolhas em conjunto com a utilização da transformada randomizada de Hough (TRH). Este procedimento visa a extração das propriedades geométricas da figura analítica que melhor se ajuste à borda externa de cada bolha detectada. Esta borda é considerada como representativa da interface gás-líquido do escoamento. Ainda que necessária para a realização dos cálculos, esta integração assegura uma maior precisão e consequente "robustez" ao cálculo geral do volume total das bolhas visto que:

- as bordas de falsas bolhas detectadas ("falsos positivos") pela rede neural, dificilmente serão consistentes a ponto de serem associadas a uma figura analítica pela TRH;

- a TRH somente associará os supostos pixels de borda da imagem à uma bolha se, pelo menos, 55\% deles pertencerem a uma elipse ou circunferência definida analiticamente dentro das dimensões da máscara de varredura. Esta consideração torna-se muito útil para a avaliação mais precisa da ocorrência de bolhas quando estão localizadas em uma região do tubo que está no limiar da profundidade de campo da aquisição da imagem ou da ocorrência daquelas bolhas que estejam parcialmente oclusas e

- o acréscimo gradual nas dimensões da máscara de varredura visando a detecção de uma única bolha na subimagem evita a associação de duas figuras analíticas próximas a uma 
única forma na imagem (uma das principais possíveis fontes de erros pela utilização da $\mathrm{TRH}$ ), devido à proximidade de seus pixels.

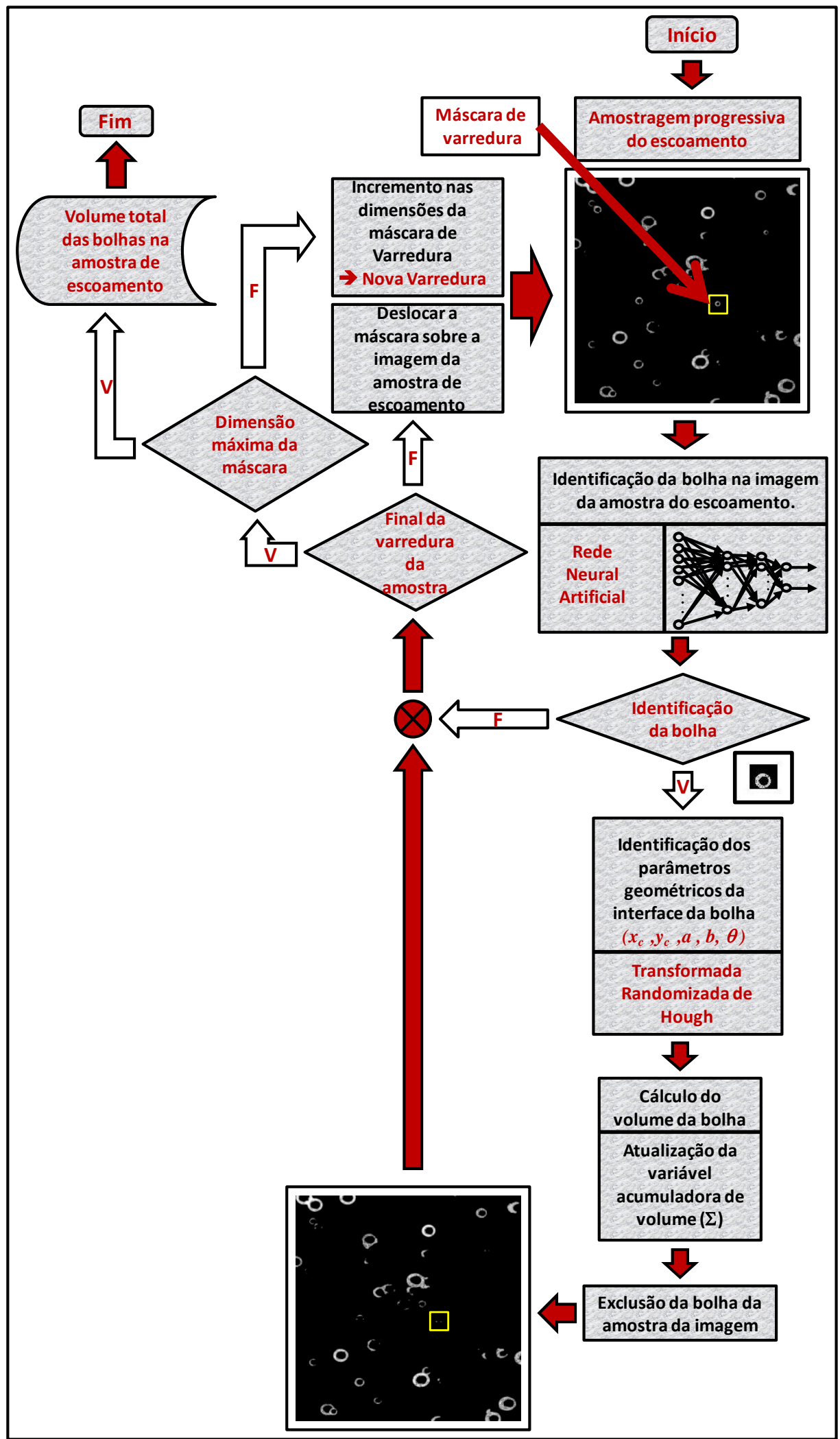

FIGURA 14 - Representação esquemática do cálculo do volume total das bolhas na amostra de escoamento 
Redes Neurais Artificiais (RNA) são algoritmos inteligentes com arquitetura inspirada no modelo biológico de funcionamento do cérebro. Elas são constituídas por uma rede interligada de elementos de processamento chamados de neurônios artificiais. Esta rede em geral é organizada em colunas destes elementos que são chamadas de camadas de neurônios artificiais (podem ser camadas de entrada, escondidas e de saída). As camadas de entrada são as que recebem os sinais sensoriais, no caso, a intensidade dos pixels da subimagem selecionada pela máscara virtual. O número de elementos da camada de entrada da rede neural artificial multicamadas (RNA) é definida em função da dimensão da subimagem, ou seja, pela altura e largura da máscara de varredura. Ela consiste no total de pixels tanto da máscara de varredura como na sub imagem correspondente. Estes algoritmos RNA serão melhor descritos na seção 4.2.2.

O número de elementos da camada de entrada da rede neural artificial multicamadas (RNA), neste trabalho, é definido em função da dimensão da subimagem, ou seja, pela altura e largura da máscara de varredura. Ela consiste no total de pixels tanto da máscara de varredura como da sua correspondente subimagem. A saída da RNA é um vetor com dois elementos e para um resultado positivo este vetor deverá ter o valor do seu primeiro elemento igual a um ("1") e do segundo igual a zero ("0"). Qualquer outra combinação dos valores dos elementos desse vetor representará uma saída "negativa" e isto significa a ausência de bolhas na subimagem. O número inicial de elementos da camada de entrada da RNA é de 901, correspondente a uma subimagem de 30 por 30 pixels vetorizada, ou seja, com as colunas da matriz 30 x 30 da subimagem rearranjadas sequencialmente e pela introdução de um primeiro elemento com valor igual a um ("1"), representando uma entrada correspondente ao elemento independente da RNA para fins de padronização do seu modelo de cálculo. $\mathrm{O}$ valor de 30 pixels representa o diâmetro de uma bolha circular ou comprimento máximo do maior eixo de uma bolha elíptica a ser detectada. Este valor é estabelecido em consequência de análises quantitativas sobre um conjunto significativo de imagens de amostras de escoamento tendo como principal restrição a não detecção de duas bolhas, mesmo que parcialmente oclusas.

Após a varredura de uma amostra de imagem a dimensão da máscara de varredura é aumentada seguindo estas mesmas restrições para início de uma nova varredura. Uma nova camada de entrada será acrescentada a esta rede neural e o conjunto de pesos sinápticos serão substituídos por outro, correspondente a esta nova configuração. Este processo iterativo se repetirá até as dimensões da máscara de varredura atingir valores 
correspondentes aos das maiores bolhas observadas nestas 100 imagens de amostra de escoamento.

O treinamento da RNA é realizado de forma iterativa e tem como elemento de entrada um conjunto de amostras "rotuladas", também conhecido como amostras de treinamento. Trata-se de um arquivo contendo um grande número de subimagens vetorizadas e suas saídas correspondentes. Este arquivo de treinamento, é construído manualmente pela seleção de diversas amostras "positivas" e "negativas". São consideradas "positivas" as amostras que:

- apresentarem apenas uma única bolha completa inscrita em suas dimensões;

- todos os seus pixels de borda terem ao menos um pixel vazio de espaço vazio entre os limites da máscara virtual de varredura e

- apenas um dos limites da máscara virtual de varredura poderá conter pixels de borda de bolhas inscritas.

As subimagens "negativas" são caracterizadas:

- pela ausência de bolhas completas nos limites da máscara virtual de varredura podendo conter apenas;

- bolhas que contenham pixels de borda ocupando mais de uma das linhas limitantes da máscara de varredura;

- partes de bolhas eliminadas por varreduras anteriores;

- bolhas incompletas, mesmo que nos limites da máscara virtual de varredura e

- bolhas parcialmente fora dos limites da amostra de escoamento.

Estas últimas restrições são impostas devido a possibilidade de seleção errada de bolhas com dimensões maiores que a própria máscara virtual de varredura. A seleção das amostras de treinamento é realizada sobre cada uma das imagens da amostra de escoamento bifásico. São selecionadas cerca de quatro a cinco mil amostras para construção de um arquivo de treinamento correspondente às dimensões de uma única máscara de varredura.

O treinamento de cada rede neural utiliza a minimização de uma função de custo e de suas variações em relação aos pesos sinápticos para a correspondente configuração da RNA. $\mathrm{O}$ resultado de cada treinamento é um conjunto de pesos sinápticos associado às configurações da RNA para cada dimensão de máscara de 
varredura, figura 15. Este conjunto de pesos sinápticos representam a base de conhecimento da RNA e é implementado sempre que a rede for executada para reconhecimento de uma bolha dentro dos limites de uma subimagem.

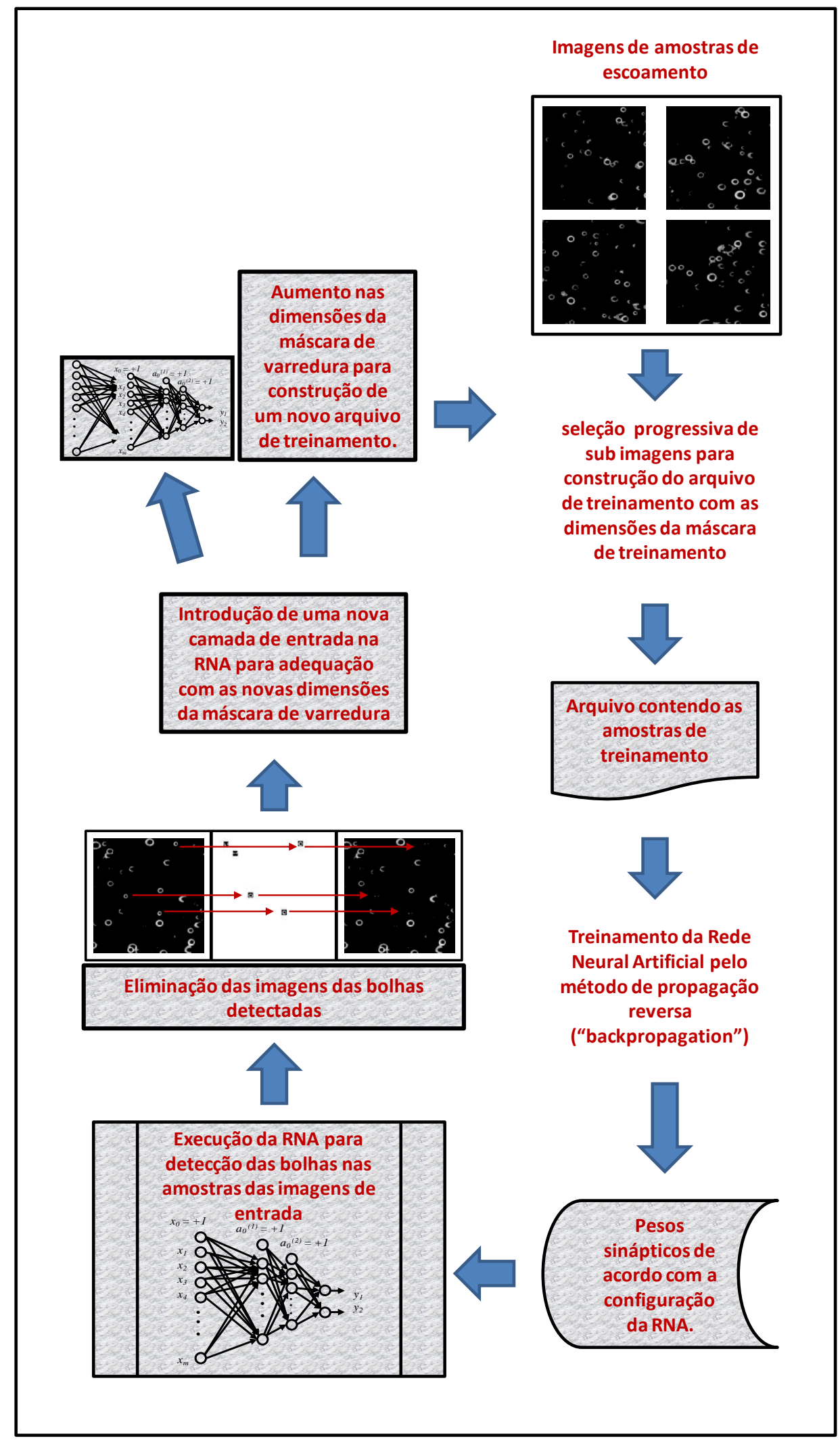

FIGURA 15 - Treinamento de redes neurais com amostragem progressiva. 


\subsubsection{Cálculo da fração de vazio da amostra do escoamento}

As fases anteriores fornecem os valores suficientes para o cálculo da fração de vazio considerando as condições de escoamento no instante em que a imagem da amostra foi capturada. Da primeira fase tem-se a seleção de uma amostra de escoamento e seu volume corresponde à representação proporcional do volume total de gases e líquido no circuito. O resultado da segunda fase representa o volume total de gases (ar ou vapor d'água) nas dimensões da amostra selecionada no instante da captura da imagem. A fração de vazio pode ser estimada pela razão entre estes dois valores e é calculada pela expressão:

$$
\varepsilon=\frac{\text { Volume total de gases na amostra }}{\text { Volume total da amostra de escoamento (gases + líquido) }}
$$

\subsection{Fundamentação teórica das principais aplicações}

As fases de seleção da amostra do escoamento e do cálculo do volume de gases na amostra contém diversas inovações baseadas em processos de segmentação de imagens, algoritmos inteligentes, modelos para extração de propriedades geométricas de figuras analíticas em imagens digitais, além de processos dinâmicos de varredura de imagens.

A essência na seleção da amostra é o mapeamento da imagem via composição de parâmetros de segmentação segundo um modelo de lógica fuzzy. Este modelo, doravante denominado sistema de inferência focal fuzzy faz uso de um modelo que procura relacionar o foco de uma imagem com a profundidade de campo em que ela fora capturada.

O cálculo do volume de gases em uma amostra de imagem de escoamento envolve aplicações com redes neurais artificiais integradas com um modelo aprimorado da transformada randomizada de Hough. Este processo integrado evolui sobre a amostra da imagem do escoamento segundo um processo de varredura empregando máscaras virtuais para seleção de subimagens com dimensões progressivas.

\subsubsection{Método fuzzy para seleção da profundidade na imagem da amostra de escoamento}

A fase de seleção da amostra sobre a imagem capturada por imageamento direto tem o propósito de estabelecer as dimensões de uma amostra volumétrica do escoamento e evidenciando as imagens das bolhas dentro destes limites. Não se trata de 
uma mera melhoria da qualidade da imagem e sim na evidenciação das bolhas dentro dos limites de uma amostra volumétrica do escoamento com dimensões controladas.

A imagem original colorida do escoamento bifásico é capturada de uma secção da tubulação de vidro do circuito experimental por uma câmera de alta resolução posicionada de modo a alinhar o maior do lado do sensor retangular da câmera com a maior extensão (vertical) da seção retangular fotografada da tubulação do circuito. No sistema, a imagem é rotacionada de $90^{\circ}$ no sentido horário. Posteriormente ela é convertida para uma imagem normalizada para seus níveis de intensidades de cinza, ou seja, com domínio [0,1]. Esta imagem será utilizada como base para cálculo dos parâmetros indicados por KROTKOV (1987) na análise da qualidade do foco dos pixels da imagem. Ela é posteriormente convertida em intensidade negativa de cinza normalizada e também é empregada na composição final dos parâmetros para análise de foco. A imagem negativa de intensidade de cinza normalizada apresenta a propriedade de representação dos pixels das bordas das fases gasosas com intensidade próxima de branco (valores próximos de um como intensidade de cinza). Algumas avaliações preliminares apresentadas por NG (2011) constataram uma melhor resposta da rede neural na detecção de padrões com estas propriedades.

O estabelecimento das dimensões da vista frontal da imagem tem o objetivo de seleção da amostra em regiões em que as distorções óticas, ocasionadas pela refração devido à lente formada pelo tubo de vidro cilíndrico, sejam minimizadas. Estudos para avaliação e mensuração do desvio dos feixes de luz em virtude do efeito de refração da luz, principal fenômeno ótico responsável pelas distorções das imagens apontam para um ângulo de visão da largura da amostra inferior à $10^{\circ}$. Este ângulo pode ser representado como o ângulo do vértice do triângulo formado pelo centro da lente da câmera e as referências laterais esquerda e direita da vista frontal da amostra. Estabelece-se, portanto, uma amostra com forma quadrada e dimensões correspondentes à 50\% do diâmetro interno da tubulação de vidro na seção de captura das imagens do experimento. $O$ centro da amostra coincide com o eixo longitudinal da tubulação e suas medidas correspondentes. Estes valores estarão sujeitos a avaliação durante o processo de calibração e ajuste do sistema em função dos valores medidos experimentalmente e dos resultados obtidos através da execução do sistema.

A profundidade da amostra é definida em função de algumas propriedades relacionadas à qualidade do foco da imagem em conjunto com a profundidade de campo 
ajustada na câmera no momento da aquisição da imagem e suas possíveis variações. Para isto optou-se pela composição de três parâmetros representativos da qualidade do foco da imagem de acordo com o modelo apresentado por KROTKOV(1987) e combinados, segundo um modelo fuzzy de inferência (MENDEL, 1995), para melhor lidar com as variações do comportamento destes parâmetros causados por possíveis mudanças das condições de aquisição da imagem ao longo do experimento.

Um sistema fuzzy de inferência consiste em um sistema de modelagem lógica que estima o valor de veracidade de suas sentenças numa faixa contínua de valores entre 0 e 1. Assim há a criação de uma máquina de inferência em que um conjunto de sentenças lógicas são avaliadas a partir de funções que podem também conter variáveis linguísticas que também assumem valores intermediários entre 0 e 1 . Ele utiliza como base a teoria de conjuntos clássica e faz uma extensão desta teoria, incluindo elementos que podem pertencer parcialmente a mais de um conjunto. Assim os elementos podem pertencer simultaneamente a dois conjuntos diferentes no mesmo universo. Podemos dizer que os universos de elementos precisos (também denominados universos "crisp") podem ser casos especiais dos universos de conjuntos nebulosos (também conhecidos por "fuzzy").

Segundo MENDEL (1995) um sistema de lógica fuzzy ("FLS - Fuzzy Logic System") é um mapeamento de um vetor de dados de entrada (características precisas crisp) em um vetor de dados de saída escalar crisp intermediados por uma inferência que usa sentenças de variáveis nebulosas (“fuzzy”). Uma das maiores vantagens da utilização da lógica fuzzy é a possibilidade de se construir um grande número de possíveis mapeamentos entre as variáveis tradicionais na engenharia e em outras áreas. Outra vantagem é a simplificação do modelamento computacional destes mapeamentos já que possibilita a utilização de variáveis com variáveis linguísticas que incorporam faixas de valores crisp em sua máquina de inferência.

A figura 16 ilustra um diagrama de blocos de um sistema de lógica fuzzy, nela estão apresentados os principais elementos deste sistema.

A entrada do sistema consiste em um vetor contendo valores das características relevantes para a inferência. Estes valores são denominados como valores precisos ou "crisp". No caso da amostra da imagem do escoamento bifásico estas características foram escolhidas para o fim de identificação da quantificação do foco de cada pixel. Assim, através do sistema, infere-se se o pixel está em foco ou não, baseado em métodos sugeridos por KROTKOV (1987). Os elementos constituintes deste vetor de entrada 
passam por um processo inicial de "fuzzificação" que consiste na associação dos seus valores a funções de pertinências (funções que mensuram o quanto o valor de entrada pertence a um valor linguístico da variável fuzzy) com resultados no intervalo [0,1].

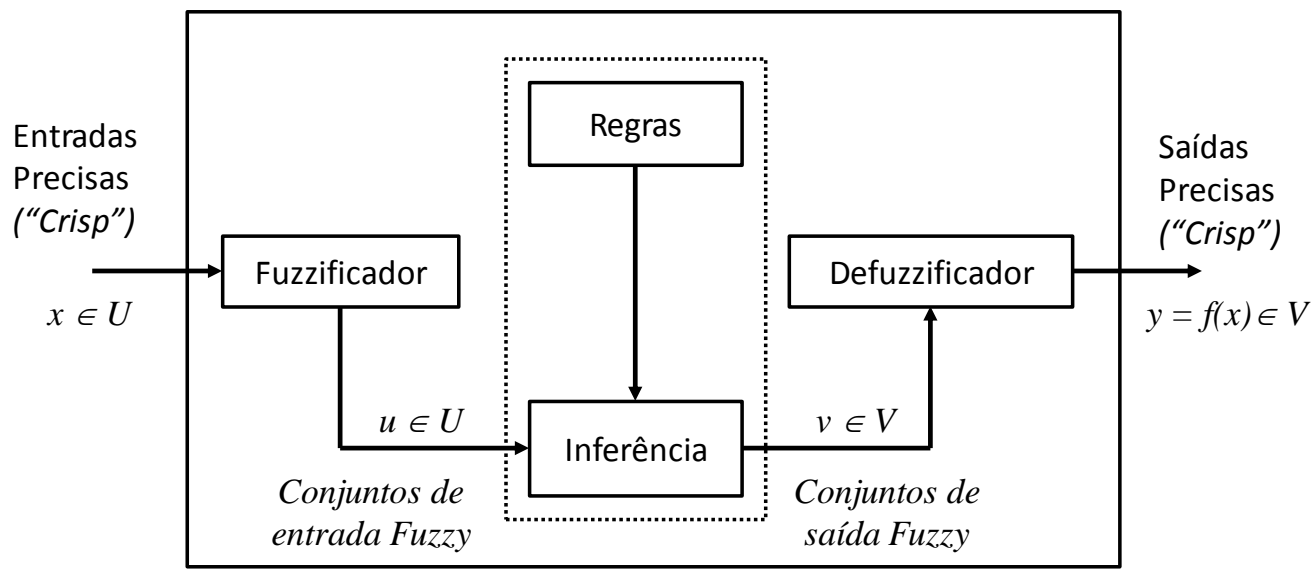

FIGURA 16 - Sistema de Lógica Fuzzy

FONTE: MENDEL (1995)

As funções de pertinência são em geral construídas considerando avaliações do especialista quanto ao grau de inserção de cada variável crisp aos conjuntos nebulosos (fuzzy) utilizados para a construção da máquina de inferência. Neste trabalho elas foram avaliadas segundo diferentes propriedades do pixel que se quer avaliar para inferir se está ou não no foco.

Os parâmetros indicados por KROTKOV (1987) e empregados como variáveis de entrada do sistema de inferência fuzzy foram:

- $\quad$ a intensidade de cinza normalizada, $I(x, y)$ : valores baixos da intensidade de cinza normalizada, próximos de zero, indicam pixels de imagens em foco. A posterior conversão desta imagem em intensidade negativa de cinza normalizada presta-se a associação de uma função crescente a este parâmetro, tal qual os demais parâmetros considerados na análise;

- $\quad$ operador Sobel, $S(x, y)$ : representa a primeira derivada direcional da intensidade de cinza do pixel. Estes valores identificam um valor ascendente ou descendente da intensidade de cinza. Esta propriedade é uma evidência da ocorrência de uma borda na imagem e

- $\quad$ operador Laplaciano, $L(x, y)$ : consiste na segunda derivada da intensidade de cinza. Ele representa uma rápida variação na intensidade de cinza, característica apropriada para detecção de bordas. Deve-se tratar com cautela os resultados deste parâmetro. Eles podem representar a ocorrência de ruídos na imagem. 
KROTKOV (1987) relata que este conjunto de parâmetros com a definição de limiares apropriados podem estabelecer um padrão de qualidade de cada pixel da imagem que, para este trabalho, poderia identifica-lo dentro de uma profundidade de campo.

A estimativa do gradiente para cada pixel é, segundo KROTKOV(1987):

$$
|\nabla I(x, y)|=\sqrt{I_{x}^{2}+I_{y}^{2}}
$$

Emprega-se o operador Sobel como convolução de kernel sobre cada pixel da imagem:

$$
i_{x}=\frac{1}{4}\left[\begin{array}{lll}
-1 & 0 & 1 \\
-2 & 0 & 2 \\
-1 & 0 & 1
\end{array}\right] \quad i_{y=} \frac{1}{4}\left[\begin{array}{rrr}
1 & 2 & 1 \\
0 & 0 & 0 \\
-1 & -2 & 1
\end{array}\right]
$$

O cálculo da magnitude do gradiente é dado por:

$$
S(x, y)=\sqrt{i_{x}[I(x, y)]^{2}+i_{y}[I(x, y)]^{2}}
$$

O Laplaciano é representado pela derivada segunda da intensidade de cinza e é considerado, segundo KROTKOV (1987), como uma técnica de passagem das altas frequências espaciais. Ele é expresso por:

$$
\left|\nabla^{2} I(x, y)\right|=\frac{\partial^{2} I}{\partial x^{2}}+\frac{\partial^{2} I}{\partial y^{2}}
$$

Seu cálculo aproximado é realizado pela aplicação da máscara de convolução de kernel:

$$
L(x, y)=\frac{1}{6} \cdot\left[\begin{array}{ccc}
1 & 4 & 1 \\
4 & -20 & 4 \\
1 & 4 & 1
\end{array}\right] . I(x, y)
$$

Os valores da intensidade de cinza tratados isoladamente aliados aos valores da intensidade negativa de cinza em conjunto com os resultados da aplicação dos operadores Sobel e Laplaciano sobre cada pixel da amostra da imagem compuseram o vetor de entrada do denominado sistema de inferência focal fuzzy. O resultado da sua aplicação sobre cada pixel da imagem teve como objetivo a classificação deste pixel como dentro ou fora da profundidade de campo da amostra volumétrica do escoamento bifásico. 
Para a construção das funções de pertinência foram consideradas a intensidade de cinza, $I(x, y)$ e a composição da intensidade negativa de cinza, $1-I(x, y)$, com os demais operadores Sobel, $[1-I(x, y)]+S(x, y)$ e Laplaciano, $[1-I(x, y)]+L(x, y)$. Considerou-se estes parâmetros como representativos para a classificação dos pixels das bordas das bolhas como "em foco" e "fora de foco". Os valores para a construção das funções de pertinência foram obtidos de análises estatísticas sobre um conjunto de perfis de bordas de bolhas "em foco" e "fora de foco" capturadas de amostras de imagens do escoamento bifásico. O resultado dessas análises representa os valores médios e limitantes dessas propriedades e de suas composições. A figura 17 apresenta o modelo construído para a função de pertinência de intensidade de cinza. Nela são representados os valores de pertinência de perfis extraídos das imagens das bordas de bolhas "em foco" e "fora de foco". Os valores da intensidade de cinza para perfis de bordas de bolhas "em foco" são próximos de zero (coloração escura ou preta) e possuem o valor médio considerado na figura como sendo a média da intensidade de cinza dos pixels que compõe o perfil da borda. O valor máximo de "bordas em foco" será considerado a média dos perfis adicionada de um desvio padrão da média. As mesmas considerações são feitas para perfis de bordas "fora de foco" tendo como valor mínimo, a média subtraída do desvio padrão.

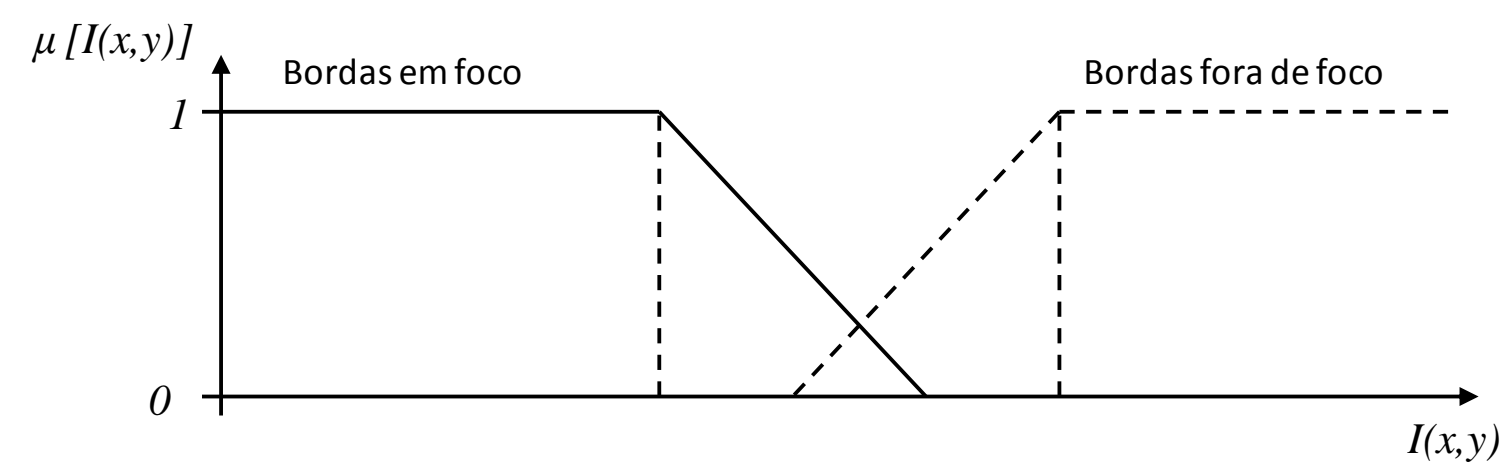

FIGURA 17 - Modelo de função de pertinência Pertinência de Intensidade de cinza

As equações (4.6) e (4.7) consistem em expressões gerais para cálculo da média $\bar{m}$ de uma variável $m$ qualquer e do seu correspondente desvio padrão $\sigma$, respectivamente:

$$
\bar{m}=\frac{\sum_{i=1}^{n} m_{i}}{n}
$$




$$
\sigma=\sqrt{\frac{\sum_{i=1}^{n}\left(m_{i}-\bar{m}\right)^{2}}{n-1}}
$$

O valor de " $n$ " corresponde ao número de pixels do perfil de cada borda de uma bolha "em foco" ou "fora de foco" selecionada na imagem do escoamento e o valor de $m_{i}$ corresponde ao valor do parâmetro em análise referente ao pixel " $i$ ".

As figuras 18 e 19 ilustram os demais parâmetros considerados nas análises. Nelas são consideradas as composições da Intensidade negativa de cinza com o resultado da aplicação dos operadores Sobel e Laplaciano.

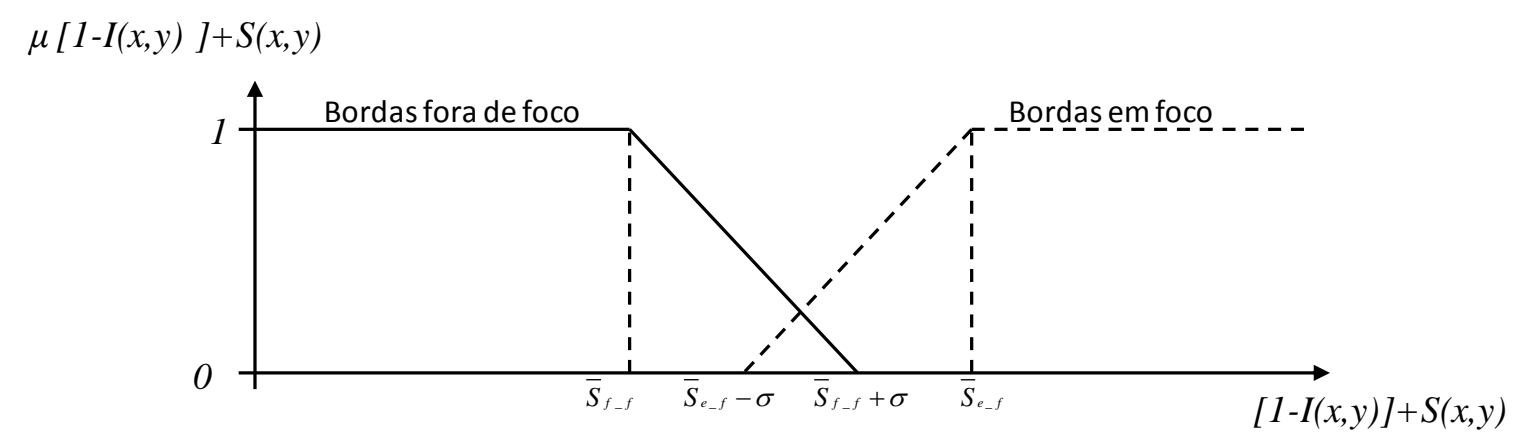

FIGURA 18 - Modelo de função de pertinência

Pertinência de Intensidade negativa de cinza + Sobel

$\mu[1-I(x, y)]+L(x, y)$

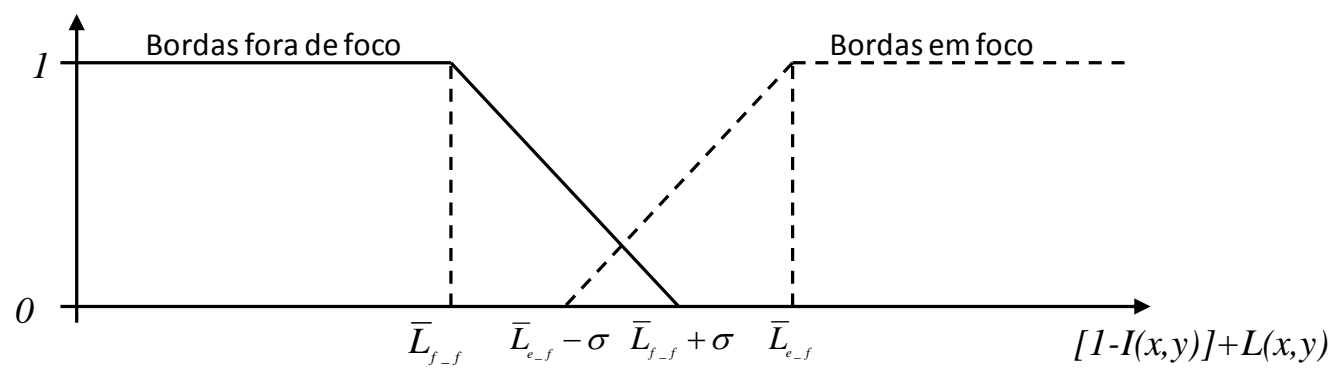

FIGURA 19 - Modelo de função de pertinência

Pertinência de Intensidade negativa de cinza + Laplaciano

As variáveis descritas nas funções de pertinência apresentadas nas figuras 17, 18 e 19 consistem em:

$\mu[I(x, y)] \quad$ função de pertinência para o valor de intensidade de cinza de um pixel da imagem da amostra do escoamento;

$\bar{I}_{f_{-} f}$ média da intensidade de cinza de perfis de bolhas fora de foco. Valor resultante da análise estatística sobre uma amostragem de perfis de bolhas fora de foco; 
$\bar{I}_{e_{-} f}$

$\bar{I}_{f_{-} f}-\sigma$

$\bar{I}_{e_{-} f}+\sigma$

$\mu[1-I(x, y)]+S(x, y) \quad$ função de pertinência para o valor da intensidade negativa de cinza adicionada ao resultado do operador Sobel de um pixel da imagem da amostra do escoamento bifásico;

média da soma da intensidade negativa de cinza com o resultado do operador Sobel para uma amostragem de perfis de bordas de bolhas fora de foco. Valores resultantes da análise estatística sobre uma amostra de perfis de bolhas fora de foco;

limite superior para soma da intensidade negativa de cinza com o resultado do operador Sobel para pixels de bolhas com perfis fora de foco. Este valor corresponde à média normalizada da soma entre a intensidade negativa de cinza adicionada com o valor do resultado do operador Sobel sobre uma amostragem de perfis de bolhas fora de foco, adicionado de um desvio padrão da média calculado sobre este mesmo parâmetro;

média da soma da intensidade negativa de cinza com o resultado do operador Sobel para uma amostragem de perfis de bordas de bolhas em foco. Valores resultantes da análise estatística sobre uma amostra de perfis de bolhas em foco; 
$\bar{S}_{e_{-} f}-\sigma$

$\bar{L}_{f_{-} f}$

$\bar{L}_{f_{-} f}+\sigma$

$\bar{L}_{e_{-} f}$

$\bar{L}_{e_{-} f}-\sigma$ limite inferior para a soma da intensidade negativa de cinza com o resultado do operador Sobel para pixels de bolhas com perfis em foco. Este valor corresponde à média normalizada da soma entre a intensidade negativa de cinza adicionada com o valor do resultado do operador Sobel sobre uma amostragem de perfis de bolhas em foco, subtraído de um desvio padrão da média calculado sobre este mesmo parâmetro;

$\mu[1-I(x, y)]+L(x, y) \quad$ função de pertinência para o valor da intensidade negativa de cinza adicionada ao resultado do operador Laplaciano de um pixel da imagem da amostra do escoamento bifásico;

média da soma da intensidade negativa de cinza com o resultado do operador Laplaciano para uma amostragem de perfis de bordas de bolhas fora de foco. Valores resultantes da análise estatística sobre uma amostra de perfis de bolhas fora de foco;

limite superior para soma da intensidade negativa de cinza com o resultado do operador Laplaciano para pixels de bolhas com perfis fora de foco. Este valor corresponde à média normalizada da soma entre a intensidade negativa de cinza adicionada com o valor do resultado do operador Laplaciano sobre uma amostragem de perfis de bolhas fora de foco, adicionado de um desvio padrão da média calculado sobre este mesmo parâmetro;

média da soma da intensidade negativa de cinza com o resultado do operador Laplaciano para uma amostragem de perfis de bordas de bolhas em foco. Valores resultantes da análise estatística sobre uma amostra de perfis de bolhas em foco;

limite inferior para a soma da intensidade negativa de cinza com o resultado do operador Laplaciano para pixels de bolhas com perfis em foco. Este valor corresponde à média normalizada da soma entre a intensidade negativa de cinza adicionada com o valor do resultado do operador Laplaciano sobre uma amostragem de perfis de bolhas 
em foco, subtraído de um desvio padrão da média calculado sobre este mesmo parâmetro;

O processo de "fuzzificação" consiste no mapeamento do vetor de características definido em um universo preciso para um universo denominado nebuloso, ou fuzzy. Este processo consiste no cálculo dos valores de pertinência no domínio $[0,1]$ para cada uma das características do vetor de entrada e associadas a variáveis linguísticas. Estes valores de pertinência são submetidos a um processo de inferência gerido por um conjunto de regras estabelecidas segundo um modelo lógico matemático adaptado para aplicação em um universo fuzzy. O resultado da aplicação dessas regras identifica o grau de pertinência sobre funções de pertinências de saída que identificam o pixel de borda como "em foco" ou "fora de foco". Tal qual apresentada na figura 20 abaixo.

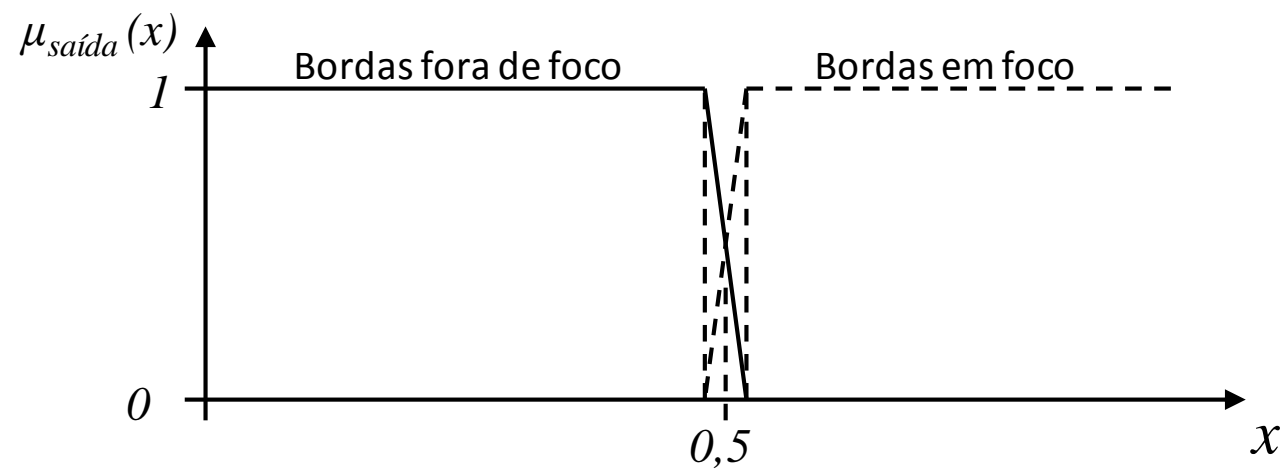

FIGURA 20 - Modelo de função de pertinência representando a saída do sistema

O módulo de inferência representado pela linha pontilhada apresentada na figura 16 tem, em sua condição básica, oito regras de inferência fuzzy, são elas:
1) $\mu\left(I_{f_{-} f}\right) \cap \mu\left(S_{f_{-} f}\right) \cap \mu\left(L_{f_{-} f}\right) \Rightarrow \mu\left(\right.$ saída $\left._{f_{-} f}\right)$
2) $\mu\left(I_{f_{-} f}\right) \cap \mu\left(S_{f_{-} f}\right) \cap \mu\left(L_{e_{-} f}\right) \Rightarrow \mu\left(\right.$ saída $\left._{f_{-} f}\right)$
3) $\mu\left(I_{f_{-} f}\right) \cap \mu\left(S_{e_{-} f}\right) \cap \mu\left(L_{f_{-} f}\right) \Rightarrow \mu\left(\right.$ saída $\left._{f_{-} f}\right)$
4) $\mu\left(I_{f_{-} f}\right) \cap \mu\left(S_{e_{-} f}\right) \cap \mu\left(L_{e_{-f}}\right) \Rightarrow \mu\left(\right.$ saída $\left._{e_{-}}\right)$
5) $\mu\left(I_{e_{-} f}\right) \cap \mu\left(S_{f_{-} f}\right) \cap \mu\left(L_{f_{-} f}\right) \Rightarrow \mu\left(\right.$ saída $\left._{e_{-} f}\right)$
6) $\mu\left(I_{e_{-} f}\right) \cap \mu\left(S_{f_{-} f}\right) \cap \mu\left(L_{e_{-} f}\right) \Rightarrow \mu\left(\right.$ saída $\left._{e_{-} f}\right)$
7) $\mu\left(I_{e_{-} f}\right) \cap \mu\left(S_{e_{-} f}\right) \cap \mu\left(L_{f_{-} f}\right) \Rightarrow \mu\left(\right.$ saída $\left._{e_{-} f}\right)$
8) $\mu\left(I_{e_{-} f}\right) \cap \mu\left(S_{e_{-} f}\right) \cap \mu\left(L_{e_{-} f}\right) \Rightarrow \mu\left(\right.$ saída $\left._{e_{-} f}\right)$

Os subscritos $f \_f$ e $e_{-} f$ complementam o significado das variáveis linguísticas com os termos "em foco" e "fora de foco", respectivamente. Os valores das pertinências para estas condições representam os antecedentes das regras e são os resultados da aplicação das funções de pertinência sobre os elementos do vetor de entrada preciso. Os 
valores das funções de saída são os resultados fuzzy das operações lógicas enumeradas nas expressões contidas em (4.8).

Os operadores de intersecção representam a função lógica " $E$ " que consiste na operação mínimo (min) na lógica fuzzy, realizando a interseção das funções de pertinência descritas em lógica fuzzy. A expressão (4.9) representa um exemplo desta operação:

$$
\mu_{e_{-} f}[I(x, y)] \cap \mu_{f_{-f}}[S(x, y)]=\min \left\{\mu_{e_{-f}}[I(x, y)], \mu_{f_{-f}}[S(x, y)]\right\}
$$

Pode-se também empregar o produto limitado para a função lógica "E", uma vez que ela preserva os princípios da contradição e do meio excluído em universos nebulosos, ou seja:

$$
\begin{gathered}
\mu_{e_{-} f}[I(x, y)] \cap \mu_{f_{-} f}[S(x, y)]=\mu_{e_{-} f}[I(x, y)] * \mu_{f_{-} f}[S(x, y)] \\
\mu_{e_{-} f}[I(x, y)] * \mu_{f_{-} f}[S(x, y)]=\max \left\{0, \mu_{e_{-} f}[I(x, y)]+\mu_{f_{-f}}[S(x, y)]-1\right\}
\end{gathered}
$$

A relação de implicação fuzzy emprega um modelo relacionado à lógica clássica, traduzida por uma representação generalizada do Modus Ponens e apresentado conforme a sequência de expressões abaixo:

- Premissa 1: $x$ é $A^{*}$;

- Premissa 2: se (x é A) então (yé B);

- Consequente: $y$ é $B$;

No modelo clássico, se a Premissa 1 ou primeiro antecedente for verdadeira e a Premissa 2 ou segundo antecedente for verdadeira, então a Consequente é verdadeiro. No Modus Ponens Generalizado, esta inferência funciona com graus de verdade que variam de 0 a 1.

Esta relação evidencia o grau de similaridade entre um modelo fuzzy e um modelo preciso, no entanto, o resultado da inferência das regras expressas em (4.8) sobre os valores fuzzificados do vetor de entrada, resultam em valores de pertinência segundo funções de saída. Estas funções de saída podem ser convertidas em um resultado preciso relacionado com a classificação do pixel da borda como "em foco" ou como "fora de foco" e seria obtido pela obtenção de um único valor final para a máquina de inferência fazendo a união das 8 expressões de (4.8). A partir deste valor pode-se fazer o processo inverso que é chamada de "defuzzificação" para a obtenção de um valor numérico (crisp) final para a inferência. Para este trabalho foi utilizado o método geométrico ou método do centróide. 
As expressões (4.12) e (4.13) apresentam estes cálculos para saídas discretas e contínuas, respectivamente.

$$
\begin{gathered}
C_{o g}=\frac{\sum x \cdot \mu_{\text {saida }}(x)}{\sum \mu_{\text {saida }}(x)} \\
C_{o g}=\frac{\int x \cdot \mu_{\text {saida }}(x) d x}{\int \mu_{\text {saida }}(x) d x}
\end{gathered}
$$

A classificação do pixel será realizada mediante os valor do centroide dos valores de pertinência de saída e as relações descritas abaixo , ou seja:

$$
\begin{gathered}
C_{o g} \leq 0,5 \Rightarrow \text { pixel "fora de foco" } \\
C_{o g}>0,5 \Rightarrow \text { pixel "em foco" }
\end{gathered}
$$

\subsubsection{As redes neurais artificiais (RNAs) no processo de identificação das bolhas}

O processo de identificação das bolhas na amostra da imagem do escoamento é realizado através de um conjunto de redes neurais artificiais multicamadas com alimentação adiante ("feedforward multilayer perceptron").

As redes neurais artificiais são algoritmos concebidos com base na forma de processamento das informações pelo cérebro humano. Segundo HAYKIN (2001):

" Uma rede neural é um processador maciçamente paralelamente distribuído constituído de unidades de processamento simples, que têm a propensão natural para armazenar conhecimento experimental e torná-lo disponível para o uso. Ela se assemelha ao cérebro em dois aspectos:

1. O conhecimento é adquirido pela rede a partir de seu ambiente através de um processo de aprendizagem.

2. Forças de conexão entre neurônios, conhecidas como pesos sinápticos, são utilizadas para armazenar conhecimento adquirido. "

Um neurônio artificial representa a unidade básica para a construção de uma rede neural. Sua arquitetura e seus elementos constituintes estão ilustrados na figura 21 abaixo. É com base nesta representação que uma rede neural artificial é projetada e implementada computacionalmente. 
Os elementos básicos do modelo representado na figura 21 são:

- os pesos sinápticos, $w_{k 1}, w_{k 2}, \ldots, w_{k n}$ : reconhecidos como a base de conhecimento de uma RNA, tratam-se dos elementos ponderadores do sinal de entrada $x_{1}, x_{2}, \ldots, x_{m}$. Eles agem como atenuadores ou amplificadores do sinal de entrada;

- um somador dos sinais de entrada ponderados pelos respectivos pesos sinápticos. Estas operações constituem um combinador linear e

- uma função de ativação para restringir a amplitude do sinal de saída do neurônio. O intervalo normalizado da amplitude da saída de um neurônio é unitário fechado $[0,1]$.

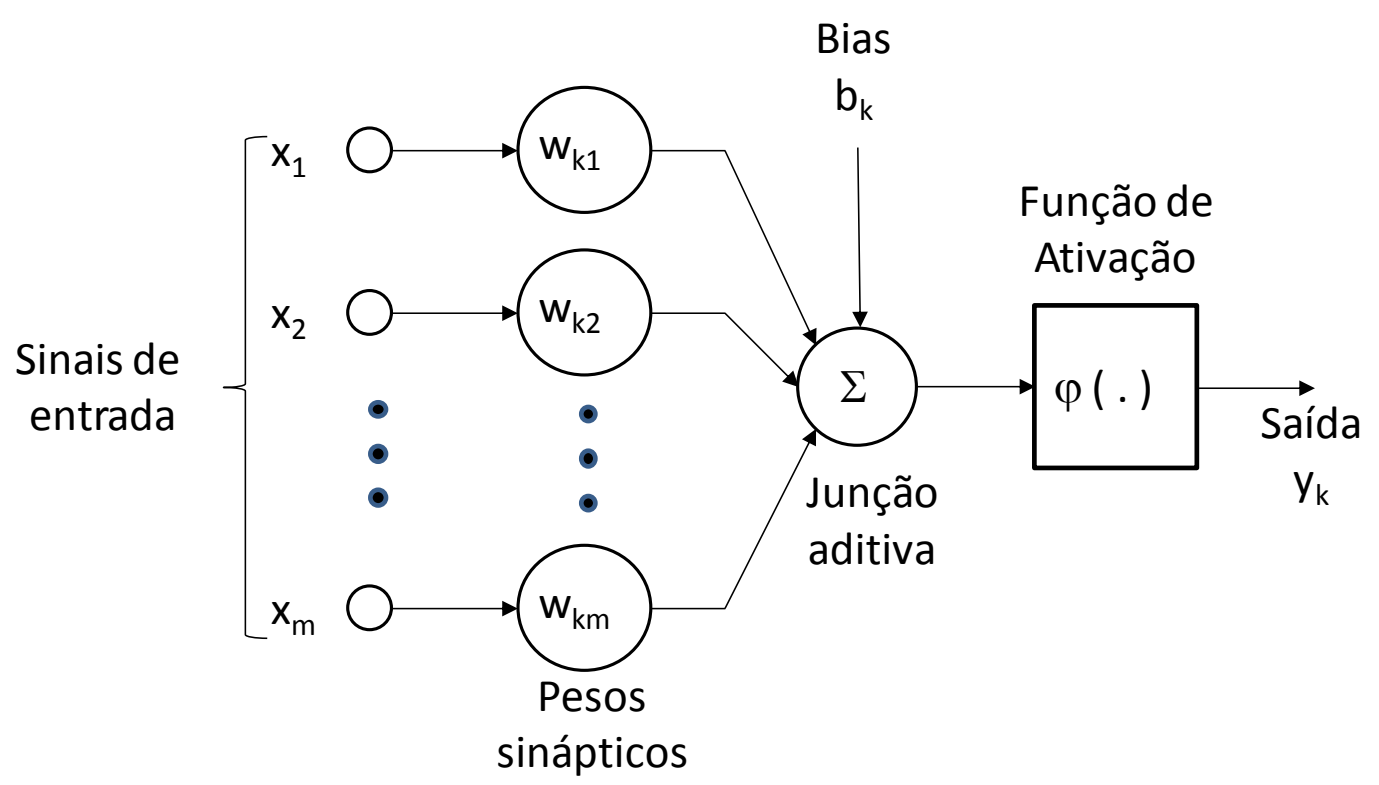

FIGURA 21 - Representação esquemática de um neurônio artificial.

FONTE: HAYKIN (2001)

Pode-se escrever um neurônio k pelas seguintes equações:

$$
\begin{gathered}
u_{k}=\sum_{i=1}^{m} w_{k j} x_{j} \\
y_{k}=\varphi\left(u_{k}+b_{k}\right)
\end{gathered}
$$

onde:

$$
\begin{array}{ll}
w_{k 1}, w_{k 2}, \ldots, w_{k m}: & \text { pesos sinápticos do neurônio } \mathrm{k} ; \\
x_{1}, x_{2}, \ldots, x_{m}: & \text { sinais de entrada; } \\
u_{k}: & \text { saída do combinador linear; }
\end{array}
$$




$$
\begin{array}{ll}
\varphi(.): & \text { função de ativação; } \\
b_{k}: & \text { bias e } \\
y_{k}: & \text { sinal de saída do neurônio }
\end{array}
$$

O bias, $b_{k}$, tem o efeito de aplicar uma transformação afim à saída do combinador linear. O termo $v_{k}$ é denominado de campo local induzido e é descrito pela expressão:

$$
v_{k}=u_{k}+b_{k}
$$

O bias é um parâmetro externo do neurônio artificial. Um procedimento comum é assumir o bias como uma nova sinapse, " $w_{k 0}$ ", adicionando-se uma nova entrada, $x_{0}$, ao conjunto de entradas do neurônio $\mathrm{k}$. Com isto o neurônio artificial pode ser representado matematicamente pelas expressões:

$$
\begin{gathered}
v_{k}=\sum_{j=0}^{m} w_{k j} x_{j} \\
y_{k}=\varphi\left(v_{k}\right)
\end{gathered}
$$

Esta adequação do modelo matemático facilita a representação do neurônio sob a forma vetorial através da consideração dos elementos de entrada da rede neural pelo vetor:

$$
X=\left[\begin{array}{llll}
x_{0} & x_{1} & \ldots & x_{m}
\end{array}\right]^{T}
$$

Os pesos sinápticos passariam também a ser representados vetorialmente:

$$
W_{k}=\left[\begin{array}{llll}
w_{k 0} & w_{k 1} & \ldots & w_{k m}
\end{array}\right]^{T}
$$

Seguindo este formato, a saída do neurônio $\mathrm{k}$ pode ser representada pela expressão:

$$
y_{k}=\varphi\left(X^{T} \cdot W_{k}\right)
$$

A arquitetura de uma rede neural artificial corresponde à representação da estrutura pela qual os neurônios de uma rede neural estão interligados. Para o processo de reconhecimento de padrões, HAYKIN (2001) indica o emprego de uma rede neural alimentada adiante com múltiplas camadas. Esta arquitetura de rede consiste em uma 
camada de entrada, representada pelos próprios elementos do vetor de entrada, um conjunto de camadas intermediárias denominadas camadas ocultas e, uma camada de saída. O procedimento de cálculo desta rede é similar ao apresentado para um neurônio artificial, lembrando que a entrada da segunda camada corresponde às saídas da camada anterior, ou seja, da camada de entrada e assim por diante até chegar na camada de saída da rede. A figura 22 ilustra uma rede neural alimentada adiante com múltiplas camadas.

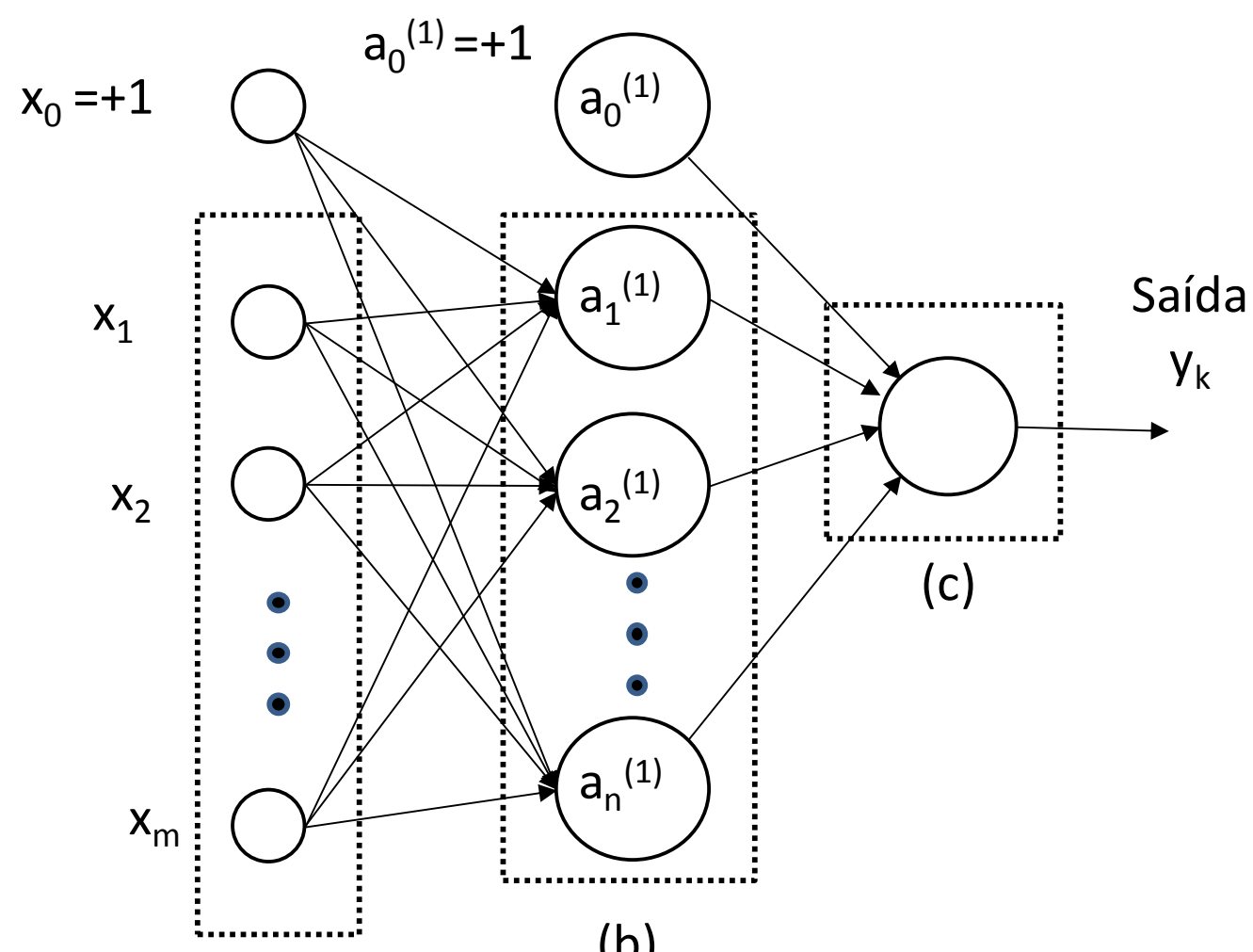

(a)

FIGURA 22 - Grafo arquitetural de uma rede neural artificial alimentada adiante (a) Camada de entrada; (b) Camada oculta; (c) Camada de saída

A rede neural apresentada na figura 22 tem uma camada de entrada, representada pelo vetor $X=\left[\begin{array}{llll}x_{1} & x_{2} & \ldots & x_{m}\end{array}\right]^{T}$. A execução desta rede alimentada adiante requer a inclusão do primeiro elemento do vetor $X$, ou seja, $x_{0}=+1$. Trata-se da inclusão de um sinal unitário ponderado pelo bias da rede neural, tal qual apresentado nas expressões (4.21) e (4.22). Esta atualização do vetor de entrada resultará no vetor $a^{(0)}=\left[\begin{array}{lllll}x_{0} & x_{1} & x_{2} & \ldots & x_{m}\end{array}\right]^{T}$. Os elementos da primeira e única camada oculta da rede neural são resultantes da ponderação deste vetor de entrada pela matriz de pesos sinápticos com a posterior aplicação da função de ativação. Ela é representada pelo vetor $a^{(1)}$,já considerando a adição do elemento representante do bias para esta camada, também representado na figura 22. A expressão para cálculo deste vetor é: 


$$
a^{(1)}=\left[\begin{array}{ll}
+1 & \varphi\left(a^{(0)^{T}} \cdot W^{(0)}\right)
\end{array}\right]^{T}
$$

Onde $W^{(0)}$ é a matriz de pesos sinápticos da camada de entrada da rede neural. Ela é representada por:

$$
W^{(0)}=\left[\begin{array}{ccc}
w_{1,1} & \ldots & w_{1, n} \\
\cdot & \cdot & \cdot \\
\cdot & \cdot & \cdot \\
\cdot & \cdot & \cdot \\
w_{m+1,1} & \ldots & w_{m+1, n}
\end{array}\right]_{(m+1 \times n)}
$$

Ainda em conformidade com o modelo de rede apresentado na figura 22, a expressão da saída da rede neural, $y_{k}$, é:

$$
y_{k}=\varphi\left(a^{(1)^{T}} \cdot W^{(1)}\right)
$$

A matriz $W^{(1)}$ é a matriz de pesos sinápticos da camada oculta. A saída da rede neural pode ser representada por um escalar ou vetor com dois ou mais elementos. A definição do formato desta saída depende do tipo de classificação que será aplicada a rede neural. Quando uma rede neural for projetada para classificação de três ou mais classes, sua saída correspondente apresentará um número equivalente de elementos. Nestas ocasiões a rede neural será conhecida por rede neural artificial multiclasse.

O resultado do treinamento de uma rede neural artificial são as matrizes de pesos sinápticos empregadas na ponderação de cada uma de suas camadas interligadas.

A técnica de treinamento por retropropagação (ou "backpropagation") é a mais conhecida e diretamente aplicada em redes neurais multicamadas e alimentadas adiante. Trata-se de um método iterativo que consiste na propagação reversa, sobre a própria rede neural, do erro médio calculado sobre um conjunto de amostras rotuladas, ou seja, amostras com seus respectivos resultados.

JAIN et al.(1996) descrevem detalhadamente o algoritmo de retropropagação como:

1. Inicialização aleatória dos termos das matrizes de pesos sinápticos em valores pequenos;

2. aleatoriamente, escolha um padrão de entrada $x^{(i)}$;

3. execute a rede adiante sobre este sinal de entrada 
4. Execute a rede neural adiante para esta amostra de entrada e calcule seu sinal de saída, $y_{i}^{L}$;

5. Calcule $\delta_{i}^{L}$ na camada de saída:

$$
\delta_{i}^{L}=g^{\prime}\left(h_{i}^{L}\right)\left[d_{i}^{U}-y_{i}^{L}\right]
$$

Onde $h_{i}^{L}$ representa a entrada da rede na $i$-ézima unidade da L-ézima camada e $g^{\prime}$ é a derivada da função de ativação $g$.

6. Calcule os "deltas" para as camadas precedentes pela retropropagação do erro:

$$
\delta_{i}^{l}=g^{\prime}\left(h_{i}^{l}\right) \sum_{j} w_{i j}^{l+1} \delta_{j}^{l+1} ; \quad \text { para } l=L-1, \ldots 1
$$

7. Atualize os pesos sinápticos usando:

$$
\Delta w_{j i}^{l}=\eta \delta_{i}^{l} y_{j}^{l-1}
$$

8. Vá para o passo 2 e repita o procedimento para o próximo padrão até que o erro na camada de entrada seja menor que um limiar estabelecido ou um número máximo de iterações seja alcançado.

A taxa de aprendizagem, " $\eta$ " estabelece o grau de aproximação dos pesos sinápticos para cada iteração. A escolha por valores de taxas de aprendizado menores, proporciona robustez ao processo de aprendizagem, porém, torna-o mais lento. Um valor muito alto da taxa de aprendizagem pode resultar na instabilidade do processo de treinamento.

O processo de reconhecimento de padrões associado a um modelo de máscaras virtuais com dimensões progressivas representa uma das principais inovações deste projeto. A máscara virtual progressiva, com dimensões iniciais pré-estabelecidas, executa uma varredura ordenada de uma amostra da imagem do escoamento para a seleção sequencial de subimagens e identificação de uma única bolha. $O$ treinamento e a aplicação da rede neural artificial (RNA) ocorre iterativamente de duas formas distintas, ambas em composição com as subimagens selecionadas pela máscara virtual progressiva. Nesta parte do projeto foram feitas as seguintes considerações:

- as dimensões da máscara virtual progressiva foram escolhidas iguais em altura e largura, ou seja, as máscara virtuais progressivas constituíram quadrados virtuais. 
Estas dimensões eram compatíveis com o número de elementos de entrada da rede neural. Seus valores iniciais perfizeram uma máscara de 30 x 30 pixels, ou seja, uma matriz correspondente a um total de 900 pixels;

- a configuração inicial da rede neural artificial (RNA) foi estabelecida em uma camada de entrada, duas escondidas e uma de saída. Esta configuração, segundo JAIN et al. (1996), estimula a não linearidade entre o mapeamento dos pixels de entrada e o resultado das camadas subsequentes, característica inerente no reconhecimento de padrões em imagens complexas. Estudos com avaliação da configuração de RNA's são realizados para este fim;

- $\quad$ tanto na fase de treinamento como na execução sobre uma amostra de imagem ocorrerá a inclusão progressiva de uma nova camada de entrada, sempre que concluída uma varredura completa. O número de elementos dessa nova camada deve ser compatível com o aumento da máscara virtual de varredura para identificação de bolhas com dimensões maiores. Este processo, denominado varredura progressiva, irá ser repetido até que as dimensões da máscara de varredura, também denominada "máscara de varredura progressiva" venha a atingir a dimensão das maiores bolhas observadas nas imagens do escoamento e

- foi estabelecida uma saída vetorial multiclasse, ou seja, $y=\left[\begin{array}{ll}1 & 0\end{array}\right]^{T}$. A razão do estabelecimento desta forma de saída para classificação da presença de uma bolha na subimagem deve-se à possível necessidade de redução de classificações erradas em função de um excessivo número de execuções da rede neural na varredura completa de uma amostra de imagem. Estas classificações são denominadas de falso-positivos, ou seja, ocasião em que a rede classifica erroneamente subimagens sem bolhas como positivas. Outra situação é a ocorrência de verdadeiro-negativos representada por situações em que subimagens sem bolhas são classificadas como positivas. Um dos recursos para minimização dessas ocorrências é o estabelecimento de limiares sobre os valores de saída da rede neural. Estes limiares devem assegurar a classificação positiva nos casos de detecção de bolha nas subimagens, ou seja, assegurem uma aproximação da saída da rede neural em que seus elementos, nestes casos, tenham valores próximos suficientes dos elementos de $y=\left[\begin{array}{ll}1 & 0\end{array}\right]^{T}$. A definição desses dois limiares é realizada via tentativa e erro e devem ser criteriosos no sentido de assegurar a detecção das verdadeiras bolhas nas subimagens. 


\section{Configuração inicial da rede neural}

Baseando-se nas metodologias de projetos de redes neurais apresentados por NG (2011), MEHTA et al. (2006) e HAYKIN (2001), optou-se por uma rede neural artificial com múltiplas camadas e alimentada adiante segundo a arquitetura inicial apresentada na figura 23.

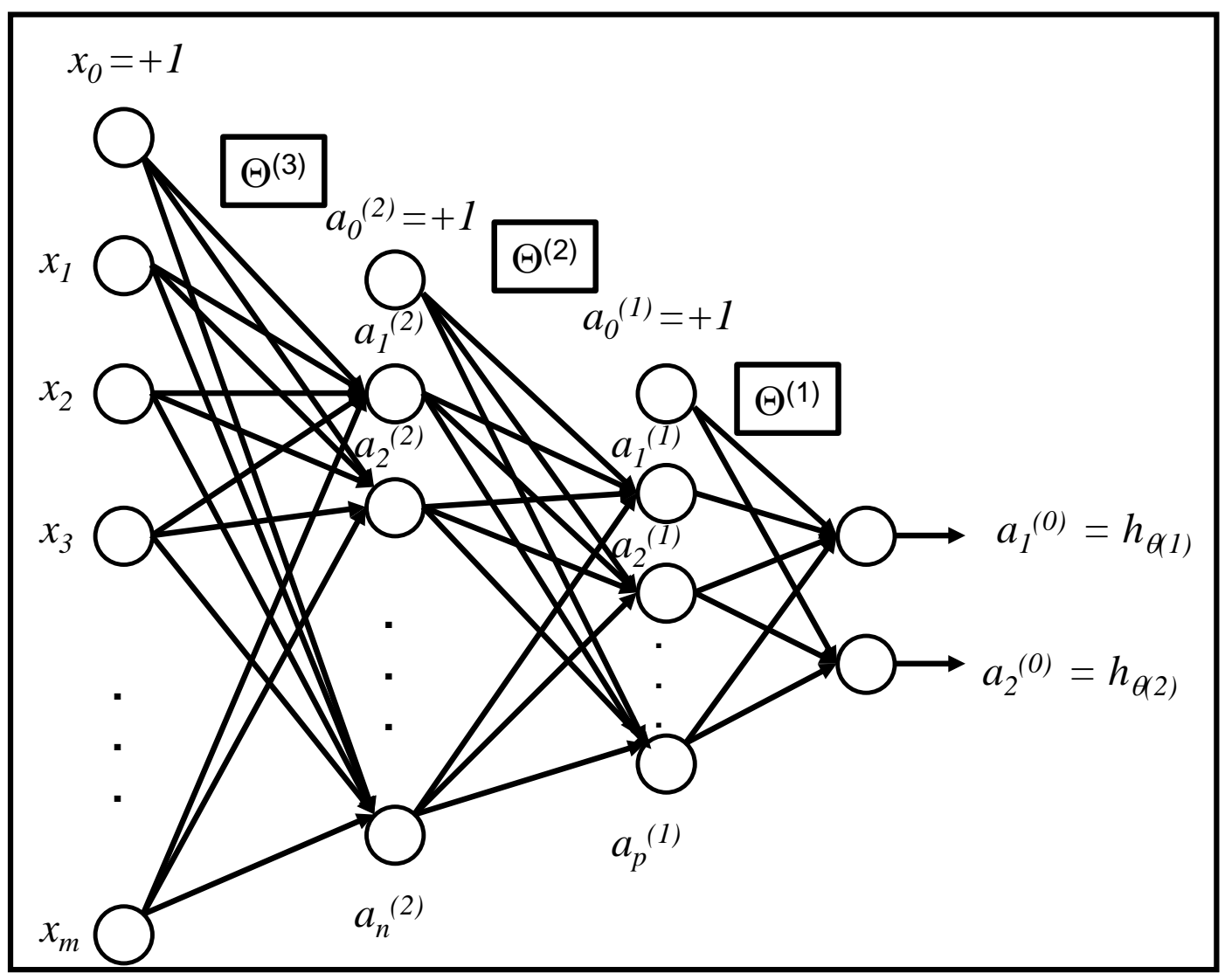

FIGURA 23 - Configuração da rede neural artificial empregada na identificação de bolhas via máscara virtual de varredura com dimensões $30 \times 30$.
$\mathrm{N}$. de camadas $=3$
N. de elementos:
$1^{\mathrm{a}}$ camada $=900+1$
$2^{\mathrm{a}}$ camada $=144+1$
$3^{\underline{a}}$ camada $=25+1$

O número de elementos da camada de entrada corresponde ao número de pixels da máscara de varredura progressiva. O valor de $x_{0}=+1$ corresponde ao elemento acrescentado ao vetor de entrada para fins de inclusão do bias na constituição e cálculo do campo local induzido correspondente ao resultado do produto matricial entre os pesos sinápticos e os valores do vetor de entrada da rede. Este procedimento é repetido para as camadas subsequentes da rede. O procedimento de execução da rede na forma alimentada adiante ("feedforward") e vetorizada é representado abaixo. Este procedimento considera uma função de ativação do tipo sigmoide aplicada em processos de classificação. Sob esta forma, a rede é executada nas fases de treinamento, tendo como entrada um conjunto de 
imagens rotuladas, e na aplicação final quando ela é executada diversas vezes durante o processo de varredura de uma amostra de imagem. Assim, tem-se:

$x^{(i)}$ vetor correspondente aos valores dos pixels da máscara de varredura na forma vetorizada, ou seja, seguindo a sequência de posicionamento de coluna após coluna: $x^{(i)}=\left[x_{1,1} \ldots x_{1, n} x_{2,1} \ldots x_{2, n} \ldots x_{n, n}^{T}\right]^{T}$. O valor de $n$ corresponde a dimensão da máscara. Seu valor inicial é 30 e corresponde às subimagens com 30 x 30 pixels;

i $\quad i=1, \ldots, m$ corresponde ao número de amostras de treinamento, por exemplo, no caso de amostras $30 \times 30, \mathrm{~m}=5500$, visto o arquivo com amostras rotuladas (amostra de treinamento supervisionado) conter 5500 elementos. Para execução da rede sobre uma única subimagem capturada por uma máscara de varredura $i=1$;

$\Theta^{(j)} \quad$ matriz de pesos sinápticos da camada correspondente;

g(z) função de ativação do tipo sigmoide, comumente aplicada em processos de classificação logística: $g(z)=\frac{1}{1+e^{-z}}$;

$h_{\theta}\left(x^{(i)}\right)$ saída da rede neural para uma subimagem ou conjunto de subimagens de entrada $x^{(i)}$ (amostra de treinamento).

A execução da rede neural na identificação de uma bolha nos limites de uma subimagem é realizada em seu modo de cálculo de alimentação adiante, ou seja, "feedforward" conforme o procedimento descrito:

- Leitura da imagem dentro dos limites da máscara de varredura sob a forma vetorizada e representada pelo vetor $x=\left[\begin{array}{llllllll}x_{1,1} & x_{1,2} & \ldots & x_{1, n} & x_{2,1} & \ldots & x_{n, n}\end{array}\right]$;

- $\quad$ inclusão do valor de $x_{0}=1$ como primeiro elemento do vetor de entrada da rede neural;

$$
X=\left[\begin{array}{ll}
x_{0} & x
\end{array}\right]
$$

- $\quad$ cálculo dos valores do campo local induzido da primeira camada da rede:

$$
z^{(2)}=X \cdot \Theta^{(3)}
$$

- cálculo dos elementos de entrada da segunda camada (escondida) da rede e acrescentando o valor correspondente ao bias, ou seja, $a_{0}^{(2)}=1$, tem-se:

$$
a^{(2)}=\left[\begin{array}{ll}
1 & g\left(z^{(2)}\right)
\end{array}\right]
$$


- $\quad$ a função de ativação tendo $z^{(2)}$ como argumento é:

$$
g\left(z^{(2)}\right)=\frac{1}{1+e^{-z^{(2)}}}
$$

- $\quad$ cálculo do campo local induzido para a segunda camada da rede:

$$
Z^{(1)}=a^{(2)} \Theta^{(2)} \quad ;
$$

- cálculo dos elementos da terceira camada da rede, acrescentando o valor correspondente ao bias, tem-se:

$$
a^{(1)}=\left[1 \quad g\left(z^{(1)}\right)\right]
$$

- $\quad$ cálculo do campo local induzido referente à terceira camada da rede:

$$
Z^{(0)}=a^{(1)} \Theta^{(1)}
$$

- $\quad$ cálculo da saída da rede neural correspondente à imagem vetorizada de entrada:

$$
h_{\theta}(x)=g\left(z^{(0)}\right)
$$

Os elementos de $h_{\theta}(x)$ que identificam a detecção de uma, ou até mais, bolhas em uma única subimagem definida pela máscara progressiva de varredura são:

$$
h_{\theta}(x)=\left[\begin{array}{l}
1 \\
0
\end{array}\right]
$$

Qualquer outra combinação de valores será identificada como ausência de bolhas na subimagem.

\section{$\underline{\text { Treinamento da rede neural }}$}

O treinamento da rede neural é realizado segundo o método de propagação reversa, ou "backpropagation", de forma iterativa. Uma vez obtidas as matrizes de pesos sinápticos, a rede neural é executada sobre as amostras de imagens utilizadas como base para a sua própria construção. Neste processo, a transformada randomizada de Hough é executada nos casos de identificação positiva de bolhas nos limites da máscara virtual progressiva. Seus resultados são as coordenadas do centro, o semieixo maior, o semieixo menor e o ângulo de inclinação entre o semieixo maior e a horizontal local da elipse descrita analiticamente e representante da borda de interesse da bolha, ou seja, da interface gás-líquido. Estes parâmetros são utilizados na limpeza da imagem da bolha da amostra da imagem do escoamento. A varredura completa desta amostra tem o objetivo de limpá-la 
para a construção de uma nova amostra de treinamento, empregando uma máscara progressiva de varredura com dimensões maiores. Este ciclo: construção da amostra de treinamento - limpeza das amostras s das imagens do escoamento bifásico - incremento nas dimensões da máscara progressiva de varredura, repete-se até que as dimensões da máscara progressiva de varredura atinjam as das maiores bolhas observadas em todas as imagens do escoamento. Ao final deste processo, acumulam-se um conjunto de arquivos, cada qual contendo os pesos sinápticos para execução da rede neural artificial de forma vetorizada.

Ainda durante a fase de treinamento, a rede neural pode ser executada para fins de definição dos limiares de refinamento. O principal critério adotado para este processo de tentativa e erro é a eliminação do máximo de "falsos positivos" sem o comprometimento da detecção de bolhas com as dimensões apropriadas à máscara de varredura progressiva.

$\mathrm{O}$ arquivo de amostras de treinamento da rede neural artificial para uma dimensão específica da máscara progressiva de varredura é composto de um conjunto de amostras organizadas linha por linha. Cada linha deste arquivo corresponde à uma subimagem vetorizada com as dimensões da máscara progressiva de varredura. Esta subimagem pode apresentar bolha ou não. Por se tratar de uma amostra de treinamento rotulada, o arquivo também contém a saída correspondente de cada subimagem.

O treinamento via "backpropagation" consiste na propagação do erro da rede neural no sentido reverso. Este processo apresenta como resultado a minimização de uma função de custo $J_{\theta}\left(x^{(i)}\right)$ em relação aos pesos sinápticos. Esta função é específica para aplicações de classificação logística e é construída empregando uma associação de funções logarítmicas com um processo de regularização para evitar a ocorrência de falsos valores que indicariam sua condição mínima, NG (2012). Emprega-se o método de otimização denominado gradiente conjugado e executado segundo uma função implementada em MATLAB ("fmincg"). Este método tem como característica principal a finalização do processo de minimização em função do número de iterações fornecida pelo usuário. Ele também estabelece um valor inicial e atualiza, conforme conveniência, a taxa de aprendizagem aplicada ao processo de treinamento.

O processo de treinamento se inicia com a construção das matrizes de pesos sinápticos. Seus valores são gerados aleatoriamente segundo modelo estabelecido heuristicamente e apresentado por NG (2011). Posteriormente é realizada a aplicação da 
rede neural em seu modo de execução "feedforward", ou seja, de propagação adiante. Aplica-se o processo conforme a sequência:

- Cálculo da função de custo considerando um modelo adequado para classificação logística:

$$
J(\theta)=\frac{1}{m} \sum_{i=1}^{m} \sum_{k=1}^{K}\left[-y_{k}^{(i)} \log \left(h_{\theta}\left(x^{i}\right)\right)_{k}-\left(1-y_{k}^{(i)}\right)\left(\log \left(1-h_{\theta}\left(x^{i}\right)\right)_{k}\right)\right]+\frac{\lambda}{2 m} \sum_{j=1}^{n} \sum_{l=1}^{p} \Theta_{j, l}^{2}
$$

- Cálculo do erro na saída da rede para todas as amostras:

$$
\delta^{0}=h_{\theta}-y_{k}
$$

- Cálculo da propagação reversa do erro:

$$
\delta^{1}=\left(\Theta^{(1)}\right)^{T} \cdot \delta^{(0)} \cdot * g^{\prime}\left(z^{(1)}\right)
$$

- Elimina-se o elemento $\delta_{0}^{1}$

- Repete-se o procedimento para cálculo de $\delta^{2}$, ou seja:

$$
\delta^{2}=\left(\Theta^{(2)}\right)^{T} \cdot \delta^{(1)} \cdot g^{\prime}\left(z^{(2)}\right)
$$

- Elimina-se o elemento $\delta_{0}^{2}$

- Inicializa-se uma variável acumuladora $\Delta^{(i)}$ e atribuí iterativamente os resultados:

$$
\Delta^{(i+1)}=\Delta^{(i+1)}+\delta^{(i)} \cdot\left(a^{(i+1)}\right)^{T}
$$

- Calculam-se portanto os valores de $\Delta^{(1)} ; \Delta^{(2)} \mathrm{e} \Delta^{(3)}$. Os valores do gradiente da função de custo sem a consideração dos fatores de regularização são obtidos de:

$$
\frac{\partial J_{\theta}}{\partial \Theta^{(i)}}=\frac{1}{m} \Delta^{(i)}+\frac{\lambda}{m} \Theta^{(i)}
$$

Os valores da função de custo e de seu gradiente em relação aos pesos sinápticos serão empregados na minimização numérica da função de custo em relação aos valores dos pesos sinápticos. Tal condição é suficiente para assegurar valores adequados dos pesos sinápticos para seu emprego na rede neural. O método para tal procedimento é o método de otimização por gradiente conjugado e tem, segundo NG (2011) apresentado bons resultados em aplicações similares. A função fmincg implementada em ambiente MATLAB executa este método. 
O resultado do treinamento da rede neural são as matrizes de pesos sinápticos de acordo com a configuração da rede neural artificial para cada máscara progressiva de varredura. Este resultado só é obtido após o treinamento de todas as opções de dimensões da máscara de varredura.

$\underline{\text { Execução da rede neural }}$

A execução da rede neural sobre uma amostra de imagem do escoamento bifásico consiste na realização de sucessivas varreduras com máscaras virtuais progressivas para fins de detecção das bolhas. A sequência de procedimentos retrata este processo:

I. inicialização das dimensões da máscara virtual progressiva de varredura para o menor valor definido, ou seja, 30 x 30 pixels;

II. varredura, segundo um estabelecido modelo de progressão, da amostra da imagem com a separação de cada subimagem, selecionada pelos limites da máscara virtual progressiva de varredura;

a. $\quad$ execução da rede neural sobre cada subimagem e, em caso de identificação de uma bolha na subimagem:

i. aplicação de um detector de borda na subimagem, no caso, detector Canny;

ii. identificação dos parâmetros geométricos das bordas da imagem;

iii. verificação da ocorrência de bordas concêntricas e, caso positivo, eliminação dos parâmetros geométricos das bordas de menores raios ou de menor composição modular entre os semieixos maior e menor;

iv. cálculo do volume da bolha e atribuição do resultado do volume a uma variável acumuladora de volume da amostra da imagem e

v. eliminação da imagem da imagem da bolha da amostra da imagem do escoamento evitando sua detecção em duplicidade via máscaras de varreduras progressivas com dimensões maiores;

b. em caso de não detecção de bolha nos limites da máscara de varredura progressiva procede-se com o avanço da máscara de um pixels de acordo com as seguintes restrições de varredura da amostra :

i. caso não seja possível o avanço devido ao final da linha da amostra, o avanço será sobre a primeira coluna da próxima linha da amostra;

ii. caso tenha sido finalizada a varredura da imagem para uma determinada dimensão da máscara de varredura e não seja a maior 
dimensão estabelecida para a máscara de varredura. Atribuir um acréscimo nas dimensões da máscara de varredura e retornar o processo para o item II ou

iii. caso tenha sido finalizada a varredura da imagem para uma determinada dimensão da máscara de varredura e caso seja a maior dimensão estabelecida para a máscara de varredura. Finalizar o processo de execução da rede neural e seguir o processo para o item III;

III. seguir para a fase final do sistema que realiza o cálculo da fração de vazio para a amostra da imagem.

\subsubsection{Identificação dos parâmetros geométricos das interfaces gás-liquido}

Tanto na fase de treinamento como na execução da RNA ocorre uma interação com o processo para obtenção das propriedades geométricas das figuras analíticas que se ajustem às interfaces gás líquido, no caso de detecção de bolha na subimagem.

A extração dessas propriedades geométricas de uma única bolha em uma subimagem é realizada empregando-se a transformada de Hough por ser reconhecidamente uma técnica robusta para detecção de formas definidas analiticamente em uma imagem (YIP, TAM e LEUNG, 1992).

A transformada de Hough, em sua implementação convencional compreende duas fases. A primeira delas consiste na realização de incrementos em uma matriz acumuladora baseada no mapeamento da transformação e na regra de votação. A segunda trata de um exaustivo processo de pesquisa por parâmetros na matriz acumuladora e na verificação de formas candidatas associadas a estes parâmetros. A implementação da transformada de Hough requer o emprego de uma matriz acumuladora de dimensão 5 para detecção de elipses (coordenadas do centro da elipse, semieixo maior e menor e ângulo de inclinação) e tridimensional para círculos (coordenadas do centro e raio).

A complexidade de tempo e espaço de algoritmos que aplicam esta transformada cresce exponencialmente em função do aumento de cada parâmetro desta matriz.

Partindo-se desta afirmação muitos métodos modificados foram propostos. Embora efetivos em termos computacionais, eles comprometiam a robustez da 
transformada, podendo prejudicar seus resultados em aplicações mais complexas, TSUJI e MATSUMOTO (1978), DAVIES (1989), MUAMAR e NIXON (1989) e LEAVERS (1989).

YIP, TAM e LEUNG (1992) apresentaram um modelo modificado da transformada de Hough com a redução da necessidade de memória, sem comprometimento de sua eficiência e robustez. Tal modelo consiste na redução da matriz acumuladora para uma matriz bidimensional. Partindo de imagens sintéticas e binárias digitalizadas com 128 x 128 pixels e com o uso do operador de gradiente Sobel, a figura 24 (a) consiste na imagem de borda com 108 pixels. Os pontos maiores indicam as posições de picos detectados com um limiar ("threshold") de 10\% do valor máximo do histograma. Na figura 24(b), YIP, TAM e LEUNG (1992), mostram o histograma correspondente do acumulador bidimensional.

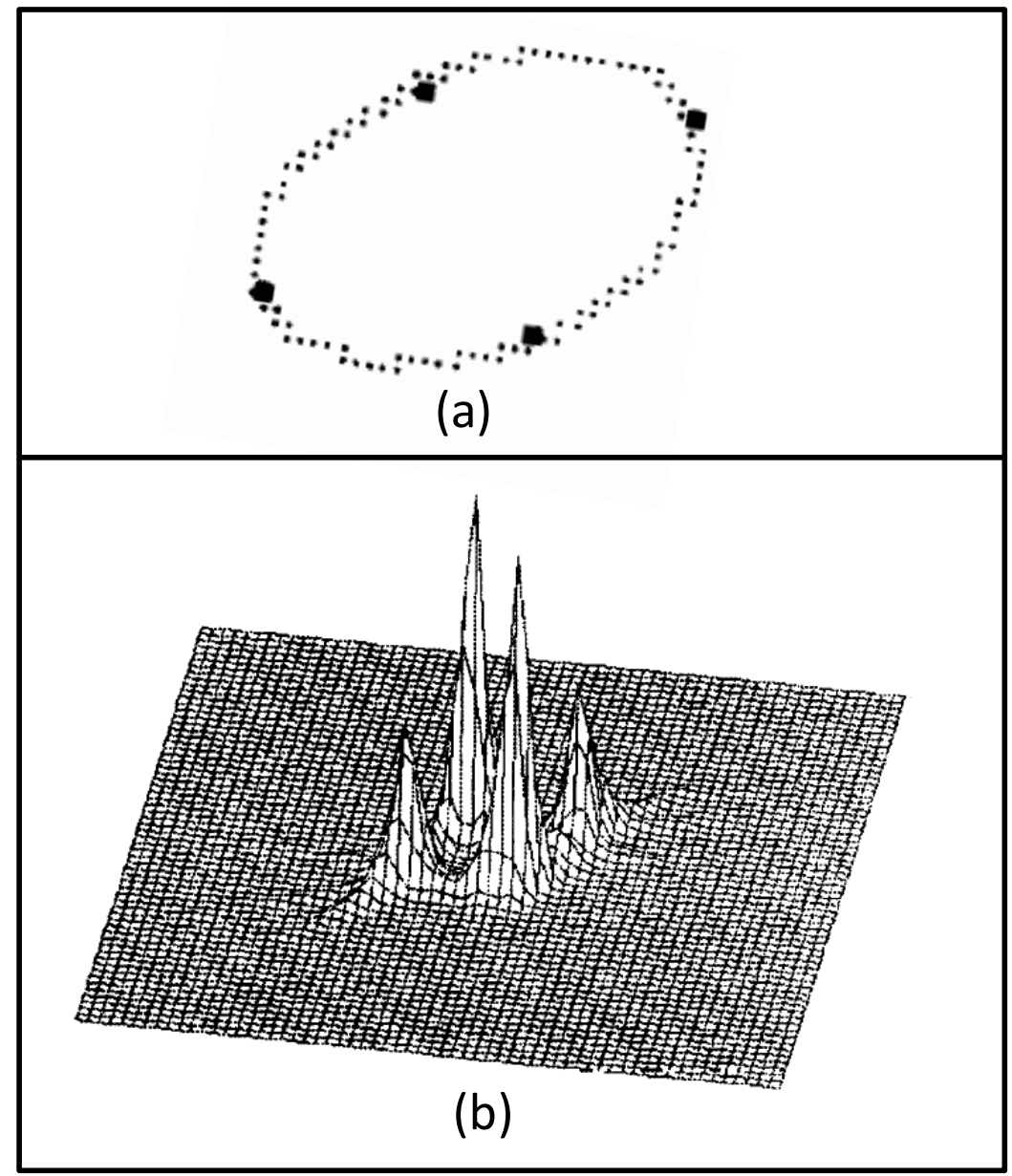

FIGURA 24 - (a) posições dos picos locais detectados do acumulador sobre a imagem da borda. (b) histograma bidimensional do acumulador com picos correspondentes. FONTE: YIP, TAM e LEUNG (1992) 
O modelo desenvolvido por YIP, TAM e LEUNG (1992) apresenta como restrição a geração de resultados positivos apenas para figuras analiticamente bem definidas. Sua aplicação em situações reais é comprometida em função dessas restrições, pois é perceptível que bolhas reais em um escoamento bifásico sofrem deformações em função das características do próprio experimento, como do fenômeno da circulação natural e suas instabilidades. Isto impossibilita sua associação integral a figuras analiticamente definidas, caso de elipses e circunferências. YIP, TAM e LEUNG (1992) também não consideram figuras sobrepostas, ou seja, com oclusões parciais das imagens das bolhas. Isto poderia comprometer os resultados, pois na sua ocorrência, as figuras após a separação em subimagens, apresentariam falhas de continuidade em suas bordas.

A transformada randomizada de Hough (RHT - Randomized Hough Transform) apresentada por YU, LIU e HE (2008) tem como principal benefício a significativa redução das amostras e da matriz acumuladora resultando em uma expressiva melhoria de desempenho. Ela também permite a extração das propriedades de elipses parcialmente oclusas. Este recurso é importante, pois, a extração gradual das subimagens contendo bolhas deixa lacunas nas imagens resultantes quando as bolhas estão oclusas, mesmo que parcialmente.

O potencial da transformada aleatória de Hough pode ser verificado em outras aplicações. TENG, KIM e KANG (2012) e ZHANG, JIANG E LIU (2012) apresentaram exemplos de aplicações destas variações da transformada de Hough sendo, o último, na identificação de bolhas em escoamento bifásico empregando uma única imagem contendo diversas bolhas dispersas.

Além da expectativa por um melhor desempenho, justifica-se o emprego da transformada randomizada de Hough em subimagens com uma única bolha pela eliminação da possibilidade de cálculo das propriedades geométricas de uma única bolha em ocasiões de ocorrência da composição de duas bolhas próximas.

O modelo desenvolvido tem como base o apresentado por McLaughlin (1997 e 2000). Deve-se relevar que este modelo aplicado em imagens com poucas elipses ou circunferências (tratada como um caso particular de elipse) apresentam desempenho superior às demais variantes desta transformada no que diz respeito a precisão e desempenho computacional. Seu desempenho é comparável a própria metodologia apresentada por McLaughlin (2000) conforme exposto na figura 25. 


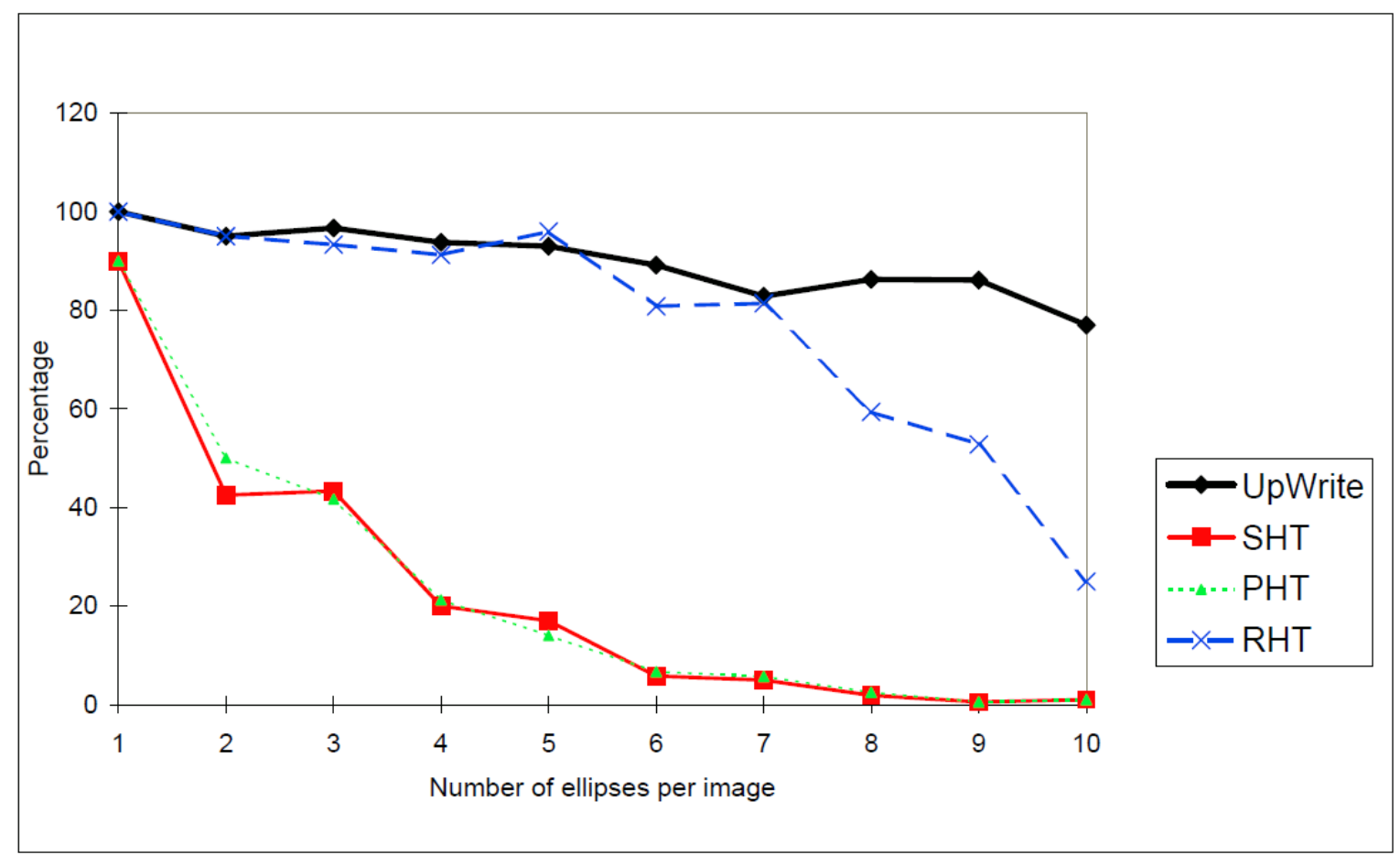

FIGURA 25 - Comparação da precisão de detecção de elipses empregando-se diversos métodos e variantes da transformada de Hough. FONTE: MC LAUGHLIN (2000)

A aplicação da transformada randomizada de Hough ocorre após a aplicação de um detector de bordas sobre a imagem. Apesar do método da declividade ser mais recomendado para esta operação segundo BHARDWAJ e MITTAL (2012), sua aplicação estaria limitada em função da necessidade do conhecimento prévio da intensidade de cinza de um número considerável de pixels anterior e posterior a borda da bolha. Valores estes que poderiam estar fora das dimensões da máscara progressiva de varredura e seriam de difícil identificação. O operador Canny, segunda opção apresentada por BHARDWAJ e MITTAL (2012) mostrou ser o mais indicado visto não necessitar destes parâmetros e já disponibilizar os valores da primeira derivada direcional da intensidade de cinza dos pixels da borda da bolha. Estas derivadas são empregados na transformada randomizada de Hough visto representarem o coeficiente angular das retas tangentes aos pixels da borda da bolha.

A notação empregada para representação das coordenadas dos pontos nas imagens emprega o sistema de eixos padrão de uma imagem digital tendo sua origem localizada no extremo superior esquerdo da imagem. Elas são identificadas pelas letras "r", para a coordenada da linha e "c", para a da coluna.

A transformada randomizada de Hough parte da seleção aleatória de pixels distintos da suposta borda e das suas possíveis combinações segundo um modelo de 
distribuição uniforme de probabilidades. As coordenadas desses supostos pixels da borda da bolha, $\left(c_{b}, r_{b}\right)$, e das suas derivadas direcionais são obtidas da aplicação do detector Canny. A dimensão dessa amostragem é de $50 \%$ de todas as possíveis combinações dois a dois entre todos os pixels de borda da subimagem após a aplicação do detector Canny. As derivadas direcionais sobre estes pixels, $g_{y}\left(c_{b}^{(i)}, r_{b}^{(i)}\right)$ e $g_{x}\left(c_{b}^{(i)}, r_{b}^{(i)}\right)$, consideram o padrão de eixos correspondentes à convenção para representação de imagens digitais e a razão entre elas representam o coeficiente angular da reta tangente, $m_{t}$, por um pixel de borda com coordenadas $\left(c_{b}, r_{b}\right)$, ou seja:

$$
m_{t}^{(i)}=\frac{g_{y}\left(c_{b}^{(i)}, r_{b}^{(i)}\right)}{g_{x}\left(c_{b}^{(i)}, r_{b}^{(i)}\right)} \quad i=1,2
$$

O índice $i=1,2$ é empregado para diferenciar o pixel de borda e o seu par na correspondente seleção aleatória. Pode-se extrair os coeficientes lineares das retas tangentes, $c_{l}^{(i)}$, a partir dos coeficientes angulares obtidos da equação 4.23 e das coordenadas dos pixels correspondentes:

$$
c_{l}^{(i)}=r_{b}^{(i)}-m_{t}^{(i)} \cdot c_{b}^{(i)} \quad i=1,2
$$

As coordenadas $\left(c_{t}, r_{t}\right)$ do ponto de intersecção das retas tangentes aos pixels da borda são obtidas por:

$$
\begin{aligned}
& c_{t}=\frac{c_{l}^{(2)}-c_{l}^{(1)}}{m_{t}^{(1)}-m_{t}^{(2)}} \\
& r_{t}=m_{t}^{(1)} \cdot c_{t}+c_{l}^{(1)}
\end{aligned}
$$

O cálculo das coordenadas do ponto médio entre os pares de pixels de borda pode ser realizado através das expressões:

$$
\begin{gathered}
c_{m}=\frac{c_{b}^{(1)}+c_{b}^{(2)}}{2} \\
r_{m}=\frac{r_{b}^{(1)}+r_{b}^{(2)}}{2}
\end{gathered}
$$

Sabe-se que o centro da elipse ou circunferência, " $C\left(x_{c}, y_{c}\right)$ ", está localizado na reta que passa pelas intersecções das retas tangentes, ponto " $\boldsymbol{t}$ ", e pelo ponto médio dos respectivos pontos das bordas, ponto " $\boldsymbol{m}$ ". Os coeficientes angular, $m_{t m}$, e linear, $c_{l t m}$, desta reta para cada par de pontos da amostragem pode ser calculado empregando-se as expressões abaixo: 


$$
\begin{gathered}
m_{t m}=\frac{r_{t}-r_{m}}{C_{t}-C_{m}} \\
C_{l t m}=r_{m}-m_{t m} \cdot C_{m}
\end{gathered}
$$

A figura 26 ilustra a aplicação destes conceitos que resultam na equação reduzida desta reta, expressa pela equação (4.53):

$$
X_{\text {rol }}=m_{t m} \cdot y_{c o l}+c_{l t m}
$$

A partir do cálculo dos pontos sobre todas as retas geradas ao longo da extensão da subimagem e de uma votação sobre os pixels resultantes deste cálculo, será possível constatar a ocorrência de uma maior concentração de votos sobre as coordenadas do centro da elipse, " $\boldsymbol{C}\left(\boldsymbol{x}_{\boldsymbol{c}}, \boldsymbol{y}_{\boldsymbol{c}}\right)$ ".

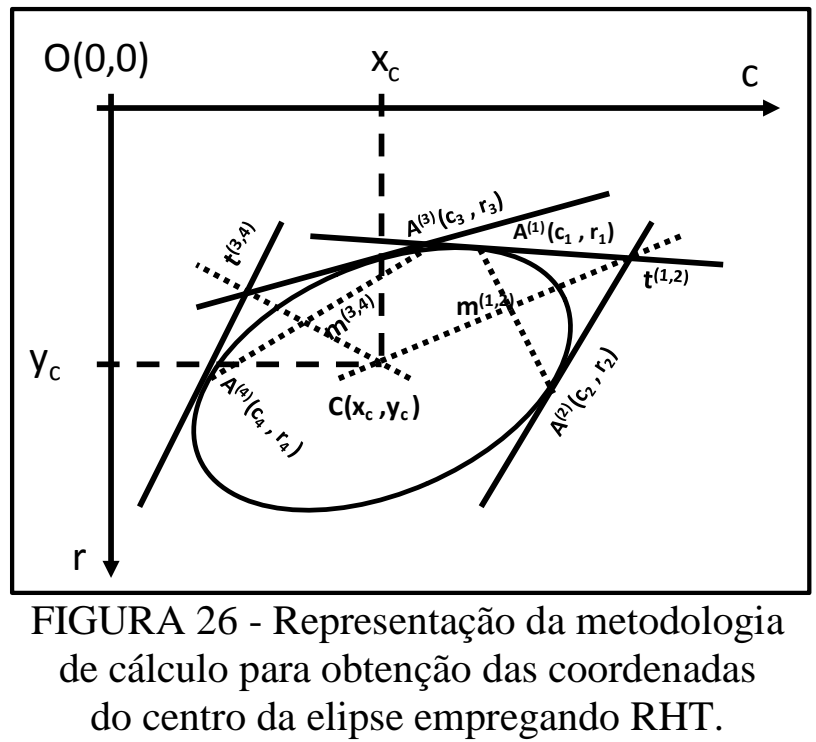

Na figura 26 estão ilustradas estas propriedades que fundamentam este modelo de cálculo e votação. A partir dela é possível constatar que a maior concentração de pontos estará na região do centro da elipse. Muitos autores adotam as coordenadas com maior votação como sendo o centro da figura analítica, no entanto, acredita-se que o processo aleatório na seleção de pares de pontos, aliado a uma pequena diferença na votação para pontos com coordenadas próximas (cerca de dois pixels), introduzem uma incerteza neste processo. Neste sentido, algumas modificações foram implementadas no modelo convencional da transformada aleatória de Hough a fim de melhorar a qualidade da figura analítica obtida como a que melhor se ajusta ao conjunto de pares dos pixels das bordas detectadas na imagem. O primeiro passo consiste na seleção das quatro coordenadas mais promissoras do centro da elipse, identificadas por uma diferença de votos inferior a dois pixels e com coordenadas distantes de, pelo menos, dois pixels. 
A continuidade deste processo é a obtenção dos demais parâmetros da figura geométrica, ou seja, a dimensão dos semieixos maior e menor e o ângulo do semieixo maior em relação à horizontal local. A extração desses parâmetros requer a translação da coordenada do centro da elipse para a origem do sistema $\mathrm{O}(0,0)$ e, consequentemente, de todos os pixels selecionados aleatoriamente da subimagem. Este processo é realizado sobre a combinação aleatória de três pontos ( $i=1,2$ ou 3) necessários para a definição de uma elipse e, vetorialmente, consiste na aplicação das duas expressões descritas abaixo:

$$
\begin{aligned}
& r_{00}^{(i)}=r^{(i)}-y_{c} \\
& c_{00}^{(i)}=c^{(i)}-x_{c}
\end{aligned}
$$

A equação geral da elipse segundo este modelo é:

$$
A\left(c_{00}^{(i)}\right)^{2}+B\left(c_{00}^{(i)}\right)\left(r_{00}^{(i)}\right)+C\left(r_{00}^{(i)}\right)^{2}=1
$$

sendo:

$$
\begin{gathered}
A=\frac{\cos ^{2} \theta}{a^{2}}+\frac{\operatorname{sen}^{2} \theta}{b^{2}} \\
B=2 \cdot\left(\frac{1}{a^{2}}-\frac{1}{b^{2}}\right) \cdot \operatorname{sen} \theta \cdot \cos \theta \\
C=\frac{\operatorname{sen}^{2} \theta}{a^{2}}+\frac{\cos ^{2} \theta}{b^{2}}
\end{gathered}
$$

Os valores de "a", "b" e " $\boldsymbol{\theta}$ " correspondem aos semieixos maior e menor e a inclinação da elipse que consiste no ângulo formado entre o semieixo maior e a horizontal local, figura 27.

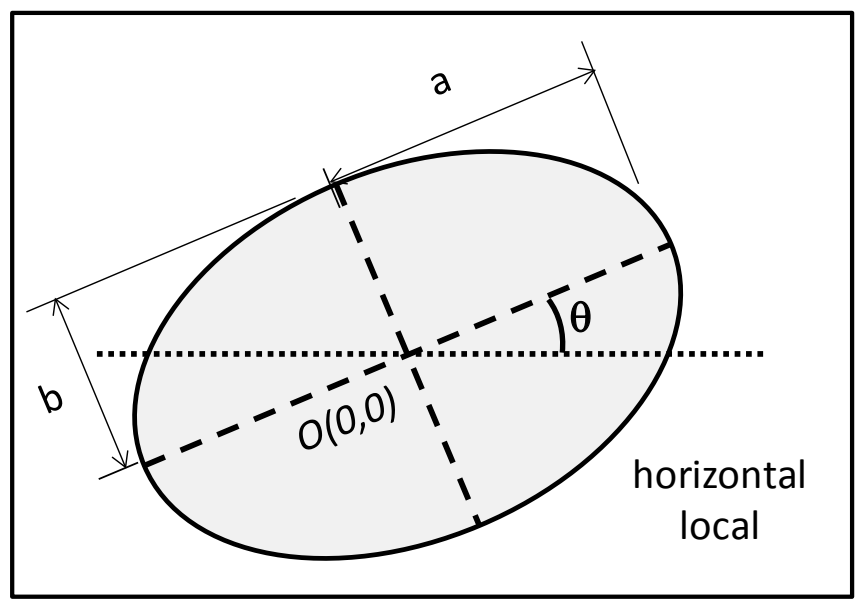

FIGURA 27 - Representação dos parâmetros geométricos da elipse 
Com um conjunto formado por três pontos da borda da elipse (tripla) é possível construir o sistema linear:

$$
\left[\begin{array}{l}
A \\
B \\
C
\end{array}\right]=\left[\begin{array}{lll}
\left(c_{00}^{(1)}\right)^{2} & c_{00}^{(1)} r_{00}^{(1)} & \left(r_{00}^{(1)}\right)^{2} \\
\left(c_{00}^{(2)}\right)^{2} & c_{00}^{(2)} r_{00}^{(2)} & \left(r_{00}^{(2)}\right)^{2} \\
\left(c_{00}^{(3)}\right)^{2} & c_{00}^{(3)} r_{00}^{(3)} & \left(r_{00}^{(3)}\right)^{2}
\end{array}\right]^{2}\left[\begin{array}{l}
1 \\
1 \\
1
\end{array}\right]
$$

A solução do sistema linear consiste na obtenção dos valores de A, B e C e os valores dos parâmetros geométricos da elipse são obtidos mediante a condição:

$$
\text { A.C }-\left(\frac{B}{2}\right)^{2}>0
$$

Uma vez satisfeita a condição descrita pela desigualdade 4.61, pode-se calcular os valores dos parâmetros da elipse.

$$
\begin{gathered}
b^{2}=\frac{2}{A+C+\sqrt{(A-C)^{2}+B^{2}}} \\
a^{2}=\frac{1}{A+C-\frac{1}{b^{2}}} \\
\theta= \begin{cases}a \cos \left(\sqrt{\frac{a^{2} b^{2} A-a^{2}}{b^{2}-a^{2}}}\right) & B \leq 0 \\
a \cos \left(-\sqrt{\frac{a^{2} b^{2} A-a^{2}}{b^{2}-a^{2}}}\right) & B>0\end{cases}
\end{gathered}
$$

Na ocorrência da igualdade entre os valores de " $\boldsymbol{a}$ " e "b", identifica-se a borda de uma bolha circular. Nesta condição não haveria sentido a aplicação de qualquer uma das expressões descritas em 4.64. Na ocorrência de situações como estas, o valor de " $\theta$ " será assumido como zero. Isto ocorre visto que bolhas circulares são casos particulares de elipses com semieixos iguais.

A detecção final dos parâmetros da elipse consiste em um complexo sistema de votação desses três parâmetros calculados sobre uma grande amostra de tripla de pixels. A matriz acumuladora possui três parâmetros governantes, os semieixos maior e menor e o ângulo de inclinação da elipse. Os votos são contabilizados sobre o conjunto identificado sobre estes três parâmetros e são atribuídos a um único elemento dessa matriz.

A escolha pela figura analítica que melhor se ajusta aos supostos pixels da interface gás-líquido representada pela borda externa da bolha inicia-se pelo processo de 
varredura da matriz acumuladora e identificação do conjunto de parâmetros $(\boldsymbol{a}, \boldsymbol{b}, \boldsymbol{\theta})$ com maior votação.

É realizada a construção da figura analítica com centro na origem do sistema cartesiano, ou seja, $\boldsymbol{O}(\mathbf{0 , 0 )}$. Realiza-se a translação dos pixels desta figura obtida analiticamente segundo cada uma das quatro opções de coordenadas de centro da elipse obtidas pelo primeiro processo de votação. Para cada uma das quatro opções de coordenadas de centro da elipse, é realizada uma contagem dos pixels de borda identificados na imagem original coincidentes com o das figuras analíticas. A figura com maior contagem de pixels coincidentes será considerada a principal figura. As demais opções são descartadas. A relação entre os pixels de borda e os da figura analítica deverá ser superior à um limiar de $60 \%$ para que os parâmetros da figura analítica sejam considerados descritivos da interface gás-líquido da bolha.

Este limiar visa ainda a identificação de elipses parcialmente oclusas e serve também como um fator adicional na identificação de bolhas fora de foco.

Após a identificação dos parâmetros da elipse, a borda da bolha correspondente é apagada da imagem das bordas e o processo é repetido até atingir uma taxa de pixels de borda inferior ao limiar estabelecido. Na ocorrência da detecção de outra elipse, é realizada uma verificação de concentricidade entre elas. Caso isto venha acontecer, entende-se que a bolha inscrita é proveniente da ocorrência de sombras sobre sua interface e os parâmetros que a descrevem, ou seja, com menores valores de semieixos serão eliminados dos resultados. Caso contrário, é identificada uma segunda interface gás líquido nos mesmos limites da subimagem. O sistema estará reconhecendo esta, mesmo que indesejável, segunda bolha dentro dos limites da subimagem. A imagem da bolha na amostra do escoamento será apagada para continuidade do processo.

O resultado do processo de captura dos parâmetros das figuras analíticas descritivas das interfaces gás líquido nas subimagens será o número de figuras identificadas e uma matriz contendo em suas linhas o conjunto de parâmetros $\left(\begin{array}{lllll}x_{c} & y_{c} & a & b & \theta\end{array}\right)$ descritivo de cada bolha. 


\subsubsection{Cálculo da fração de vazio da amostra do escoamento}

WHALLEY (1996) define a fração de vazio como a média temporal da fração transversal entre a área ou volume que é ocupada pela fase gasosa. Ele também define a fração de vazio pela proporção do volume total que é ocupado por gás no escoamento. Entende-se que esta segunda definição se refere à fração de vazio volumétrica por se tratar de uma proporção de volumes.

O cálculo do volume de cada uma das bolhas identificada nas amostras de escoamento, considera sua simetria em torno de seu semieixo maior, ou seja, a terceira dimensão da bolha seria descrita por um semieixo com comprimento igual ao do semieixo menor identificado na aplicação da transformada randomizada de Hough:

$$
b=c
$$

O volume da bolha é calculado com esta consideração:

$$
V=\frac{4}{3} \pi \cdot a \cdot b^{2}
$$

A figura 28 apresenta um elipsoide com estas características e dela já se pode observar sua similaridade com as bolhas visualmente identificadas nas imagens do circuito experimental.

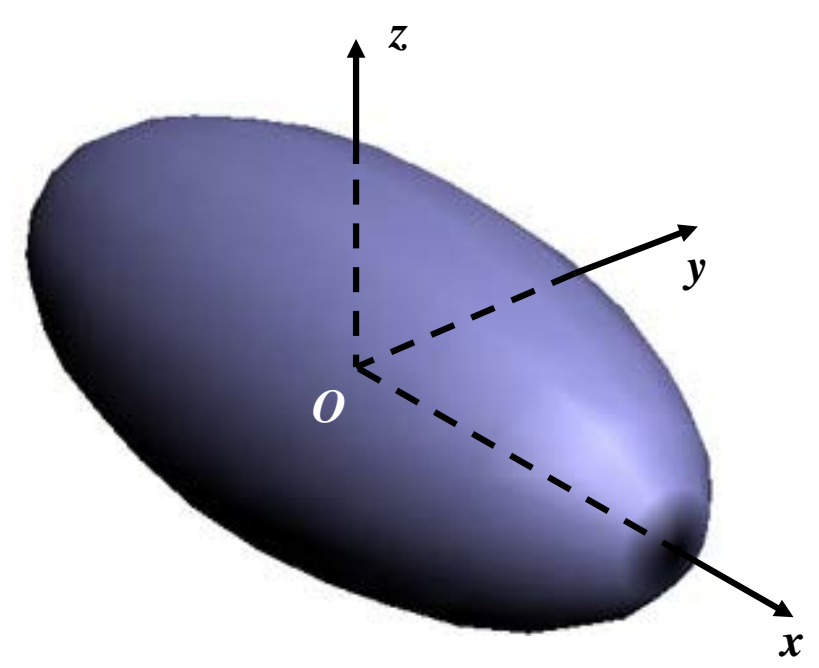

FIGURA 28 - Elipsóide regular empregado na representação de uma bolha.

FONTE: <http://pt.wikipedia.org/wiki/Elipsoide>, acesso em 31/03/2014

O volume de cada bolha é adicionado a uma variável acumuladora que é atualizada toda vez que uma bolha é identificada durante o processo de varredura de uma 
amostra de escoamento. Ao final de todas as varreduras, esta variável acumuladora representa o volume total de gases na amostra, " $V_{g_{\text {ot }}}$ ", ou seja:

$$
V_{g_{\text {tot }}}=V_{g}(30)+V_{g}(36)+V_{g}(44)+V_{g}(54)+V_{g}(66)+V_{g}(80)+V_{g}(96)+V_{g}(114)+\ldots
$$

onde:

$V_{g_{\text {tot }}} \ldots \quad$ volume total de gases em uma amostra de escoamento;

$V_{g}(d s) \ldots$ volume total das bolhas detectadas em uma amostra de escoamento por uma máscara virtual progressiva de varredura de dimensões " $d s "$ ";

$d s$... dimensões da máscara virtual progressiva para cada varredura da amostra do escoamento. $d s=30,36,44,54,66,80,96,114, \ldots$

Os valores para incremento nas dimensões da máscara virtual progressiva de varredura são escolhidos segundo uma progressão aritmética com razão 2. Estes valores são selecionados a partir da observação do aumento progressivo do espaço entre as bolhas de dimensões maiores a medida que as varreduras progressivas vão ocorrendo.

O cálculo da estimativa amostral da fração de vazio volumétrica, " $\alpha$ ", consiste na razão entre o volume total de gases na amostra, " $V_{g_{\text {ot }}}$ " e o volume total da amostra, " $V_{g l}$ " ilustrada nas figuras 29 e 30.

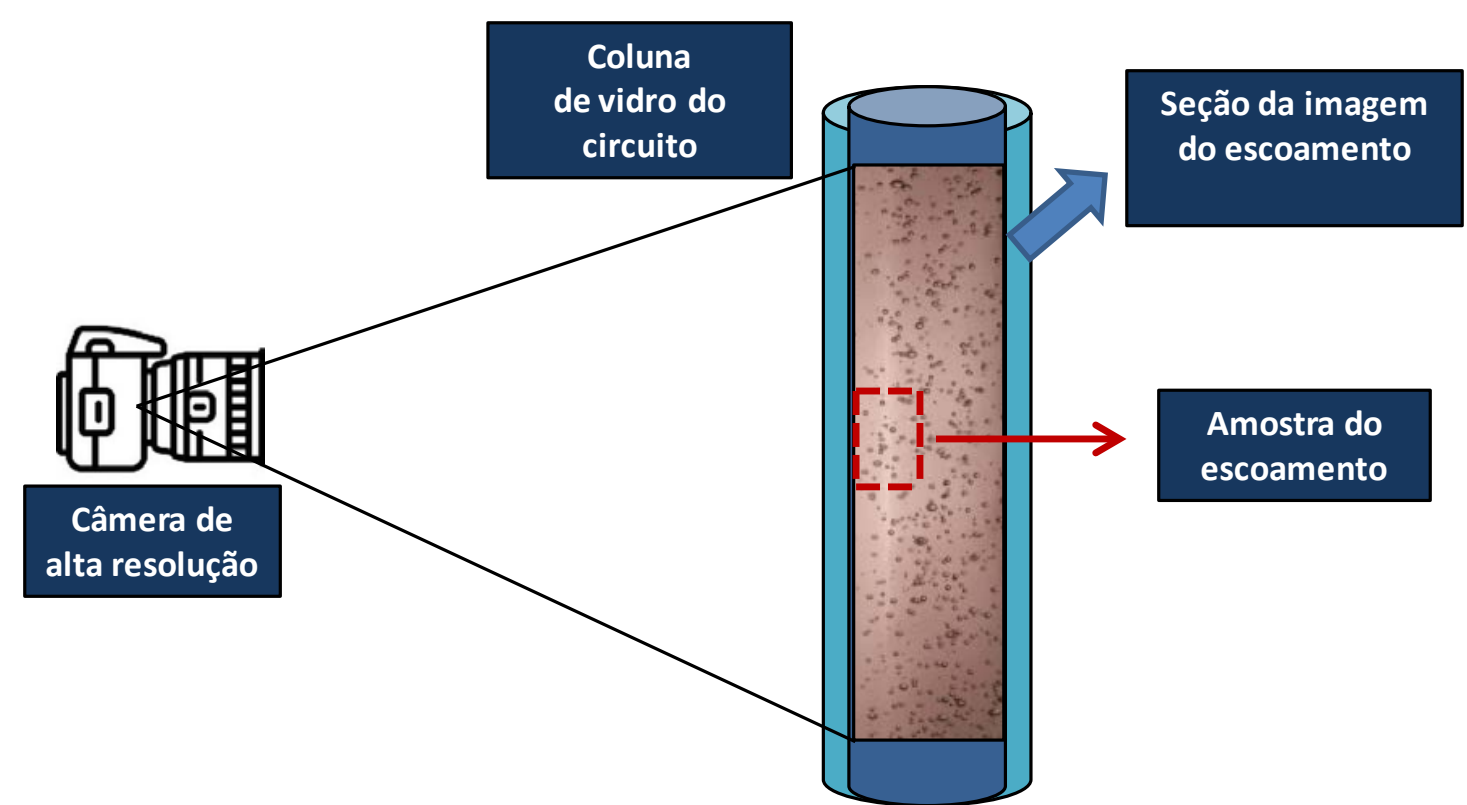

FIGURA 29 - Representação esquemática da amostra da imagem do escoamento bifásico (vista lateral) 


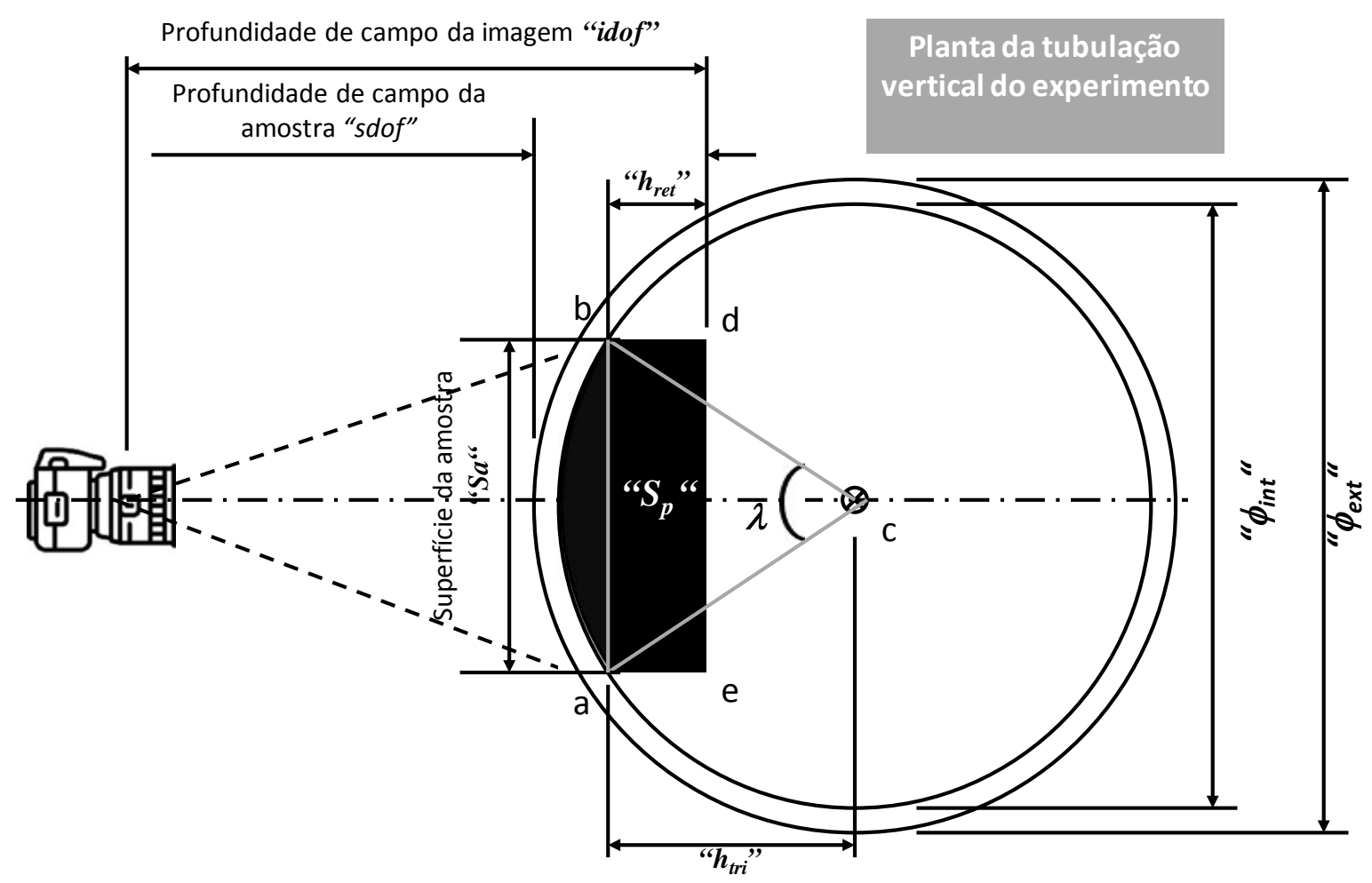

FIGURA 30 - Representação esquemática da amostra da imagem do escoamento bifásico (vista de cima)

A vista frontal da amostra, representada pela projeção da imagem do escoamento sobre o sensor da câmera, possui dimensões iguais, ou seja, sua altura " $h$ " é igual sua largura " $S_{a}$ ".

O cálculo do volume total da amostra, " $V_{g l}$ ", consiste no cálculo da área da planta, " $S_{p}$ " (ou área da amostra vista por cima) multiplicada pela sua altura, "h", ou seja:

$$
V_{g l}=S_{p} \cdot h
$$

A área da planta, " $S_{p}$ " é constituída pela adição da área interna do arco circular, " $S_{a c}$ ", limitado pelos pontos "a" e "b", o raio interno do tubo, " $\mathrm{r}_{\text {int }}$ " com ângulo de abertura " $\lambda$ " em relação ao centro da tubulação, com a área do retângulo, " $\boldsymbol{S}_{\text {ret }}$ ", com sua base formada pela linha de comprimento " $S_{a}$ " (segmento " $\overline{a b} "$ ) e com altura, " $h_{\text {ret }}$, igual ao comprimento do segmento $\overline{a e}$. A altura do retângulo é limitada pela profundidade de campo selecionada na câmera e aferida segundo a escada de nível ilustrada na figura 13.

A área do arco circular é resultante extração da área do triângulo com vértices nos pontos a,b e c, da área do setor circular, formada pelo ângulo " $\lambda$ " e com os mesmos pontos. Os segmentos $\overline{c a}$ e $\overline{c b}$ possuem o mesmo comprimento do " $r_{i n t}$ " que é calculado segundo a expressão (4.69): 


$$
r_{\text {int }}=\frac{\phi_{e x t}-\Delta \phi}{2}
$$

Onde $\Delta \phi$ é a expessura do vidro da tubulação do experimento. O ângulo de abertura referente às dimensões da amostra é obtido de:

$$
\lambda=2 \cdot \operatorname{arcsen}\left[\frac{\left(\frac{S_{a}}{2}\right)}{r_{\text {int }}}\right]
$$

A área do setor circular, $S_{s c}$ é obtida da expressão :

$$
S_{\mathrm{sc}}=\frac{r_{\mathrm{int}}^{2} \cdot \lambda}{2} \quad(\lambda \text { em radianos })
$$

O cálculo da área do triângulo abc, " $S_{\Delta}$ ", inscrito no setor circular, requer o cálculo da sua altura, " $h_{\Delta}$ ", que é obtida da expressão (4.72), ou seja:

$$
h_{\Delta}=r_{\text {int }} \cdot \cos \left(\frac{\lambda}{2}\right)
$$

Logo:

$$
S_{\Delta}=\frac{S_{a} \cdot h_{\Delta}}{2}
$$

A área interna do arco circular é:

$$
S_{a c}=S_{s c}-S_{\Delta}
$$

A altura do retângulo "abde" é:

$$
h_{\text {ret }}=r_{\text {int }}-\left(\frac{\phi_{\text {ext }}}{2}-s_{\text {dof }}\right)-\left(r_{\text {int }}-h_{\Delta}\right)
$$

A área do retângulo é;

$$
S_{\text {ret }}=S_{a} \cdot h_{\text {ret }}
$$

A adição da área do arco circular com a área do retângulo, resulta na área da planta, ou seja:

$$
S_{p}=S_{a c}+S_{r e t}
$$

O volume da amostra, " $V_{g l}$ ", pode ser calculado com a consideração que a altura da amostra é igual à " $S_{a}$ " e a equação (4.68) fica: 


$$
V_{g l}=S_{p} \cdot S_{a}
$$

O cálculo da estimativa da fração de vazio da amostra, " $\alpha$ ", pode ser calculada pela expressão:

$$
\alpha=\frac{V_{\text {gtot }}}{V_{g l}}
$$

O processo pode ser reiniciado considerando outra imagem com as mesmas propriedades das amostras volumétricas das imagens anteriores pela captura do escoamento bifásico em outro instante de tempo, ou seja, no instante em que a imagem fora adquirida. O cálculo da variação temporal da fração de vazio, ou seja, para uma sequência de imagens em intervalos contínuos de exposição, representa a evolução temporal do escoamento bifásico.

\subsection{Calibração e ajustes do sistema computacional}

O desenvolvimento do sistema computacional considera as imagens do escoamento bifásico capturadas de circuitos de circulação natural como sua principal aplicação. As imagens são adquiridas pelo processo de imageamento direto que, consiste na captura direta de imagens digitais do escoamento bifásico, objeto de estudo no fenômeno da circulação natural, via câmeras de alta velocidade e resolução diretamente de uma seção longitudinal da tubulação de vidro do circuito.

A calibração e os ajustes do sistema computacional farão uso das imagens capturadas de uma bancada de calibração de fração de vazio. Projetada e desenvolvida para este fim, a bancada de calibração de fração de vazio encontra-se nas dependências do Centro de Engenharia Nuclear do Instituto de Pesquisas Energéticas e Nucleares (CEN/IPEN). Ela consiste em um circuito aberto gerador de escoamento bifásico com tomadas de pressão em dois pontos diferentes. A figura 31(c) apresenta a imagem de uma visão geral da bancada de calibração de fração de vazio e as demais imagens, suas partes

principais como: (a) o painel de tomada de pressão; (b) seção da tubulação em que as imagens do escoamento bifásico são capturadas; (d) a tomada de pressão no ponto superior do circuito aberto e (e) elemento poroso e tomada de pressão no ponto inferior do circuito aberto. A diferença de pressão entre os pontos superior e inferior do circuito permite a estimativa da fração de vazio para as condições de execução do experimento. Os resultados desta bancada de calibração serão confrontados com os resultados da execução do sistema 
sobre as correspondentes imagens capturadas durante a execução do experimento, ou seja, nas mesmas condições da sua realização.

Este processo tem como fundamento a aquisição das imagens digitais capturadas diretamente do circuito aberto gerador de escoamento bifásico desta bancada de calibração. Esta parte da bancada é composta de uma coluna de vidro cilíndrica preenchida com água e com um sistema poroso de injeção de ar em sua base. As principais características físicas deste circuito aberto reproduzem as dos experimentos realizados no CCN nas dependências do CEN /IPEN (Centro de Engenharia Nuclear / IPEN), ou seja, o diâmetro interno da tubulação de vidro neste circuito, a distância em que a câmera de alta velocidade e resolução está posicionada da tubulação de vidro e o comprimento da secção longitudinal da imagem da tubulação do circuito.

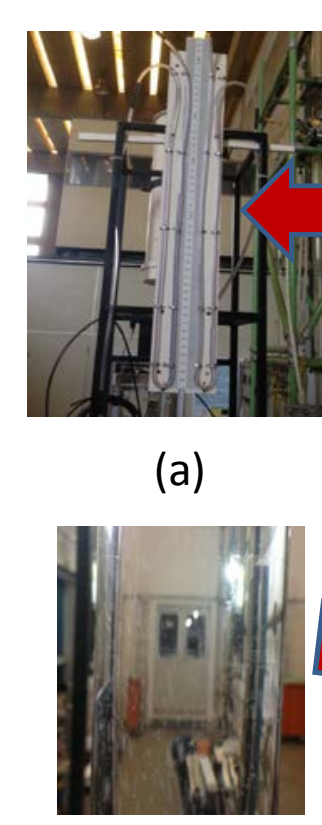

(b)

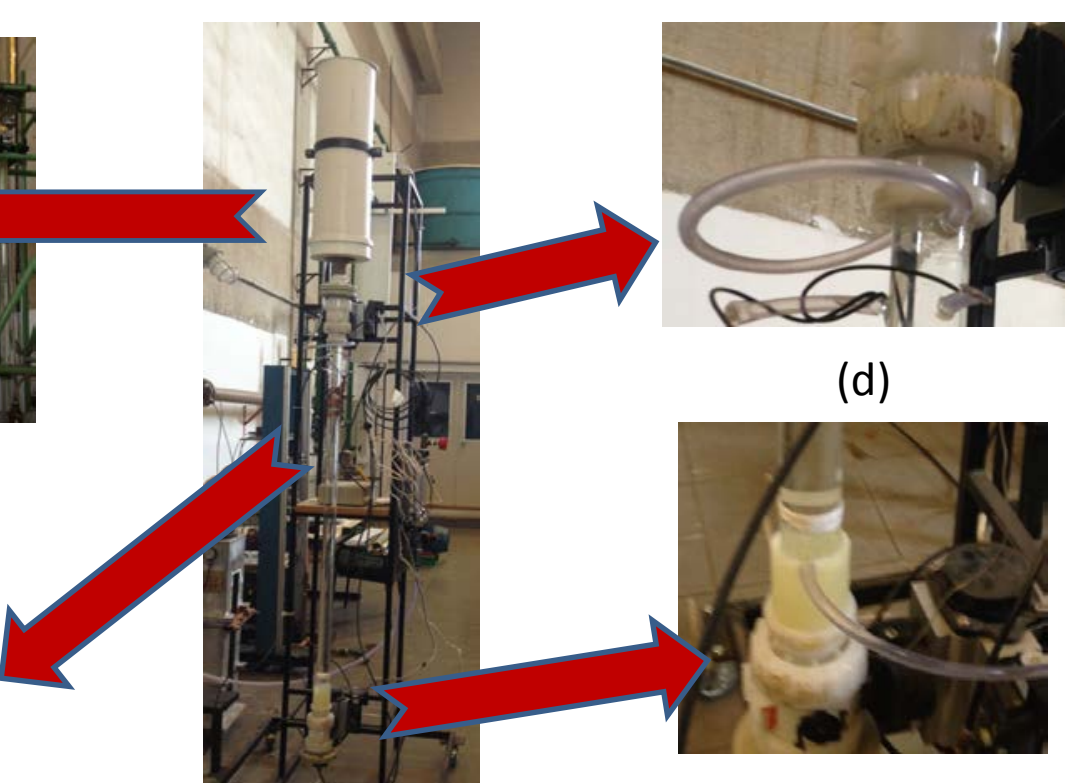

(e)

(c)

FIGURA 31 - Imagens da bancada de calibração de fração de vazio. (a) Painel de tomada de pressão; (b) seção da tubulação de captura das imagens do escoamento; (c) Visão geral da bancada; (d) Tomada de pressão da parte superior do circuito aberto; (e) Tomada de pressão da parte inferior do circuito aberto.

A fração de vazio pode ser estimada experimentalmente através do diferencial entre a pressão extraída dos dois pontos do circuito gerador apresentados na figura 31(d) e 31(e). Esta diferença de pressão é representada pela diferença entre as colunas d'água expostas no painel de tomadas de pressão, também capturado por imagem sincronizada com a do escoamento bifásico durante a execução do experimento. A figura 32 apresenta um esquema da bancada de calibração e suas respectivas partes. 


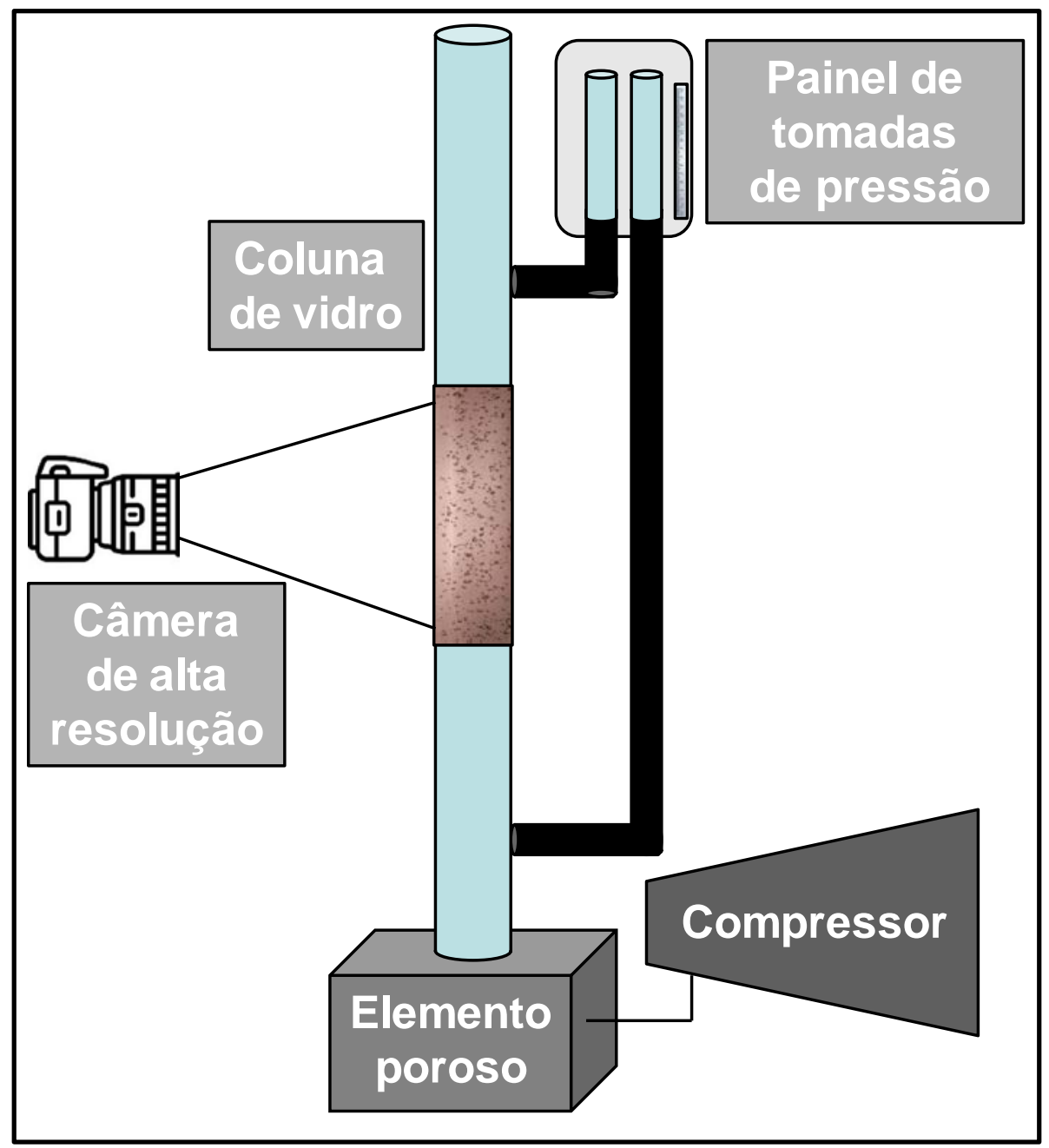

FIGURA 32 - Representação esquemática do circuito gerador de escoamento bifásico

As imagens do escoamento bifásico correspondentes aos valores medidos da fração de vazio são capturadas da seção longitudinal ilustrada nas figuras 31(b) e 32 e são utilizadas como entrada do sistema computacional, figura 33.

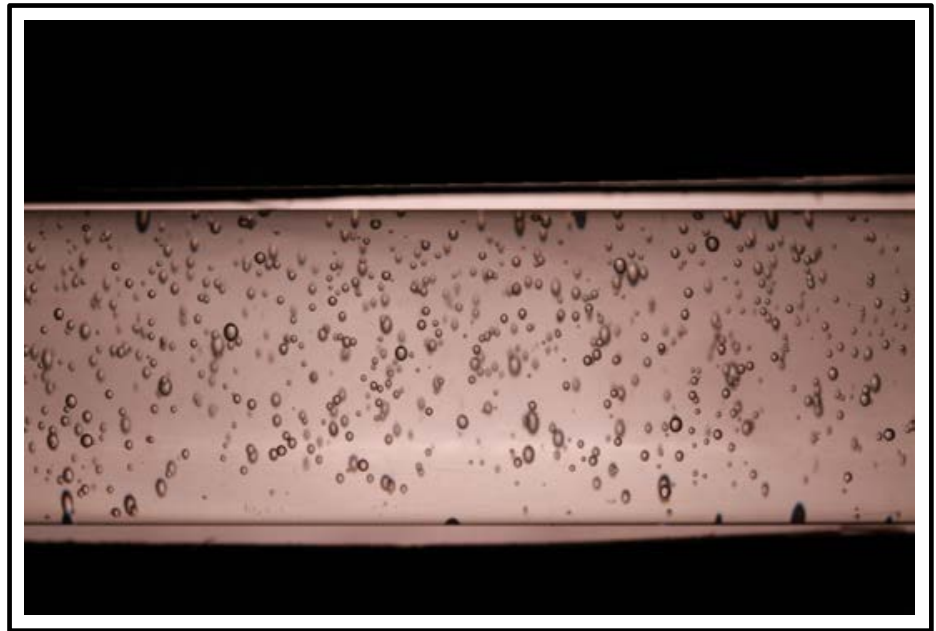

FIGURA 33 - Imagem capturada da bancada de calibração da fração de vazio. 
A calibração e os ajustes deste sistema são realizadas com base no confronto direto dos valores da fração de vazio obtidos através da sua execução para diversas imagens digitais de escoamento bifásico com os valores obtidos experimentalmente por um método denominado gravimétrico.

Este processo de calibração e ajuste do sistema computacional habilita sua aplicação em circuitos que fazem uso do imageamento direto para estudos do fenômeno da Circulação Natural, em particular, o Circuito de Circulação Natural (CCN) instalado no Centro de Engenharia Nuclear do IPEN (DE MESQUITA et al., 2012).

Em sua concepção original, o sistema computacional foi desenvolvido para aplicações sobre imagens obtidas por imageamento direto com o propósito de aplicação direta no Circuito de Circulação Natural. A perspectiva de universalizar sua aplicação para imagens de escoamento capturadas por imageamento por nêutrons visa a diversificação do sistema em termos de imagens provenientes de tecnologias diferentes para análise e estudo do fenômeno da circulação natural.

\section{Método gravimétrico para cálculo da fração de vazio}

A leitura da diferença de pressão realizada no circuito de simulação do escoamento é representada pela diferença na altura dos níveis de água no painel de tomadas de pressão, " $h$ ", figura 34(b).

O método empregado para obtenção experimental da fração de vazio através desta leitura é denominado método gravimétrico e, para sua aplicação devem ser consideradas as seguintes restrições:

- deve ser aplicado em escoamentos verticais tipo bolhas e com velocidade de líquido muito baixa;

- a medida do diferencial de pressão permite o cálculo da fração de vazio volumétrica $\langle\alpha\rangle_{3}$ das fases no trecho do escoamento em questão e

- se a distribuição axial das fases varia pouco (L pequeno e assim como as perdas por atrito) ao longo de L, pode-se afirmar que a fração de vazio média na seção é igual à concentração volumétrica, $<\alpha>\approx<\alpha\rangle_{3}$, figura 34. 


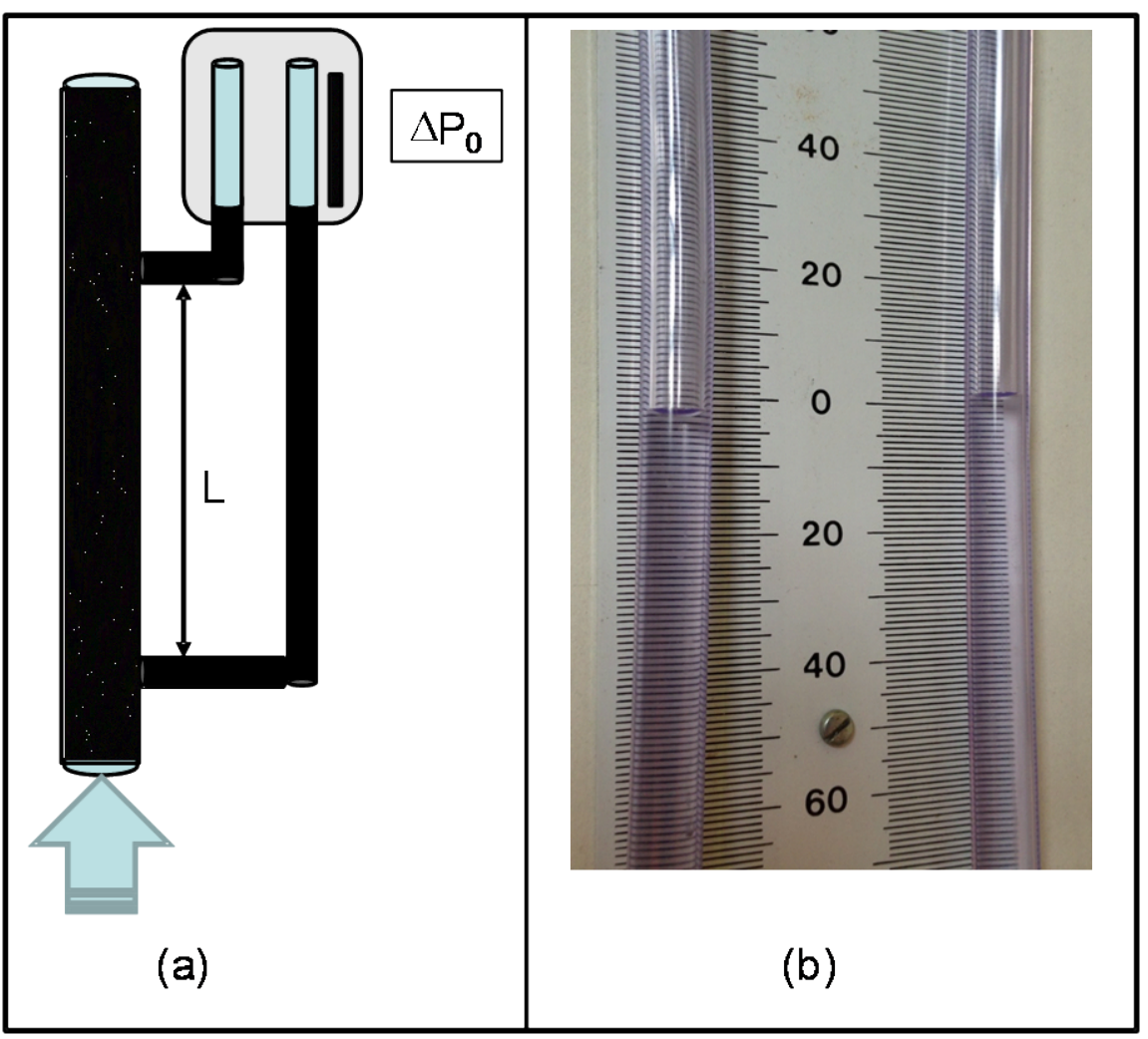

FIGURA 34 - (a) Representação esquemática do painel de tomada de pressão em dois pontos do circuito; (b) Imagem do painel de tomada de pressão no circuito gerador do escoamento bifásico.

A diferença de pressão, $\Delta P_{0}$, é resultante da concentração de gás entre os dois pontos do escoamento devido a injeção de gás, da variação de pressão devido ao atrito entre as fases gasosa e líquida:

$$
\Delta P_{0}=\left(\rho_{m} g L+\Delta P_{t}\right)-\rho_{L} g L
$$

onde:

$$
\begin{array}{ll}
\rho_{m} & \text { densidade da mistura }\left(\mathrm{kg} / \mathrm{m}^{3}\right) \\
\rho_{L} & \text { densidade do líquido }\left(\mathrm{kg} / \mathrm{m}^{3}\right) \\
\Delta_{t} & \text { diferencial de pressão causado pelo atrito do escoamento da } \\
& \text { mistura } \\
h & \text { diferença na altura das colunas d'água no painel de tomada de } \\
& \text { pressão (mm) } \\
& \text { diferença na altura da coluna d'água devido a injeção de gases } \\
& \text { no sistema (mm) }
\end{array}
$$

A densidade da mistura é obtida em função da fração de vazio média $\langle\alpha>$, 
tem-se:

$$
\rho_{m}=(1-\alpha) \rho_{L}+\alpha \rho_{G}
$$

Substituindo a equação (4.80) em (4.79) e assumindo como $\Delta \rho=\rho_{L}-\rho_{G}$, desprezando-se o diferencial de pressão devido ao atrito da mistura, visto a velocidade da fase líquida ser próxima de zero, obtém-se a fração de vazio $\alpha$ :

$$
\alpha=\frac{\rho_{L}}{\rho_{L}+\rho_{G}} \cdot \frac{h}{L}
$$

Para a bancada de calibração de instrumentos dedicados aos escoamentos bifásicos localizada no Laboratório de Termo-hidráulica Experimental do Centro de Engenharia Nuclear (CEN-IPEN) os parâmetros são:

$$
\begin{aligned}
& \mathrm{g}=9,81 \mathrm{~m} / \mathrm{s}^{2} \\
& \mathrm{~L}=1,295 \mathrm{~m} \\
& \rho_{\mathrm{L}}=997,82 \mathrm{~kg} / \mathrm{m}^{3}\left(@ 15^{\circ} \mathrm{C}, \mathrm{P}_{\mathrm{amb}}\right) \\
& \rho_{G}=0,2502 \mathrm{~kg} / \mathrm{m}^{3}\left(@ 15^{\circ} \mathrm{C}, \mathrm{P}_{\mathrm{amb}}\right)
\end{aligned}
$$

A descrição detalhada do método gravimétrico é realizada por ROCHA (2005, p. 50 - 53) onde é apresentada uma análise da incerteza sobre a aplicação deste mesmo método (p. I2 - I3). Esta incerteza é definida como o parâmetro associado ao resultado de uma medição e caracteriza a dispersão dos valores. A incerteza para a fração de vazio," $\delta \alpha$ " é obtida, especificamente para o caso da aplicação do método gravimétrico, pela expressão:

$$
(\delta \alpha)^{2}=\left(\frac{\delta h}{L}\right)^{2}+\left(\frac{h \delta L}{L^{2}}\right)^{2}
$$

As imagens que servirão de base para calibração e ajustes das aplicações que compõe o sistema computacional foram adquiridas da bancada experimental de calibração da fração de vazio do escoamento bifásico buscando condições representativas do Circuito de Circulação Natural (CCN) do Centro de Engenharia Nuclear do IPEN (DE MESQUITA et al., 2012). 


\subsection{Descrição do Circuito de Circulação Natural (CCN)}

O CCN é constituído de tubos cilíndricos de vidro preenchidos com 20 litros de água desmineralizada, um aquecedor de calor controlado por um Variac (fonte de calor) e um trocador de calor helicoidal trabalhando como uma fonte fria (resfriamento). A visualização é possível em todo o circuito. O aquecedor é composto de dois resistores elétricos que podem ser controlados até $8000 \mathrm{~W}$. O refrigerador é um circuito de água a temperatura ambiente. Existe um tanque de expansão parcialmente preenchido com água e posicionado acima do circuito agindo como um pressurizador. A figura 35 ilustra este circuito com destaques às suas principais partes integrantes.

Das partes integrantes dessa figura pode-se ter uma visão completa do circuito, figura 35(c), do pressurizador posicionado na parte superior do circuito para fins de simulação de um modelo de refrigeração de um circuito aplicado em reatores nucleares pressurizados a água, figura 35(a), do Variac utilizado para fins de controle de temperatura, ou de adição de calor, figura 35(b), do trocador de calor para simulação do sistema de resfriamento , figura 35(d) e do aquecedor empregado para adição de calor ao circuito, figura $35(d)$.

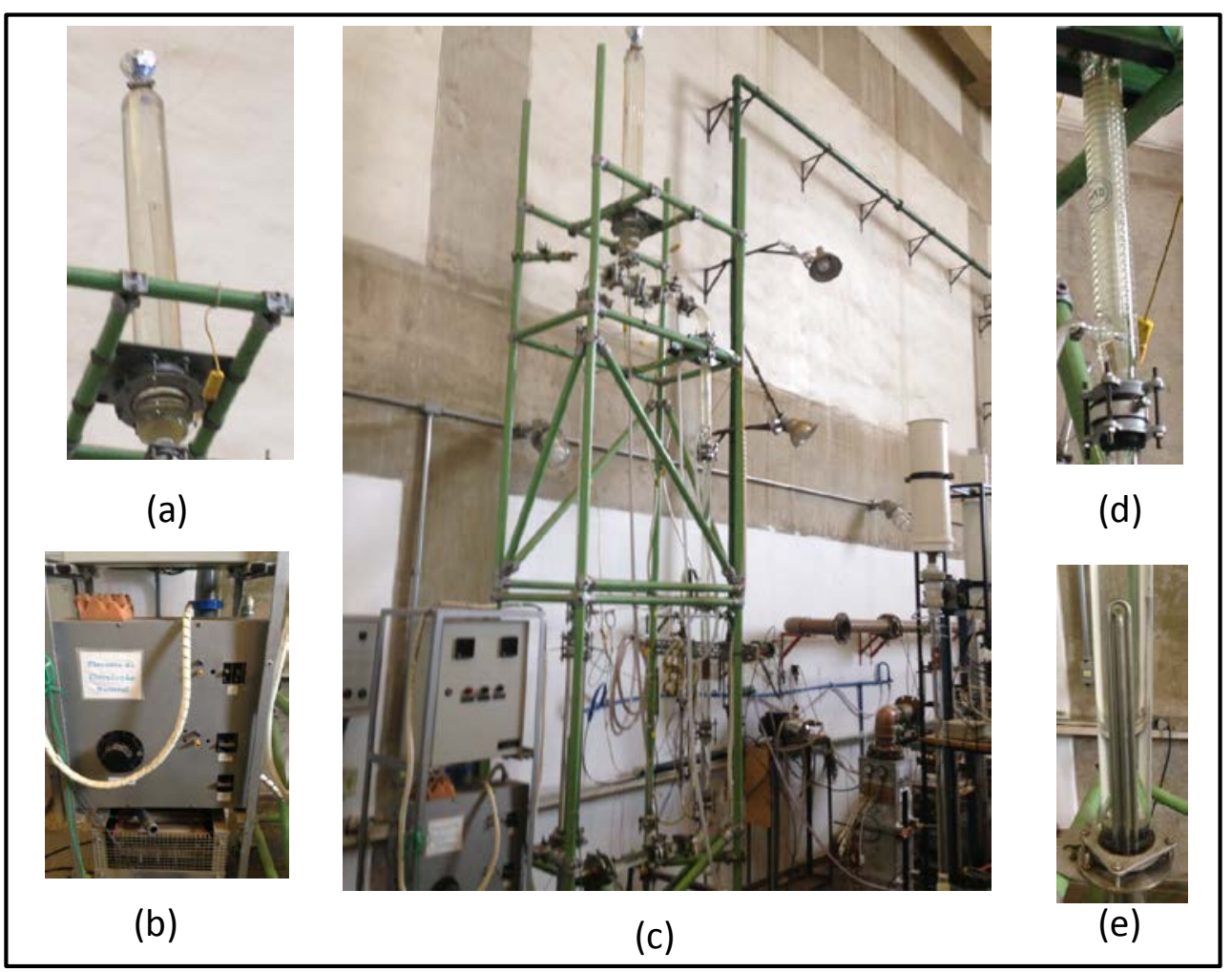

FIGURA 35 - Circuito de Circulação Natural (CCN). (a) Pressurizador;

(b) Variac (controlador de calor); (c) Visão global do circuito;

(d) Trocador de calor helicoidal; (e) Aquecedor. 
As aquisições de imagens são feitas simultaneamente com as medidas de temperatura e empregam câmeras de alta resolução (20 Mpixels).

A frequência de captura das imagens em um experimento típico neste circuito (MESQUITA et al., 2009) foi de 1 quadro por segundo em experimentos com duração variável de 1000 a 1500 s.

Uma estrutura foi elaborada para iluminação do escoamento pelo fundo de forma a estabelecer um contraste ideal e reduzir os efeitos de reflexão da face anterior do tubo, figura 36. O perfil das imagens capturadas foi de quadros de 3888 x 2592 pixels com uma resolução de $0.03 \mathrm{~mm} /$ pixel. Estas imagens foram adquiridas para uma secção longitudinal de 110 mm e transversal de 43.6 mm (diâmetro externo), figuras 36 e 37.

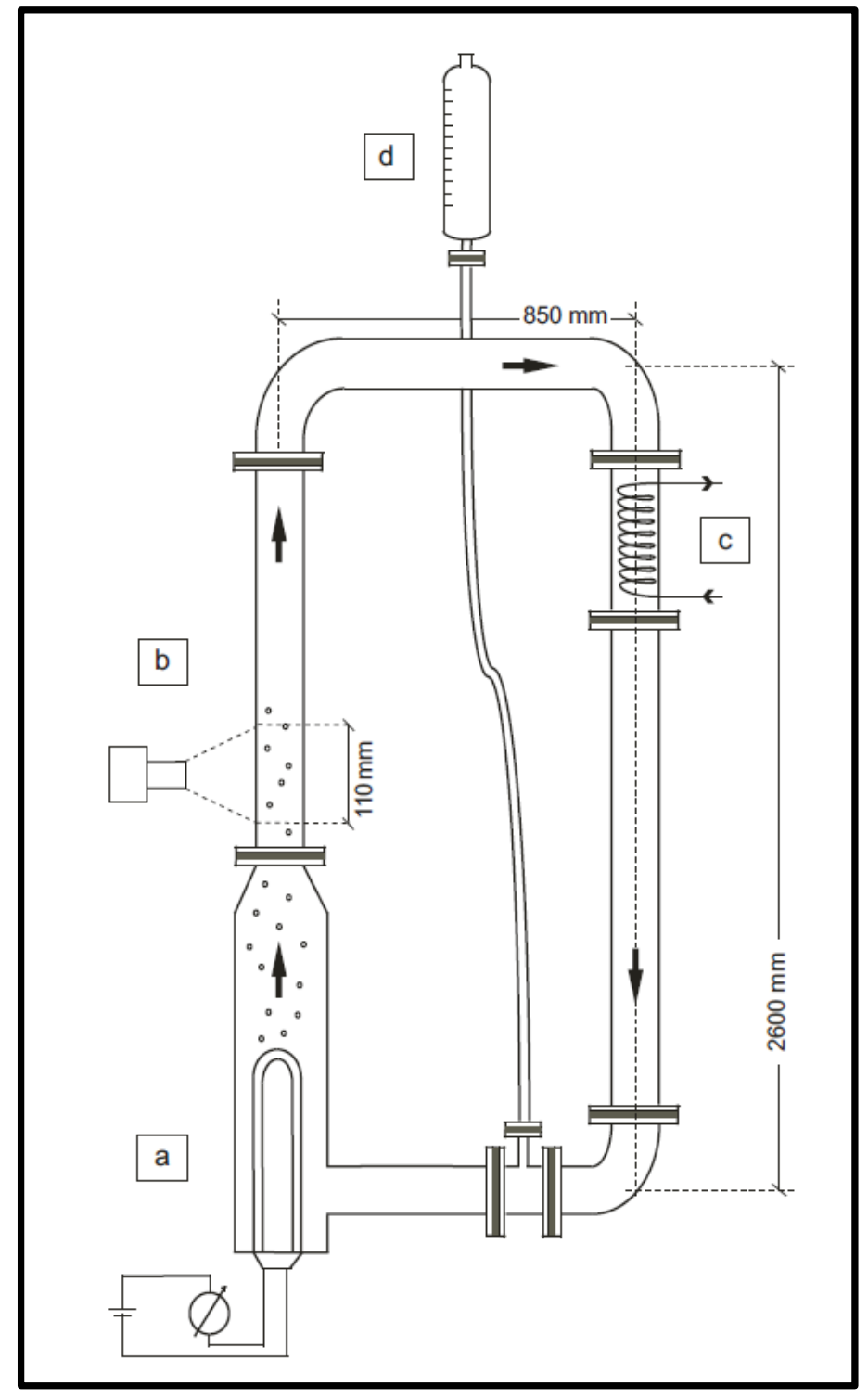

FIGURA 36 - Representação esquemática do Circuito de Circulação Natural (CCN). FONTE: DE MESQUITA, R.N. et al. (2012) 
O experimento que simula o escoamento bifásico neste circuito consiste em um ciclo de duas a três horas de operação que incluem o aquecimento inicial da massa de água com observação através dos sensores de temperatura, pressão e visualização dos diversos regimes de escoamento.

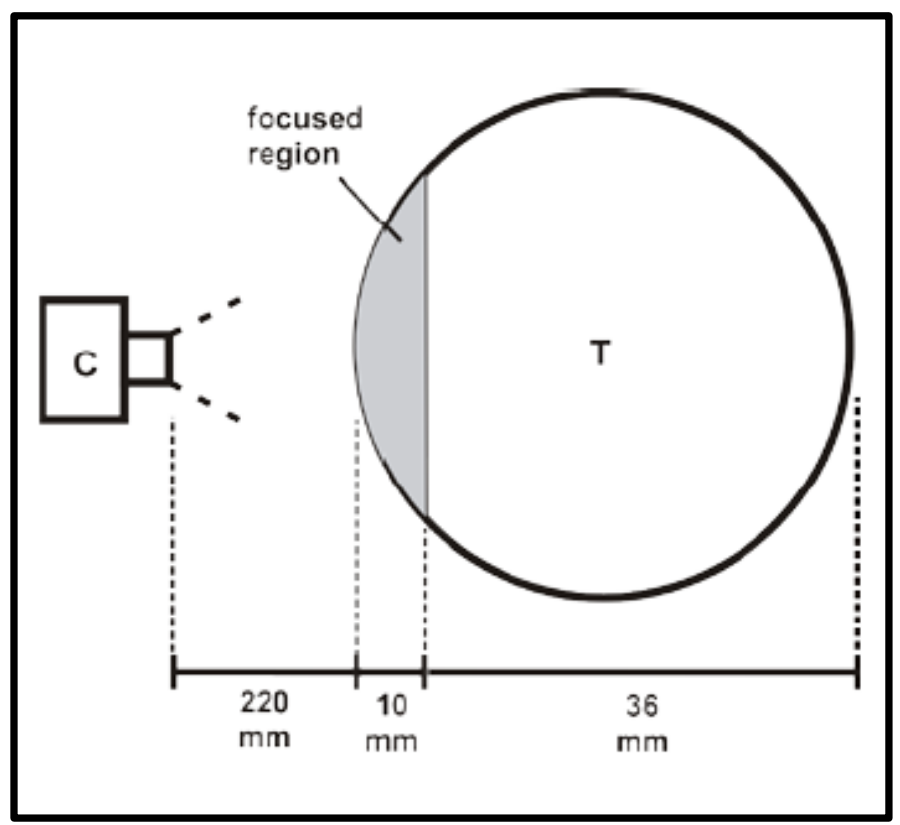

FIGURA 37 - Região focal da câmera.

FONTE: MESQUITA et al. (2009)

O circuito gerador do escoamento bifásico para fins de calibração e ajuste do sistema computacional tem por princípio a reprodução de condições similares do CCN. Estas condições incluem a reprodução de características próprias do escoamento bifásico e são relevantes na captura das imagens para fins de aplicações no CCN:

- $\quad$ a infraestrutura de aquisição de imagens no circuito gerador de escoamento bifásico emprega os mesmos equipamentos para aquisição de imagens, iluminação em posições similares as do circuito CCN;

- $\quad$ as características físicas da tubulação de vidro do circuito experimental gerador do escoamento bifásico possui as mesmas características da tubulação do CCN, ou seja, foram utilizados tubos de vidro com mesmo diâmetro e espessura aos empregados no CCN;

- $\quad$ a aquisição das imagens no circuito gerador do escoamento bifásico só poderá ser realizada a partir da observação da ocorrência de homogeneidade do escoamento, ou seja, em condições tais que uma imagem parcial seja representativa do escoamento em todo o circuito e, por conseguinte, do seu resultado experimental e 
- $\quad$ as condições de iluminação na aquisição das imagens bem como os parâmetros relacionados aos ajustes das câmeras devem ser rigorosamente controlados de forma a assegurar a reprodução dos resultados em condições experimentais similares entre elas e as empregadas no CCN. 
O sistema computacional foi implementado contendo diversas aplicações e será mencionado neste texto por VFTools. O termo VFTools é uma sigla ("Void Fraction Tools" - Ferramentas de Fração de Vazio) e refere-se à uma caixa de ferramentas com um conjunto de aplicações (ou ferramentas) empregadas no cálculo da fração de vazio. As aplicações do VFTools executam a adequação de imagens digitais e seleção de amostras volumétricas do escoamento bifásico, o reconhecimento de bolhas, a identificação das propriedades geométricas das bolhas, o cálculo do volume de gases nos limites destas amostras de escoamento e o cálculo da fração de vazio.

As aplicações foram desenvolvidas em MATLAB empregando recursos de interface gráfica para melhor visualização dos resultados e interatividade com o usuário. Todas as indicações, legendas e textos das interfaces gráficas estão na língua inglesa visando futuras utilizações em conjunto com outras universidades ou centros de pesquisa. As principais aplicações e suas funcionalidades são:

- selecTool: realiza a seleção da amostra da imagem do escoamento bifásico segundo um modelo de captura das medidas superficiais, ou frontais e da profundidade da imagem do escoamento capturada do experimento. Esta última é associada a um valor de profundidade de campo selecionado na câmera de alta resolução e a um sistema de inferência focal fuzzy. Esta composição de profundidade de campo à um modelo fuzzy de inferência procura classificar e associar os pixels em foco das imagens do escoamento à um valor máximo de profundidade limitador do volume da amostra da imagem do escoamento;

- maSamTool: é a principal aplicação do VFTools. Ela realiza a construção das amostras de treinamento das redes neurais artificiais e o treinamento da rede dedicada à cada dimensão da máscara virtual de varredura progressiva. Executa o treinamento e realiza uma avaliação prévia do resultado do treinamento. Realiza a limpeza da amostra da imagem do escoamento bifásico para uma específica dimensão de máscara virtual de varredura 
progressiva sobre uma amostra da imagem do escoamento e realiza o cálculo da fração de vazio e

- saManTool: atua como suporte da maSamTool na construção e preparação do arquivo de amostras de treinamento. Esta aplicação realiza a reclassificação das amostras de "positiva" para "negativa" ou vice-versa. Ela possibilita a eliminação da amostra deste arquivo de amostras de treinamento assim como sua reorganização.

O suporte para o desenvolvimento das aplicações e no emprego de recursos que melhorem a interatividade com o usuário e desempenho do sistema foram referências específicas de desenvolvimento e aplicações em MATLAB, tais como ATTAWAY (2012), GONZALES (2009) e LENT (2013). Embora não estejam ainda incorporadas ao sistema VFTools na forma de uma interface gráfica com o usuário, duas outras aplicações foram desenvolvidas, também em MATLAB:

- lapsob: realiza o cálculo dos perfis de bordas de bolhas "em foco" e "fora de foco" para fins de análise estatística e

- V_Sample: executa o cálculo do volume das amostras das imagens do escoamento bifásico com base nas suas dimensões e resolução.

\subsection{Condições gerais e de contorno dos experimentos}

Dois conjuntos de imagens foram utilizados de forma interativa no desenvolvimento do sistema. Estas imagens foram capturadas em datas diferentes que serão referenciadas na identificação de cada experimento. $\mathrm{O}$ primeiro experimento, e mais abrangente, foi realizado em 24/10/2013 e o segundo, mais restrito em termos de número de imagens, foi realizado em 10/05/2017.

As imagens capturadas nestes experimentos e utilizadas nos estudos, bem como a identificação dos seus arquivos correspondentes, estão organizadas e apresentadas no apêndice $\mathrm{A}$.

Embora tratem de uma mesma bancada de calibração da fração de vazio, algumas variações nas configurações dos componentes do circuito aberto, configuração e posicionamento da câmera de alta resolução e iluminação, de fundo e ambiental, ocorreram nestes experimentos. Tais variações resultaram em tratamentos diferenciados na fase de pré-processamento e seleção das amostras de escoamento. O uso e a execução das demais 
aplicações a partir do resultado da selecTool são idênticos. Necessitando apenas da atualização dos volumes correspondentes das amostras selecionadas diante da alteração da configuração da tubulação de vidro do circuito aberto e da profundidade de campo selecionada na câmera de alta resolução. Assim, tem-se:

\section{$\Rightarrow$ Experimento de 24/10/2013}

- Resolução da imagem: 0,02 mm/pixel;

- Profundidade de campo: $15 \pm 3 \mathrm{~mm}$ da face anterior da tubulação de vidro;

- Diâmetro externo da tubulação de vidro: 42 mm;

- Espessura do vidro: $4 \mathrm{~mm}$;

- Dimensões frontais da amostra da imagem do escoamento: 800 x 800 pixels e

- Volume da amostra, $V_{a}(18 \mathrm{~mm})=4,53 \times 10^{8}$ pixels $^{3}$

\section{$\Rightarrow$ Experimento de 10/05/2017:}

- Resolução da imagem: 0,019 mm/pixel;

- Profundidade de campo: $20 \pm 5 \mathrm{~mm}$ da face anterior da tubulação de vidro;

- Diâmetro externo da tubulação de vidro: 46 mm;

- Espessura do vidro: $4 \mathrm{~mm}$;

- Dimensões frontais da amostra da imagem do escoamento: 800 x 800 pixels e

- Volume da amostra, $V_{a}(20 \mathrm{~mm})=5,12 \times 10^{8}$ pixels $^{3}$.

\subsection{Análise estatística dos perfis das bordas das bolhas (aplicação lapsob)}

A aplicação lapsob é responsável pelo cálculo dos parâmetros empregados na construção das funções de pertinência do sistema de inferência focal fuzzy. Ela apresenta como resultado a variação desses parâmetros segundo o perfil da borda de uma bolha "em foco" ou "fora de foco" capturada de uma das imagens do escoamento bifásico. Seus resultados são gráficos que apresentam a bolha selecionada e os valores da variação da intensidade de cinza, da primeira derivada da intensidade de cinza e da segunda derivada da intensidade de cinza resultantes da aplicação dos operadores Sobel e Laplaciano sobre a imagem. Ela apresenta também a composição da primeira e segunda derivadas da intensidade de cinza, com a intensidade negativa de cinza. As derivadas da intensidade de cinza são mencionadas como "Sobel" para a primeira derivada e "Laplaciano" para a 
segunda derivada. Todos os valores resultantes da aplicação lapsob são normalizados segundo o domínio [0,1]. Os valores da média e desvio padrão de cada um desses parâmetros estão expostos e identificados abaixo de cada um dos gráficos apresentados nas figuras. Os gráficos apresentados nas figuras 38 e 39 correspondem à variação desses parâmetros para perfis de bordas extraídos de imagens de uma bolha. Elas correspondem aos arquivos de imagens IMG_797_3.JPG e IMG_797_2.JPG, respectivamente. Estes perfis foram extraídos de imagens do escoamento bifásico capturadas no experimento de $24 / 10 / 2017$.

As figuras 40 e 41 apresentam gráficos dos parâmetros de segmentação das imagens do escoamento bifásico capturadas no experimento de 10/05/2017 e correspondem aos arquivos, IMG_2137.JPG e IMG_2145.JPG, respectivamente. Os perfis avaliados e analisados nas imagens 38 e 40 correspondem a perfis de imagens em foco. Já os perfis das imagens 39 e 41, a imagens de bordas de bolhas fora de foco. Uma avaliação comparativa dessas figuras já é possível verificar a ausência de um padrão no perfil das bordas ilustradas nas figuras 39 e 41, ou seja, perfis de bordas fora de foco. Embora os valores do desvio padrão sejam significativos em comparação com os das bordas em foco, as médias da intensidade de cinza, da intensidade negativa de cinza adicionada ao operador Sobel e da intensidade de cinza adicionada ao Laplaciano são menores que os das bordas em foco. Este comportamento é esperado de bordas fora de foco visto haver uma grande variação nos valores de intensidade de cinza, porém, em níveis baixos. Nas figuras 38 e 40 os valores dos parâmetros apresentam poucas e contínuas variações. Este comportamento é típico de um perfil de bolha em foco. Os valores médios para estes perfis de bolhas em foco são, significativamente, maiores que os das bolhas fora de foco, no entanto, os valores do desvio padrão são da mesma ordem de grandeza.

Os valores coletados dos 192 perfis de bordas do experimento de 24/10/2013 e dos 110 perfis de bordas do experimento de 10/05/2017 estão organizados e tabelados no apêndice B. Com base nestes dados foi realizado o cálculo do valor médio e do desvio padrão global dos parâmetros de segmentação considerados no modelo de inferência focal fuzzy. Essas análises e a construção do modelo estatístico baseado em uma distribuição gaussiana, foram realizadas isoladamente para cada um dos experimentos em função da ocorrência de uma significativa diferença de iluminação entre eles. A composição adequada desses valores com o desvio padrão global de cada um desses parâmetros viabiliza a construção das funções de pertinência. 

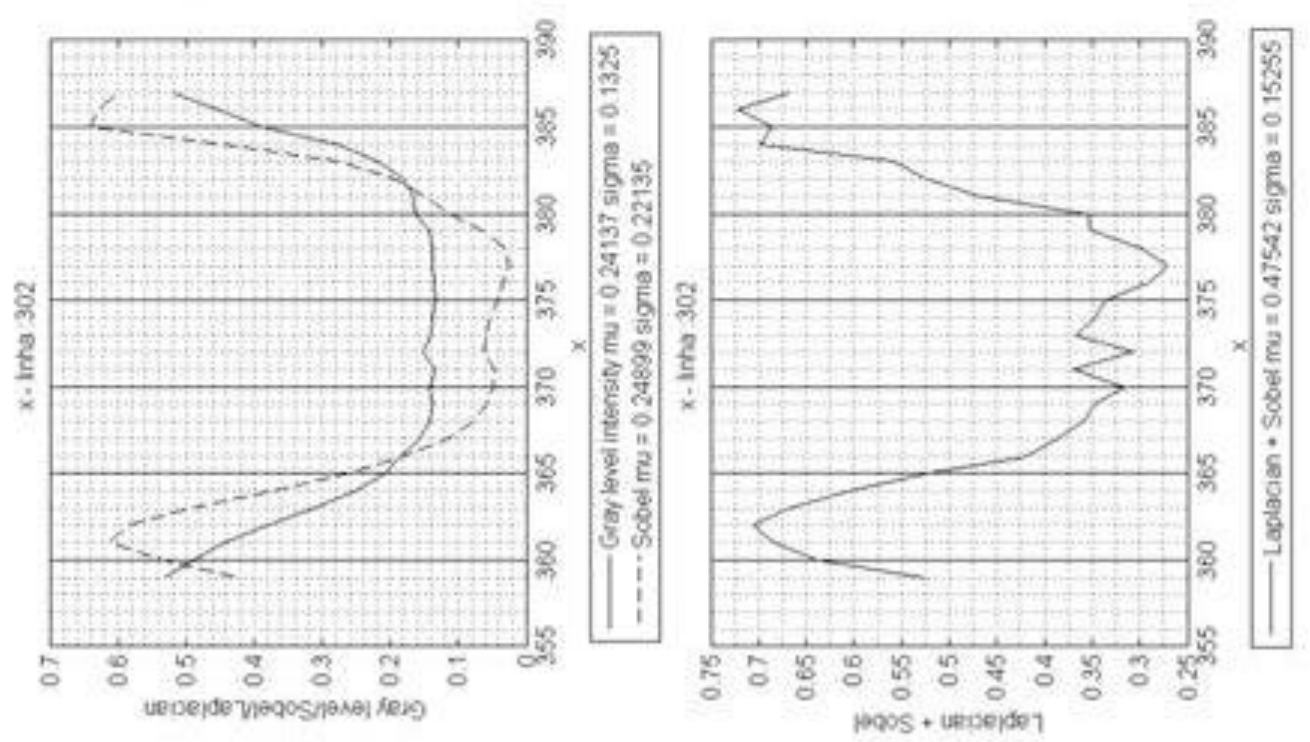

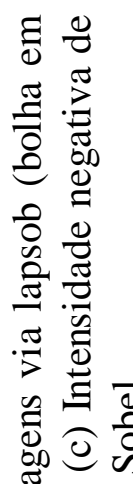

可 + की ठ \& 0 : 䒿
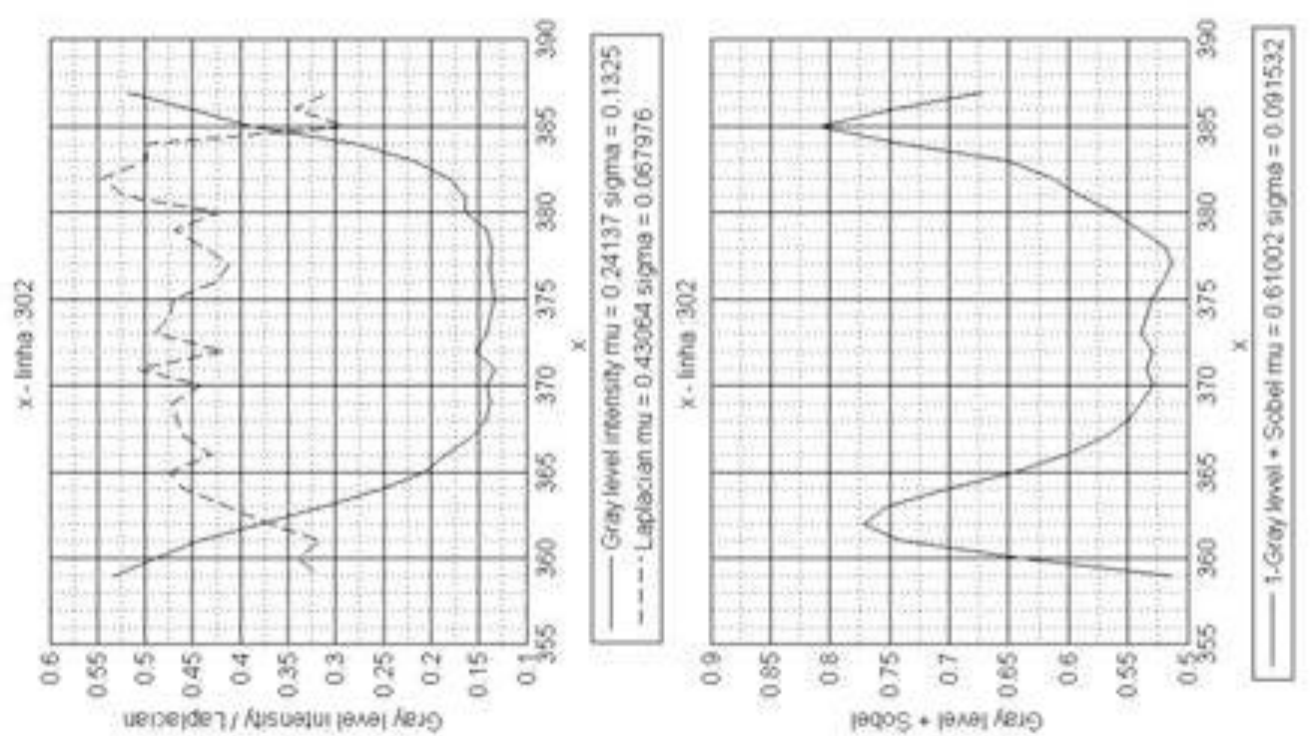

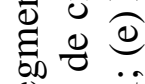

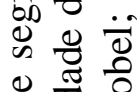
ช 웡 苛 离 ชี 卷 a

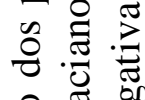
을 휼 苂先 율 总 竞 吾
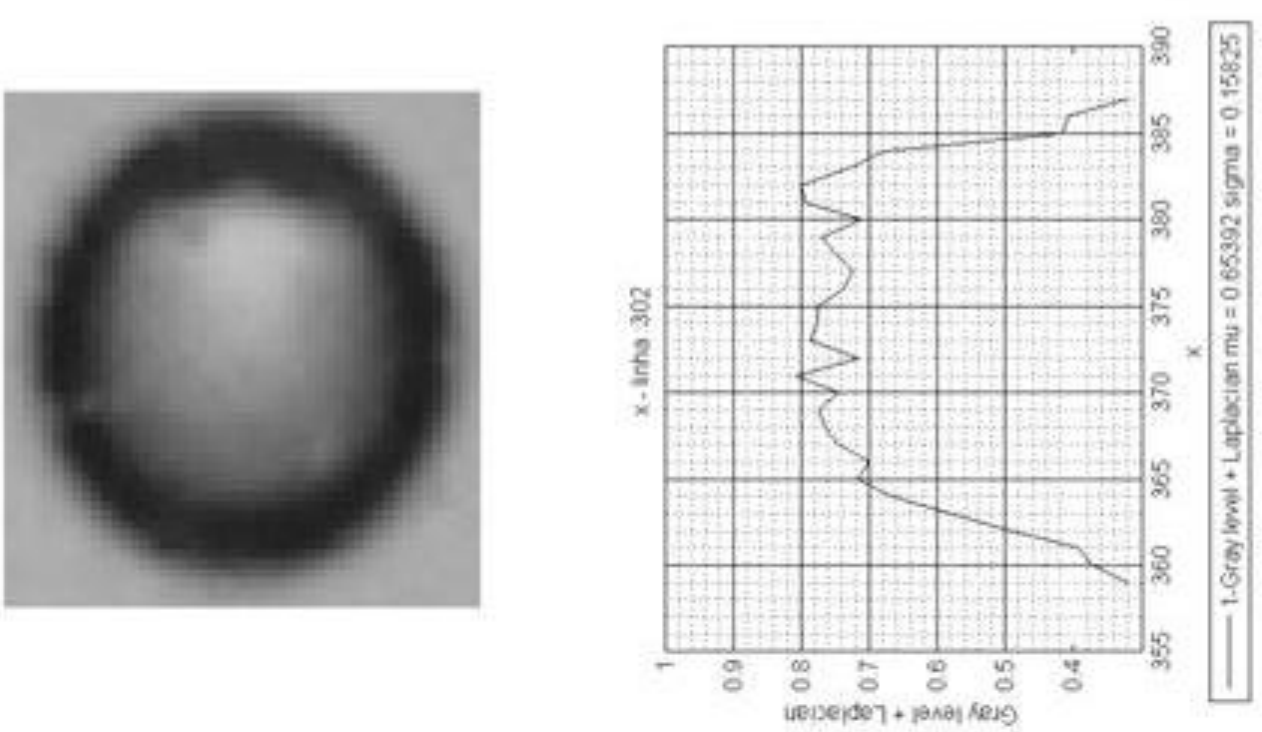

।

$\infty \stackrel{\sim}{\Xi}$ త 웡

ลิ อ

ब จ 

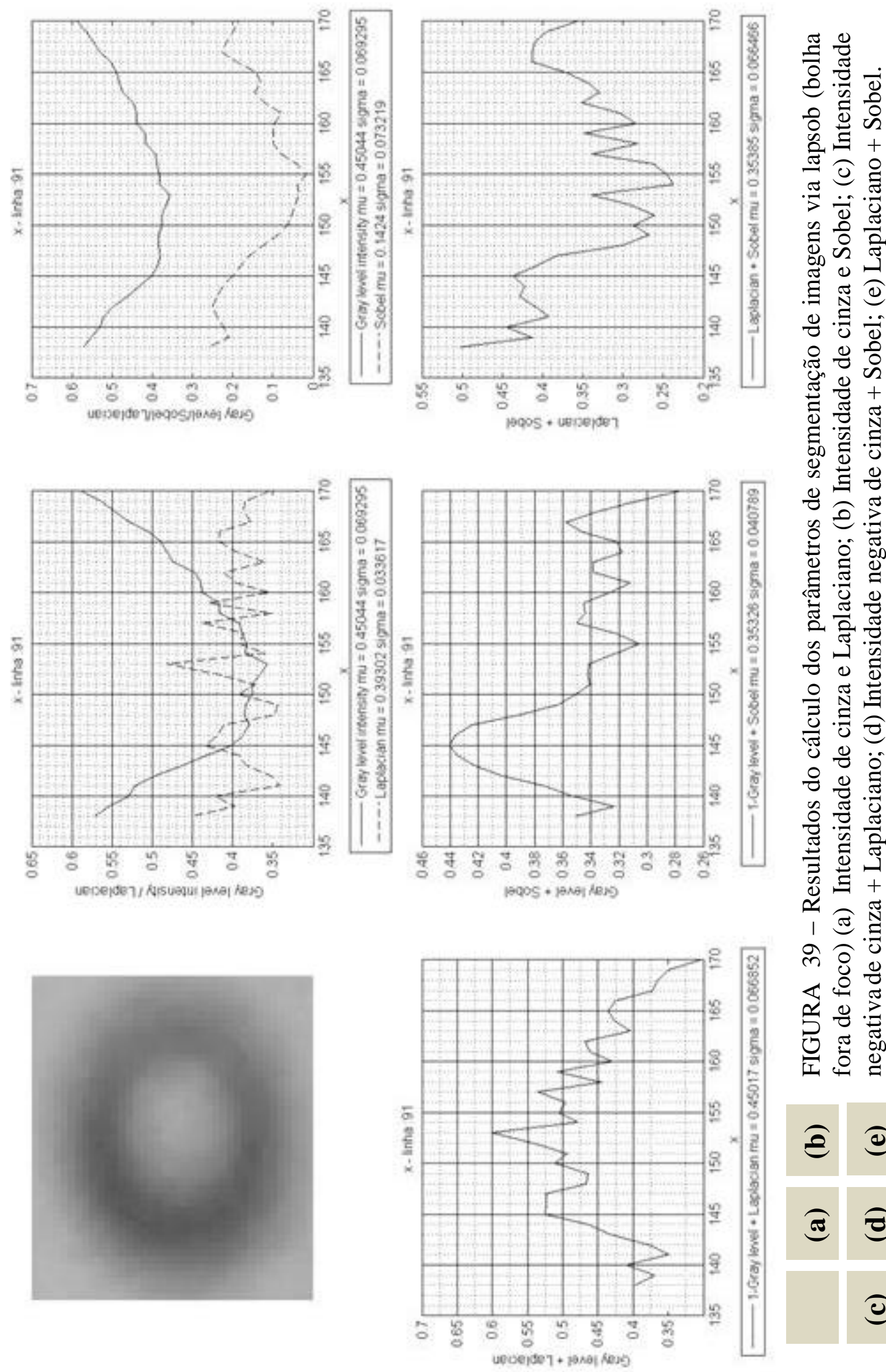

䒕 胥 क्ष \& $\stackrel{0}{\Xi}$ 응 \& 2 苟 त्च $\frac{\pi}{0}$ 营 尝 율 글 을 올 ปี

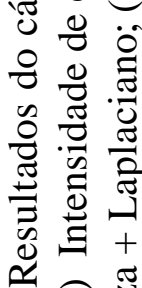
오 졸

กิ $\varangle \circlearrowright$

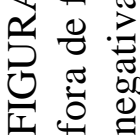

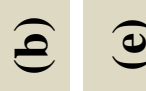

ซ્త 

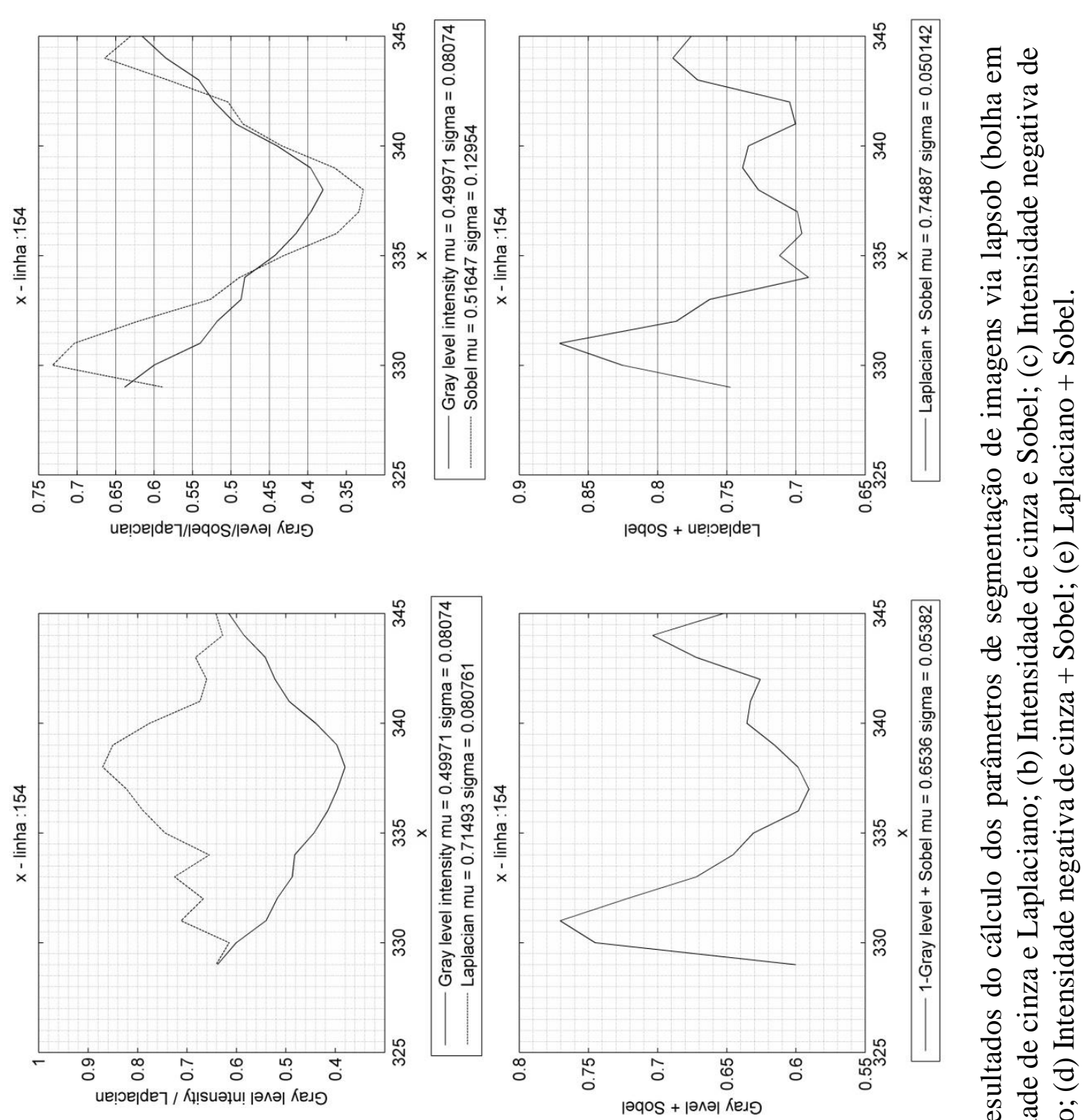

बे

焉

\&

章

킁

曱 仓ิ

ํ.

ô. 흥

윽 흘

䨌寻

욜

。․

吾 。

范

要

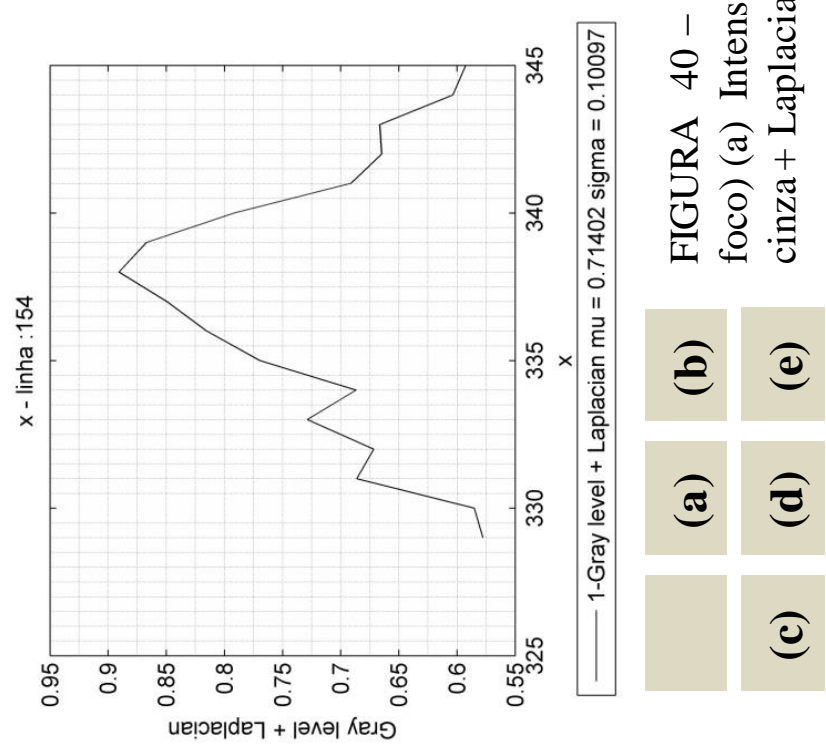



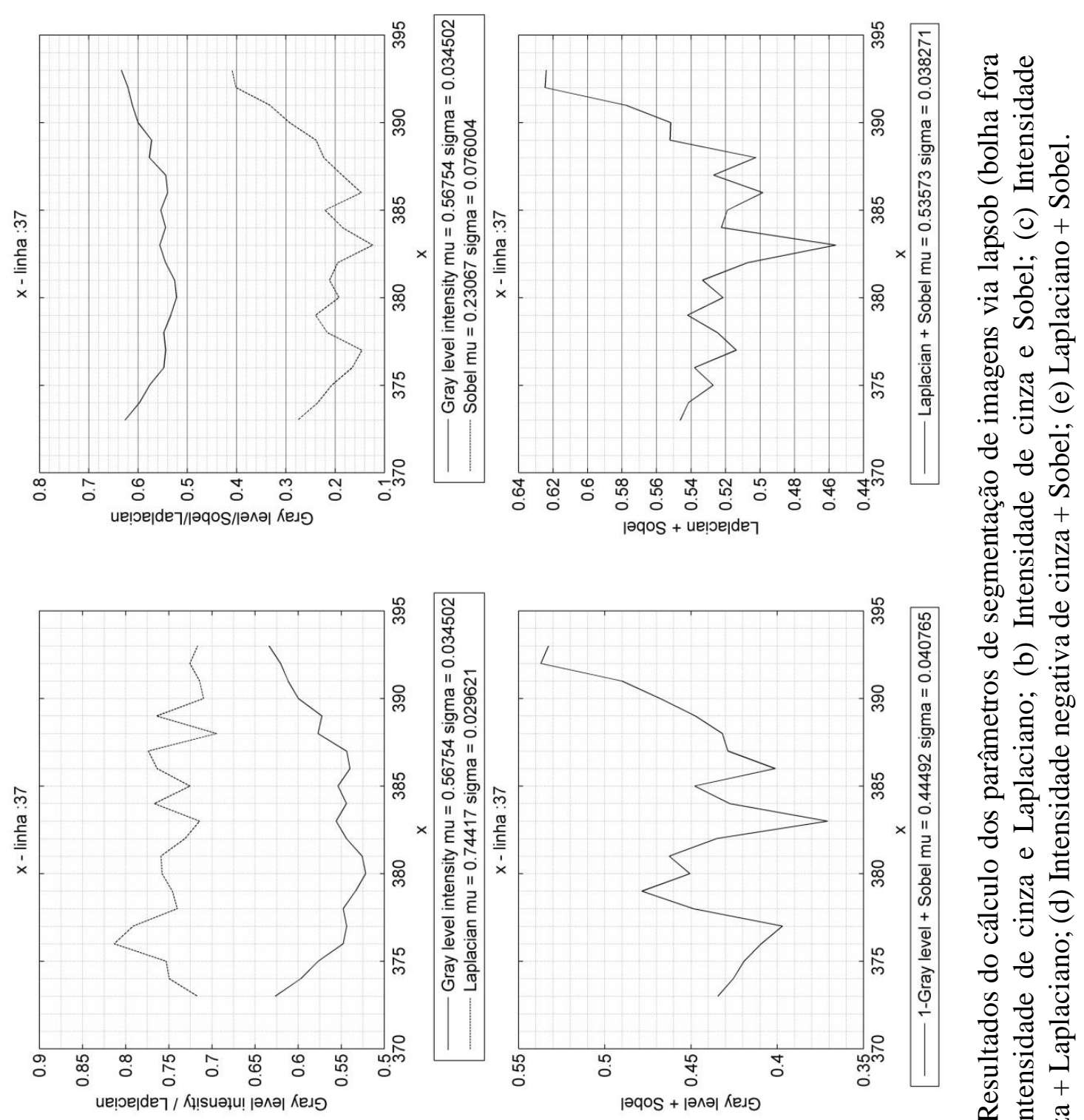

路 ช 2 ? 苟 0

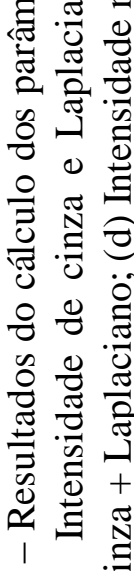
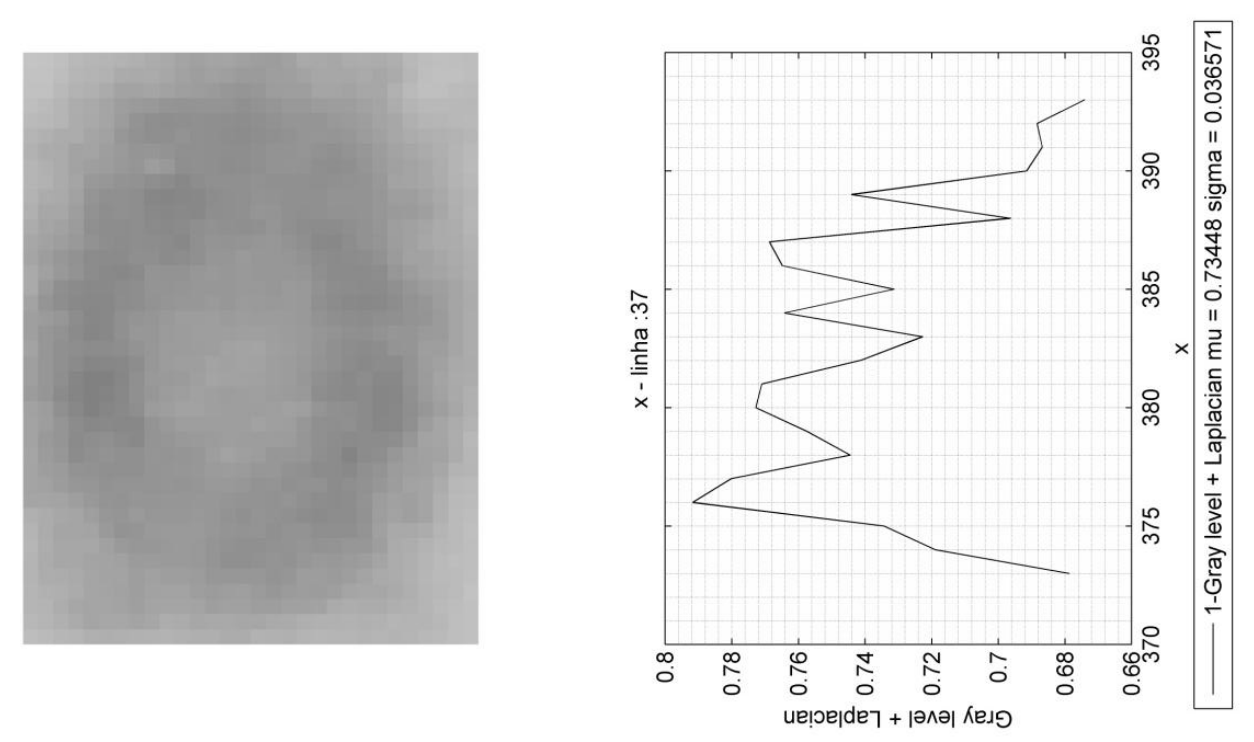

ซ త્ర

ฐิ

可

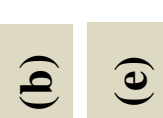

ङ 
As tabelas 1 e 2 apresentam os resultados desses estudos. Os resultados demonstram uma significativa variação entre os parâmetros das imagens capturadas nos experimentos de 23/10/2013 e nos de 10/05/2017.

TABELA 1 - Média e desvio padrão das variáveis linguísticas empregadas na construção do sistema de inferência focal fuzzy - experimento de 24/10/2013

\begin{tabular}{|c|c|c|c|c|c|c|}
\hline & \multicolumn{3}{|c|}{ IMAGENS COM BORDAS EM FOCO } & \multicolumn{3}{|c|}{ IMAGENS COM BORDAS FORA DE FOCO } \\
\hline & $(1-I)+$ Lap & $(1-I)+$ Sob & 1 & $(1-I)+$ Lap & $(1-I)+$ Sob & 1 \\
\hline Média & 0,53455 & 0,51154 & 0,33615 & 0,47058 & 0,32559 & 0,47336 \\
\hline$\sigma$ & 0,16203 & 0,09311 & 0,09577 & 0,12065 & 0,09017 & 0,08838 \\
\hline$\mu+\sigma$ & 0,69659 & 0,60466 & 0,43192 & 0,59123 & 0,41576 & 0,56173 \\
\hline$\mu-\sigma$ & 0,37252 & 0,41843 & 0,24037 & 0,34993 & 0,23541 & 0,38498 \\
\hline
\end{tabular}

TABELA 2 - Média e desvio padrão das variáveis linguísticas empregadas na construção

\begin{tabular}{|c|c|c|c|c|c|c|}
\hline & \multicolumn{3}{|c|}{ IMAGENS COM BORDAS EM FOCO } & \multicolumn{3}{|c|}{ IMAGENS COM BORDAS FORA DE FOCO } \\
\hline & (1-I)+Lap & $(1-I)+$ Sob & $\mathbf{I}$ & (1-I)+Lap & $(1-I)+$ Sob & I \\
\hline Média & 0,65984 & 0,49546 & 0,44363 & 0,60348 & 0,32103 & 0,60171 \\
\hline$\sigma$ & 0,11195 & 0,11064 & 0,12544 & 0,12613 & 0,06800 & 0,09821 \\
\hline$\mu+\sigma$ & 0,77179 & 0,60610 & 0,56907 & 0,72961 & 0,38903 & 0,69992 \\
\hline$\mu-\sigma$ & 0,54790 & 0,38481 & 0,31819 & 0,47736 & 0,25302 & 0,50349 \\
\hline
\end{tabular}

Onde:

I imagem representada pela intensidade de cinza

1-I imagem representada pela intensidade negativa de cinza

Sob matriz com as mesmas dimensões da imagem contendo os resultados da aplicação do operador Sobel empregando a máscara de Kernel para varredura da imagem

Lap matriz com as mesmas dimensões da imagem contento os resultados da aplicação do operador Laplaciano empregando a máscara de Kernel para varredura da imagem

$\mu \quad$ média

$\sigma \quad$ desvio padrão da média

\subsection{Sistema de inferência focal fuzzy}

O sistema de inferência fuzzy foi elaborado com base nos resultados obtidos das análises dos perfis das bordas das bolhas. Estes resultados mostraram que as condições de iluminação interferem nos valores empregados no sistema focal de inferência fuzzy. Diante desta constatação, foram construídos dois sistemas de inferência focal baseado em 
modelos fuzzy. O primeiro deles para os experimentos de 2013 e o segundo para o experimento de 2017.

As funções de pertinência de entrada foram construídas de acordo com o experimento realizado e estão apresentadas nas figuras 42, 43 e 44 para o experimento de 24/10/2013 e 45, 46 e 47 para o de 10/05/2017.

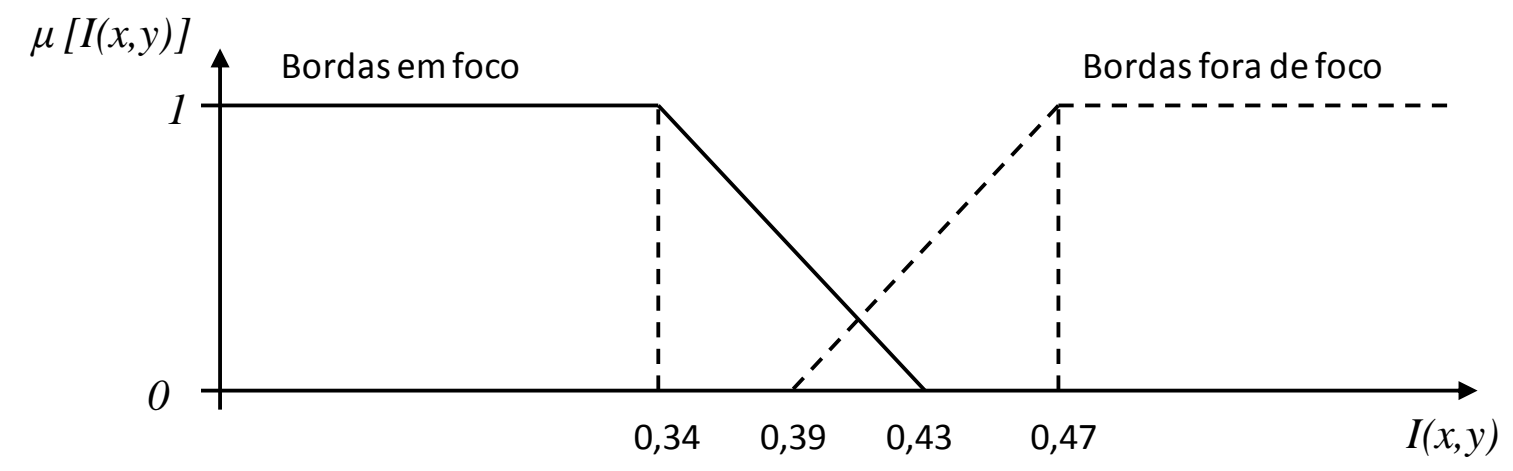

FIGURA 42 - Função de pertinência

Intensidade de cinza - 24/10/2013

$\mu[1-I(x, y)]+S(x, y)$

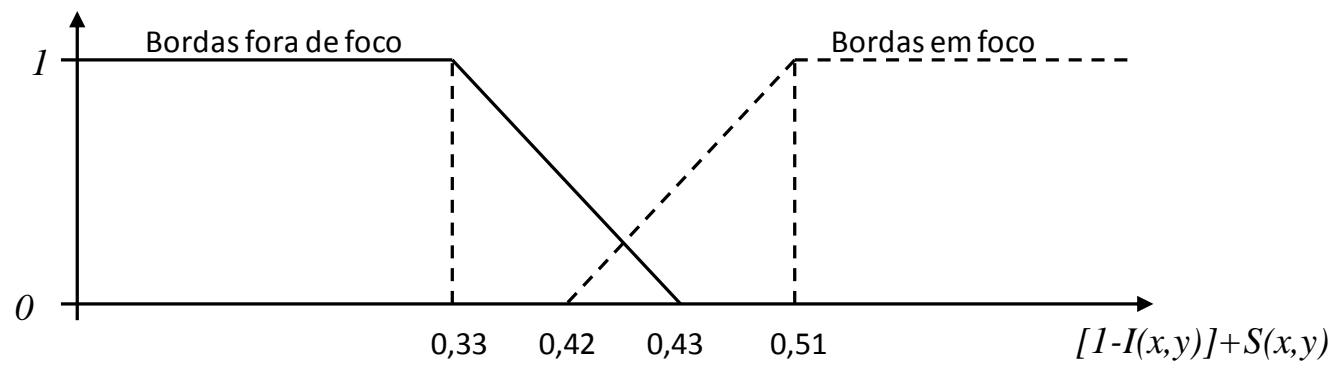

FIGURA 43 - Função de pertinência

Intensidade negativa de cinza + Sobel

24/10/2013

$\mu[1-I(x, y)]+L(x, y)$

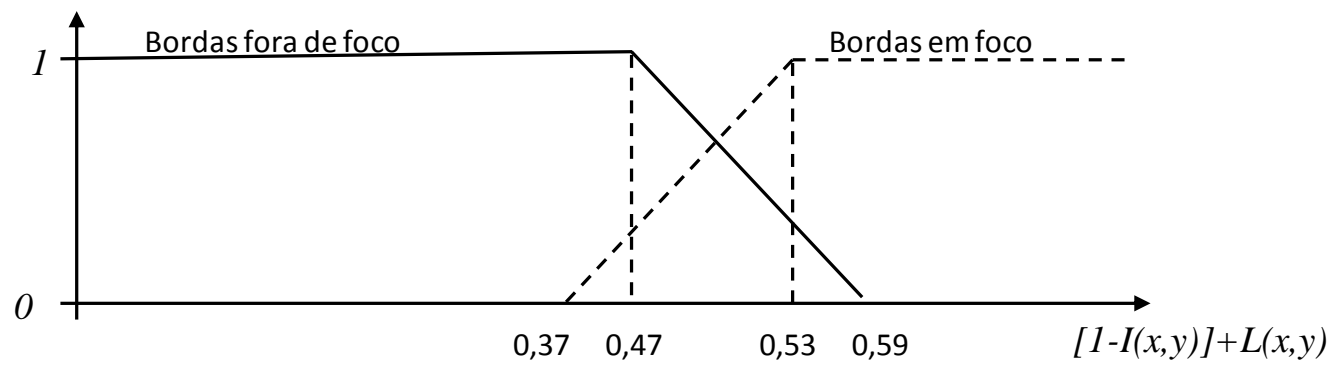

FIGURA 44 - Função de pertinência

Intensidade negativa de cinza + Laplaciano

$24 / 10 / 2013$ 


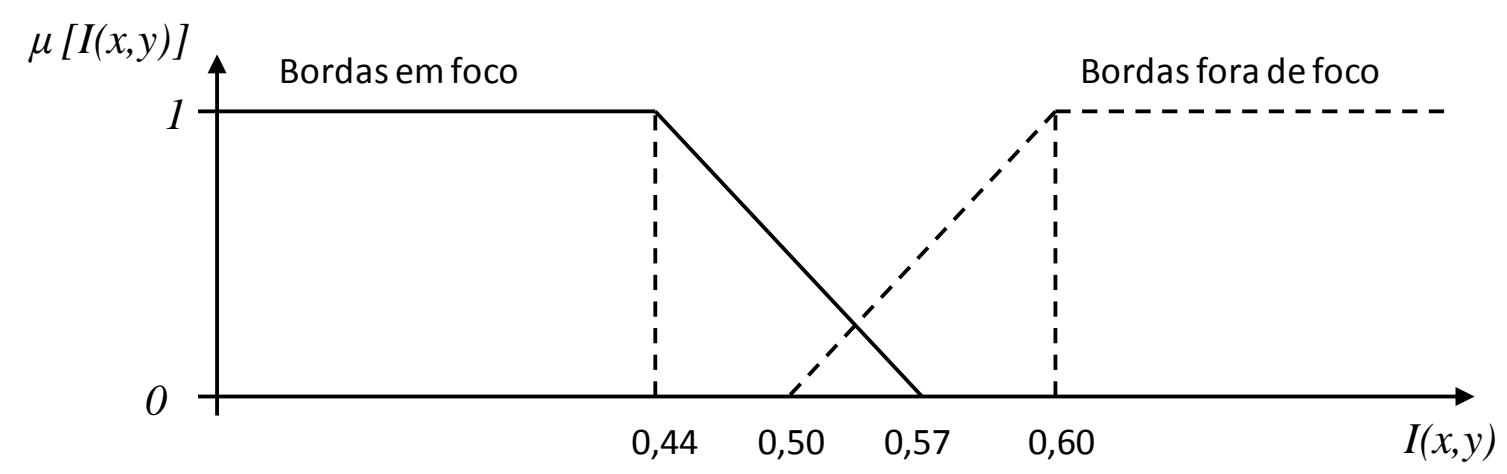

FIGURA 45 - Função de pertinência

Intensidade de cinza - 10/05/2017

$\mu[1-I(x, y)]+S(x, y)$

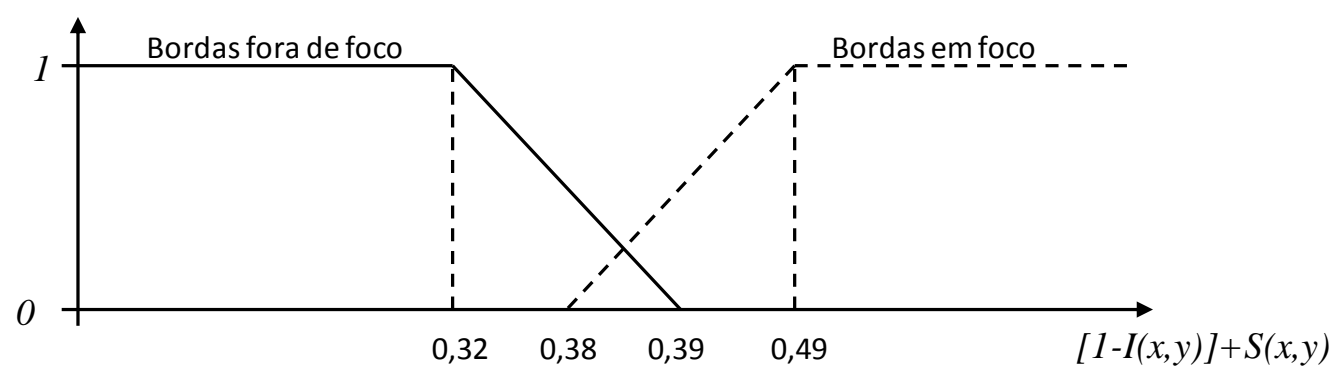

FIGURA 46 - Função de pertinência

Intensidade negativa de cinza + Sobel

$10 / 05 / 2017$

$\mu[1-I(x, y)]+L(x, y)$

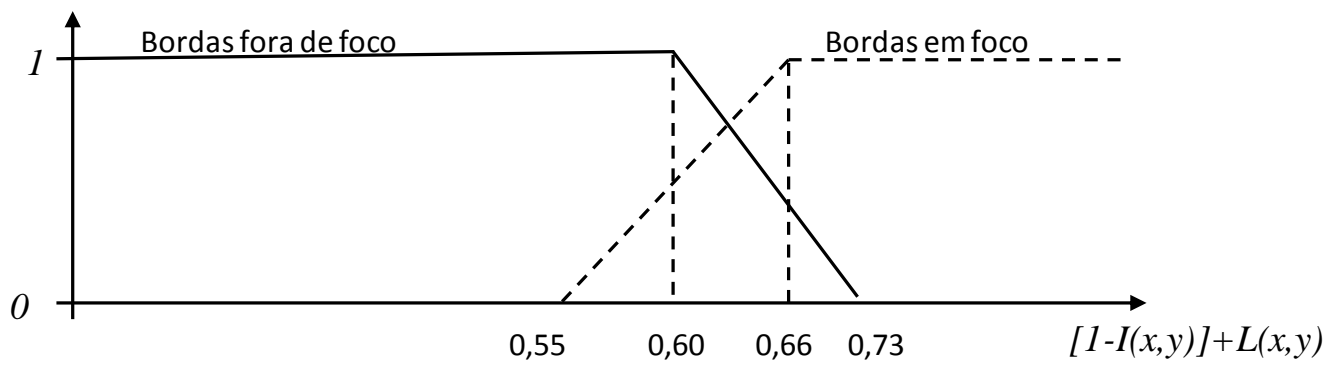

FIGURA 47 - Função de pertinência

Intensidade negativa de cinza + Laplaciano

$10 / 05 / 2017$

Um conjunto de oito regras foram elaboradas e implementadas no módulo de inferência fuzzy. Elas foram minuciosamente elaboradas considerando-se os objetivos da aplicação que é a classificação de um pixel como "fora de foco" ou "em foco". Pixels "fora de foco" são considerados fora dos limites da amostra da imagem do escoamento e, portanto, serão descartados da imagem final, caso contrário, o pixel será preservado. Os valores input1, input2 e input3 são características extraídas de cada pixel da imagem e correspondem aos valores resultantes da aplicação do operador Laplaciano adicionado à intensidade negativa de cinza, do operador Sobel adicionado a intensidade negativa de 
cinza e da intensidade de cinza respectivamente. Todos estes valores foram normalizados e as oito regras finais são apresentadas na TABELA 3.

TABELA 3 - Regras implementadas no Sistema de Inferência Focal Fuzzy

\begin{tabular}{|l|l|l|l|l|l|l|l|}
\hline N $^{\circ}$ & ANTECEDENTE 1 & & ANTECEDENTE2 & & ANTECEDENTE 3 & & CONSEQUENTE \\
\hline 1 & If(input1 is lap-out) & AND & If(input2 is sob-out) & AND & If(input3 is int-out) & THEN & If(output1 is out-focus) \\
\hline 2 & If(input1 is lap-out) & AND & If(input2 is sob-out) & AND & If(input3 is int-in) & THEN & If(output1 is in-focus) \\
\hline 3 & If(input1 is lap-out) & AND & If(input2 is sob-in) & AND & If(input3 is int-out) & THEN & If(output1 is out-focus) \\
\hline 4 & If(input1 is lap-out) & AND & If(input2 is sob-in) & AND & If(input3 is int-in) & THEN & If(output1 is in-focus) \\
\hline 5 & If(input1 is lap-in) & AND & If(input2 is sob-out) & AND & If(input3 is int-out) & THEN & If(output1 is out-focus) \\
\hline 6 & If(input1 is lap-in) & AND & If(input2 is sob-out) & AND & If(input3 is int-in) & THEN & If(output1 is in-focus) \\
\hline 7 & If(input1 is lap-in) & AND & If(input2 is sob-in) & AND & If(input3 is int-out) & THEN & If(output1 is in-focus) \\
\hline 8 & If(input1 is lap-in) & AND & If(input2 is sob-in) & AND & If(input3 is int-in) & THEN & If(output1 is in-focus) \\
\hline
\end{tabular}

Elas apresentam como resultado valores fuzzificados para a saída do sistema. A defuzzificação é realizada pelo método do centroide e a classificação da saída ocorrerá conforme as funções de pertinência ilustradas na figura 48. Os parâmetros de saída foram definidos em função de simulações do próprio sistema implementado em ambiente MATLAB, ATTAWAY (2012).

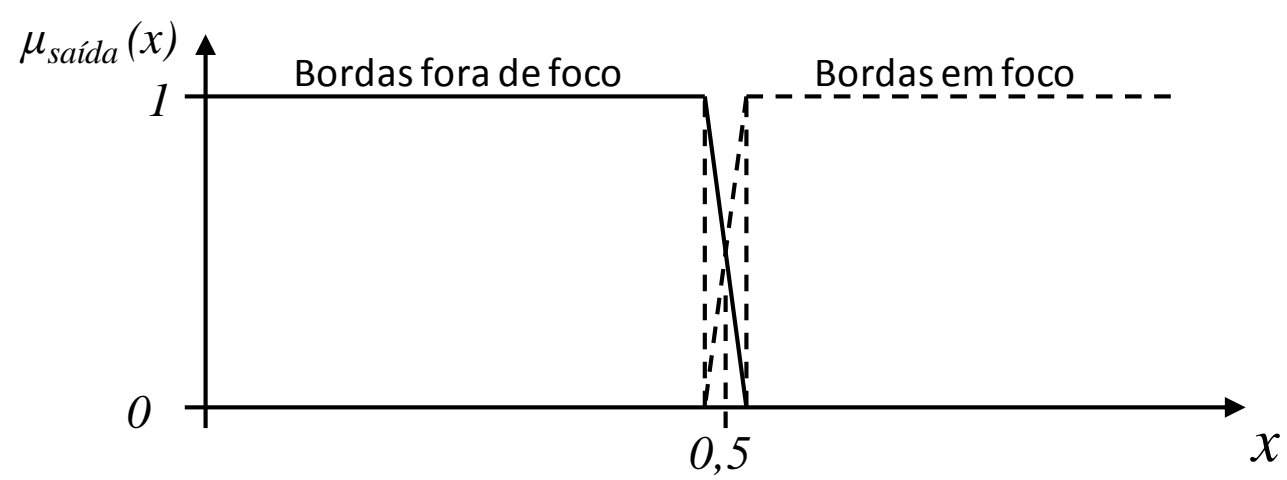

FIGURA 48 - Modelo de função de pertinência representando a saída do sistema

\subsection{Ferramenta de seleção da amostra - selecTool}

A aplicação selecTool (abreviatura de "selection Tool" - ferramenta de seleção) realiza a adequação e a seleção da amostra volumétrica do escoamento bifásico a partir das imagens digitais capturadas por imageamento direto de circuitos experimentais. A selecTool apresenta uma única tela (interface gráfica) para o imageamento direto. Embora disponibilize a opção de seleção de imagens capturadas por imageamento por nêutrons, a única funcional e apta para seleção é a metodologia de aquisição de imagens de circuitos experimentais via imageamento direto. A opção de seleção de imagens por imageamento por nêutrons presta-se a uma das evoluções concebidas para a aplicação. Estas opções são 
apresentadas em um painel localizado na parte superior direita da aplicação e a única que deve ser selecionada é a por imageamento direto, figura 49. A imagem original é apresentada no painel esquerdo da aplicação e consiste em uma imagem do escoamento bifásico capturada com a câmera de alta resolução posicionada verticalmente para cobrir uma maior extensão longitudinal da tubulação do circuito. Os parâmetros descritivos do experimento e da metodologia de aquisição das imagens são também representados em caixas de textos posicionadas abaixo da imagem. O sistema realiza a seleção de uma área frontal de interesse da amostra. Esta área é capturada levando-se em consideração a simetria com o eixo longitudinal da tubulação e suas dimensões, 400 pixels para cada lado do eixo e 800 pixels longitudinalmente, correspondem àquelas em que as distorções óticas do escoamento podem ser consideradas desprezíveis. Estes parâmetros foram selecionados a partir de observações visuais do escoamento e de suas imagens e estarão sujeitos a alterações mediante o processo de calibração e ajustes do sistema. Posteriormente, o sistema executa a rotação da imagem original para fins de compatibilização da imagem com o sentido do escoamento e em seguida, sua conversão em nível de cinza normalizado. A imagem colorida com as dimensões selecionadas para a amostra volumétrica é também apresentada no painel inferior direito. Sua exposição presta-se à comparação e uma avaliação visual dos resultados após a execução da aplicação.

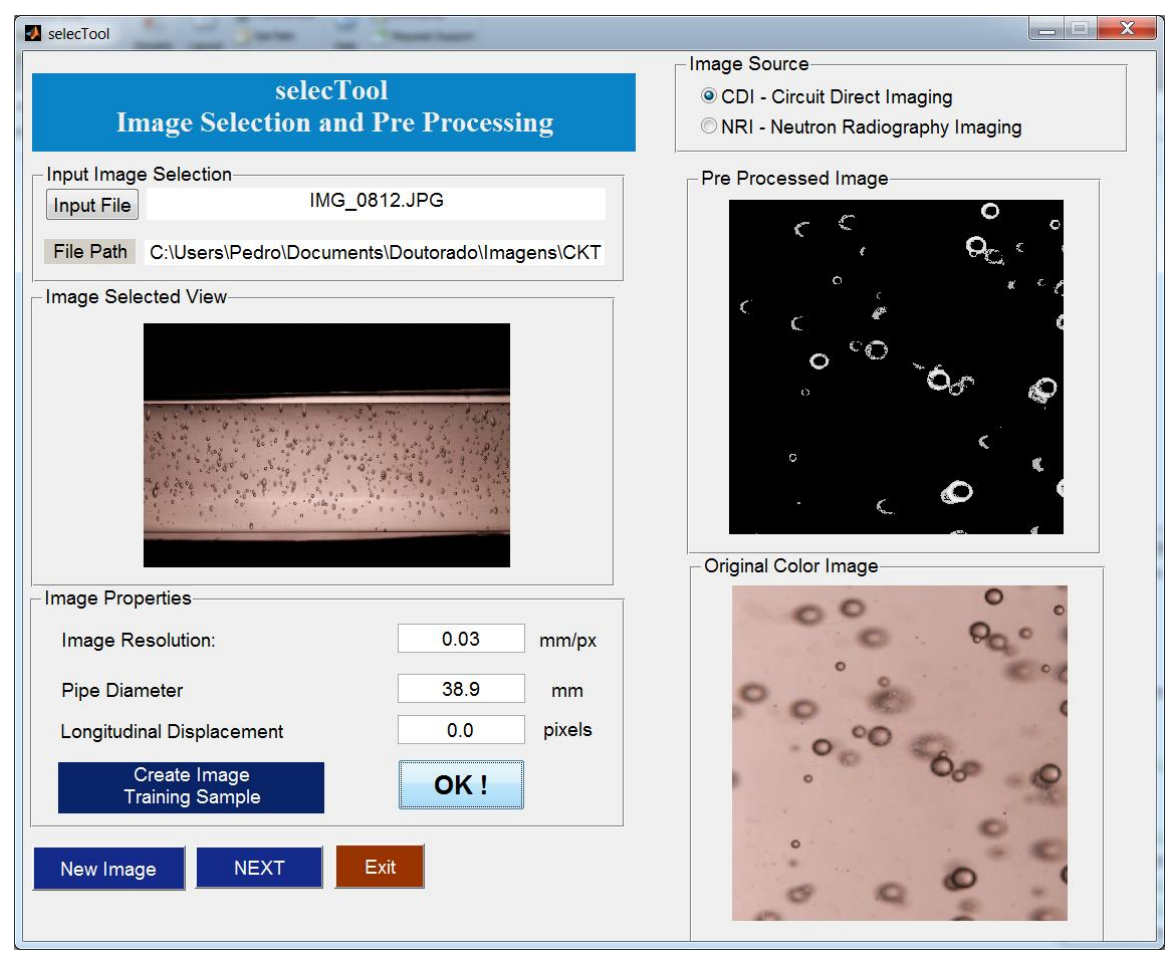

FIGURA 49 - Interface gráfica da aplicação selecTool 
A seleção da profundidade da imagem é realizada mediante a aplicação do modelo de inferência focal fuzzy que relaciona a profundidade de campo em que a imagem digital foi capturada e a inferência fuzzy empregando os parâmetros de segmentação de imagens considerados para estabelecimento da qualidade de foco.

A tela superior direita exibe a imagem da amostra do escoamento bifásico selecionada. As bolhas exibidas nesta imagem estão de acordo com a profundidade de campo estabelecida para seleção da amostra. Os pixels das bolhas que estão totalmente ou parcialmente fora desses limites foram eliminados da imagem. A comparação visual entre esta amostra selecionada e a imagem original, permite a identificação do processo de exclusão das bolhas fora dos limites da amostra e proporciona maior segurança à avaliação do usuário do sistema, evidenciando a execução de permitindo um processo controlado de seleção de amostras das imagens.

\subsection{Ferramenta construtora das amostras de treinamento}

A segunda e principal aplicação do sistema, denominada maSamTool (abreviatura de "make Samples Tool" - ferramenta de construção de amostras), executa um conjunto de operações independentes, figura 50. A primeira delas consiste na construção de um arquivo de amostras (subimagens) de treinamento para a rede neural. Nesta operação a aplicação recebe como entrada uma amostra de imagem de uma seção volumétrica do escoamento bifásico previamente selecionada pela aplicação selecTool. Uma vez carregada, a amostra é exibida em um painel localizado a esquerda, com dimensões maiores que sua correspondente colorida. Esta última é exibida em um painel intermediário a sua direita para fins de avaliação da compatibilização entre as subimagens candidatas a amostra de treinamento selecionadas na imagem do painel esquerdo com sua correspondente na imagem original. Esta subimagem candidata é selecionada com as dimensões de uma máscara virtual selecionada na janela de opções localizada na parte superior direita da aplicação. Ela é exibida em detalhes no painel a direita da aplicação. A seleção da candidata à amostra de treinamento poderá ser realizada aleatória ou manualmente. A subimagem selecionada passa a representar uma candidata à amostra de treinamento e deve ser classificada como uma bolha (classificação positiva) ou não através dos botões posicionados abaixo do seu painel de visualização. Uma vez selecionada como amostra de uma bolha, a aplicação irá calcular os somatórios dos pixels de sua diagonal principal, secundária e de todos os pixels da subimagem. Estes valores são empregados na 
atualização do cálculo da média geral e do desvio padrão de todas as amostras positivas do arquivo de amostras de treinamento e atualizado nas caixas de textos correspondentes na aplicação. Eles podem, e devem ser considerados e avaliados pelo usuário em uma revisão do arquivo de amostras de treinamento. As atualizações da amostra de treinamento correspondem a inclusão de novas subimagens vetorizadas e sua classificação correspondente. O painel contador indicador do número de amostras positivas, negativas e o total de amostras, é atualizado após cada inclusão. A não classificação de uma subimagem candidata com a consequente seleção de outra representará a sua exclusão e a classificação e inclusão no arquivo de amostras de treinamento será atribuída à imagem em exposição, caso seja classificada.

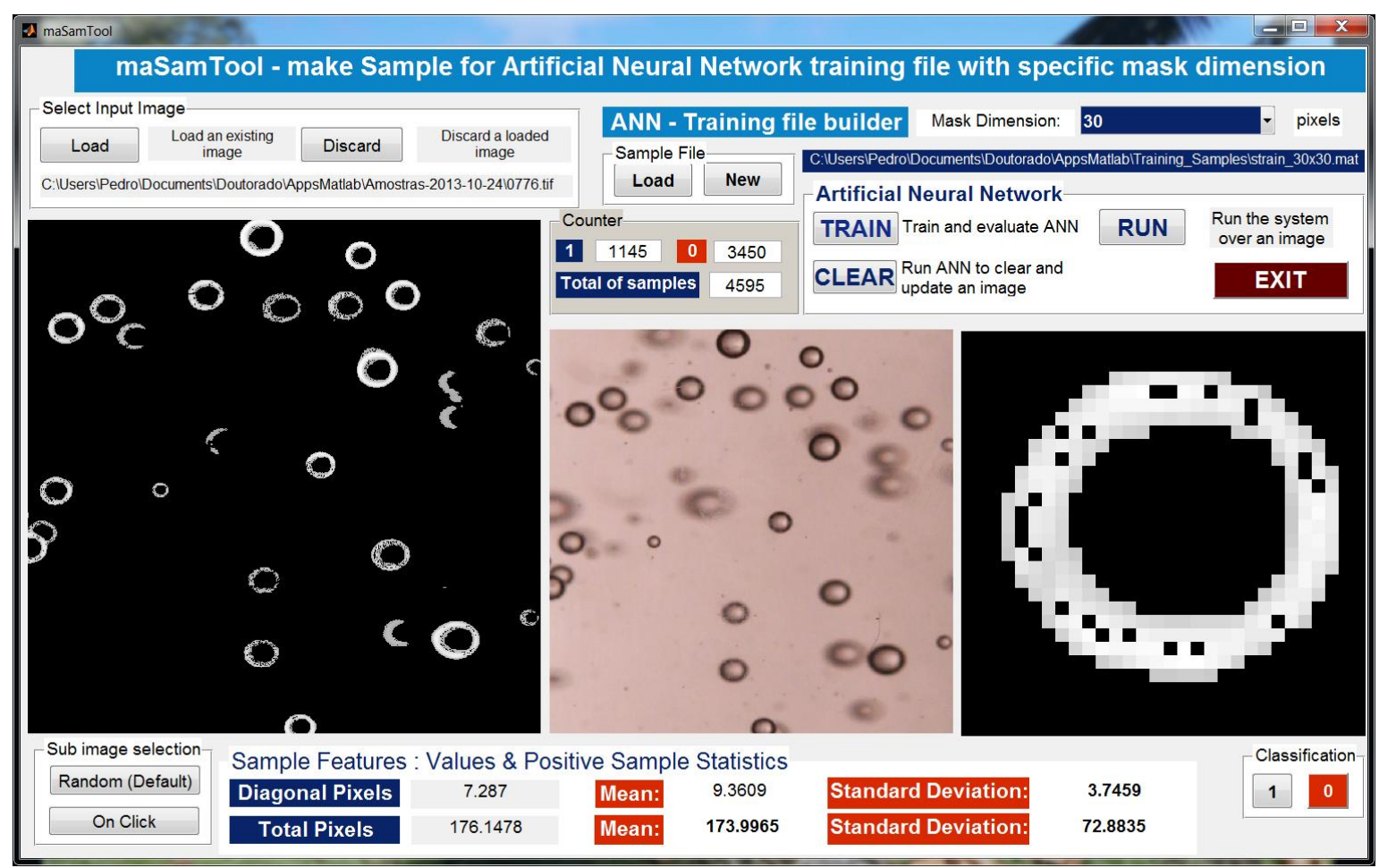

FIGURA 50 - Interface gráfica da aplicação maSamTool

A terceira aplicação tem o objetivo de prestar suporte na construção do arquivo de amostras de treinamento da rede neural. Ela é denominada saManTool (abreviatura de "sample Manager Tool" - Ferramenta de gerenciamento de amostras), figura 51. Ela executa o gerenciamento do arquivo de amostras de treinamento com as opções de exclusão de imagens mal selecionadas, reclassificação de imagens selecionadas e de organização das amostras no arquivo. Esta aplicação também apresenta os dados estatísticos das amostras contidas no arquivo. A aplicação saManTool permite a varredura sequencial ou pelo índice de todas as imagens das amostras de treinamento, bem como a 
ordenação e reordenação dessas subimagens quer seja na eliminação de uma imagem, quer seja pela classificação das amostras.

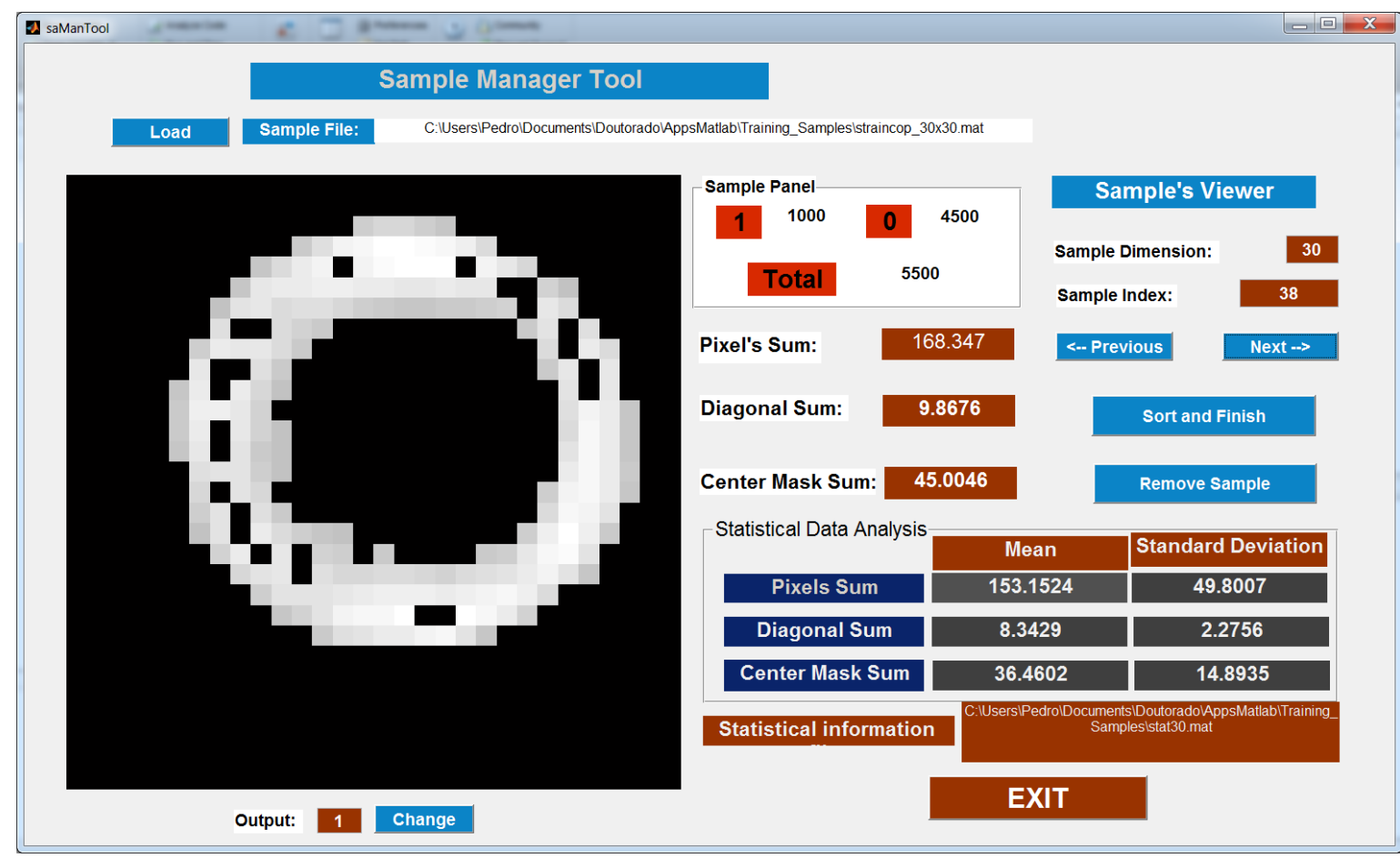

FIGURA 51 - Interface gráfica da aplicação saManTool

O processo de construção e gestão do arquivo de amostras de treinamento requer um rigoroso critério de classificação manual das amostras de treinamento e um significativo número de amostras para assegurar a ocorrência de resultados confiáveis.

A opção por construção de arquivos com 4 a 5 mil amostras de treinamento foi baseado nos exercícios apresentados por NG (2011). A construção e treinamento de uma rede neural artificial para classificação múltipla, com dez classes, foi utilizado um arquivo com 5000 amostras de treinamento.

Concluída a construção do arquivo de amostras de treinamento para reconhecimento de bolhas com dimensões compatíveis às da máscara virtual de varredura progressiva, executa-se o processo de treinamento e teste via aplicação maSamTool. Este treinamento é realizado empregando método de propagação reversa, mais conhecido como "backpropagation". Os testes são realizados empregando a própria amostra de treinamento construída para uma máscara de varredura de subimagens com a dimensão especificada na sua construção e na própria aplicação. Os resultados apresentados se referem a subimagens com 30 x 30 pixels. O treinamento da rede neural artificial é iniciado com a execução da opção "TRAIN" na aplicação maSamTool. É solicitada a seleção do nome e caminho do arquivo contendo as amostras de treinamento e de um segundo arquivo com as 
características de cada bolha empregada no cálculo das propriedades estatísticas da amostra. A figura 52 apresenta a tela de execução da aplicação maSamTools durante a fase de treinamento da rede neural. A execução do treinamento é específica para a dimensão selecionada da máscara virtual de varredura progressiva exibida na parte superior direita da interface gráfica . O painel que anteriormente era utilizado para exposição de amostras de imagens, agora apresenta um quadro com 100 imagens das amostras de treinamento selecionadas aleatoriamente.

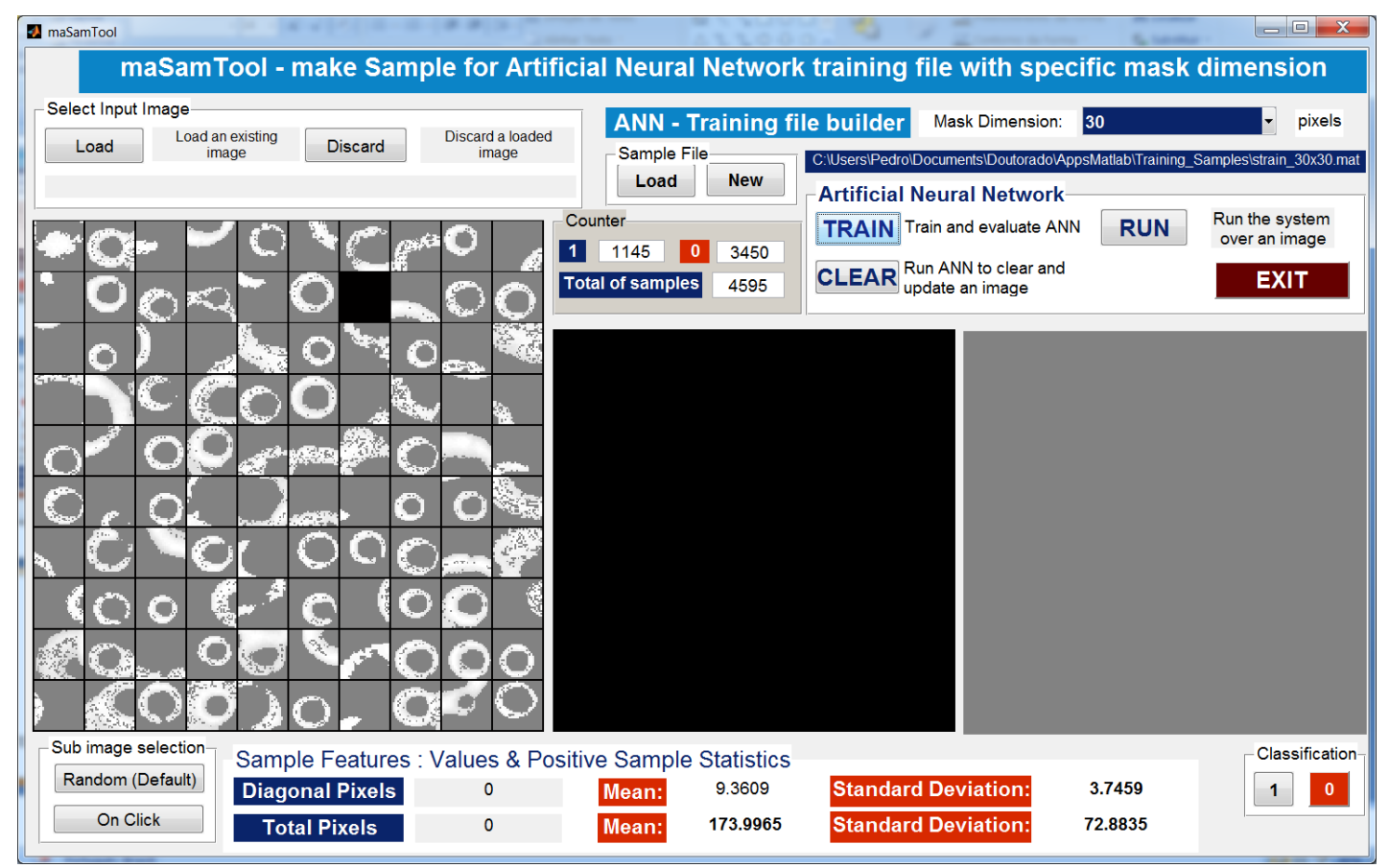

FIGURA 52 - Apresentação da aplicação maSamTool durante a execução do treinamento para uma máscara virtual de varredura progressiva com 30 x 30 pixels.

A figura 53 apresenta a tela do resultado do teste de treinamento considerando um arquivo de amostras de treinamento com 4595 amostras sendo 1145 amostras positivas, ou seja, contendo até duas bolhas e 3450 negativas que representam imagens sem nenhuma bolha ou com apresentação de apenas partes de bolhas nos limites da profundidade de campo das imagens.

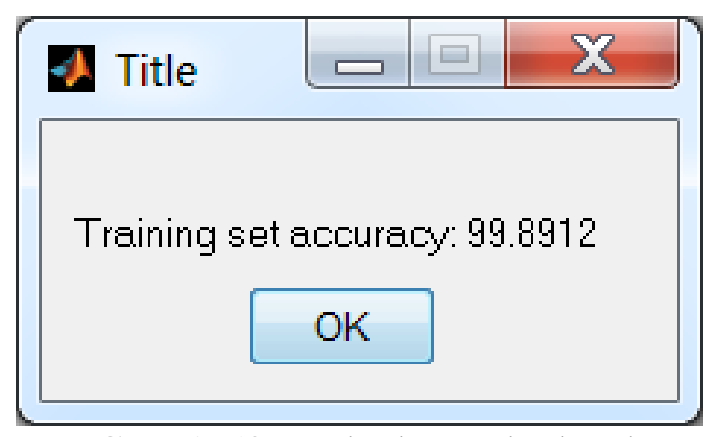

FIGURA 53 - Tela de resultados do treinamento da rede neural 
Este teste consiste na execução da rede neural, considerando as matrizes de pesos sinápticos resultantes do treinamento, sobre a própria amostra de treinamento. A precisão representada na tela de resultados representa a razão entre o número de acertos , ou seja, "verdadeiros positivos" para resultados positivos da rede nos casos em que a amostra contém bolhas e "verdadeiros negativos" nos casos contrários, ou seja, resultados da aplicação da rede em subimagens sem bolhas. O número total de execuções da rede neural artificial nesta avaliação corresponde ao número total das amostras de treinamento. A finalização da maSamTool para a condição de treinamento é a apresentação de uma tela para gravação das matrizes dos pesos sinápticos em um arquivo nomeado pelo próprio usuário com posterior apresentação das sub imagens descritas na primeira camada oculta da rede neural artificial, figura 54.

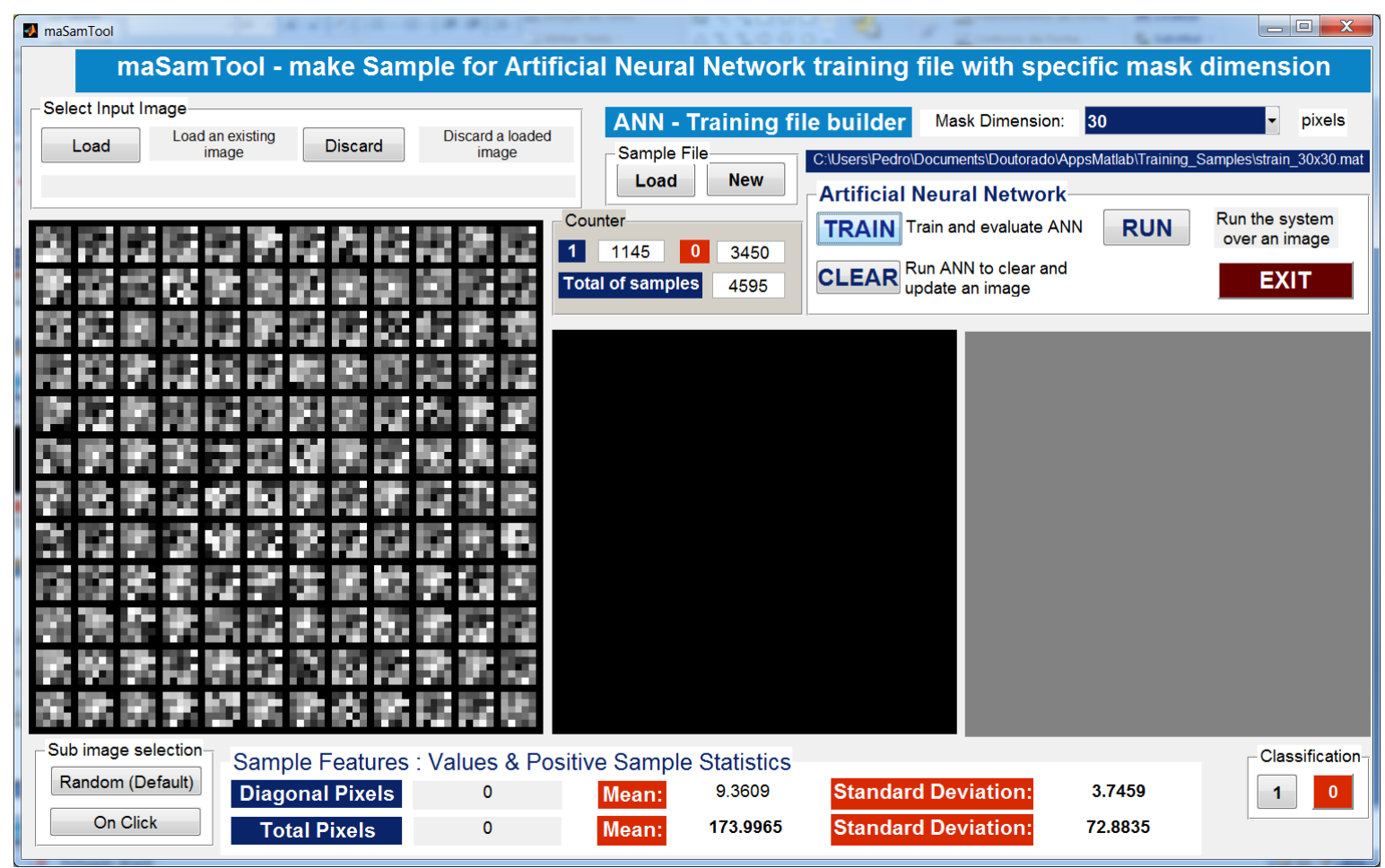

FIGURA 54 - Finalização da fase de treinamento da rede neural com apresentação das subimagens da segunda camada.

Observa-se nesta figura o grau de aleatoriedade das imagens representantes da segunda camada da rede neural indicando uma inicialização assimétrica dos pesos sinápticos. Esta verificação é importante e justifica sua apresentação em função da necessidade de se evitar a simetria na segunda camada da rede neural que poderia ocasionar a anulação de ramificações de entradas da rede neural.

Uma vez concluído o treinamento da rede neural para uma dimensão específica de máscara virtual de varredura progressiva, as amostras de imagens devem ser preparadas 
para construção de outras amostras de treinamento utilizando máscaras virtuais progressivas com dimensões maiores. Este procedimento consiste na execução da rede neural sobre as amostras de imagens do escoamento realizando a varredura com consequente eliminação das bolhas detectadas. Assim que finalizada a execução do maSamTool para esta funcionalidade, a nova amostra de imagem do escoamento bifásico sem as bolhas identificadas dentro dos limites da máscara virtual de varredura progressiva, será novamente armazenada e disponibilizada para construção de um novo arquivo de amostra de treinamento para sub imagens com dimensões maiores. Este procedimento é executado sucessivamente até ser concluído com a detecção e eliminação das bolhas com maiores dimensões observadas nas imagens do escoamento bifásico.

A calibração e os ajustes desses processos são interativos e ocorrem à medida em que eles são implementados. As formas de apresentação dos resultados são modificadas para fins de compatibilização com o parâmetro em análise.

\subsection{Configuração final do conjunto de redes neurais}

A definição da configuração final da rede neural considera os resultados produzidos sobre uma amostra de imagem selecionada no processo anterior, no caso a figura do arquivo 0812.tif. Esta configuração é estabelecida em função de sucessivas execuções da rede neural para realização de análises de tentativa e erro. O melhor resultado define a configuração definitiva da rede, ou seja, o número de camadas e o de elementos por camada. Considera-se o melhor resultado com aquele que reconhece a menor quantidade de "falso-positivos" em uma amostra do escoamento. Também é levado em consideração que a rede deverá, nesta mesma execução, reconhecer todas as bolhas existentes, ou seja, "verdadeiro-positivos", nos limites da amostras. .

Os resultados das análises estão apresentados na TABELA 4. O número de "falso-positivos", que representam o falso reconhecimento de bolhas, estão apresentados em função do número de elementos das camadas ocultas da rede. O número de elementos das camadas de entrada e saída são fixos. O número de elementos da camada de entrada deve ser compatível com o número total de pixels estabelecido pelas dimensões da máscara virtual de varredura progressiva. Esta análise é realizada apenas para a varredura da primeira amostra de imagens do escoamento bifásico por se tratar do uso da máscara virtual de varredura progressiva com as menores dimensões, ou seja, 30 x 30 pixels. Isto já 
estabelece uma camada de entrada com 901, ou seja, 900 elementos referente ao número de pixels da subimagem e um elemento com valor fixo e igual a "1" referente a entrada do "bias" (elemento externo ou termo independente) da rede neural artificial. Os valores dos demais 900 elementos correspondem ao valor da intensidade negativa de cinza normalizada de cada pixel da subimagem. A configuração de número 10 é a adotada para esta aplicação e consiste de 901 elementos da camada de entrada, 145 elementos para a primeira camada oculta, 26 elementos para a segunda camada oculta e 2 elementos para a camada de saída. Com exceção da camada de saída, todas as camadas consideram a inserção do elemento correspondente à bias.

A configuração das demais redes neurais artificiais, ou seja, para entradas com subimagens capturadas via máscaras virtuais de varreduras progressivas maiores são resultantes da introdução de novas camadas de entrada com dimensões compatíveis com as novas máscaras virtuais de varredura progressiva adicionada do elemento específico para a consideração do "bias" no algoritmo da RNA.

TABELA 4 - Resultados da análise para definição da configuração da rede neural artificial

\begin{tabular}{c|ccccc}
\hline $\begin{array}{c}\text { Configurações } \\
\text { da RNA }\end{array}$ & $\begin{array}{c}\text { Camada de } \\
\text { entrada }\end{array}$ & $\begin{array}{c}\text { Primeira } \\
\text { camada oculta }\end{array}$ & $\begin{array}{c}\text { Segunda } \\
\text { camada oculta }\end{array}$ & $\begin{array}{c}\text { Camada de } \\
\text { saída }\end{array}$ & $\begin{array}{c}\text { Número de } \\
\text { falsos positivos }\end{array}$ \\
\hline$(1)$ & 900 & 225 & 36 & 2 & 28 \\
$(2)$ & 900 & 196 & 36 & 2 & 26 \\
$(3)$ & 900 & 169 & 36 & 2 & 25 \\
$(4)$ & 900 & 144 & 36 & 2 & 24 \\
$(5)$ & 900 & 121 & 36 & 2 & 28 \\
$(6)$ & 900 & 144 & 144 & 2 & 23 \\
$(7)$ & 900 & 144 & 81 & 2 & 25 \\
$(8)$ & 900 & 144 & 64 & 2 & 28 \\
$(9)$ & 900 & 144 & 49 & 2 & 22 \\
$(10)$ & 900 & 144 & 25 & 2 & 25 \\
$(11)$ & 900 & 144 & 16 & 2 & \\
\hline
\end{tabular}

A ocorrência de "falso-positivos" como resultado da RNA deve-se à grande quantidade de execuções para varredura completa de uma amostra volumétrica de imagem do escoamento. Este número de execuções oscila entre 50000 a 120000 . Ele depende de um valor mínimo para o somatório da intensidade de cinza de todos os pixels da subimagem, estabelecido como limite para execução e do número de bolhas existentes nos limites da amostra volumétrica do escoamento bifásico. O valor mínimo do somatório da intensidade de cinza da subimagem é consequência da análise estatística realizada na construção do arquivo de amostra de treinamento. Ele considera um valor de 40 para a soma da intensidade negativa de cinza dos pixels nos limites da máscara virtual de varredura progressiva. Este valor representa um limite inferior (média - 2,17 $\sigma$ ) indicando uma probabilidade inferior a $2,5 \%$ da ocorrência de bolhas com valores menores. São 
adotados dois limiares para a saída da rede neural. Estes limiares são aplicados sobre os valores dos elementos do vetor de saída da rede neural, ou seja, $y=\left[\begin{array}{ll}1 & 0\end{array}\right]^{T}$. O valor inicial desses limiares consideram a ordem de grandeza do valor da função de custo, $J_{\theta}(x)$ na fase de treinamento da rede. A função de custo representa o erro médio da rede neural na condição final do processo de treinamento. Tratam-se de dois valores que minimizam a detecção de "falso-positivos" sem o comprometimento da qualidade da rede na detecção das verdadeiras bolhas na amostra do escoamento bifásico, ou seja, dos "verdadeiro-positivos" .

A figura 55 apresenta a tela da aplicação maSamTool após a execução da rede neural sobre uma amostra de escoamento. Esta execução é realizada via botão "RUN" e executa um processo de limpeza da imagem da amostra do escoamento, pela eliminação das bolhas detectadas pela rede neural artificial integrada com a transformada randomizada de Hough, nos limites da máscara virtual de varredura progressiva.

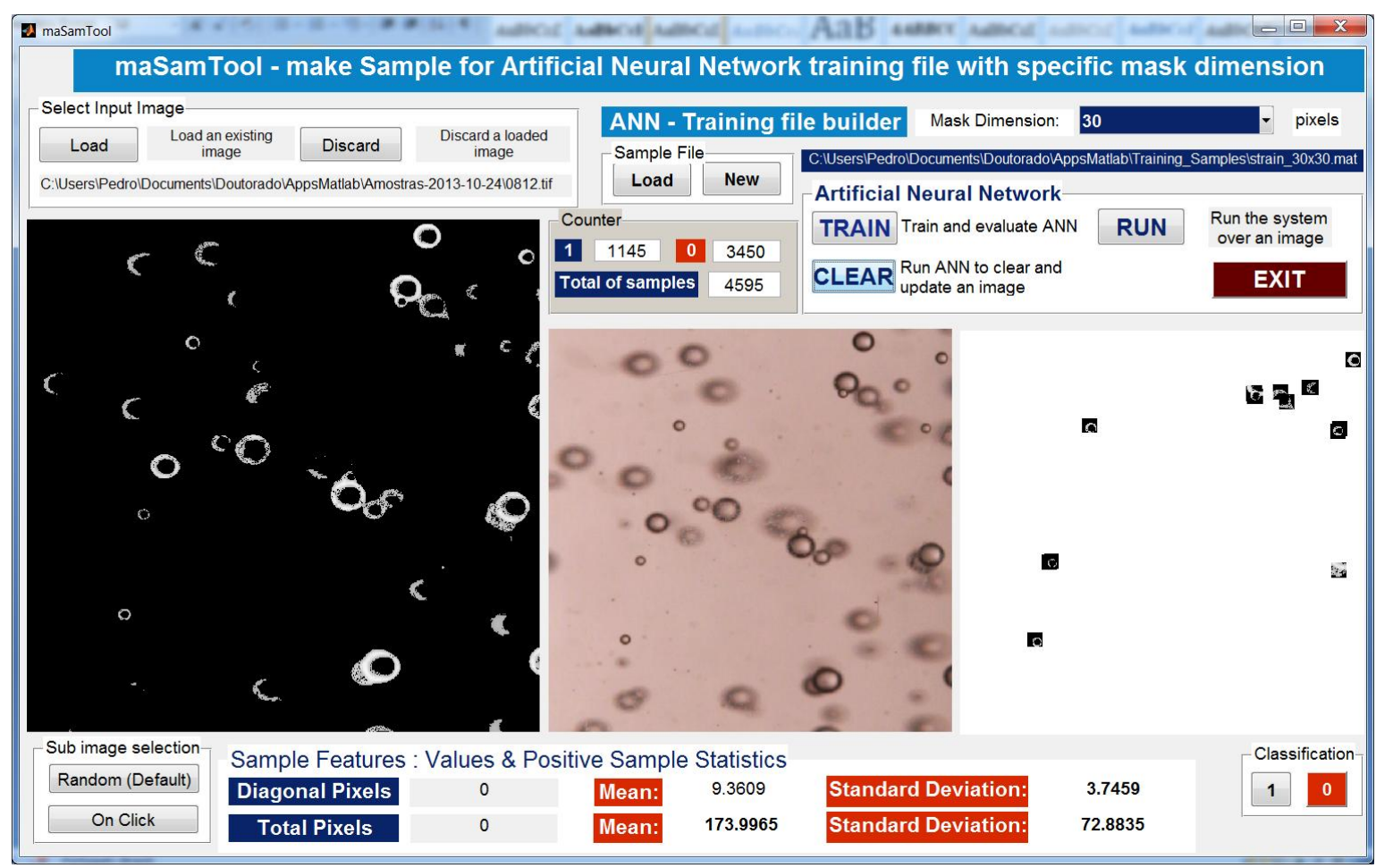

FIGURA 55 - Apresentação final da execução da rede neural sobre a amostra da imagem do escoamento bifásico pré processada. ARQUIVO: 0812.tif

A imagem apresentada no painel à direita da interface gráfica da aplicação apresenta apenas as bolhas detectadas pela rede neural artificial como consequência de uma varredura completa da amostra da imagem do escoamento bifásico por uma máscara virtual de varredura progressiva com dimensões de 30 x 30 pixels. 
A expectativa dos resultados era a detecção de cinco bolhas, no entanto eles resultaram na detecção de nove, sendo as cinco bolhas esperadas, ou seja, "verdadeiropositivos" e quatro "falso-positivos". Deve-se considerar ainda que:

- execuções anteriores para estabelecimento da configuração da rede, resultaram em números maiores de "falso-positivos". Elas ainda não consideravam os limiares sobre os valores de saída da rede;

- foram considerados limiares bastante rigorosos sobre os elementos de saída da rede neural artificial, ou seja, somente os resultados com erros inferiores a $2.10^{-5}$ foram classificados como uma bolha nos limites da subimagem;

- a progressão da varredura da imagem ocorre pixel a pixel e isto requer um grande número de execuções da rede neural artificial. Neste caso foram realizadas 59107 execuções da rede, valores estes traduzidos em classificações de subimagens. Sendo assim, observa-se que o número de "falso-positivos" é insignificante e pouco representativo diante do número de execuções, ou seja, houve $6,78.10^{-3} \%$ de casos com "falso-positivos". Estes resultados refletem a especificação de limiares para os valores de saída de cada execução da rede neural. Em simulações anteriores, sem a aplicação de limiares, os resultados apresentavam números maiores de "falso-positivos", cerca de 22 a 30 casos para cada imagem.

\subsection{Eliminação das bolhas detectadas na amostra da imagem do escoamento e identificação geométrica via transformada randomizada de Hough (TRH)}

O processo de eliminação das bolhas após sua detecção na execução da rede neural artificial é o mesmo da identificação dos parâmetros geométricos da interface gás líquido para cálculo do seu volume. Ambos necessitam da eliminação da imagem da bolha e sua realização requer as informações das coordenadas do centro, a dimensão de seus semi-eixos e do ângulo de inclinação da elipse que descreve analiticamente a interface gás líquido. A eliminação da bolha consiste, inicialmente, no cálculo e eliminação dos pixels da forma analítica que representa sua borda externa com posteriores e sucessivas eliminações das elipses circunscritas a ela via decremento das dimensões dos semi-eixos até se tornarem mínimos. 
A detecção dos centros das elipses e de seus parâmetros (semi-eixo maior, semi-eixo menor e ângulo de inclinação) é realizado por uma função específica para este fim, denominada rht_center. Trata-se da aplicação da transformada randomizada de Hough sobre as subimagens com a identificação da ocorrência de bolhas.

Identificação da bolha por votação - parte I

As figuras 56, 57 e 58 apresentam a aplicação da transformada randomizada de Hough sobre uma subimagem contendo uma bolha bem definida.

A sequência apresentada na figura 56 parte da detecção da bolha na subimagem, ou seja, uma vez detectada a existência de, pelo menos, uma bolha dentro dos seus limites, a subimagem passa a representar o resultado, no caso "positivo", da aplicação da rede neural artificial. O processo continua com a execução do operador Canny sobre esta subimagem com a consequente detecção dos pixels da borda da bolha e do cálculo das derivadas direcionais sobre eles. Estes resultados são armazenados em matrizes com as mesmas dimensões da subimagem para posterior aplicação no cálculo do coeficiente angular das retas tangentes aos pixels selecionados aleatoriamente. É realizada uma seleção aleatória dos "supostos" pixels da borda da bolha. Estes pontos, representados por suas coordenadas, são organizados, aleatoriamente, em conjuntos contendo $50 \%$ do total das possíveis combinações de pares. É perceptível a convergência das votações das coordenadas do centro da elipse. As quatro coordenadas mais votadas são selecionadas e a partir delas, os pixels são recombinados aleatoriamente formando triplas para identificação dos demais parâmetros. A maior diferença deste segundo processo é que os parâmetros são extraídos mediante a constatação da existência de uma elipse descrita, analiticamente, por eles. As combinações dos parâmetros da elipse com as quatro coordenadas mais votadas do seu centro servirão de base para identificação da forma que melhor se ajusta aos pixels de borda. Esta verificação consiste no cálculo da taxa de pertinência entre as coordenadas dos pontos da elipse, calculados analiticamente, com os pontos das bordas da bolha. A combinação que apresentar maior taxa de pertinência e apresentar um valor superior a 60\%, será considerada descritiva da borda da bolha, ou seja, da interface gás líquido. A eliminação da borda desta elipse da subimagem, é realizada pela eliminação dos pixels resultante do seu cálculo analítico com a aplicação dos parâmetros identificados.

Além do armazenamento dos parâmetros da elipse obtida, um parâmetro indicador da existência de uma figura analítica na imagem, "flag", é alterado, e o número de elipses encontradas na imagem"n_el", é também atualizado. 


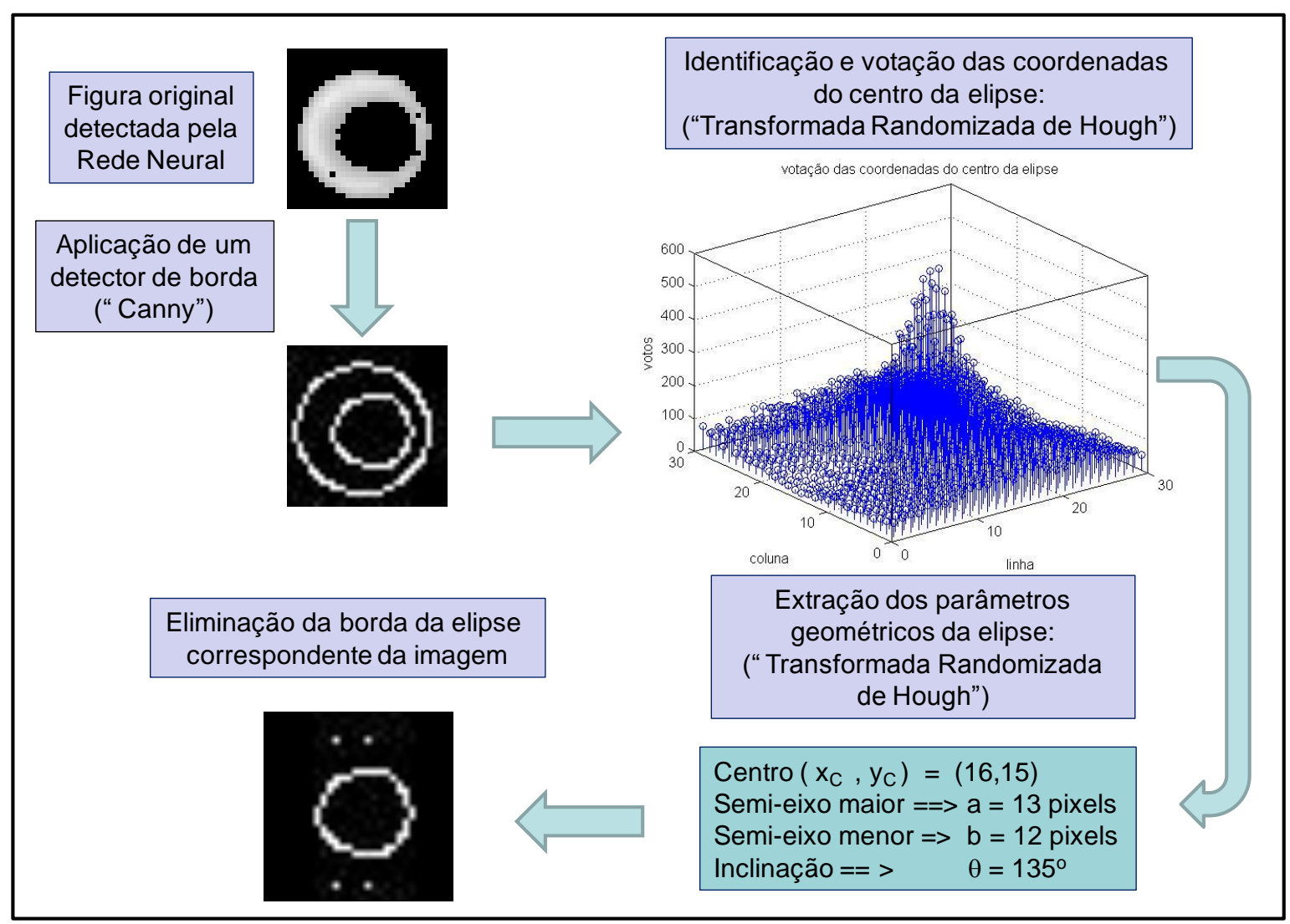

FIGURA 56 - Parte I - Aplicação dos procedimentos para detecção dos parâmetros geométricos da elipse.

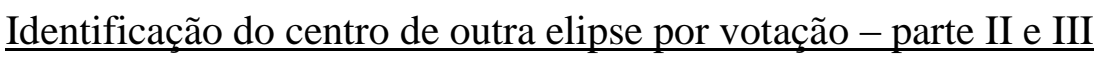

Uma segunda verificação é efetuada diante da possibilidade da existência de mais de uma bolha na imagem. A figura 57 ilustra esta nova execução da rotina rht_center, como a parte II do processo. Nela também é possível observar a existência de uma nova elipse e ficando clara a convergência da votação sobre as coordenadas do centro desta nova elipse. O cálculo dos demais parâmetros e a eliminação desta elipse ocorre dentro dos mesmos moldes da parte I na extração dos parâmetros da primeira elipse. As variáveis indicadoras da existência de uma nova figura analítica na imagem, "flag", e do número de elipses, "n_el", ainda não são atualizadas. Estas atualizações ocorrerão mediante a verificação da circunscrição de qualquer uma das duas elipses detectadas. Caso isto venha a ocorrer, é necessário a identificação da elipse com semi-eixos maiores por representar a borda externa da bolha, considerada interface gás-líquido. A borda interna é identificada como borda da sombra, formada em função dos efeitos óticos ocorridos durante a aquisição da imagem. Esta elipse com semi-eixos menores é eliminada da imagem e os parâmetros indicadores dela são desconsiderados. Caso as elipses não sejam concêntricas, identifica-se uma segunda bolha nos limites da sub imagem e o processo de captura e análise dos parâmetros que a descreve serão realizados, identificados e inseridos nos dados de saída da 
função "rht_center". Nestas ocasiões, a saída da função será representada por uma matriz onde cada linha conterá os cinco parâmetros descritivos de cada elipse detectada e, complementando as informações de saída, a variável "flag", indicando a existência de elipses nos limites da máscara virtual de varredura e "n_el", indicando o número de elipses encontradas correspondendo ao número de linhas da matriz de saída da função contendo os parâmetros das elipses encontradas.

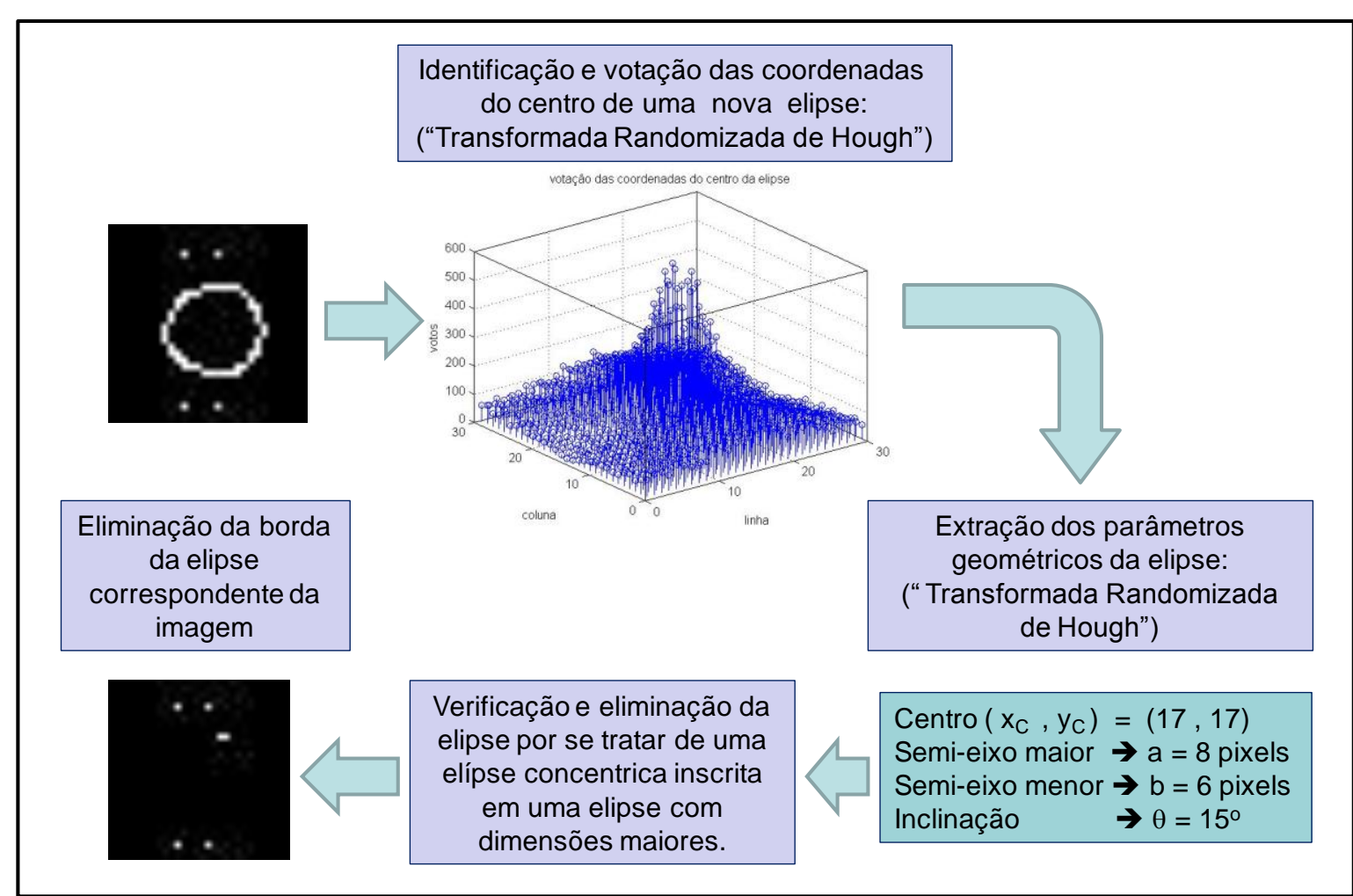

FIGURA 57 - Parte II - (Continuação) Procedimentos para detecção dos parâmetros
geométricos da elipse.

A parte III deste processo, ilustrado na figura 58, consiste na execução de uma nova verificação e finalização da função. Observa-se que da parte II, figura 57, sobraram poucos pixels na imagem e, dificilmente outra elipse seria identificada nesta subimagem, pois, a razão entre o número de pontos da subimagem e da borda da elipse analítica é visivelmente inferior ao limiar de $60 \%$. Isto é confirmado pelos resultados e a variável de controle de existência de elipse na subimagem, "flag", é atualizada com um valor igual a "2", indicativo da finalização da função retornando o número de elipses e os parâmetros geométricos correspondente a cada uma delas. A disponibilização dos parâmetros geométricos das figuras representativas das bolhas detectadas nas subimagens viabilizam a eliminação da imagem da bolha da subimagem e o cálculo do volume de cada uma delas para atualização da variável acumuladora do volume total de gás nos limites da amostra da imagem do escoamento bifásico. 


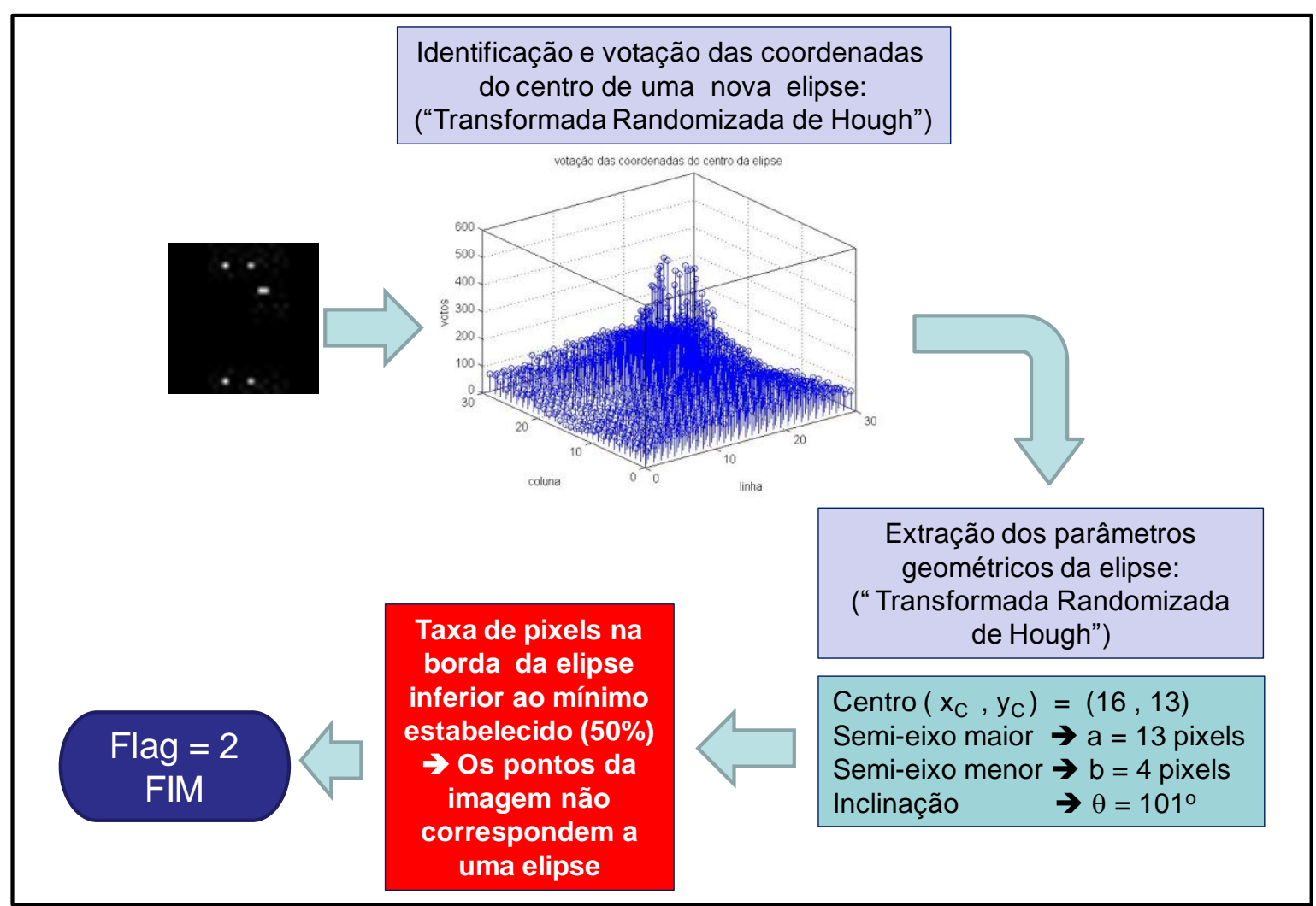

FIGURA 58 - Parte III - (Continuação) Procedimentos para detecção dos parâmetros geométricos da elipse.

Existem ocasiões, além da ocorrência de elipses circunscritas, em que a detecção da elipse na subimagem será desconsiderada:

- o cálculo da elipse analítica resultou em coordenadas de pixels localizados fora, ou na borda da máscara de varredura empregada pela rede neural para detecção da interface gás-líquido;

- as coordenadas do centro da elipse estão fora, ou no limite, da máscara virtual de varredura progressiva empregada pela rede neural artificial na detecção da bolha;

- imagens de bolhas selecionadas com partes na região limiar ou fora da profundidade da imagem da amostra volumétrica do escoamento bifásico. Neste caso, a rede neural detecta a bolha, no entanto sua taxa de pixels na borda analítica detectada é inferior ao limite estabelecido, em função da ocorrência de muitas falhas na sua borda externa e

- mesmo com aparência nítida da imagem da bolha, a seleção da imagem da bolha identificou e extraiu alguns de seus pixels por estarem fora dos limites de profundidade de campo. Isto é passível de ocorrência em bolhas no limiar do controle deste parâmetro e podem resultar na ocorrência de baixa taxa de 
pixels de borda não identificando a bolha como válida para cálculo da fração de vazio.

$\underline{\text { Resultados da integração da transformada randomizada de Hough com os outros }}$ algoritmos na detecção das bolhas em foco

Estas situações ressaltam a importância da integração da transformada randomizada de Hough com os demais algoritmos, contribuindo diretamente para a robustez dos resultados. As figuras que seguem demonstram estas situações. A figura 59 apresenta uma ocasião de uma bolha parcialmente fora de foco. Neste caso é visível que o conjunto de pixels da borda não foram suficientes para sua identificação como uma elipse válida. Esta situação é diferente da ocorrência de bolhas parcialmente oclusas devido a sobreposição por outras bolhas diante da possibilidade de não ocorrência de pixels fora de foco e o conjunto de pixels fora da região oclusa seja suficiente para identificá-la.

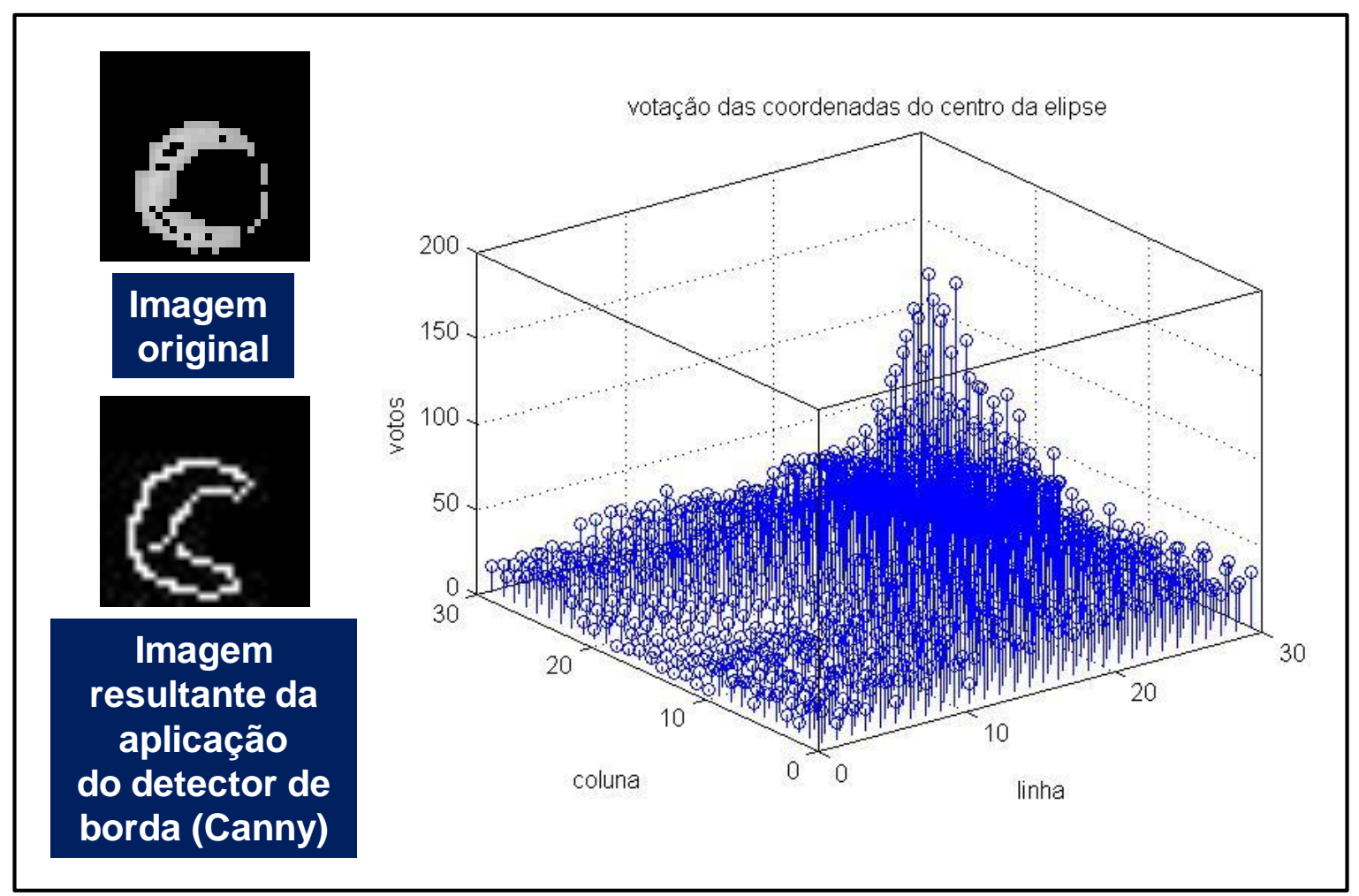

FIGURA 59 - Imagem parcialmente fora de foco. Taxa de pertinência <60\%

A figura 60 representa um caso similar a este, onde a bolha está totalmente representada, porém, com sua imagem degradada em função da sua localização no limiar da profundidade de campo. Nesta situação a borda da bolha, obtida pela aplicação do operador Canny, apresenta várias descontinuidades. Embora compensadas e preenchida pelo operador, apresenta muitas distorções, dificultando seu ajuste a um modelo de 
representação analítico de uma elipse. O resultado da taxa de pixels desta imagem, assim como a subimagem representada na figura 60 , foi inferior ao limiar de $60 \%$ estabelecido para sua consideração como elipse válida.

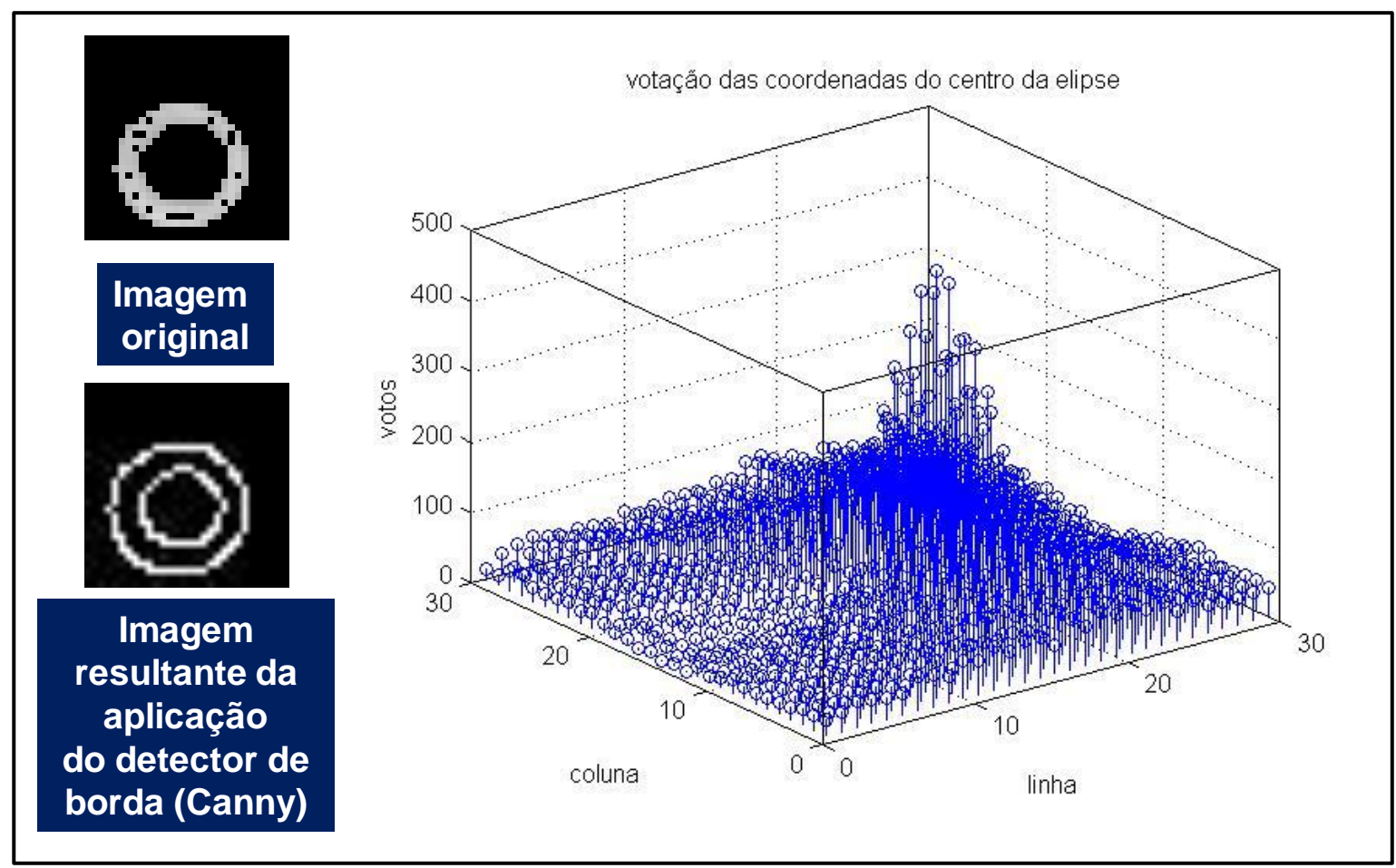

FIGURA 60 - Imagem de uma bolha no limiar da profundidade de campo.

A figura 61 ilustra uma evidente situação de identificação "falso-positivo". Trata-se uma mancha ocasionada na imagem por uma bolha quase que totalmente fora da profundidade de campo.

A forma desta imagem já demonstra tratar-se de uma figura totalmente fora dos padrões de uma bolha e que dificilmente seria identificada e ajustada analiticamente como uma forma elíptica. Uma particularidade observada nesta figura é a não convergência na votação das coordenadas do seu centro.

A figura 62 apresenta a ocorrência de detecção de um falso positivo talvez em decorrência da generalização da rede neural. Embora com uma curva bem definida e com possibilidade de ajuste por uma elipse definida analiticamente, a imagem da fase gasosa sugere a ocorrência de pontos fora da máscara virtual de varredura progressiva e foi imediatamente desconsiderada pela função "rht_center". 


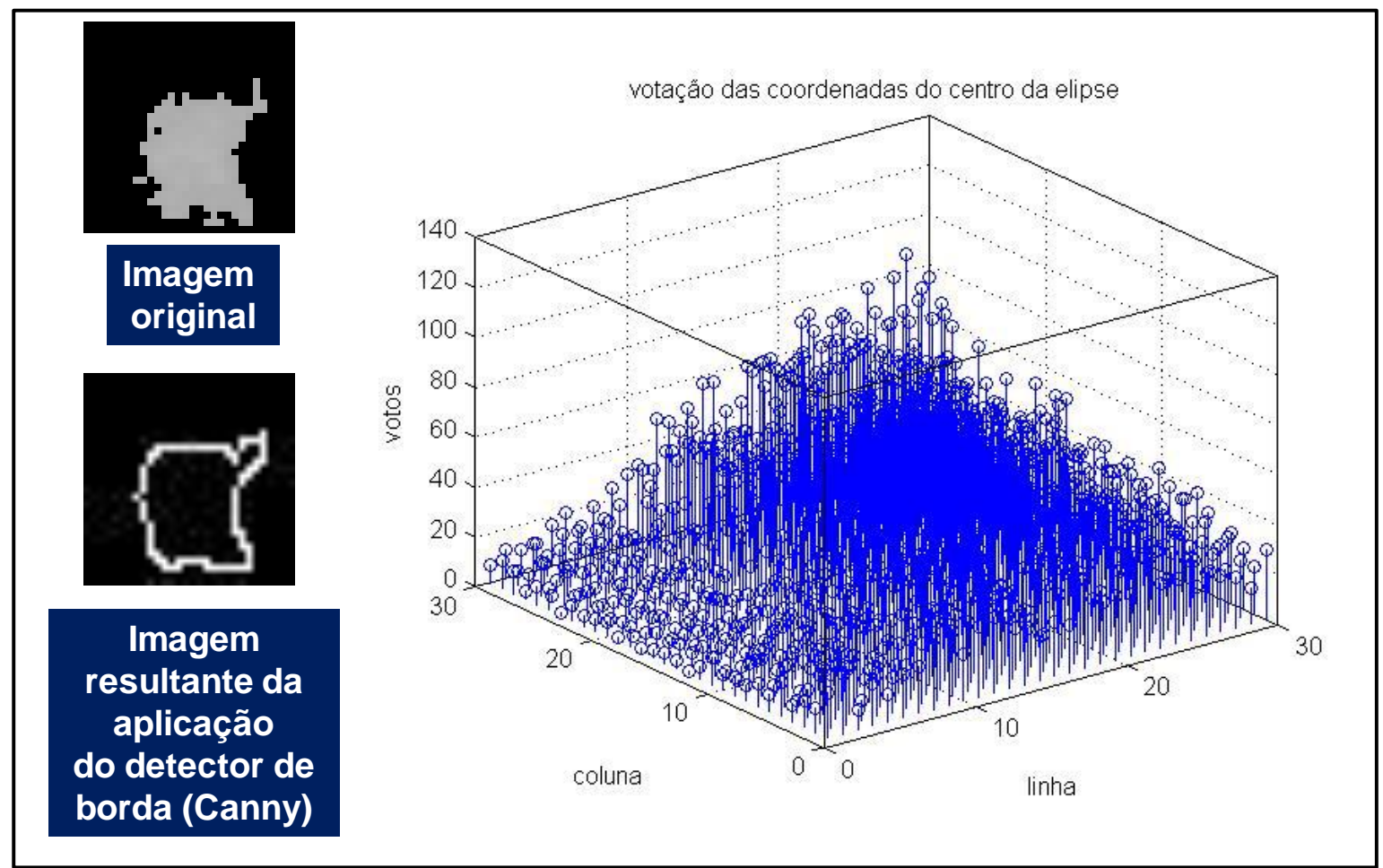

FIGURA 61 - Aplicação da transformada de Hough em falsos positivos.

Também é possível observar a ocorrência de uma dispersão na votação das coordenadas do centro desta elipse. Observa que se trata de uma votação dispersa devido a localização fora dos limites da máscara virtual de varredura progressiva.

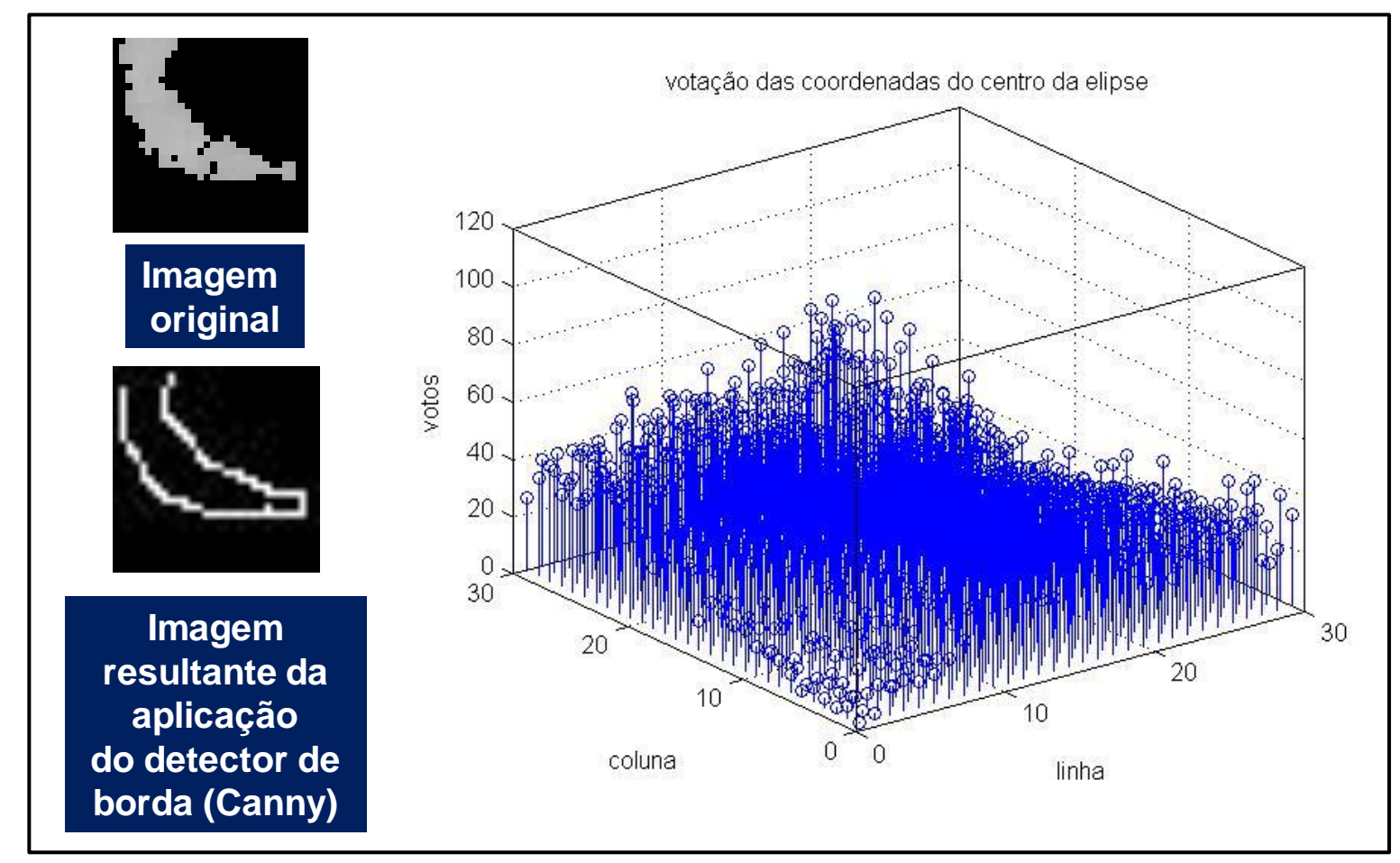

FIGURA 62 - Aplicação da transformada randomizada de Hough em falsos positivos.

Em todas as ocasiões em que os padrões geométricos não são detectados, a saída da função rht_center apresenta o número de elipses nulo. Isto evita que a imagem 
seja eliminada da amostra do escoamento. Ela permanecerá presente em futuras varreduras com máscaras virtuais de varredura progressiva com dimensões maiores. Este fator é importante pois, neste último caso pode-se supor tratar-se da parte de uma bolha que, embora parcialmente dentro da profundidade de campo, pode possuir dimensões maiores.

A figura 63 ilustra uma sequência de varredura de uma amostra da imagem do escoamento bifásico com máscaras virtuais de varredura progressiva com 30 x 30 pixels e $36 \times 36$ pixels.

A imagem original rotacionada e com dimensões superficiais idênticas às da amostra volumétrica do escoamento é apresentada no item "a" desta figura. A resposta do processo de seleção da amostra volumétrica e eliminação das bolhas fora do limite da profundidade de campo é ilustrada na imagem apresentada no item "b" desta mesma figura. Comparando-se esses itens da figura 63, pode-se constatar a ocorrência da seleção das imagens das bolhas dentro do limite de profundidade de campo. A imagem seguinte, figura 63(c), ilustra o resultado da aplicação da rede neural artificial sobre a amostra da imagem do escoamento empregando a máscara virtual de varredura com as menores dimensões estabelecidas para execução. As subimagens apresentadas neste item da figura correspondem às detectadas pela rede neural artificial. A figura 63 (d) apresenta o resultado da limpeza da imagem do item anterior. Observa-se que todas as bolhas detectadas foram excluídas do item (d) da figura 63. Isto é consequência da execução da transformada randomizada de Hough sobre cada sub imagem com a identificação dos parâmetros geométricos das interfaces gás-líquido e execução do processo de limpeza de cada bolha detectada. A figura 63(e) ilustra o resultado da rede neural artificial com o emprego de uma nova máscara virtual de varredura progressiva com dimensões de 36 x 36 pixels. O resultado final do processo de eliminação das bolhas detectadas é apresentado na figura 63(f). A imagem apresentada neste item da figura ilustra dois casos de "falso-positivos" que foram detectados pela rede neural artificial, porém, suas imagens não foram eliminadas em virtude da não identificação da existência de bolhas nos limites dessas sub imagens traduzindo o significativo aumento da robustez neste processo em função da integração entre tecnologias inteligentes para reconhecimento de padrões com a transformada randomizada de Hough. 


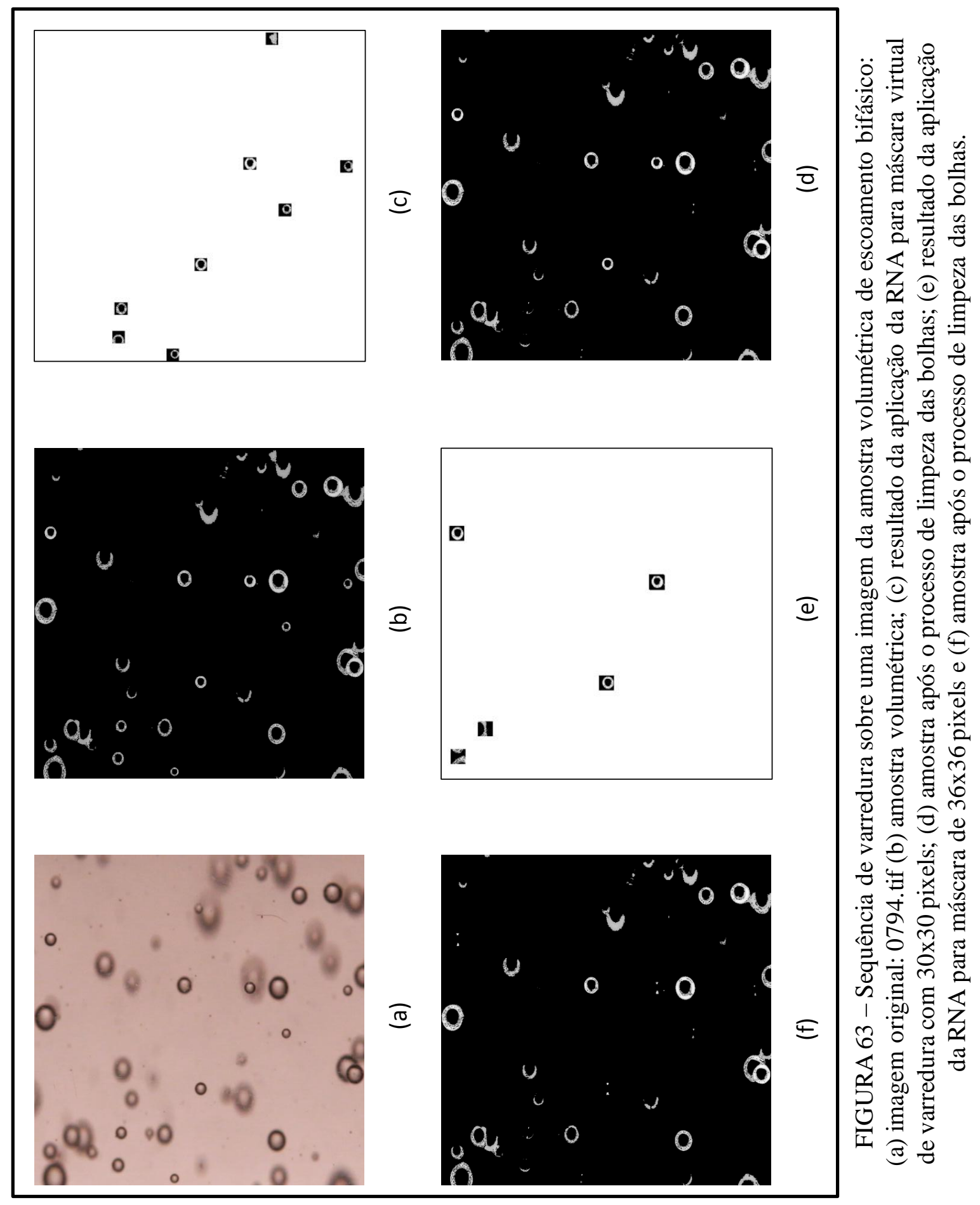




\subsection{Cálculo da estimativa da fração de vazio}

A estimativa da fração de vazio é realizada mediante o cálculo do volume total de gases na amostra. Ela é representada pela relação entre este volume de gases e o volume total (líquido + gás) no circuito. Estudos sobre o escoamento bifásico adotam valores médios, representativos deste parâmetro ao longo de todo um circuito experimental.

Os cálculos relacionados a este parâmetro neste estudo consideram a fração de vazio sobre uma amostra de escoamento e sua representação global fica comprometida caso o escoamento desta amostra não represente um valor global do circuito. A bancada de calibração de fração de vazio presta-se à esta compatibilização de resultados. Fatores de correção foram adotados para fins de ajustes nos resultados obtidos nos cálculos pelo sistema VFTools e das medições realizadas na bancada de calibração.

Foram selecionadas sete imagens capturadas dos experimentos, sendo três delas do experimento realizado em 24/10/2013 e quatro do experimento realizado em 10/05/2017. O critério para seleção destas imagens foi a utilização de imagens com dimensões de até 66 pixels das maiores bolhas identificadas no escoamento.

As figuras 64, 65 e 66 tratam das imagens capturadas no experimento de 24/10/2013. Elas estão apresentadas em forma cronológica da aquisição das imagens. As imagens desse experimento tiveram os valores de medida do desnível da coluna de água relativas aos pontos de tomada de pressão mediante leitura visual na bancada de calibração de fração de vazio.

As figuras exibem os resultados da estimativa de fração de vazio pelo método gravimétrico (descrito na seção 4.3), os resultados obtidos pelo sistema VFTools, o valor corrigido utilizando um fator de correção, e a dispersão relativa, " $\delta$ ", para cada caso analisado, calculada segundo a expressão (5.1):

$$
\delta=\frac{\left|\alpha_{c o}-\alpha_{\text {exp }}\right|}{\alpha_{\text {exp }}} .100(\%)
$$

Onde:

$\alpha_{c o} \quad$ fração de vazio corrigida

$\alpha_{\exp } \quad$ fração de vazio experimental, medida direta extraída da bancada de calibração de fração de vazio 
A figura 64 representa os resultados experimentais e os calculados via sistema VFTools.

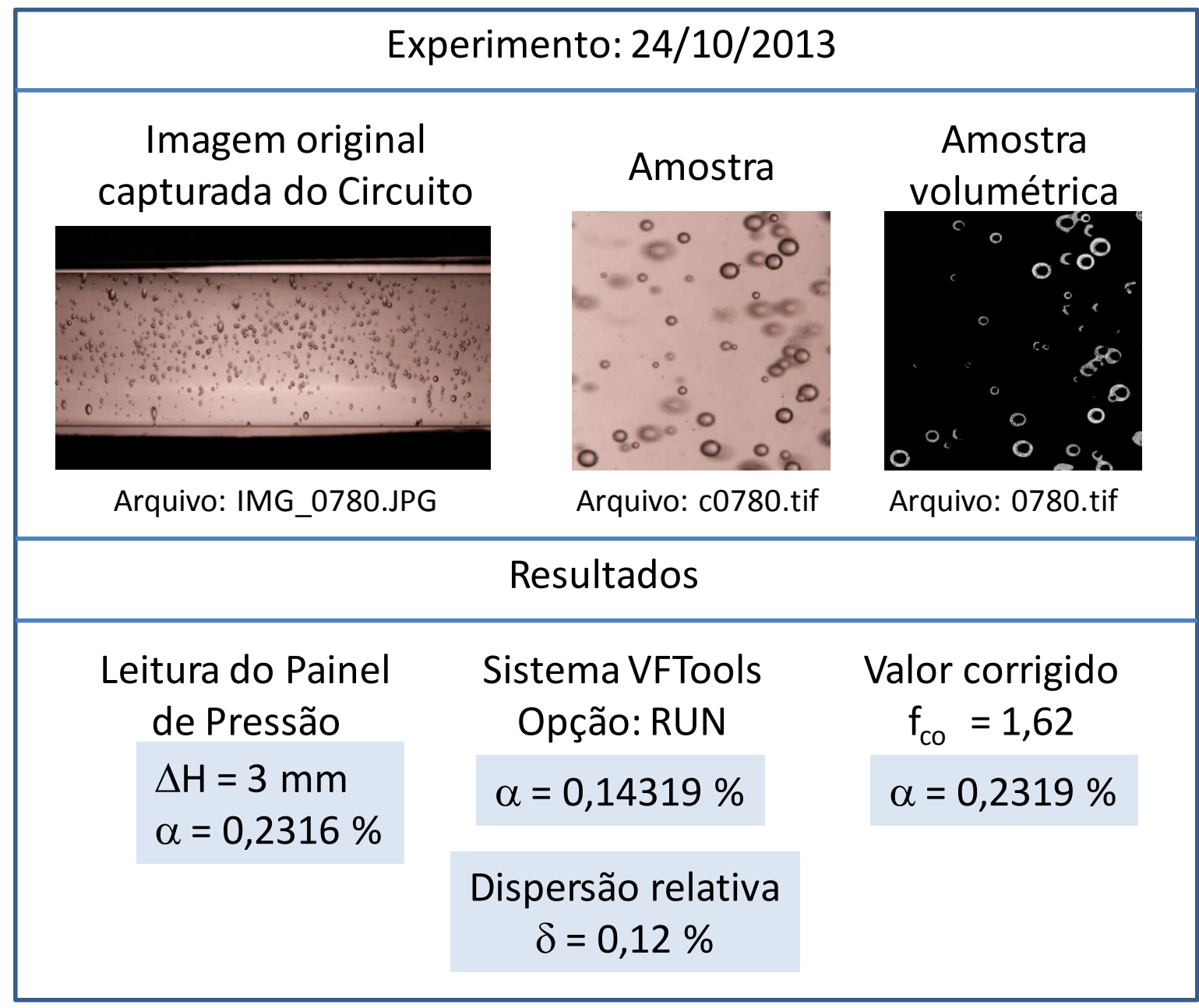

FIGURA 64 - Fração de vazio estimada da amostra capturada da imagem do arquivo IMG_0780.JPG e experimental.

A fração de vazio experimental, ou seja, adquirida pela leitura do painel de pressão da bancada de calibração apresentou um valor de $\alpha_{\text {exp }}=0,2316 \%$ correspondendo a uma diferença de pressão representada pela diferença na altura das colunas d'água no painel de pressão de $\Delta H=3 \mathrm{~mm}$. A estimativa da fração de vazio via sistema VFTools apresentou um valor de $\alpha=0,14 \%$.

Para cada experimento foi adotado uma constante denominada fator de correção. Para este primeiro experimento este fator foi ajustado para $f_{c o}=1,62$. Este fator genérico engloba, para estes estudos, vários possíveis fatores, desde fatores óticos de refração não levados em conta, não homogeneidade da distribuição do escoamento no tubo (amostra não representativa) e à imprecisão no ajuste da profundidade de campo na 
aquisição. O ajuste da profundidade de campo diante da imprecisão da escada de nível de profundidade de campo ter uma medição de $\pm 3 m m$ também inclui variações do foco que ocorrem por possíveis vibrações da tubulação e que por isto poderiam influenciar este ajuste. Se associássemos este fator genérico somente à estimativa da profundidade de campo seu valor sugeriria uma redução na profundidade de campo de $18 \mathrm{~mm}$ para $13 \mathrm{~mm}$. A aplicação deste fator de correção sobre o resultado do sistema representa a redução para $\delta=0,12 \%$ na dispersão dos resultados do sistema VFTools em relação aos extraídos experimentalmente via leitura do painel da bancada de calibração da fração de vazio.

As figuras 65 e 66 mostram os resultados obtidos utilizando este mesmo fator. Elas representam os resultados extraídos das imagens do escoamento bifásico apresentadas nos arquivos IMG_781.JPG e IMG_844.JPG respectivamente, relativas ao mesmo experimento e, portanto, com condições semelhantes de aquisição.

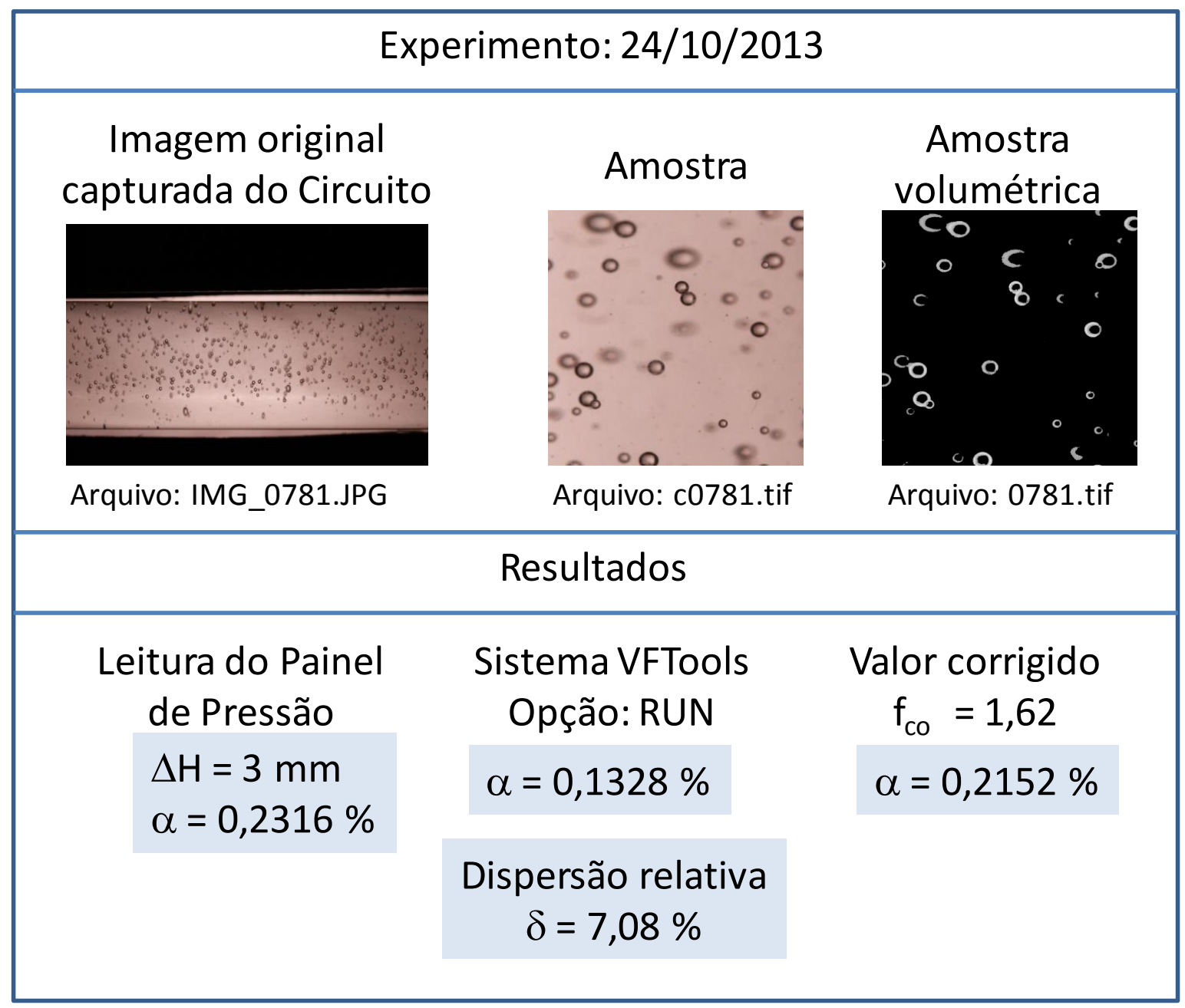

FIGURA 65 - Fração de vazio estimada da amostra capturada da imagem do arquivo IMG_0781.JPG e experimental. 
A dispersão entre os resultados da bancada experimental e da estimativa do sistema VFTools apresentou valores de 7,08 \% para a imagem do escoamento do arquivo IMG_781.JPG, figura 65 , e de 5,8\% para a imagem do escoamento do arquivo IMG_844.JPG, figura 66 .

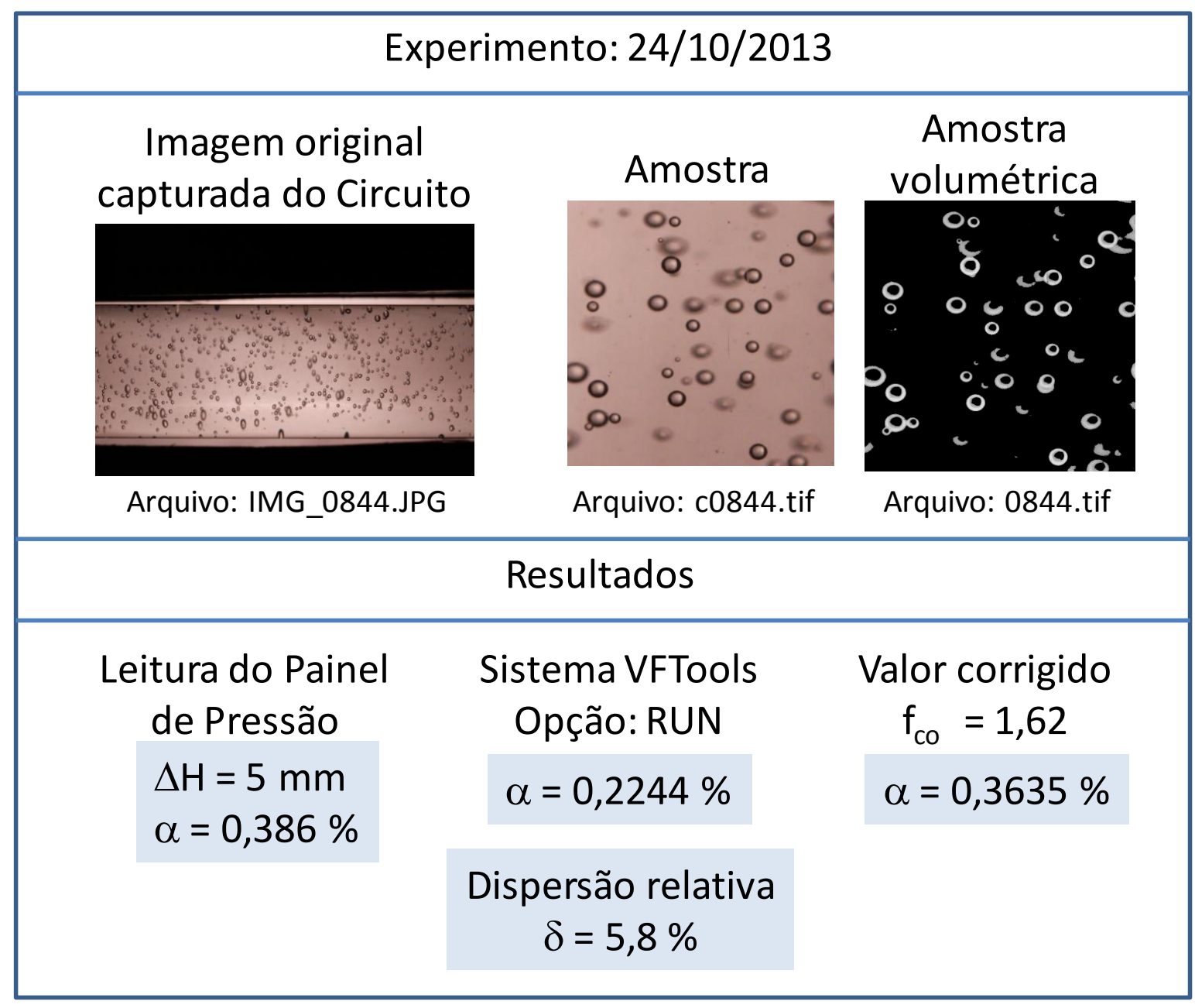

FIGURA 66 - Fração de vazio estimada da amostra capturada da imagem do arquivo IMG_0844.JPG e experimental

Outro aspecto interessante é a coerência visual entre as imagens das amostras do escoamento. As imagens representadas nas figuras 64 e 65 ilustram escoamentos com uma densidade de bolhas parecidas na imagem. A imagem da amostra do escoamento ilustrada na figura 66 apresenta uma densidade maior e isto é perceptível pelo valor da fração de vazio experimental e estimada pelo sistema VFTools.

Os resultados dos experimentos realizados em 10/05/2017 estão ilustrados nas figuras 67 a 70 apresentadas a seguir. A alteração de alguns parâmetros destes experimentos (em relação ao descrito anteriormente) devem ser ressaltados para a análise dos resultados obtidos pela aplicação do VFTools. 


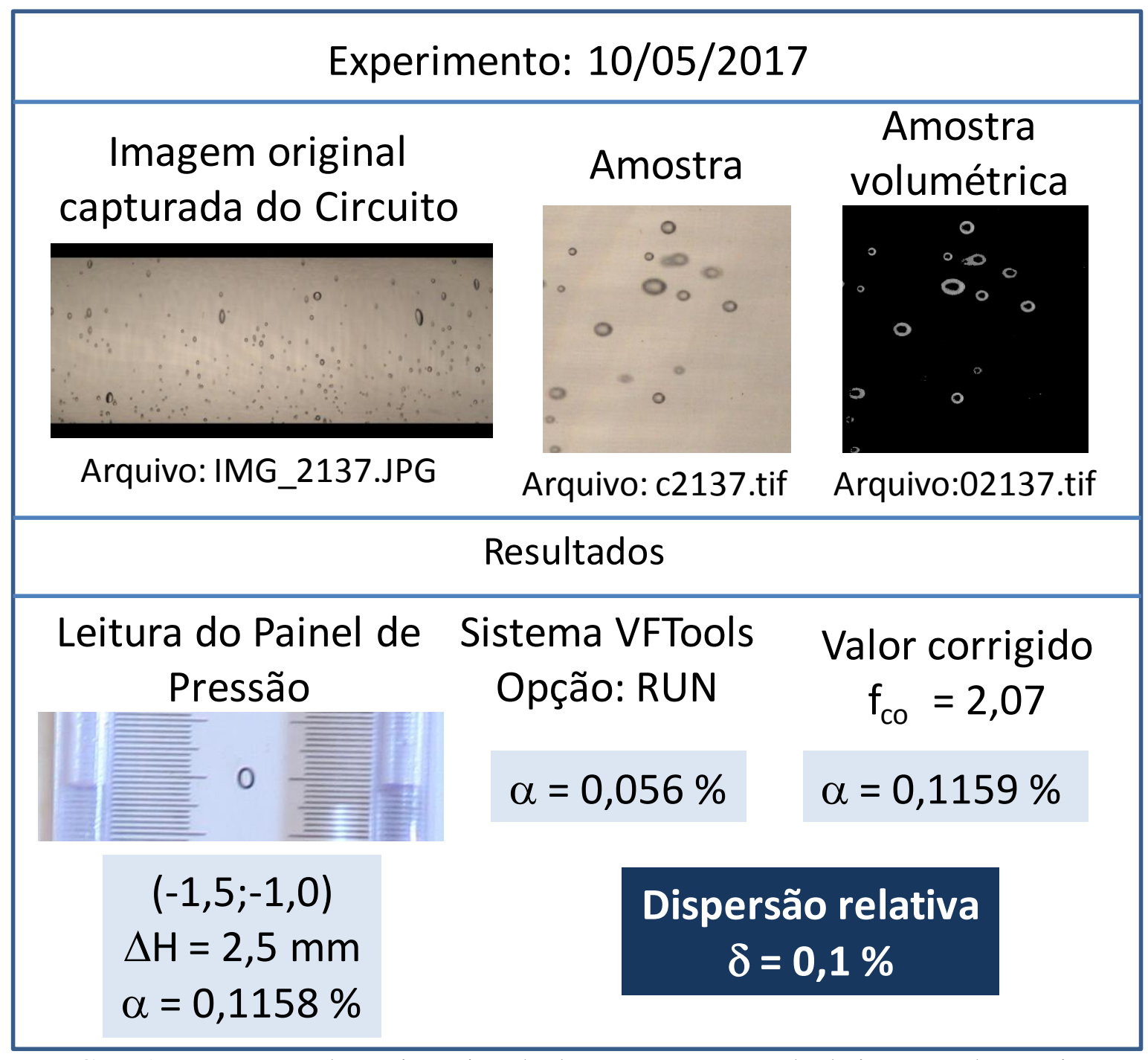

FIGURA 67 - Fração de vazio estimada da amostra capturada da imagem do arquivo IMG_2137.JPG e experimental

$\mathrm{O}$ primeiro deles diz respeito ao aumento da profundidade de campo em que as imagens foram capturadas. Enquanto no experimento de 24/10/2013 esta profundidade de campo era de $15 \pm 3 \mathrm{~mm}$, este parâmetro é de $20 \pm 5 \mathrm{~mm}$ para o experimento de 10/05/2017. As imagens mostraram a necessidade de se adotar um valor maior para o fator de correção que, associado às dimensões do volume da amostra, representariam uma redução na profundidade de campo de 20 para $12 \mathrm{~mm}$ no experimento de 10/05/2017.

Outra mudança observada neste novo experimento foi uma avaliação visual em que houve aumento da não homogeneidade na distribuição do escoamento (distribuição das bolhas) ao longo do circuito, refletindo diretamente nos resultados da estimativa da fração de vazio via sistema VFTools baseada nas amostras utilizadas. 


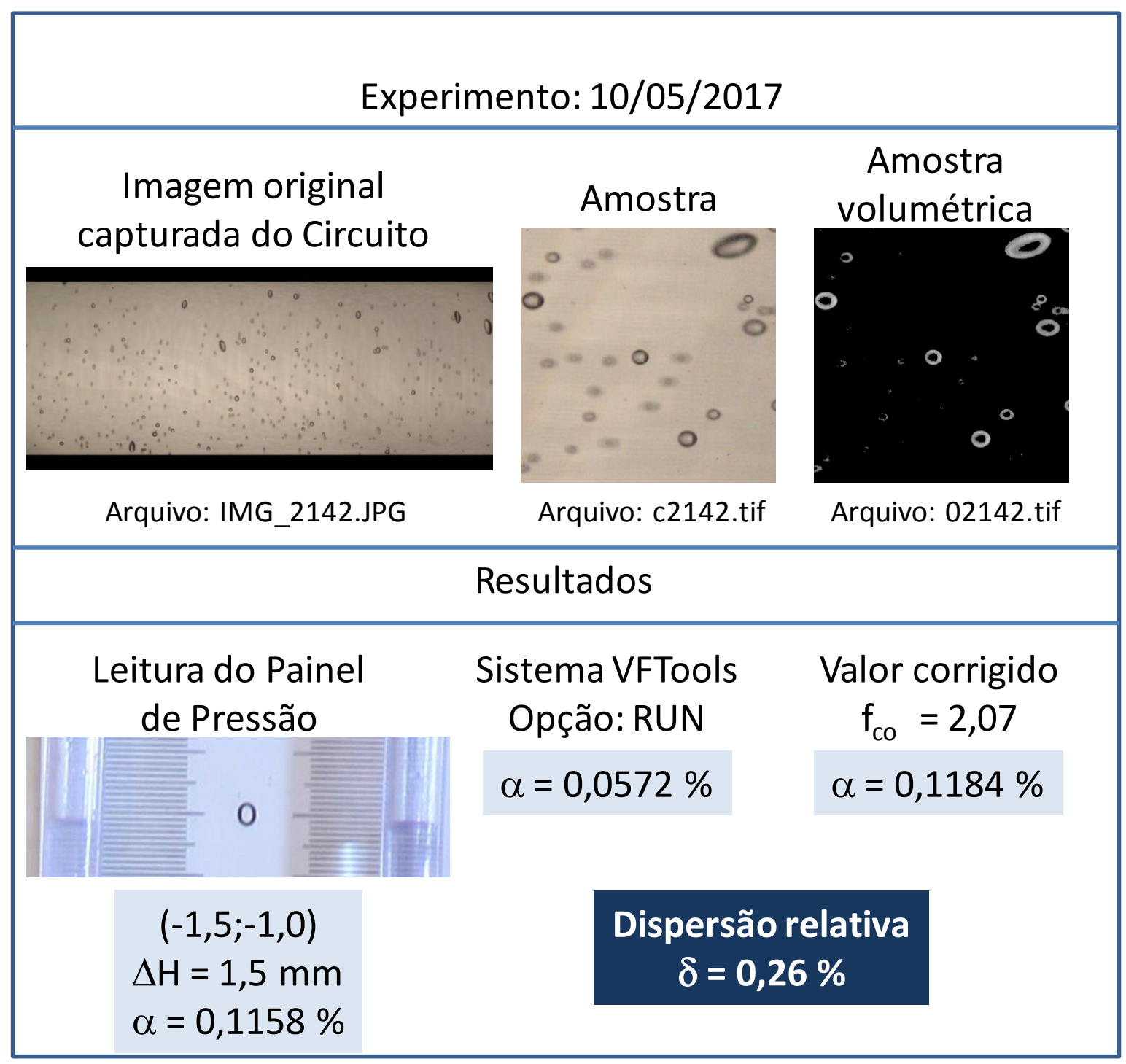

FIGURA 68 - Fração de vazio estimada da amostra capturada da imagem do arquivo IMG_2142.JPG e experimental

As figuras 67, 68 e 69 refletem isto por representar medidas efetuadas em intervalos de tempo próximos. Embora os resultados indicassem valores iguais de fração de vazio pelas leituras do painel da bancada de calibração, ocorreram variações quando comparadas com os resultados obtidos via estimativas tomando-se por base as imagens correspondentes. Isto verifica-se pela comparação das dispersões entre os resultados de cada uma delas. Presume-se portanto que os resultados dos experimentos extraídos via bancada de calibração da fração de vazio no circuito representa um valor médio deste parâmetro e correspondente à fração de vazio média caso fosse estimada em diversas localizações diferentes do circuito.

Outro fator a ser ressaltado diz respeito à incerteza nas medições experimentais. Ao admitir-se uma incerteza de $0,5 \mathrm{~mm}$ na medição do nível d'água de cada 
tomada de pressão, supõe-se uma incerteza máxima de $1,0 \mathrm{~mm}$ sobre a medição deste parâmetro. $\mathrm{O}$ impacto direto desta incerteza na medida experimental da fração de vazio, ou seja, via bancada de calibração é de um valor de $\delta \alpha=0,08 \%$. Embora represente um valor absoluto pequeno, esta incerteza é significativa quando se trata de medições experimentais em circuitos com baixa fração de vazio. Sob estas condições, o valor da incerteza poderia comprometer uma análise quantitativa dos resultados, limitando-as à associações dos resultados às observações qualitativas sobre as imagens capturadas do escoamento. Para valores maiores de fração de vazio a incerteza passa a ser insignificante e o processo de calibração e ajuste do sistema passaria a ser mais preciso.

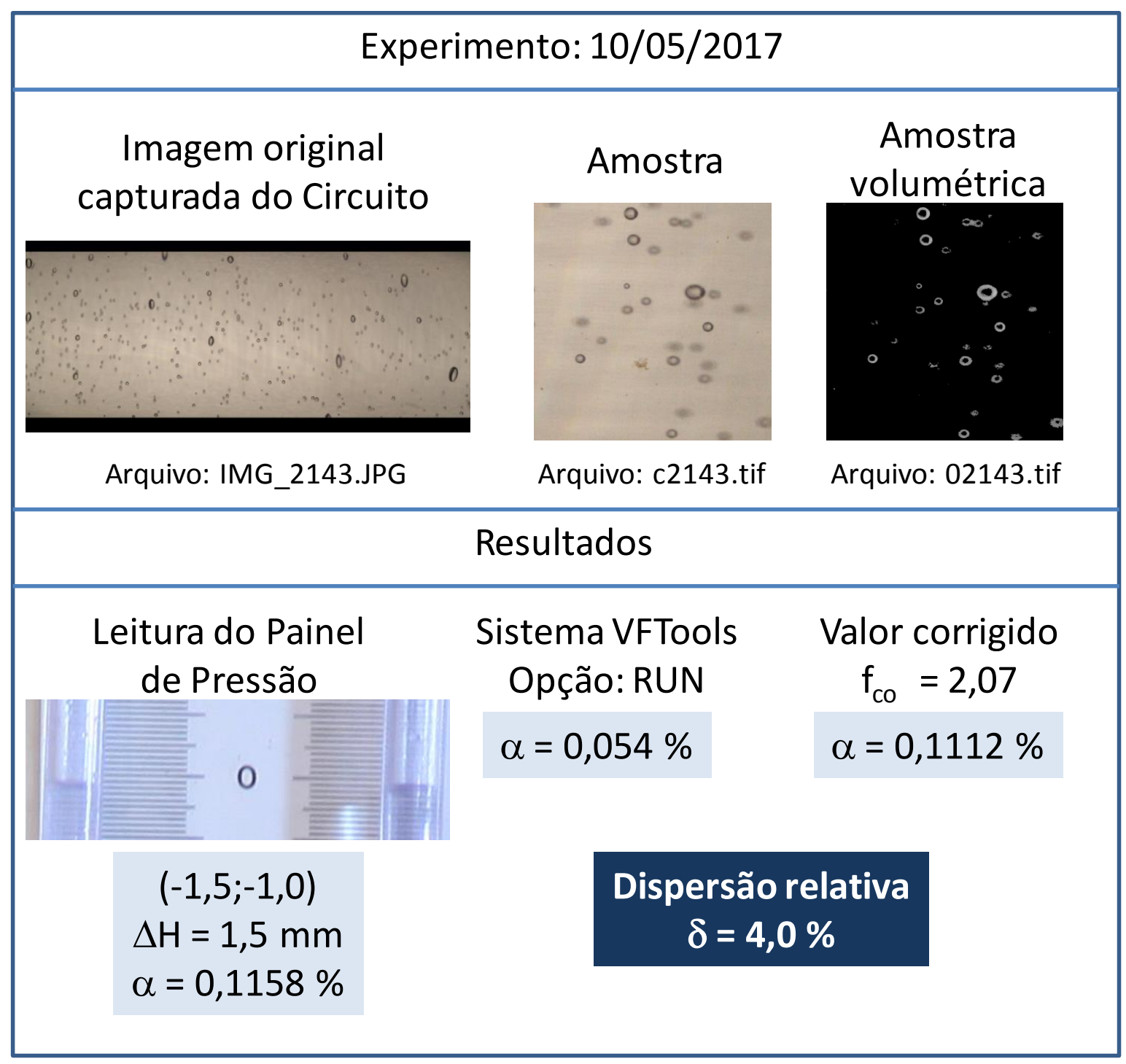

FIGURA 69 - Fração de vazio estimada da amostra capturada da imagem do arquivo IMG_2143.JPG e experimental 


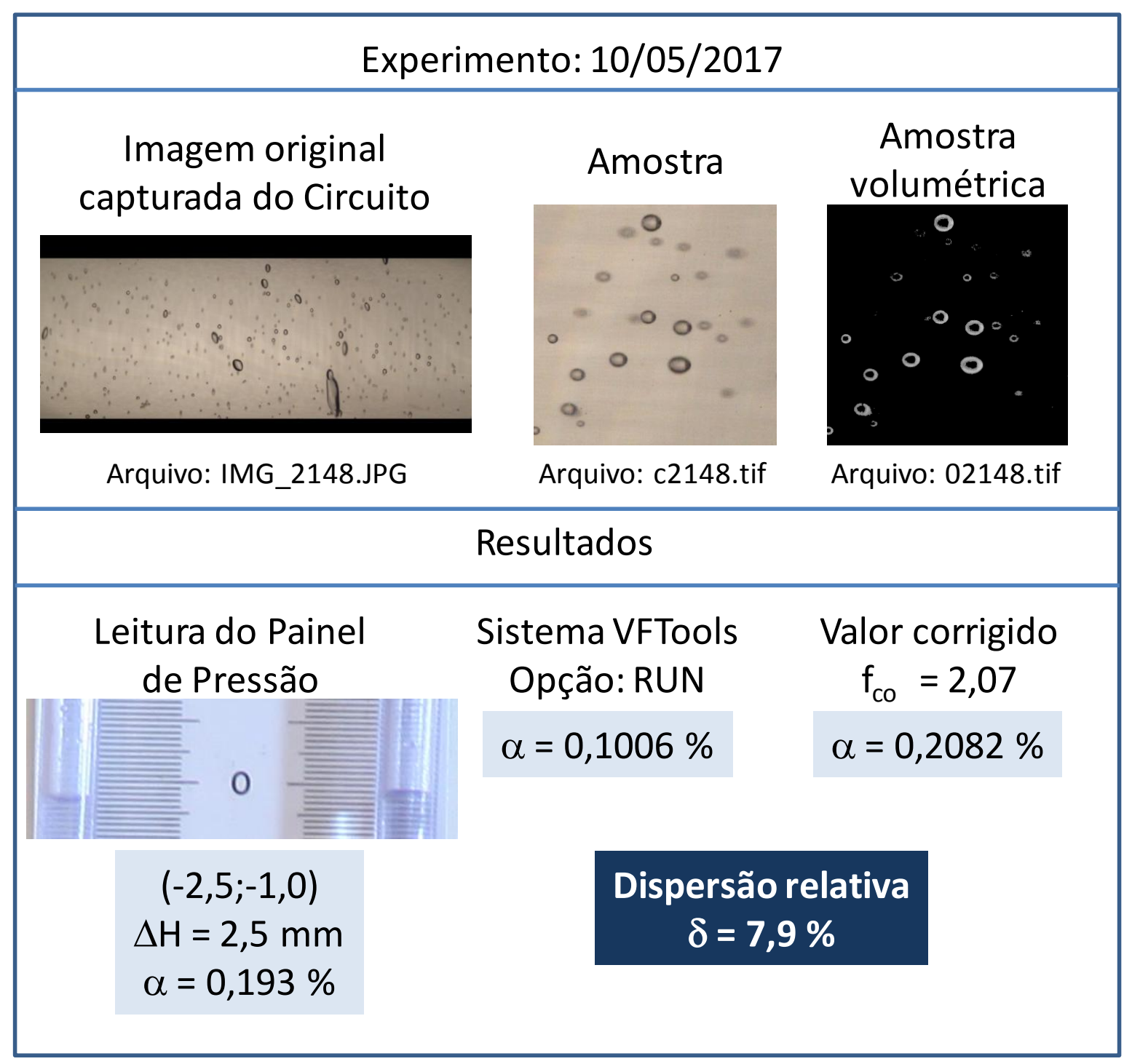

FIGURA 70 - Fração de vazio estimada da amostra capturada da imagem do arquivo IMG_2148.JPG e experimental

Análises complementares foram realizadas com base na avaliação de diversos fatores de correção que podem ser associados à profundidade de campo das imagens e nos resultados da fração de vazio para cada um dos experimentos. Este processo consiste nos cálculos de dispersão em função de diferentes valores para o fator de correção. Estes cálculos utilizaram estimativas de correções do valor de profundidade de campo (pc) considerando que todo o fator de correção utilizado fosse devido a este parâmetro. As tabelas 5 e 6 apresentam estes resultados. 
TABELA 5 - Relação das frações de vazio com a profundidade de campo (Experimento de 24/10/2013)

\begin{tabular}{|c|c|c|c|}
\hline Imagem & $\begin{array}{c}\text { IMG_780 } \\
\boldsymbol{\alpha}_{\mathbf{b}}=\mathbf{0 , 2 3 1 6} \% \\
\mathbf{f}_{\text {CO }}(\mathbf{p c})\end{array}$ & $\begin{array}{c}\text { IMG_781 } \\
\boldsymbol{\alpha}_{\text {VFTools }}=\mathbf{0 , 1 4 3 2} \%\end{array}$ & $\begin{array}{c}\text { IMG_844 } \\
\boldsymbol{\alpha}_{\mathbf{b}}=\mathbf{0 , 2 3 1 6} \%\end{array}$ \\
\hline $2,51(10 \mathrm{~mm})$ & $0,3594 \%(55 \%)$ & $0,3333 \%(44 \%)$ & $\begin{array}{c}\boldsymbol{\alpha}_{\mathbf{b}}=\mathbf{0 , 3 8 6} \% \\
\boldsymbol{\alpha}_{\text {VFTools }}=\mathbf{0 , 2 2 4 4} \%\end{array}$ \\
\hline $2,12(11 \mathrm{~mm})$ & $0,3036 \%(31 \%)$ & $0,2815 \%(22 \%)$ & $0,5632 \%(46 \%)$ \\
\hline $1,84(12 \mathrm{~mm})$ & $0,2635 \%(13 \%)$ & $0,2444 \%(5,5 \%)$ & $0,4757 \%(23 \%)$ \\
\hline $1,62(13 \mathrm{~mm})$ & $0,2320 \%(0,17 \%)$ & $0,2151 \%(7,1 \%)$ & $0,3129 \%(7 \%)$ \\
\hline $1,45(14 \mathrm{~mm})$ & $0,2076 \%(10 \%)$ & $0,1926 \%(17 \%)$ & $0,3254 \%(16 \%)$ \\
\hline
\end{tabular}

TABELA 6 - Relação das frações de vazio com a profundidade de campo (Experimento de 10/05/2017)

\begin{tabular}{|c|c|c|c|c|}
\hline Imagem & $\begin{array}{c}\text { IMG_2137 } \\
\alpha_{\mathrm{b}}=\mathbf{0 , 1 1 5 8 \%} \\
\alpha_{\text {VFTools }}=\mathbf{0 , 0 5 6 \%} \\
\end{array}$ & $\begin{array}{c}\text { IMG_2142 } \\
\alpha_{\mathrm{b}}=\mathbf{0 , 1 1 5 8 \%} \\
\alpha_{\text {VFTools }}=\mathbf{0 , 0 5 7 \%} \\
\end{array}$ & $\begin{array}{c}\text { IMG_2143 } \\
\alpha_{\mathrm{b}}=\mathbf{0 , 1 1 5 8 \%} \\
\alpha_{\text {VFTools }}=\mathbf{0 , 0 5 4 \%} \\
\end{array}$ & $\begin{array}{c}\text { IMG_2148 } \\
\alpha_{\mathrm{b}}=\mathbf{0 , 1 9 3 \%} \\
\alpha_{\text {VFTools }}=\mathbf{0 , 1 0 0 6 \%}\end{array}$ \\
\hline $2,83(10 \mathrm{~mm})$ & $0,1585 \%(37 \%)$ & $0,1613 \%(39 \%)$ & $0,1528 \%(32 \%)$ & $0,2847 \%(48 \%)$ \\
\hline $2,39(11 \mathrm{~mm})$ & $0,1338 \%(16 \%)$ & $0,1362 \%(18 \%)$ & $0,1291 \%(11 \%)$ & $0,2404 \%(25 \%)$ \\
\hline $2,07(12 \mathrm{~mm})$ & $0,1159 \%(0,1 \%)$ & $0,1180 \%(2 \%)$ & $0,1118 \%(3,5 \%)$ & $0,2082 \%(8 \%)$ \\
\hline $1,83(13 \mathrm{~mm})$ & $0,1025 \%(11 \%)$ & $0,1043 \%(10 \%)$ & $0,0988 \%(15 \%)$ & $0,0,1841 \%(4,6 \%)$ \\
\hline $1,63(14 \mathrm{~mm})$ & $0,0913 \%(21 \%)$ & $0,0929 \%(20 \%)$ & $0,0,088 \%(24 \%)$ & $0,164 \%(15 \%)$ \\
\hline
\end{tabular}

Dessas tabelas foi também possível observar a diferença relativa entre os resultados da bancada de calibração e os valores estimados pelo sistema VFTools corrigidos pelos fatores de correção ótica. As menores diferenças ocorreram sob condições em que estes resultados foram calculados utilizando um fator de correção que sugeriria uma profundidade de campo oscilante entre 12 e $13 \mathrm{~mm}$ se o fator de correção correspondesse unicamente à profundidade de campo. Estes valores induzem à condição de que, independente da seleção na profundidade de campo, os fenômenos óticos que ocorrem durante o experimento exercem grande influência sobre as imagens posicionadas posteriormente à uma distância fixa. Esta influência pode estar relacionada às características físicas da tubulação de vidro utilizada no experimento. 


\section{CONCLUSÕES}

Foi desenvolvido um sistema computacional utilizando novas metodologias para mensuração da fração de vazio a partir de imagens digitais de escoamento bifásico. Denominado VFTools por se tratar de uma sigla com menção à Void Fraction Tools ou Ferramentas de Fração de Vazio, este sistema contém, como seu próprio nome sugere, um conjunto de ferramentas aplicáveis à realização da estimativa da fração de vazio em escoamentos cujos objetos de interesse na imagem analisada contenham contornos com configurações elípticas ou circulares em sua geometria. As ferramentas podem ser utilizadas para uso isolado ou em conjunto, numa sequência de processos destinados ao cálculo da fração de vazio.

O emprego do sistema VFTools em imagens reais do escoamento bifásico, obtidas em circuito experimental existente no Centro de Engenharia Nuclear do IPEN-SP, mostrou-se com uma eficiência próxima de $100 \%$ no reconhecimento das bolhas de interesse (dentro do limite experimental definido na aquisição de imagens) em imagens de escoamentos com baixas frações de vazio e $100 \%$ preciso nos resultados de estimativa das medidas geométricas associadas a elas. Estes ótimos resultados do sistema sugerem que parte das técnicas utilizadas possa ser aplicada em outras áreas de conhecimento que necessitem mensurar cientificamente estruturas com objetos com geometria elíptica.

O método integrou de forma inédita, num sistema de varredura pixel a pixel, um conjunto de redes neurais artificiais e uma forma modificada da transformada randomizada de Hough. Além desta complexa integração, o sistema VFTools incluiu um pré-processamento da imagem para treinamento das redes neurais que permitiu uma detecção das bolhas de acordo com um procedimento experimental que limitou a aquisição das imagens a uma faixa pré-determinada de foco.

Apesar de haver necessidade de maior automatização do sistema em sua fase de treinamento, o núcleo da detecção e segmentação da imagem pode ser utilizado em muitas outras aplicações. Destacam-se como exemplo, projetos de mensuração de materiais compostos utilizando fibras de carbono com geometrias semelhantes, aplicações na área de transporte de fluídos por longas distâncias (transporte de petróleo via oleodutos), sistemas 
de refrigeração de componentes eletrônicos, refrigeração de sistemas de geração de energia solar e aplicações geotérmicas, além de sua aplicação nos sistemas de resfriamento nuclear. Outra importante área com potencial de aplicação, é a utilização do sistema em imagens médicas, onde se encontram muitas imagens digitalizadas de estruturas biológicas com esta geometria.

O sistema de votação desenvolvido neste trabalho para a utilização da transformada de Hough merece ser destacado pois, abre um novo campo de estudos desta transformada que vem crescendo sua utilização, tanto pelo aumento da capacidade de processamento dos novos hardwares, como pela simplificação de sua implementação que vem sendo alcançada pelos trabalhos mais recentes. A otimização do algoritmo possibilitaria sua utilização com maior velocidade. Um estudo mais aprofundado e específico das velocidades computacionais envolvidas com a utilização dos parâmetros já existentes deve ser desenvolvido em breve.

Por ser um sistema muito complexo, envolvendo diferentes fases de desenvolvimento, ainda apresentou tempos de processamento computacional da ordem de 2 a 4 horas para execução do sistema sobre uma imagem quando utilizando máscaras de maiores dimensões (acima de 2000 pixels). Pela mesma complexidade, o método se mostrou profícuo em abertura de novos campos de pesquisa, especialmente quanto à integração do uso de redes neurais artificiais com a transformada de Hough quando aplicadas convolucionalmente a uma imagem.

A concepção e implementação do VFTools foi realizada em fases distintas que resultaram em um sistema composto por três aplicações contendo funcionalidades que o habilitam à execução dos seguintes processos:

- adequação e seleção de uma amostra do escoamento bifásico a partir de imagens digitais capturadas de circuitos experimentais por imageamento direto (aplicação selecTool);

- seleção e classificação, via máscara virtual de varredura progressiva previamente dimensionada, de subimagens da amostra do escoamento bifásico para a construção de uma base de treinamento de uma rede neural artificial com a criação de arquivos (aplicação maSamTool);

- revisão e organização do arquivo de amostras de treinamento da rede neural artificial através da reclassificação, exclusão e reordenação das amostras de 
treinamento e de suas correspondentes classificações (aplicação saManTool);

- treinamento da rede neural artificial construída para a detecção de bolhas com dimensões menores, ou compatíveis, que as fixadas para a máscara virtual de varredura progressiva empregada na construção do arquivo de amostras de treinamento. Avaliação da qualidade do treinamento com a execução da rede neural sobre as próprias subimagens da amostra de treinamento (aplicação maSamTool);

- redução do número de detecções de "falso-positivos" pela rede neural via ajustes de limiares de classificação (aplicação maSamTool);

- execução da rede neural sobre uma amostra volumétrica de escoamento bifásico com máscara virtual de varredura progressiva com dimensões fixas e em conjunto com a função "rht_center". Esta última, executa a transformada randomizada de Hough modificada e presta-se à ocultação da imagem das bolhas detectadas, em foco e dentro dos limites da máscara de varredura da amostra do escoamento bifásico (aplicação maSamTool integrada com a função rht_center). Este processo integrado tem o objetivo de limpeza da imagem da amostra volumétrica do escoamento bifásico através da exclusão da imagem das bolhas detectadas com dimensões menores que os definidos pela máscara virtual de varredura progressiva. Ele presta-se à preparação desta imagem para ser novamente utilizada na construção de um novo arquivo de amostras de treinamento empregando uma máscara virtual com dimensões maiores e

- execução da rede neural artificial integrada com a transformada randomizada de Hough na detecção progressiva das bolhas em uma amostra de escoamento para cálculo do volume de gás nesta amostra e consequente cálculo da fração de vazio (aplicação maSamTools em composição com a função rht_center).

O desempenho e eficiência das aplicações foram sendo constatadas ao longo do desenvolvimento deste trabalho. Os resultados obtidos progressivamente indicaram interpretações e compreensões não previstas inicialmente sobre as condições envolvidas na execução dos experimentos. O cálculo da fração de vazio foi feito para um pequeno conjunto de amostras, mas que apesar de pequeno, permitiu o estabelecimento de novos 
parâmetros para avaliar a correspondência entre a profundidade de campo utilizada para aquisição e sua correspondência na avaliação pelo sistema. Outros fatores óticos envolvidos no experimento podem ser também avaliados utilizando este sistema, como o grau de uniformidade da iluminação de fundo (background). O sistema VFTools mostra-se bastante útil e eficaz para a realização destas análises uma vez que permitiria a elaboração de um mapeamento desses fatores associadas à diversas variáveis descritivas de configurações dos experimentos na própria bancada de calibração da fração de vazio.

Os resultados obtidos pelo VFTools, sobre as imagens do escoamento capturadas da bancada experimental de calibração, mostraram-se precisos com dispersões inferiores à $10 \%$ quando comparadas aos resultados experimentais aferidos via diferencial de pressão. Com base nestes resultados pode-se também concluir que o refinamento na aquisição das imagens resultaria em resultados mais precisos. A incerteza nas medições da fração de vazio via bancada de calibração exerceram um papel significativo na interpretação dos resultados em virtude de sua ordem de grandeza estar compatível dos valores constatados e estimados da fração de vazio. O emprego de condições mais estritas na técnica experimental do processo de calibração utilizando o método gravimétrico pode vir a melhorar precisão das estimativas do sistema. Entre estas melhorias do método de calibração estão: o aumento do paralelismo nos feixes de luz de fundo, o uso de cabines escuras no imageamento e o aumento do sincronismo entre os instantes de aquisição das imagens do escoamento bifásico e do painel de pressão.

A execução da rede neural artificial sobre uma amostra de imagem do escoamento bifásico é realizada em conjunto com uma máscara virtual de varredura progressiva responsável pela captura de uma subimagem do escoamento bifásico limitada às suas dimensões. A progressão desta máscara ocorre coluna a coluna sobre cada linha da amostra e em cada progressão é executada a rede neural para reconhecimento de bolhas nos limites da sub imagem definida pelas dimensões dessa máscara. O número de execuções da rede neural artificial é extremamente grande diante do número de bolhas a serem detectadas nas amostras volumétricas de imagem do escoamento. Isto resultou em um número excessivo de "falso-positivos" na identificação. O emprego de ajustes nos limiares para classificação na saída da rede neural artificial mostrou-se eficiente, porém, não suficiente para suprir esta deficiência na utilização da rede neural. Sendo assim, pode-se concluir também que a associação dos resultados da rede neural artificial com os resultados obtidos pela aplicação da transformada randomizada de Hough conduziram a 
resultados muito mais eficientes e precisos com poucos erros de detecção. Conclui-se ainda que o sucesso desta integração se deve também ao limiar de $60 \%$ sobre o número de pixels de borda sobre a elipse ou circunferência descrita analiticamente sobre a borda da imagem detectada e à implementação de um rigoroso processo de votação e combinação dos demais parâmetros dessas figuras geométricas que melhor se ajustem às bordas detectadas. As melhorias implementadas à transformada randomizada de Hough e a integração de seu uso com a rede neural artificial incrementaram a robustez no cálculo da fração de vazio e por conseguinte, a precisão dos resultados.

Embora raras, ocasiões como esta ocorreram na detecção de "falso-positivos" envolvendo a composição de duas ou mais sombras espessas de bolhas e sobrepostas. A composição destas sobreposições resulta em partes de imagens com valores de intensidade negativa de cinza maiores, mesmo na ocorrência das duas ou mais bolhas estarem fora da profundidade de campo na aquisição da imagem. O formato desta região com valores maiores de intensidade negativa de cinza pode coincidir com modelos de figuras analíticas elípticos ou circulares. A aplicação do operador Canny sobre elas resultaria na detecção de bordas com estas formas e, por conseguinte, detectadas como bolhas. A aplicação da transformada randomizada de Hough, mesmo com a evolução da versão modificada nesse trabalho, não seria capaz de evitar esta identificação. As figuras, ou partes delas seriam eliminadas das imagens e com seus volumes adicionados incorretamente ao do total de gases na amostra.

Algumas opções poderiam contribuir na melhoria desses resultados. A primeira delas é a identificação e aplicação de modelos diferenciados de varreduras que resultem em uma significativa redução do número de execuções da rede neural artificial sobre uma amostra da imagem do escoamento. Isto poderia ser suficiente na solução deste problema uma vez que haveria uma grande redução na detecção de "falso-positivos". Uma segunda opção é a realização de estudos mais detalhados sobre uma configuração otimizada da rede neural pela sua composição com um modelo de extração de características ou por uma minuciosa investigação sobre sua arquitetura. A terceira e última opção seria o uso de uma rede neural com funções de base radial (RBF), também indicada para reconhecimento de padrões complexos. A realização da captura de imagens do escoamento sincronizadas, sem distorções óticas devido a introdução de uma caixa para correção visual do escoamento, também é uma opção realizável, no entanto, deve-se relevar que as imagens capturadas com o uso deste recurso requer sua composição com imagens de outra vista do 
escoamento. Esta composição traria uma visão tridimensional do escoamento e poderiam minimizar o erro das estimativas da fração de vazio em escoamentos bifásicos. Estes estudos requerem um grande esforço no desenvolvimento de técnicas de composição de imagens bidimensionais, no entanto, representaria uma expectativa por resultados extremamente precisos deste importante parâmetro proporcionando mais uma grande evolução nos estudos do escoamento bifásico. 


\section{REFERÊNCIAS BIBLIOGRÁFICAS}

ATTAWAY,STORMY. MATLAB: a practical introduction to programming and problem solving.2. ed. Elsevier: Oxford, 2012

BARBOSA, P.R.; CRIVELARO,K.C.O.; SELEGHIM JR., PAULO. On the Application of Self-Organizing Neural Networks in Gas-Liquid and Gas-Solid Flow Regime Identification. In.: J. of the Braz. Soc. of Mech. Sci. \& Eng. - Vol. XXXII, March, 2010.

BARBOSA JR., JADER R.. Introdução aos escoamentos bifásicos gás-liquido. Apostila do curso ministrado na EBEM: Escola Brasileira de Escoamentos Multifásicos, UTFPR: Universidade Tecnológica Federal do Paraná - Curitiba, 2012.

BASAK, JAYANTA; PAL, SANKAR K.. Theoretical quantification of shape distortion in fuzzy Hough transform. Fuzzy Sets and Systems. N. 154, p. 227-250, 2005.

BHARDWAJ, SAKET; MITTAL, AJAY. A survey on various edge detector techniques. Procedia Technology. N.4, p. 220 - 226, 2012.

BOURE, J.A.;BERGLES, A.E.; TONG, L.S..Review of two-phase flow instability. Nuclear Engineering and Design. N. 25, pg. 165-192, 1973.

BUENO, RÉGIS CORTEZ. Deteç̧ão de contornos em imagens de padrões de escoamento bifásico com alta fração de vazio em experimentos de circulação natural com o uso de processamento inteligente. Tese (Doutorado). Instituto de Pesquisas Energéticas e Nucleares, 2016.

CHENG, H.D.; GUO, YANHUI; ZHANG, YINGTAO. A novel Hough transform based on eliminating particle swarm optimization and its applications. Pattern Recognition 42 p.1959-1969, 2009.

CLEVElAND, J.; CHOI,J. H.. Passive Safety Systems and Natural Circulation in Water Cooled Nuclear Power Plants. IAEA TECDOC-1624, Viena - 2009, ISBN 978-92-0111309-2.

CRIVELARO, K. C. O.; SELEGHIM JR., P. Detection of Horizontal Two-Phase Flow Patterns Through a Neural Network Model. Journal of the Brazilian Society of Mechanical Sciences, Rio de Janeiro, Brazil, March-2002.

DAVE, RAJESH N.; BHASWAN,KURRA. Adaptive Fuzzy c-Shells Clustering and Detection of Ellipses. IEEE transactions on neural networks, vol. 3, n.5, Setembro, 1992.

DAVIES, E. R..A high speed algorithm for circular object location. Pattern Recognition Letters 6, pp. 323-333, 1987. 
DE MESQUITA, R.N. et al., Classification of natural circulation two-phase flow patterns using fuzzy inference on image analysis. Nuclear Engineering and Design 250, p. 592$599,2012$.

ELSALAMONY, HANY A.. Healthy and unhealthy red blood cell detection in human blood smears using neural networks. Micron 83, p.32-41, 2016.

FICHERA, A.; MUSCATO, G.; XIBILIA, M. G.; PAGANO, A..Modeling Unstable Behavior of a Natural Circulation Loop with a Neural Network. IEEE-200, p. 75-80, 2000.

GONZALEZ, RAFAEL E.; WOODS, Richard E..Digital image processing. 3. ed., New Jersey: Pearson Education, 2008.

GONZALEZ, RAFAEL E.; WOODS, Richard E..Digital image processing: using MATLAB. 2. ed., Gatesmark, 2009.

GOUDARZI, N.; TALEBI, S.. Improving performance of two-phase natural circulation loops by reducing of entropy generation. Energy 93 p. 882-899, 2015.

GUIAASIAN, S.M..Two-phase flow, boiling and condensation in conventional and miniature systems. Cambridge University, 2007.

HAN, JOON H.; KÓCZY,LÁSZLÓ T.; POSTON, TIMOTHY. Fuzzy Hough transform. Pattern Recognition Letters, 15, p. 649 - 658, July 1994.

HAYKIN, SIMON. Redes Neurais: princípios e prática. trad. Paulo Martins Engel, 2. ed., Porto Alegre: Bookman, 2001.

INVERSO, SAMUEL. Ellipse detection using randomized Hough transform. Technical Report, Department of Computer Science, Rochester Institute of Technology, New York, 2002.

JAIN, ANIL K.; MAO, JIANCHANG; MOHIUDDIN, K. M.. Artificial Neural Networks: A Tutorial. Computer, IEEE, 1996.

JAN, FARMANULLAH; USMAN, IMRAN; AGHA,SHAHRUKH. Reliable iris localization using Hough transform, histogram-bisection and eccentricity. Signal Processing 93 p. 230-241, 2013.

KROTKOV, ERIC. Focusing. International Journal of Computer Vision, 1 p. 223 - 237, 1987.

KUDARIYAWAR, JAYARAJ YALLAPPA; VAIDYA, ABHIJEET MOHAN; MAHESHWARI, NARESH KUMAR; SATYAMURTHY, POLEPALLE. Computational study of instabilities in a retangular natural circulation loopusing 3D CFD simulation.

International Journal of Thermal Sciences 101 p. 193 - 206, 2016.

KUMAR, MUKESH; PAL, ESHITA; NAYAK, ARUN K.; VIJAYAN, PALLIPATTU K.. Conceptual design of a passive moderator cooling system for a pressure tube type natural 
circulation boiling water cooled reactor. In.: Nuclear Engineering and Design 219, p. $261-270,2015$.

LENT, CRAIG S..Learning to program with MATLAB: building GUI tools.New Jersey: John Wiley \& Sons, 2013.

MASOTTI, PAULO HENRIQUE FERRAZ; MESQUITA, ROBERTO NAVARRO. Paraconsistent logic study of image focus in cylindrical refraction experiments. In.:

Paraconsistent Intelligent-Based Systems. 1. ed., p. 175-205, 2015.

MCLAUGHLIN, ROBERT A.. Randomized Rough Transform: Improved ellipse detection with comparison. Pattern Recognition Letters, 19 p. 299-305, 1998.

MCLAUGHLIN, ROBERT A..Intelligent algorithms for finding curves and surfaces in real world data. PhD Thesis. Department of Electrical and Electronic Engineering University of Western Australia. Crawlei, Australia, 2000.

MEHTA, AXAY; MEHTA, HEMA A.; MANJUNATH, T.C.; ARDIL, C.. A Multi-Layer Artificial Neural Network Architecture Design for Load Forecasting in Power System. In.: International Journal of Applied Mathematics and Computer Sciences. n 4 - v 4, 2006.

MENDEL, JERRY M..Fuzzy logic systems for engineering: a tutorial. In.: Proceedings of IEEE v. 83 n. 3, Março, 1995.

MESQUITA, R.N. et al.. Two-Phase Flow Patterns Recognition and Parameter Estimation through Natural Circulation Test Loop Image Analysis. Proc. 7th ECI International Conference on Boiling Heat Transfer (ICBHT 2009), Florianópolis-SCBrazil, 3-7 May, p.541-546, ISBN: 978-1-61567-794-8 2009.

MICHÉ,P.; DEBRIE, R.. Fast and self-adaptive image segmentation using extended declivity. Ann. Télécommun., 50, n.3-4, p. 401-410, 1995.

MUCKHOPADHYAY, PRIYANKA; CHAUDHURI, BIDYUT B.. A survey of Hough transform. Pattern Recognition 48, p. 993-1010, 2015.

NAYAK, A.K. et al. Study on the stability behavior of two-phase natural circulation systems using a four-equation drift flux model. Nuclear Engineering and Design, 237, p.386-398, 2007.

NIXON, MARK. Improving an extended version of the Hough transform. Signal Processing 19, p. 321-335, Elsevier, 1990.

NG, ANDREW. Machine Learning. Curso a distância ministrado no período de Setembro a Novembro de 2011. disponível em <https://www.coursera.org/ \#course/ml>, Stanford University, 2011.

RICCA, GIORGIO; BELTRAMETTI, MAURO C.; MASSONE, ANNA MARIA. Detecting curves of symmetry in images via Hough transform. Mathematics in Computer Science 10, p. 179-205. Março, 2016. 
ROCHA, MARCELO DA SILVA. Projeto, construção e análise de um sensor de impedância de múltiplos eletrodos aplicado à medição da fração de vazio em escoamentos bifásicos do tipo gás-líquido. Tese (Doutorado), Escola Politécnica da Universidade de São Paulo, 2005.

ROTHMAN, PAULA. Angra pode virar uma nova Fukushima ou Chernobyl ? Disponível em: <http://exame.abril.com.br/tecnologia/angra-pode-virar-uma-novafukushima-ou-chernobyl/>. Acesso em: 27 de Dezembro de 2016.

RUSPINI, LEONARDO CARLOS; MARCEL, CHRISTIAN PABLO; CLAUSSE, ALEJANDRO. Two-phase flow instabilities: A review. International Journal of Heat and Mass Transfer. N. 71, pg. 521 - 548, 2014.

SAITO,Y.; SEKIMOTO, S.; HINO, M.; KAWABATA, Y.. Development of neutron radiography facility for boiling two-phase flow experiment in Kyoto University Research Reactor. Nuclear Instruments and Methods in Physics Research. 651, p. 36-41, 2011.

SCHLEGEL,J.P.; SAWANT,P.; PARANJAPE,S.;OZAR,B.; HIBIKI,T.; ISHII,M.. Void fraction and flow regime in adiabatic upward two-phase flow in large diameter vertical pipes. Nuclear Engineering and Design. 239, p. 2864-2874, 2009.

SMITH,T.R.;SCHLEGEL,J.P.;HIBIKI,T.;ISHII,M..Two-phase flow structure in large diameter pipes. International Journal of Heat and Fluid Flow. 33, p. 156-167, 2012.

STROKINA, NATALIYA; MATAS, JIRI; EEROLA, TUOMAS; LENSU, LASSE; HEIKKI KÄLVIÄINEN. Detection of bubbles as concentric circular arrangements. Machine Vision and Application 27, p. 387-396. Fevereiro, 2016.

SUNDE, CARL; AVDIC, SENADA; PÁZSIT, Imre. Classification on Two-Phase Flow Regimes Via Image Analysis and a Neuro-Wavelet Aproach. Progress in Nuclear Energy. Grã Bretanha, v.46, n. 3-4, p. 348-358, 2005.

SURAL, SHAMIK; DAS, P. K.. Fuzzy Hought transform and MLP with fuzzy input/output for character recognition. Fuzzy Sets and Systems, 105, p. 489 - 497, 1999.

TENG, ZHU; KIM, JEONG-HYUN; KANG, DONG-JOONG. Ellipse detection: a simple and precise method based on randomized Hough transform. Optical Engineering. Vol. 51(5), Maio de 2012.

TERREMOTO, LUÍS ANTÔNIO ALBIAC.Reatores nucleares de potência. Slides de aula proferida no curso de Fundamentos de Tecnologia Nuclear - Reatores. Instituto de Pesquisas Energéticas e Nucleares, São Paulo, 2012.

TSUJI, SABURO; MATSUMOTO,FUMIO. Detection of ellipses by a modified Hough transform. IEEE trans. Computer C-27(8), pp. 777-781, 1978.

UCHIMURA, KEIICHI; HARVEL, GLENN D.; MATSUMOTO, TAKAAKI;

MASAYUKI, KANZAKI; CHANG, JEN-SHIH. An image processing approach for two- 
phase interfaces visualized by a real time neutron radiography technique. Flow Measurement and Instrumentation 9, p. 203-210, 1998.

WANG, HONGYI; DONG, FENG. Image Features Extraction of Gas/liquid Two-Phase Flow in Horizontal Pipeline by GLCM and GLGCM. In: THE NINETH INTERNATIONAL CONFERENCE ON ELETRONIC MEASUREMENT \& INSTRUMENT-ICEMI' 2009, v.2, p.135-139. ISBN.: 978-1-4244-3864-8 IEEE-2009.

WENYIN, ZHANG; NINGDE, JIN; XIA, LIN; ZHIQIANG, NIE. Bubble image segmentation of gas/liquid two-phase flow based on improved Canny operator. Proceedings of International Conference on Computer Science and Software Engineering, IEEE, 2008.

WHALLEY, P.B..Two-Phase Flow and Heat Transfer. Oxford University, New York, 1996.

WOLDESEMAYAT, MELKAMU A.; GHAJAR, AFSHIN J. Comparison of void fraction correlations for different flow patterns in horizontal and upward inclined pipes.

International Journal of Multiphase Flow, v. 33, p. 347-370, 2007.

WOLINSKI, ALAN EDUARDO. Fissão ou fusão nuclear? Qual a diferença?.

Disponível em: <http://parquedaciencia.blogspot.com.br/2013/09/fissao-ou-fusao-nuclearqual-diferenca.html>. Acesso em: $27 \mathrm{dez} 2016$.

XU,LEI; OJA, ERKKI; KULTANEN, PEKKA. A new curve detection method:

Randomized Hough Transform (RHT). Pattern Recognition Letters 11, p. 331-338, North-Holland, 1990.

XU,LEI; OJA, ERKKI. Randomized Hough Transform (RHT): basic mechanisms, algorithms, and computational complexities. CGVIP: Image Understanding v. 57, n. 2, p. 131-154, 1993.

YIP, RAYMOND K. K.; TAM, PETER K. S. e LEUNG, DENNIS N. K.. Modification of Hough transform for circles and ellipses detection using a 2-dimensional array. Pattern Recognition, v. 25 n. 9 p. 1007-1022, Grã-Bretanha:1992.

YOO, JAE HUNG; SETHI, ISHWAR K.. An ellipse detection method from the polar and pole definition of conics. Pattern Recognition v. 26 n.2 p. 307-315. Great Britain, 1993.

YU, HAIBIN; LIU, JINGBIAO; HE ZHIWEI. A Modified RHT Method for Ellipse Detection Based on Geometric Constraints and Perceptual Grouping. In.: The 3rd International Conference on Innovative Computing Information and Control - ICICIC'08, IEEE, 2008.

YUEN, H. K.; ILLINWORTH, J.; KITTLER, J.. Detecting partially occluded ellipses using the Hough transform. Image and vision computing v. 7, n.1 p. 31-36, Fevereiro, 1989. 
ZHANG, JIAN; SHEN, XIUZHONG; FUJIHARA, YASUYUKI; SANO, TADAFUMI; YAMAMOTO, TOSHIHIRO; NAKAJIMA, KEN. Experimental study on the safety of Kyoto University Research Reactor at natural circulation cooling mode. Annals of Nuclear Energy, 76, p. 410-420, 2015.

ZHANG, WEN-HUI; JIANG, XIAOYA; LIU, YIN-MINGZI. A method for recognizing overlapping elliptical bubbles in bubble image. Pattern Recognition Letter 33, p. 1543-1548, 2012. 


\section{APÊNDICE A -Base de dados de imagens digitais do escoamento bifásico}

Foram considerados dois experimentos nos cálculos para estimativa da fração de vazio. A bancada de calibração da fração de vazio empregada na realização desses experimentos eram similares, porém, pequenas diferenças existiam entre elas. $\mathrm{O}$ fator que mais interferiu nestes diferentes experimentos foi a variação na iluminação de fundo, requerendo novas análises para obtenção dos parâmetros empregados no Sistema de Inferência Focal Fuzzy. Além da aplicação dessas imagens nos cálculos e calibração das aplicações para cálculo da estimativa da fração de vazio, as imagens organizadas e apresentadas nas tabelas, prestaram-se à realização das análises dos parâmetros relacionados ao perfil das bordas das bolhas empregados no Sistema de Inferência Focal Fuzzy.

As imagens dos experimentos foram organizadas e separadas conforme descrição:

- Experimento realizado em 24/10/2013: Imagens e arquivos correspondentes estão organizados nas tabelas $1 \mathrm{~A}$ a $5 \mathrm{~A}$ e

- Experimento realizado em 10/05/2017: Imagens e arquivos correspondentes estão organizados na tabela $6 \mathrm{~A}$.

TABELA 1A - Imagens digitais do escoamento bifásico - 24/10/2013

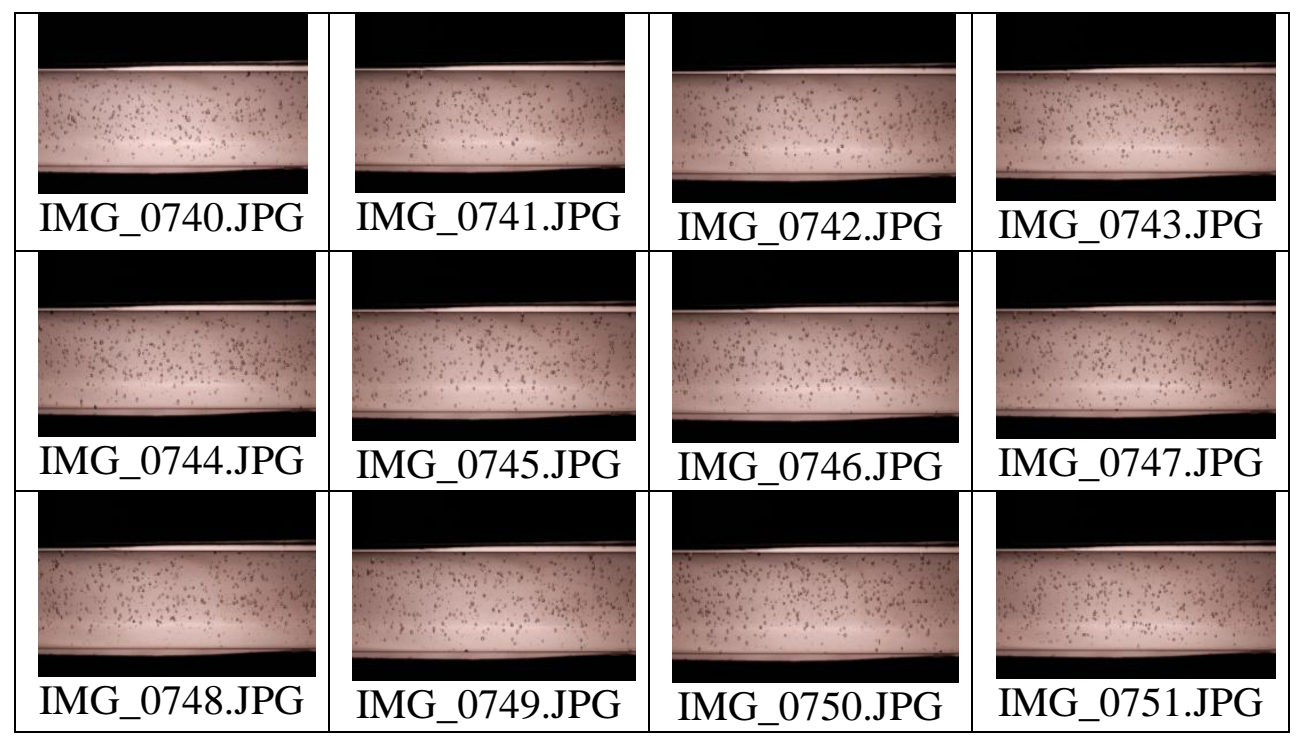


TABELA 2A - Imagens digitais do escoamento bifásico - 24/10/2013 (Continuação)

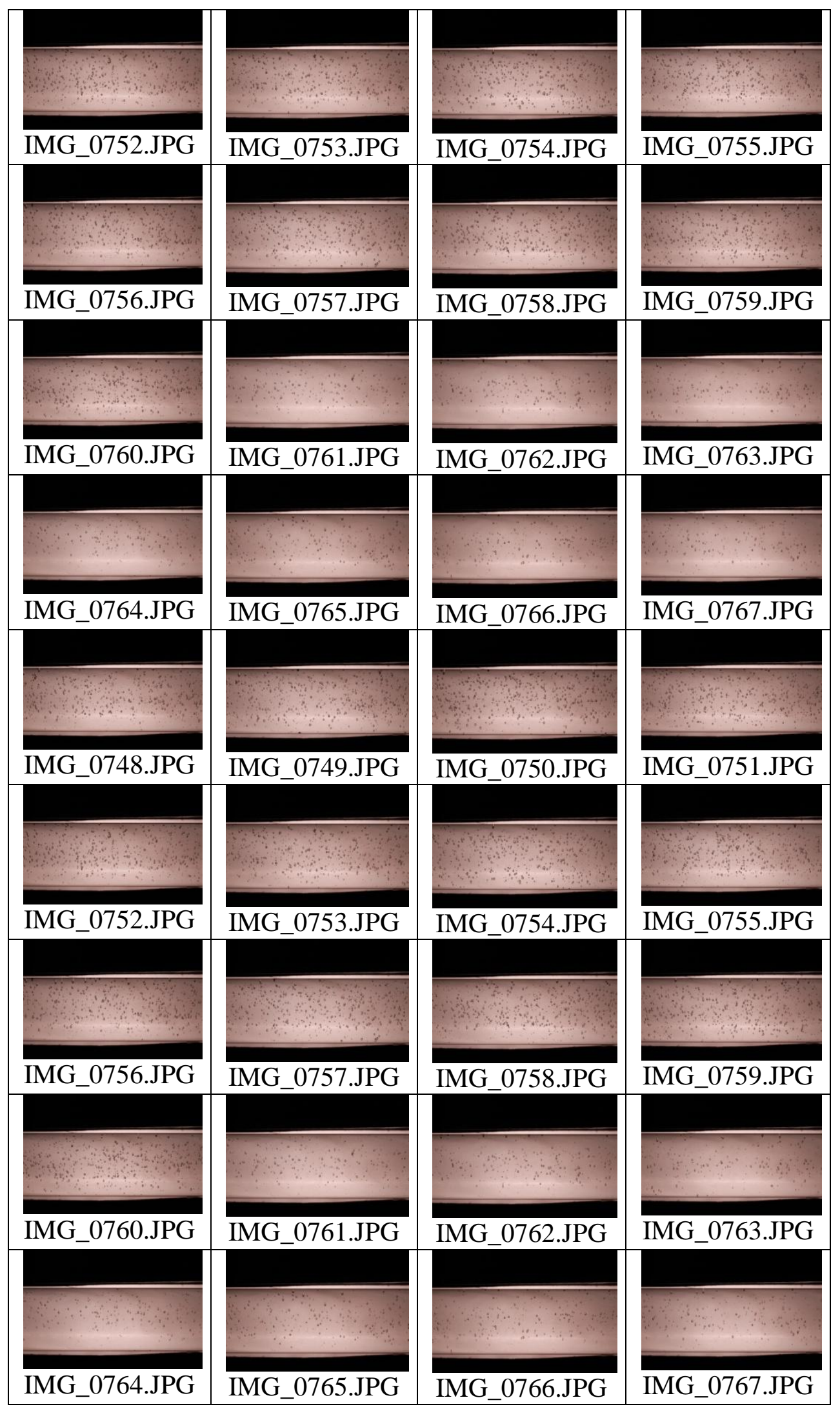


TABELA 3A - Imagens digitais do escoamento bifásico - 24/10/2013 (Continuação)

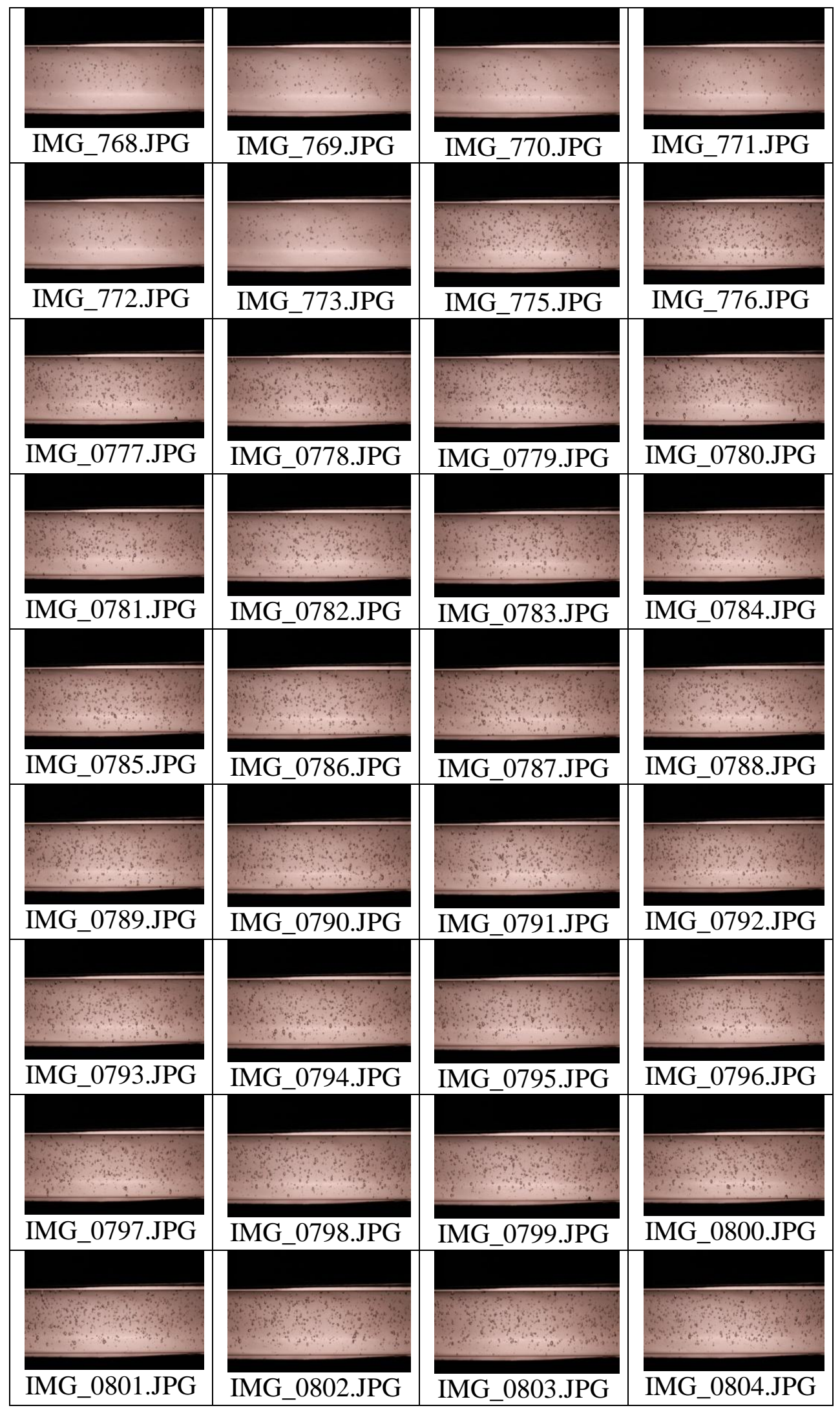


TABELA 4A - Imagens digitais do escoamento bifásico - 24/10/2013 (Continuação)

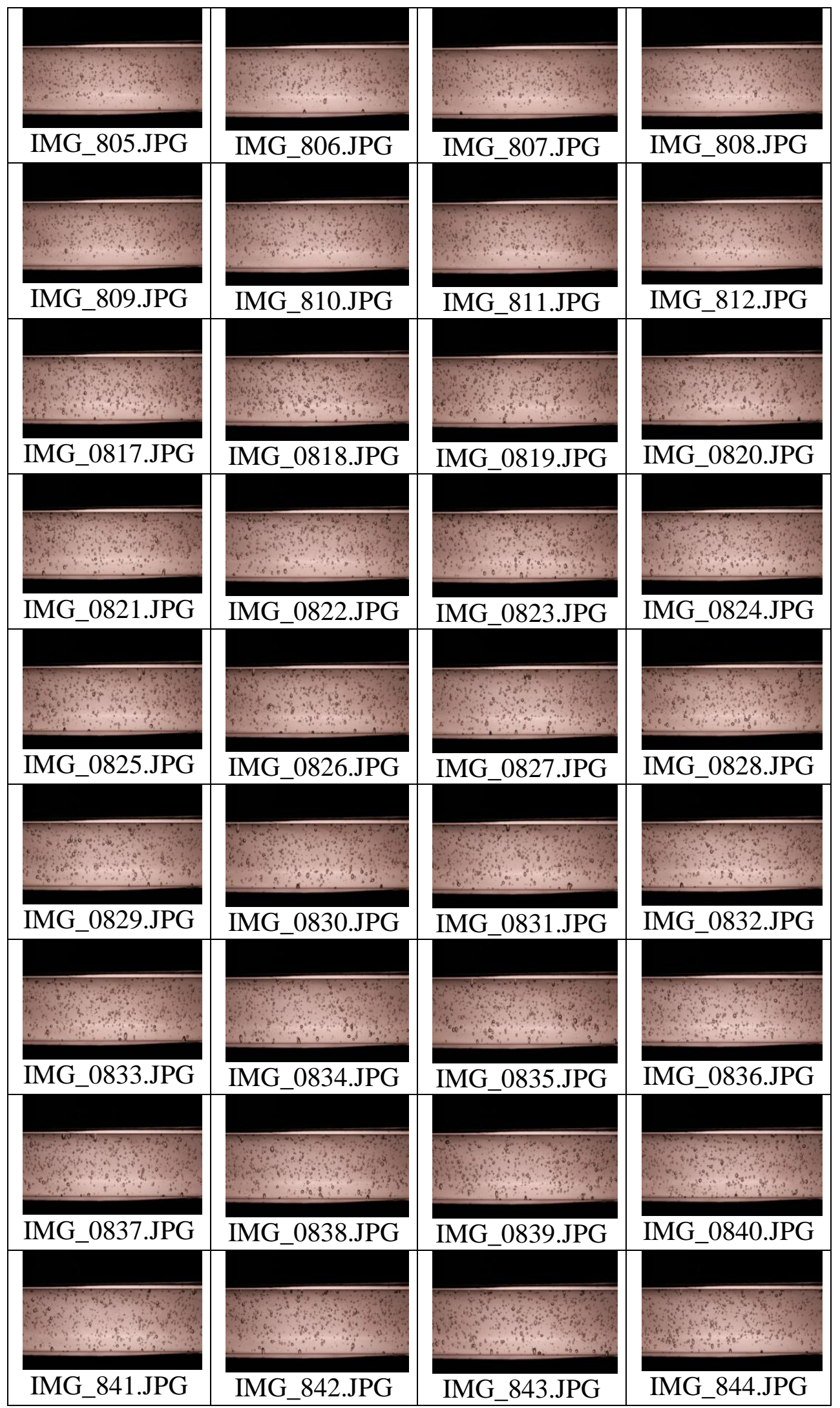


TABELA 5A - Imagens digitais do escoamento bifásico - 24/10/2013 (Continuação)

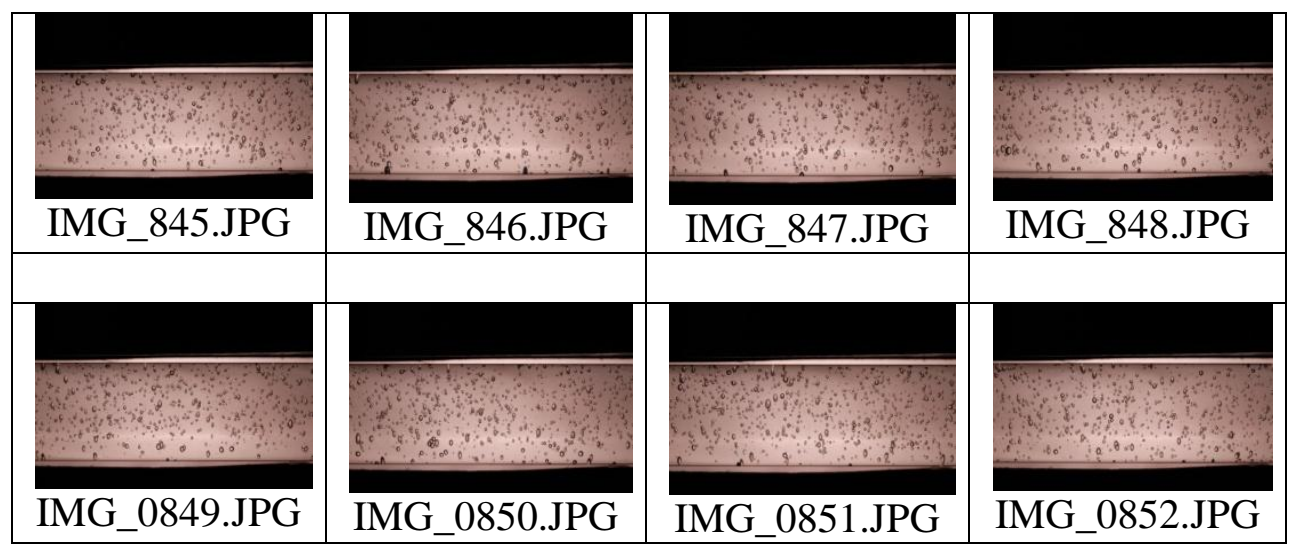

TABELA 6A - Imagens digitais do escoamento bifásico - 10/05/2017

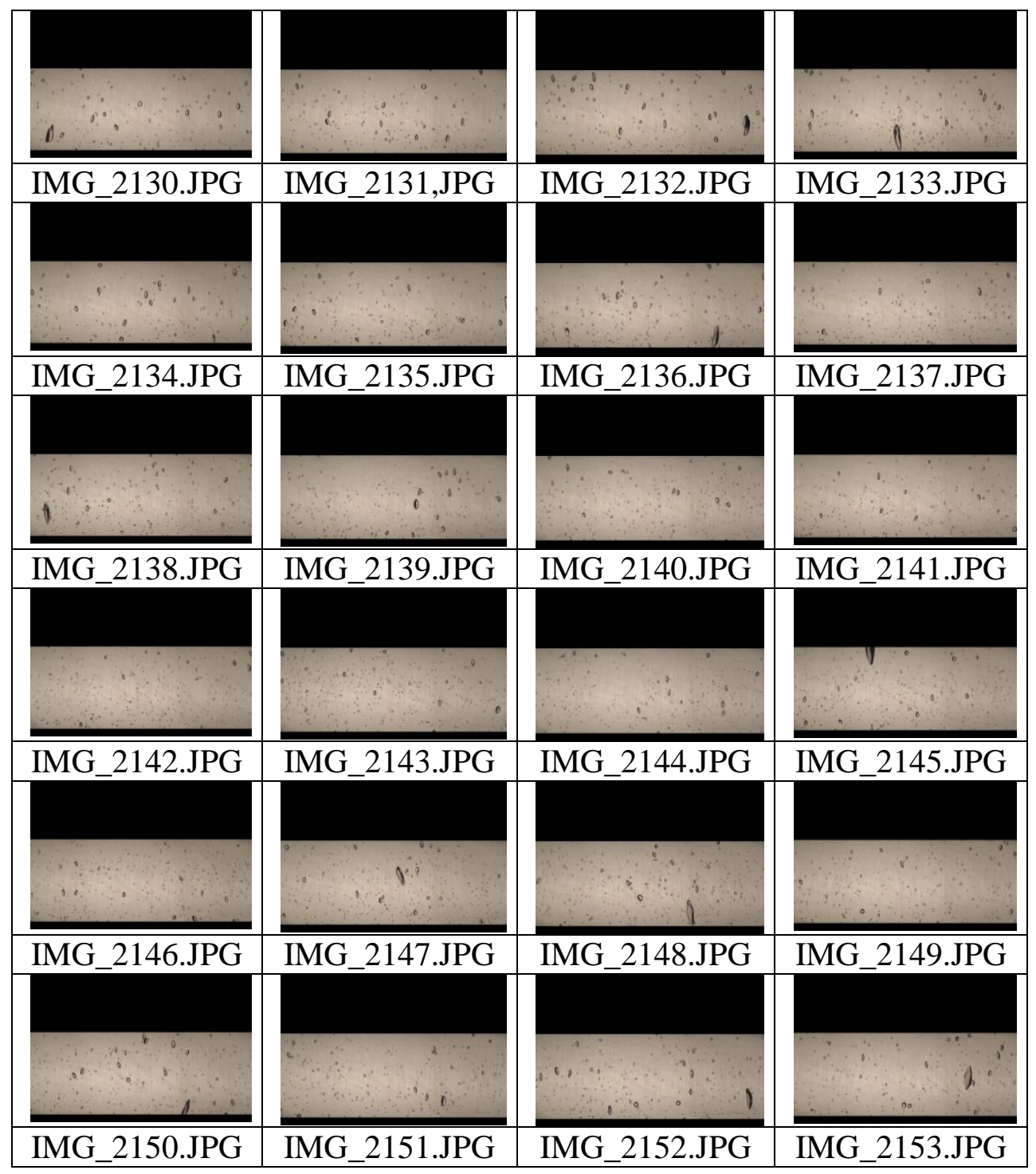




\section{APÊNDICE B - ANÁLISE ESTATÍSTICA DOS PERFÍS DE BORDAS}

A definição dos valores empregados na construção das funções de pertinência do sistema de inferência focal fuzzy foram baseadas em análises sobre as variáveis indicadas por KROTKOV (1987) para composição de uma relação entre a qualidade da imagem e a profundidade de campo. Parâmetros de segmentação de imagens como a intensidade de cinza, o Laplaciano e Sobel sobre uma imagem são fatores chaves para estabelecer uma relação entre os pixels da imagem posicionados dentro de uma região limitada pela profundidade de campo em que a imagem foi capturada . As análises foram divididas em dados coletados experimentalmente e tratam de um levantamento estatístico sobre quatro perfis de bordas de bolhas consideradas em foco e fora de foco. No experimento de 24/10/2013 foram coletadas bordas de 48 bolhas consideradas "em foco" e, portanto, dentro da profundidade de campo estabelecida na aquisição da imagem e bolhas "fora de foco" que são consideradas em posições além deste limite de profundidade. $\mathrm{O}$ resultado do levantamento dos 192 perfís de bordas foram organizados em tabelas para cálculo da média e do desvio padrão global de cada parâmetro.

A tabela 1B representa a compilação de todos os parâmetros extraídos das quatro bordas de cada uma das 48 bolhas selecionadas para análise. Ela está dividida em 24 "bolhas em foco" e 24 "bolhas fora de foco". As bolhas consideradas em foco são aquelas dentro dos limites da profundidade de campo em que as imagens do escoamento bifásico foram capturadas. Caso contrário a bolha será considerada fora de foco. Para cada bolha analisada, foi calculada a variação dos parâmetros considerados no modelo de inferência focal fuzzy em função do perfil médio de cada uma das suas bordas, ou seja, da borda superior, direita esquerda e inferior. Estes valores foram compilados e estão expostos na tabela que ao final apresenta o cálculo da média global de cada um dos parâmetros combinados, ou seja:

- Laplaciano adicionado à intensidade negativa de cinza: Lap+(1-I);

- Sobel adicionado à intensidade negativa de cinza: Sob+(1-I) e

- Intensidade de cinza. 
TABELA 1B - Análise estatística das bordas das bolhas - experimento de 23/10/2013

\begin{tabular}{|c|c|c|c|c|c|}
\hline \multicolumn{3}{|c|}{ IMAGENS COM BORDAS EM FOCO } & \multicolumn{3}{|c|}{ IMAGENS COM BORDAS FORA DE FOCO } \\
\hline Lap+(1-I) & Sob+(1-I) & $\mathbf{I}$ & Lap+(1-I) & Sob+(1-I) & $\mathbf{I}$ \\
\hline 0,44940 & 0,66206 & 0,44215 & 0.41477 & 0,34296 & 0,48912 \\
\hline 0,58371 & 0,50716 & 0,28710 & 0,47595 & 0,38676 & 0,42204 \\
\hline 0,51388 & 0,52645 & 0,40625 & 0,45017 & 0,35326 & 0,45044 \\
\hline 0,63290 & 0,59634 & 0,24722 & 0,30459 & 0,16071 & 0,61591 \\
\hline 0,60552 & 0,42128 & 0,36195 & 0,49564 & 0,29611 & 0,47191 \\
\hline 0,59090 & 0,48681 & 0,37021 & 0,43161 & 0,21699 & 0,54634 \\
\hline 0,63367 & 0,59548 & 0,37843 & 0,50148 & 0,34770 & 0,49615 \\
\hline 0,55528 & 0,53801 & 0,46897 & 0,47228 & 0,25100 & 0,52686 \\
\hline 0,57327 & 0,59907 & 0,36466 & 0,57748 & 0,56925 & 0,39056 \\
\hline 0,60020 & 0,58138 & 0,34579 & 0,51852 & 0,48353 & 0,43389 \\
\hline 0,63383 & 0,50588 & 0,23236 & 0,38786 & 0,23573 & 0,54898 \\
\hline 0,66974 & 0,52322 & 0,21200 & 0,42450 & 0,26026 & 0,50596 \\
\hline 0,59516 & 0,50372 & 0,36018 & 0,47553 & 0,33022 & 0,46409 \\
\hline 0,68490 & 0,57080 & 0,25764 & 0,52747 & 0,46301 & 0,43332 \\
\hline 0,64677 & 0,57889 & 0,31040 & 0,49100 & 0,43106 & 0,44882 \\
\hline 0,49191 & 0,39104 & 0,48768 & 0,54310 & 0,43536 & 0,42472 \\
\hline 0,53489 & 0,45883 & 0,41933 & 0,45530 & 0,33872 & 0,50189 \\
\hline 0,59810 & 0,67598 & 0,40595 & 0,39429 & 0,23078 & 0,55211 \\
\hline 0,61164 & 0,45435 & 0,31799 & 0,45585 & 0,43525 & 0,50701 \\
\hline 0,76576 & 0,55738 & 0,15858 & 0,53172 & 0,40645 & 0,42428 \\
\hline 0,66677 & 0,48226 & 0,28229 & 0,47283 & 0,30336 & 0,51436 \\
\hline 0,67846 & 0,56656 & 0,27231 & 0,60865 & 0,39535 & 0,35454 \\
\hline 0,89482 & 0,59841 & 0,15562 & 0,73818 & 0,39519 & 0,40744 \\
\hline 0,80556 & 0,52775 & 0,29965 & 0,74577 & 0,43740 & 0,38043 \\
\hline 0,57929 & 0,62693 & 0,36371 & 0,40658 & 0,32922 & 0,50110 \\
\hline 0,51719 & 0,48235 & 0,35765 & 0,47830 & 0,35278 & 0,40454 \\
\hline 0,51534 & 0,51343 & 0,40344 & 0,44134 & 0,33868 & 0,45312 \\
\hline 0,65392 & 0,61002 & 0,24137 & 0,34758 & 0,22341 & 0,59457 \\
\hline 0,59625 & 0,41288 & 0,36955 & 0,51535 & 0,30272 & 0,45118 \\
\hline 0,67123 & 0,42972 & 0,27143 & 0,44181 & 0,22770 & 0,53161 \\
\hline 0,61529 & 0,52943 & 0,39684 & 0,05108 & 0,34448 & 0,47999 \\
\hline 0,59283 & 0,56558 & 0,44574 & 0,43950 & 0,27883 & 0,56258 \\
\hline 0,60965 & 0,59086 & 0,33047 & 0,57674 & 0,49583 & 0,39088 \\
\hline 0,62238 & 0,63004 & 0,33551 & 0,48044 & 0,45885 & 0,46869 \\
\hline 0,63444 & 0,47433 & 0,24361 & 0,40369 & 0,23506 & 0,53305 \\
\hline 0,66680 & 0,52564 & 0,20894 & 0,36484 & 0,20583 & 0,57230 \\
\hline 0,59377 & 0,49534 & 0,35395 & 0,53065 & 0,33512 & 0,42305 \\
\hline 0,67341 & 0,63248 & 0,29416 & 0,52550 & 0,42654 & 0,44724 \\
\hline 0,61978 & 0,60426 & 0,33920 & 0,53526 & 0,36985 & 0,41266 \\
\hline 0,59166 & 0,46652 & 0,36246 & 0,50521 & 0,40195 & 0,45003 \\
\hline 0,53883 & 0,46725 & 0,40724 & 0,48760 & 0,36940 & 0,45398 \\
\hline 0,67634 & 0,60791 & 0,33574 & 0,41513 & 0,23252 & 0,53552 \\
\hline 0,71273 & 0,54024 & 0,20432 & 0,50183 & 0,40684 & 0,47406 \\
\hline 0,71412 & 0,56439 & 0,20693 & 0,59277 & 0,43796 & 0,36117 \\
\hline 0,70268 & 0,50909 & 0,25329 & 0,52726 & 0,33653 & 0,44756 \\
\hline 0,72333 & 0,56736 & 0,22129 & 0,64609 & 0,41711 & 0,30647 \\
\hline 0,89756 & 0,59163 & 0,15873 & 0,71458 & 0,38528 & 0,42252 \\
\hline 0,80073 & 0,49247 & 0,29746 & 0,73384 & 0,41521 & 0,39634 \\
\hline 0,38129 & 0,52124 & 0,38129 & 0,39749 & 0,32234 & 0,48643 \\
\hline 0,36968 & 0,45423 & 0,36968 & 0,47881 & 0,36931 & 0,39721 \\
\hline 0,30040 & 0,47767 & 0,30040 & 0,42645 & 0,34838 & 0,46364 \\
\hline 0,30405 & 0,52103 & 0,30405 & 0,31819 & 0,17213 & 0,56422 \\
\hline 0,40693 & 0,36005 & 0,40693 & 0,51820 & 0,33372 & 0,44321 \\
\hline 0,33778 & 0,44644 & 0,33778 & 0,46737 & 0,24337 & 0,50292 \\
\hline 0,41942 & 0,53502 & 0,41942 & 0,48319 & 0,34296 & 0,50010 \\
\hline 0,49590 & 0,45771 & 0,49590 & 0,47893 & 0,27251 & 0,50212 \\
\hline 0,33797 & 0,54053 & 0,33797 & 0,55927 & 0,47272 & 0,38127 \\
\hline 0,39598 & 0,50987 & 0,39598 & 0,56766 & 0,47169 & 0,37530 \\
\hline 0,27294 & 0,45595 & 0,27294 & 0,40940 & 0,25651 & 0,51845 \\
\hline 0,22649 & 0,48494 & 0,22649 & 0,42350 & 0,25449 & 0,50528 \\
\hline 0,43818 & 0,43617 & 0,43818 & 0,52246 & 0,34308 & 0,42859 \\
\hline
\end{tabular}




\begin{tabular}{|c|c|c|c|c|c|c|}
\hline & \multicolumn{6}{|c|}{ TABELA $1 \mathrm{~A}$ - Análise estatística das bordas das bolhas - Continuação } \\
\hline & \multicolumn{3}{|c|}{ IMAGENS COM BORDAS EM FOCO } & \multicolumn{3}{|c|}{ IMAGENS COM BORDAS FORA DE FOCO } \\
\hline & Lap+(1-I) & Sob+(1-I) & $\mathrm{I}$ & Lap+(1-I) & Sob+(1-I) & $\mathbf{I}$ \\
\hline & 0,30665 & 0,51574 & 0,30665 & 0,47391 & 0,38962 & 0,47161 \\
\hline & 0,39590 & 0,47429 & 0,39590 & 0,45641 & 0,36632 & 0,46621 \\
\hline & 0,42747 & 0,47797 & 0,42747 & 0,48581 & 0,41230 & 0,44992 \\
\hline & 0,46908 & 0,41237 & 0,46908 & 0,43217 & 0,33180 & 0,50499 \\
\hline & 0,46664 & 0,50105 & 0,46664 & 0,39801 & 0,21457 & 0,56142 \\
\hline & 0,49154 & 0,38235 & 0,49154 & 0,44264 & 0,36451 & 0,50303 \\
\hline & 0,21459 & 0,54831 & 0,21459 & 0,49076 & 0,40236 & 0,43940 \\
\hline & 0,30465 & 0,49073 & 0,30465 & 0,49832 & 0,31190 & 0,47534 \\
\hline & 0,27771 & 0,51177 & 0,27771 & 0,58766 & 0,39888 & 0,36491 \\
\hline & 0,23745 & 0,55634 & 0,23745 & 0,74582 & 0,42378 & 0,37411 \\
\hline & 0,27153 & 0,48935 & 0,27153 & 0,73859 & 0,42216 & 0,39632 \\
\hline & 0,43246 & 0,52054 & 0,45620 & 0,33640 & 0,24395 & 0,55514 \\
\hline & 0,48833 & 0,45296 & 0,40988 & 0,41368 & 0,29063 & 0,48910 \\
\hline & 0,41819 & 0,52325 & 0,39067 & 0,36783 & 0,28374 & 0,54007 \\
\hline & 0,52479 & 0,61460 & 0,34905 & 0,33053 & 0,19389 & 0,59425 \\
\hline & 0,50987 & 0,36059 & 0,44717 & 0,43913 & 0,22163 & 0,53708 \\
\hline & 0,55292 & 0,45895 & 0,39865 & 0,38599 & 0,15967 & 0,59672 \\
\hline & 0,52300 & 0,60545 & 0,46539 & 0,45481 & 0,26494 & 0,55024 \\
\hline & 0,45969 & 0,48988 & 0,53611 & 0,43216 & 0,19763 & 0,57311 \\
\hline & 0,54085 & 0,58486 & 0,39550 & 0,44640 & 0,41313 & 0,50384 \\
\hline & 0,54297 & 0,63193 & 0,40870 & 0,41787 & 0,38579 & 0,52963 \\
\hline & 0,54780 & 0,46309 & 0,33060 & 0,36243 & 0,18592 & 0,58256 \\
\hline & 0,57542 & 0,52020 & 0,31211 & 0,36150 & 0,17722 & 0,58761 \\
\hline & 0,47886 & 0,49197 & 0,46390 & 0,40038 & 0,23836 & 0,54785 \\
\hline & 0,58764 & 0,57705 & 0,34518 & 0,45220 & 0,38326 & 0,50522 \\
\hline & 0,50938 & 0,57623 & 0,42707 & 0,41395 & 0,32410 & 0,51954 \\
\hline & 0,42501 & 0,56118 & 0,49283 & 0,42739 & 0,34047 & 0,52858 \\
\hline & 0,46130 & 0,49105 & 0,48373 & 0,40271 & 0,29554 & 0,55025 \\
\hline & 0,44713 & 0,68968 & 0,47528 & 0,36593 & 0,17110 & 0,59692 \\
\hline & 0,63874 & 0,54312 & 0,28403 & 0,44034 & 0,38780 & 0,50468 \\
\hline & 0,69244 & 0,55537 & 0,23509 & 0,45214 & 0,35900 & 0,50640 \\
\hline & 0,64901 & 0,49377 & 0,29241 & 0,42939 & 0,19551 & 0,57940 \\
\hline & 0,60895 & 0,57510 & 0,34191 & 0,50556 & 0,34306 & 0,46431 \\
\hline & 0,85031 & 0,63499 & $\begin{array}{l}0,22340 \\
\end{array}$ & 0,65911 & 0,32672 & 0,50715 \\
\hline & 0,76721 & 0,51103 & 0,34924 & 0,69089 & 0,36371 & 0,46420 \\
\hline Média & 0,54200 & 0,51959 & 0,34155 & 0,47401 & 0,32934 & 0,47826 \\
\hline$\sigma$ & 0,15200 & 0,08169 & 0,09112 & 0,11266 & 0,09091 & 0,07760 \\
\hline$\mu+\sigma$ & 0,69400 & 0,60128 & 0,43267 & 0,58667 & 0,42025 & 0,55586 \\
\hline$\mu-\sigma$ & 0,39000 & 0,43790 & 0,25043 & 0,36135 & 0,23844 & 0,40067 \\
\hline
\end{tabular}

As análises sobre o experimento de 10/05/2017 foram realizadas sobre um número inferior de bolhas. Nela foram consideradas 14 bolhas em foco e 14 fora de foco, totalizando 112 perfís de bordas (56 em foco e 56 fora de foco).

A tabela 2B representa a compilação de todos os parâmetros extraídos das quatro bordas de cada uma das 28 bolhas selecionadas para análise. Ela está dividida em 14 "bolhas em foco" e 14 "bolhas fora de foco". As bolhas consideradas em foco são aquelas dentro dos limites da profundidade de campo em que as imagens do escoamento bifásico foram capturadas. Caso contrário a bolha será considerada fora de foco. Para cada bolha analisada, foi calculada a variação dos parâmetros considerados no modelo de inferência focal fuzzy em função do perfil médio de cada uma das suas bordas, ou seja, da borda superior, direita esquerda e inferior. Estes valores foram compilados e estão expostos na 
tabela que ao final apresenta o cálculo da média global de cada um dos parâmetros combinados, ou seja:

- Laplaciano adicionado à intensidade negativa de cinza: Lap+(1-I);

- Sobel adicionado à intensidade negativa de cinza: Sob+(1-I) e

- Intensidade de cinza.

TABELA 2B - Análise estatística das bordas das bolhas - experimento de 10/05/2017

\begin{tabular}{|c|c|c|c|c|c|}
\hline \multicolumn{3}{|c|}{ IMAGENS COM BORDAS EM FOCO } & \multicolumn{3}{|c|}{ IMAGENS COM BORDAS FORA DE FOCO } \\
\hline Lap+(1-I) & Sob+(1-I) & $\mathbf{I}$ & Lap+(1-I) & Sob+(1-I) & $\mathbf{I}$ \\
\hline 0,4657 & 0,3136 & 0,6877 & 0,4883 & 0,2080 & 0,7765 \\
\hline 0,4598 & 0,3191 & 0,6958 & 0,4984 & 0,2515 & 0,7633 \\
\hline 0,5311 & 0,4946 & 0,5884 & 0,5022 & 0,2931 & 0,7528 \\
\hline 0,3428 & 0,1067 & 0,8410 & 0,4933 & 0,2346 & 0,7734 \\
\hline 0,5045 & 0,4134 & 0,6609 & 0,4046 & 0,2831 & 0,7298 \\
\hline 0,4669 & 0,4652 & 0,6973 & 0,3588 & 0,2547 & 0,7816 \\
\hline 0,4981 & 0,5359 & 0,6350 & 0,4598 & 0,4843 & 0,6728 \\
\hline 0,4812 & 0,3584 & 0,6873 & 0,3784 & 0,3053 & 0,7568 \\
\hline 0,5096 & 0,4098 & 0,4770 & 0,3975 & 0,2675 & 0,7380 \\
\hline 0,4385 & 0,4515 & 0,5726 & 0,5067 & 0,3664 & 0,7085 \\
\hline 0,5635 & 0,5411 & 0,4211 & 0,4423 & 0,5345 & 0,6743 \\
\hline 0,4549 & 0,4056 & 0,5191 & 0,3897 & 0,2378 & 0,7595 \\
\hline 0,7468 & 0,5412 & 0,3482 & 0,3594 & 0,2494 & 0,7686 \\
\hline 0,7134 & 0,5201 & 0,3884 & 0,3665 & 0,2326 & 0,7559 \\
\hline 0,7512 & 0,5467 & 0,3385 & 0,4043 & 0,3390 & 0,7217 \\
\hline 0,7771 & 0,5044 & 0,3070 & 0,4019 & 0,2283 & 0,7147 \\
\hline 0,7730 & 0,5923 & 0,3485 & 0,6926 & 0,3530 & 0,4472 \\
\hline 0,6631 & 0,4952 & 0,4593 & 0,6671 & 0,3144 & 0,4878 \\
\hline 0,7375 & 0,5901 & 0,3601 & 0,6750 & 0,3132 & 0,4713 \\
\hline 0,7254 & 0,6218 & 0,3941 & 0,6712 & 0,3208 & 0,4742 \\
\hline 0,8111 & 0,5696 & 0,2645 & 0,5775 & 0,3637 & 0,4430 \\
\hline 0,6837 & 0,4414 & 0,4374 & 0,4734 & 0,2988 & 0,5576 \\
\hline 0,7819 & 0,5918 & 0,2968 & 0,5742 & 0,4119 & 0,4287 \\
\hline 0,7789 & 0,5469 & 0,3045 & 0,5231 & 0,3850 & 0,4984 \\
\hline 0,7296 & 0,4953 & 0,3195 & 0,6930 & 0,3165 & 0,4996 \\
\hline 0,5991 & 0,3803 & 0,4537 & 0,6521 & 0,2677 & 0,5497 \\
\hline 0,6630 & 0,5544 & 0,3527 & 0,6513 & 0,2613 & 0,5523 \\
\hline 0,7317 & 0,5458 & 0,3226 & 0,6714 & 0,2929 & 0,5341 \\
\hline 0,7507 & 0,4351 & 0,3665 & 0,6821 & 0,3300 & 0,5887 \\
\hline 0,6925 & 0,3756 & 0,4249 & 0,6760 & 0,2845 & 0,5881 \\
\hline 0,7405 & 0,4282 & 0,3785 & 0,6755 & 0,3034 & 0,5829 \\
\hline 0,7390 & 0,4247 & 0,3875 & 0,6777 & 0,2963 & 0,5829 \\
\hline 0,6753 & 0,5565 & 0,4032 & 0,6965 & 0,2993 & 0,5647 \\
\hline 0,6022 & 0,4304 & 0,4729 & 0,6748 & 0,2565 & 0,5882 \\
\hline 0,6938 & 0,6329 & 0,3428 & 0,6998 & 0,3143 & 0,5582 \\
\hline
\end{tabular}




\begin{tabular}{|c|c|c|c|c|c|c|}
\hline & 0,7168 & 0,5876 & 0,3587 & 0,6748 & 0,2713 & 0,5884 \\
\hline & 0,6950 & 0,5702 & 0,3829 & 0,7291 & 0,3745 & 0,5726 \\
\hline & 0,6338 & 0,4935 & 0,4377 & 0,7047 & 0,3418 & 0,6054 \\
\hline & 0,6878 & 0,5911 & 0,3543 & 0,7257 & 0,3457 & 0,5801 \\
\hline & 0,6833 & 0,5013 & 0,3696 & 0,7345 & 0,4449 & 0,5675 \\
\hline & 0,7294 & 0,5491 & 0,3615 & 0,7214 & 0,3769 & 0,5843 \\
\hline & 0,6283 & 0,5038 & 0,4579 & 0,7160 & 0,3474 & 0,5900 \\
\hline & 0,6986 & 0,6131 & 0,3729 & 0,7170 & 0,3710 & 0,5805 \\
\hline & 0,7307 & 0,5499 & 0,3864 & 0,7143 & 0,3670 & 0,5928 \\
\hline & 0,7666 & 0,5449 & 0,2914 & 0,7650 & 0,4492 & 0,5188 \\
\hline & 0,6297 & 0,4229 & 0,4686 & 0,7546 & 0,3885 & 0,5345 \\
\hline & 0,5279 & 0,1820 & 0,6178 & 0,7593 & 0,3905 & 0,5217 \\
\hline & 0,7260 & 0,5747 & 0,3276 & 0,7559 & 0,4566 & 0,5313 \\
\hline & 0,7506 & 0,5631 & 0,4122 & 0,6382 & 0,2985 & 0,5453 \\
\hline & 0,6739 & 0,4021 & 0,5277 & 0,6201 & 0,2657 & 0,5758 \\
\hline & 0,7291 & 0,4923 & 0,4308 & 0,6333 & 0,3025 & 0,5533 \\
\hline & 0,7954 & 0,5955 & 0,3836 & 0,6263 & 0,2971 & 0,5719 \\
\hline & 0,7648 & 0,7353 & 0,4569 & 0,6871 & 0,2888 & 0,5288 \\
\hline & 0,6622 & 0,4035 & 0,5490 & 0,6460 & 0,2477 & 0,5805 \\
\hline & 0,7303 & 0,5804 & 0,4408 & 0,6558 & 0,2885 & 0,5608 \\
\hline & 0,7140 & 0,6536 & 0,4997 & 0,6596 & 0,3098 & 0,5655 \\
\hline Média & 0,65984 & 0,49546 & 0,44363 & 0,60348 & 0,32103 & 0,60171 \\
\hline$\sigma$ & 0,11195 & 0,11064 & 0,12544 & 0,12613 & 0,06800 & 0,09821 \\
\hline$\mu+\sigma$ & 0,77179 & 0,60610 & 0,56907 & 0,72961 & 0,38903 & 0,69992 \\
\hline$\mu-\sigma$ & 0,54790 & 0,38481 & 0,31819 & 0,47736 & 0,25302 & 0,50349 \\
\hline
\end{tabular}




\section{APÊNDICE C - Código computacional das principais aplicações do sistema VFTools}

O sistema VFTools é composto pelas seguintes aplicações:

- selecTool: aplicação para seleção de uma amostra de escoamento. Esta aplicação foi desenvolvida sob uma interface gráfica com o usuário e consiste na aplicação sequencial de um conjunto de funções sobre a imagem capturada do experimento. Estas funções tratam da seleção de uma amostra do escoamento e da sua adequação para as aplicações posteriores. A primeira delas executa a seleção da superfície frontal da imagem do escoamento capturada do experimento com posterior rotação da imagem para compatibilização do sentido do escoamento a conversão da imagem, originalmente colorida, em intensidade de cinza normalizada. A execução da selecTool é finalizada com a aplicação do modelo de inferência focal fuzzy segundo parâmetros de segmentação de imagens normalizados sobre cada pixel da amostra com a consequente eliminação dos considerados "fora de foco" da imagem da amostra do escoamento;

- maSamTool: aplicação com interface gráfica com o usuário com múltiplas funcionalidades. A primeira delas consiste na construção de arquivos de amostras de treinamento de uma rede neural com número de elementos de entrada correspondente às dimensões (ou os limites) de uma máscara virtual de varredura progressiva. A segunda funcionalidade consiste no treinamento da rede neural apresentando como resultado as matrizes com os pesos sinápticos de cada par de camadas. A execução da rede neural sobre uma amostra de escoamento com uma máscara virtual de varredura progressiva com dimensões fixas para eliminação consiste na terceira funcionalidade desta aplicação. Sua execução presta-se à eliminação das bolhas identificadas dentro dos limites físicos desta máscara. A execução desta terceira funcionalidade é realizada via integração da rede neural com uma função, denominada "rht_center". Esta última realiza a aplicação da transformada randomizada de Hough para captura dos parâmetros da figura geométrica que se ajusta aos contornos externos da bolha (interface gás-líquido). Finalmente a execução final do conjunto de redes neurais correspondente às dimensões da máscara virtual de varredura progressiva 
para cálculo do volume de gases na amostra e consequente cálculo da fração de vazio e

- saManTool: aplicação para fins de gerenciamento e organização dos arquivos de amostra de treinamento da rede neural.

Os códigos computacionais das principais funções que compõe o sistema VFTools são apresentados e suas funcionalidades são apresentadas nos comentários das próprias funções.

\section{selecTool / lsi_edge.m}

function Isi_edge(handles)

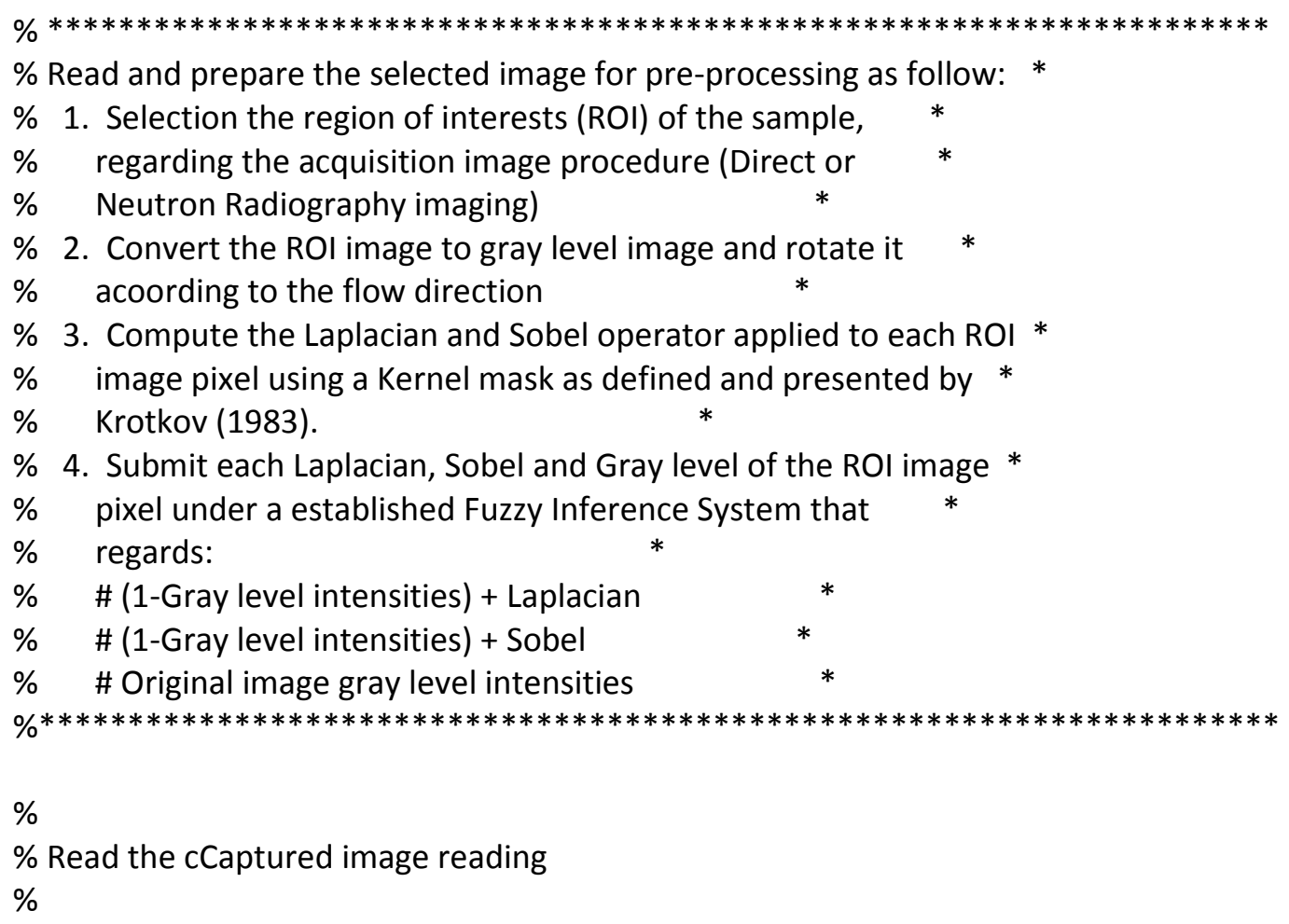

global SrcSelected;

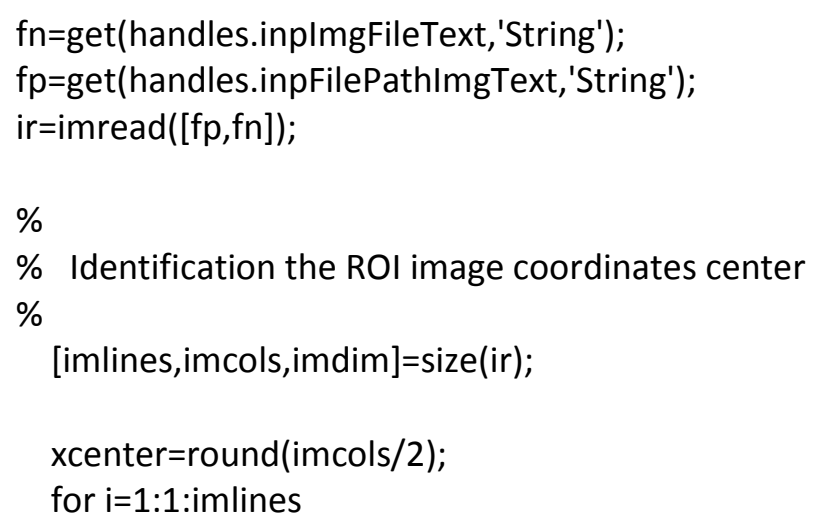




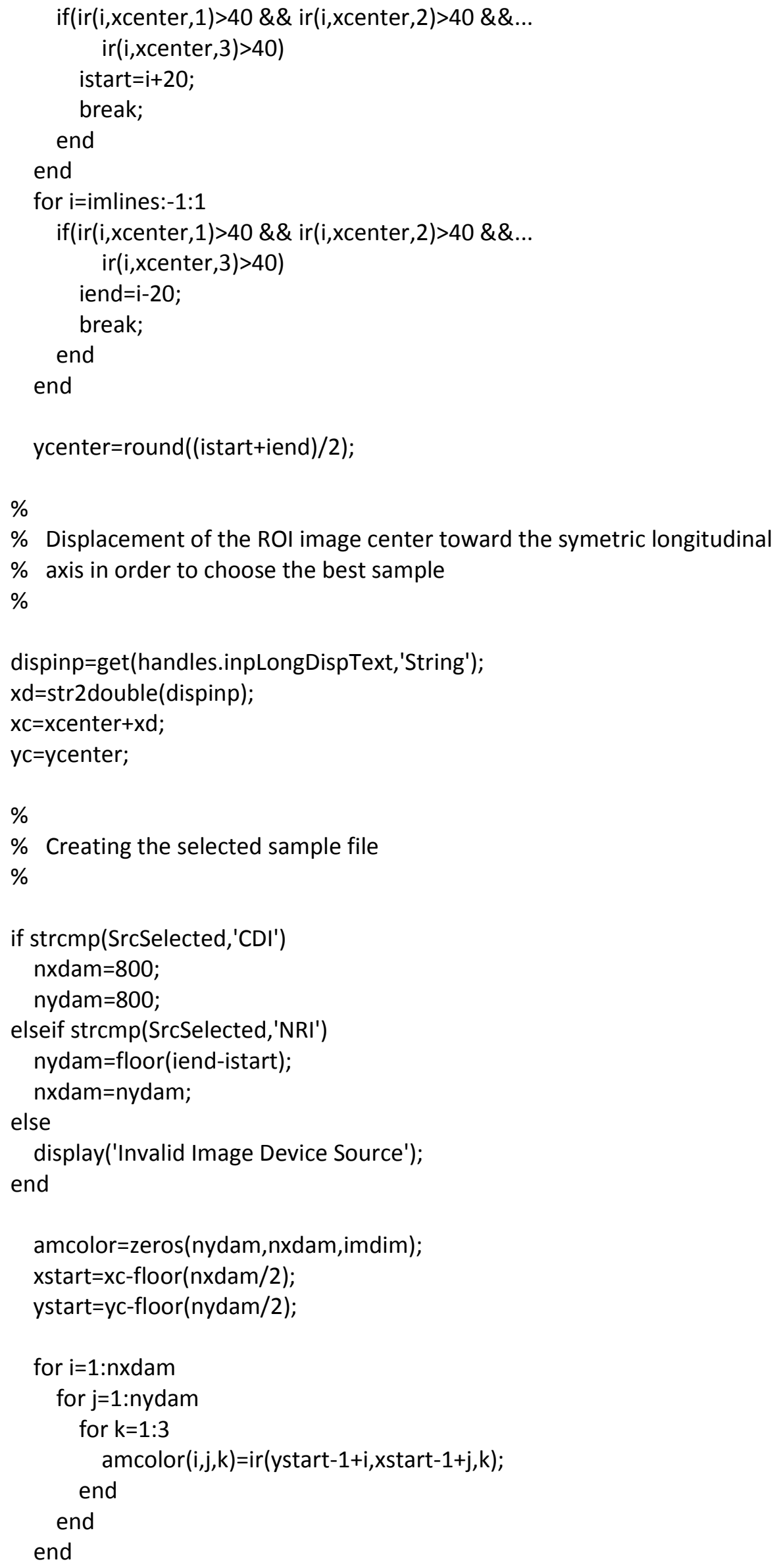


clear ir;

$\%$

$\%$ Image normalizing and rotation to agree with experimental flow

$\%$

amc=double(amcolor)/255;

theta=pi/2;

$\mathrm{T}=[\cos ($ theta) $\sin ($ theta) 0

$-\sin ($ theta) $\cos ($ theta) 0

$0 \quad 0 \quad 1]$;

$\operatorname{tr}=$ maketform('affine', $\mathrm{T}$ );

amrotc=imtransform(amc,tr);

axes(handles.ImgOriginal);

image(amrotc,'CDataMapping', 'scaled');

set(gcf,'colormap',jet);

axis image;

axis off;

amrot=rgb2gray(amrotc);

set(gcf,'colormap',gray);

$\%$

\% Krotkov's Laplacian operator application with Kernel mask

$\%$

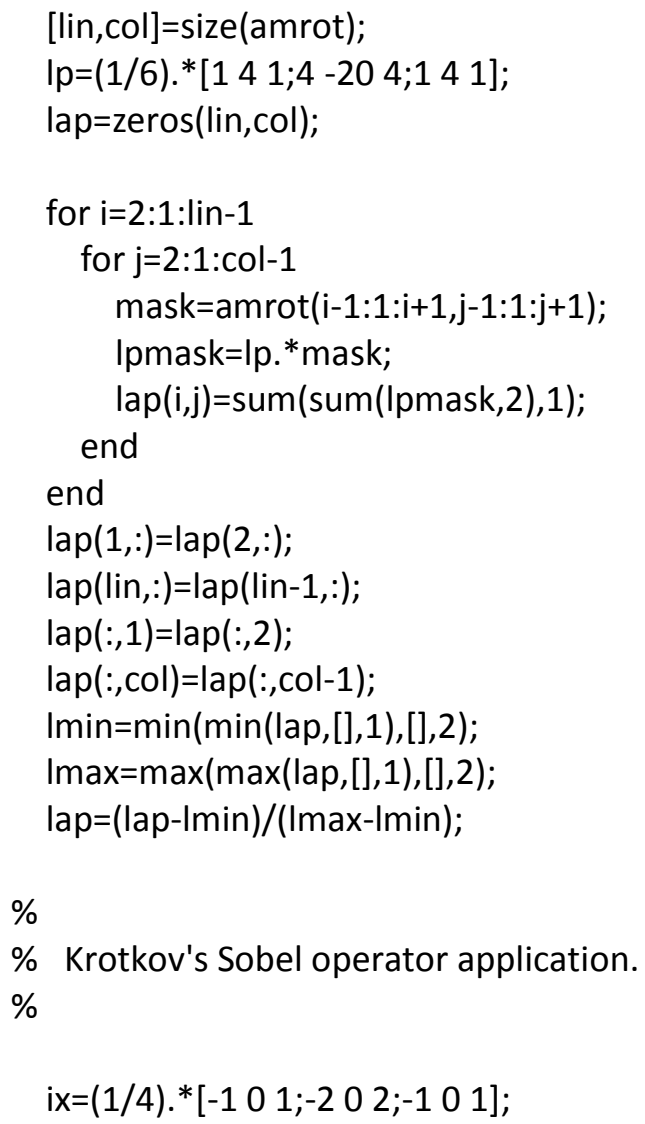




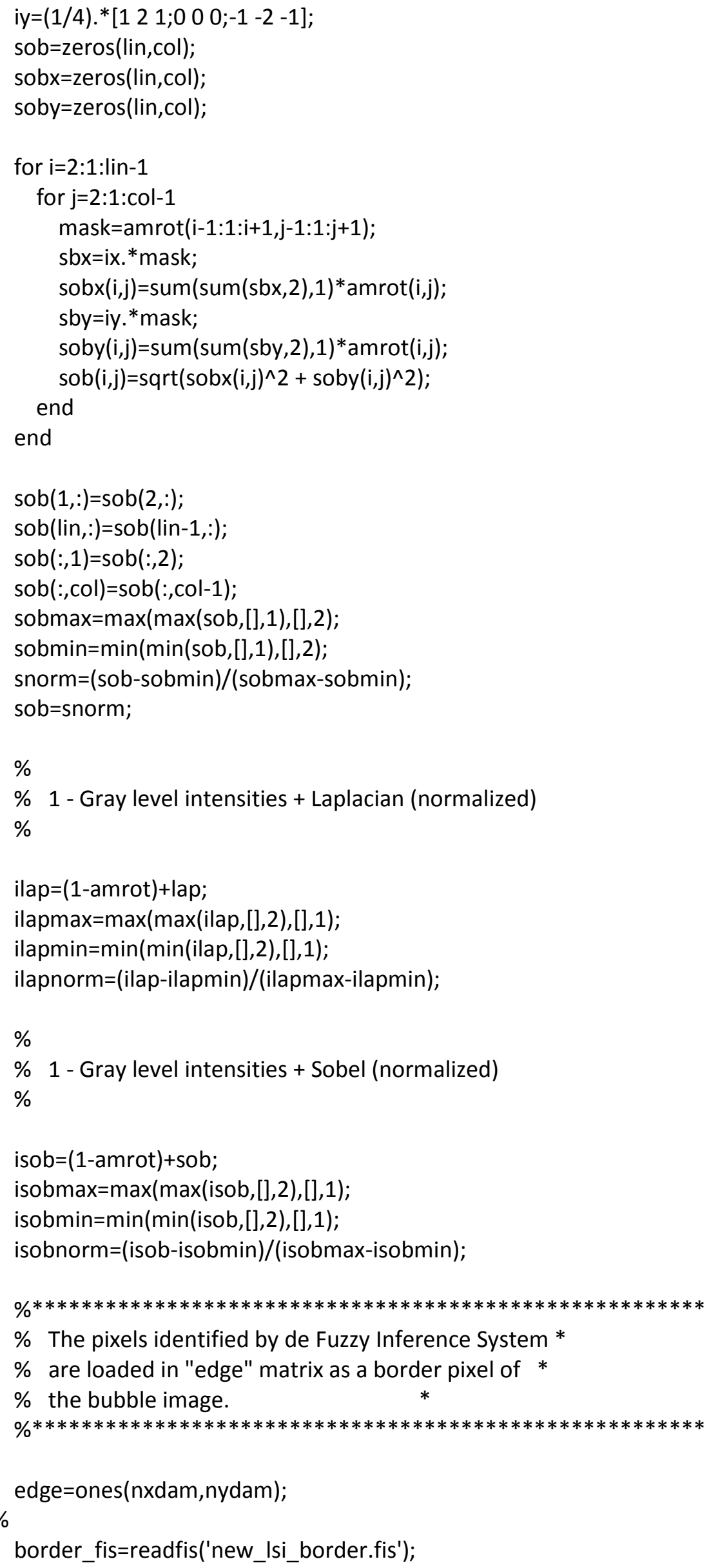


$\%$

$\%$ border_fis=readfis('Isi_border.fis');

for $i=1: 1$ :lin

for $j=1: 1: c o l$

inp_fis=[ilapnorm(i,j),isobnorm(i,j),amrot $(i, j)]$;

out_fis=evalfis(inp_fis,border_fis);

if(out_fis > 0.5)

edge $(\mathrm{i}, \mathrm{j})=\operatorname{amrot}(\mathrm{i}, \mathrm{j})$; end;

end;

end;

$\%$

$\%$ Transform to negative image

$\%$

edge=1-edge;

axes(handles.ImgProcessedAxis);

image(edge,'CDataMapping','scaled')

axis image;

axis off;

[filename, filepath]=uiputfile('*.tif','Save in .tif file', 'amostra1');

imwrite(edge,[filepath,filename],'tif');

imwrite(amrotc,[filepath, 'c', filename],'tif');

clear amrotc;

end

maSamTool / ANN_2HL_30x30

function ANN_2HL_30x30_Training(handles)

$\% \%$

$\%$

\% ANN_30X30_Training: BACKPROPAGATION TRAINING FOR IMAGES WITH $30 \times 30$

$\%$ DIMENSION ARTIFICIAL NEURAL NETWORK ARQUITECTURE HAS AN INPUT LAYER WITH

$\% 900$ INPUT DATA THAT CORRESPONDS TO THE PIXELS INTENSITY OF A $30 \times 30$

$\%$ IMAGE AND TWO HIDDEN LAYERS (WITH 144 AND 25 UNITS).

$\%$ THIS ANN WILL BE APPLIED FOR IMAGE CLASSIFICATION IN:

$\%$

$\% 1$ - IMAGE MASK WITH ONE BUBBLE

$\%$ - IMAGE MASK WITHOUT ANY BUBBLE

$\%$

$\% \mathrm{nl}$............ number of labels (output units)

$\%$ il ............ input layer units (input units related to image

$\%$ dimension)

$\%$ fhl ............ first hidden layer units

$\%$ shl ............ second hidden layer units

$\%$

$\%$ For 30x30 input layer:

$\% \quad$ il $=900$ 


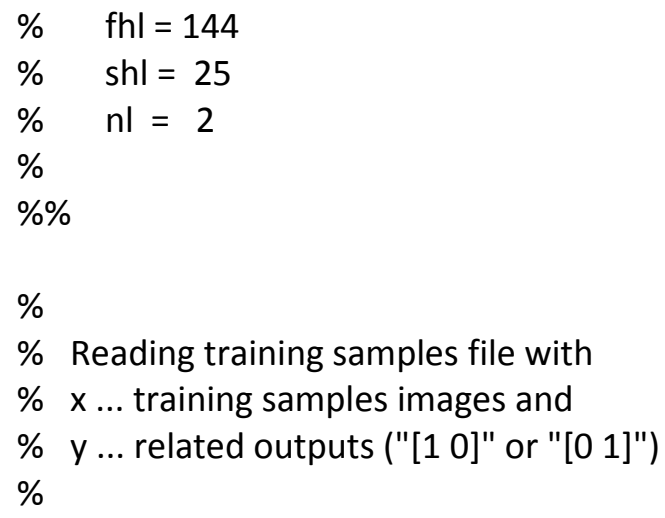


Theta3=initialTheta(il,fhl);

Theta2=initialTheta(fhl,shl);

Theta1=initialTheta(shl,nl);

$\%$

$\%$ Weight matrices randomized inicializations

$\%$

initial_ThetaV30×30 $=[$ Theta3(:);Theta2(:);Theta1(:)];

lambda=0.01;

$\%$

$\%$ Theta3 ...... (il+1) $x$ fhl

$\%$ Theta2 ...... (fhl+1) $\times$ shl

$\%$ Theta1 ...... (shl+1) $\times \mathrm{nl}$

$\%$

$\%$ initial_ThetaV30×30 ... Vectorized Weight matrices

$\%$

$\%$

$\%$ Training the ANN to compute Theta3, Theta2 and Theta1

$\%$

options=optimset('Maxlter',400);

costFunction30x30=@(p) Cost_2HL_30x30(p,il,fhl,shl,nl,x,yl,lambda);

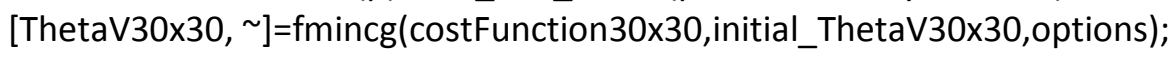

[sampname, sampath]=uiputfile(' *.mat', 'Save in .mat file','ThetaVec30×30');

wname=[sampath,sampname];

save(wname,'ThetaV30×30');

$\%$

$\%$ Seting start and end of each Weight matrix to proceed with Unrolling

$\%$ vectors

$\%$

startTheta3 $=1$;

endTheta3=(il+1)*fhl;

startTheta $2=$ endTheta $3+1$;

endTheta $2=$ endTheta $3+(\mathrm{fhl}+1) *$ shl;

startTheta1=endTheta $2+1$;

endTheta1=endTheta2+(shl+1)*nl;

Theta3 $=$ reshape $($ ThetaV30×30(startTheta3:endTheta3),(il+1),fhl);

Theta 2 reshape $($ ThetaV30×30(startTheta2:endTheta2),(fhl+1),shl);

Theta1 $=$ reshape $($ ThetaV30×30(startTheta1:endTheta1),(shl+1), nl);

displayData(Theta2(2:end,:)); 


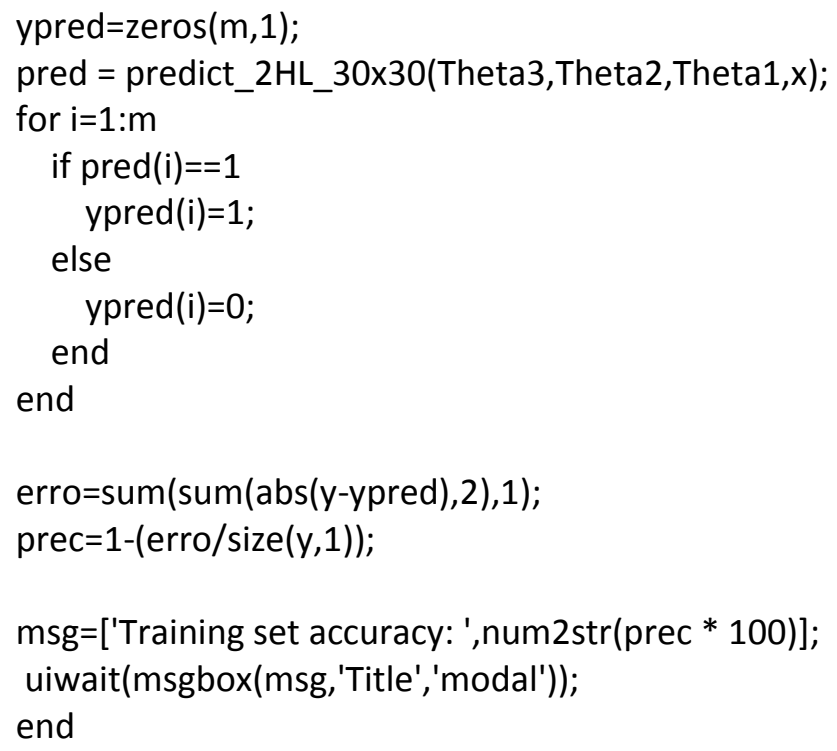




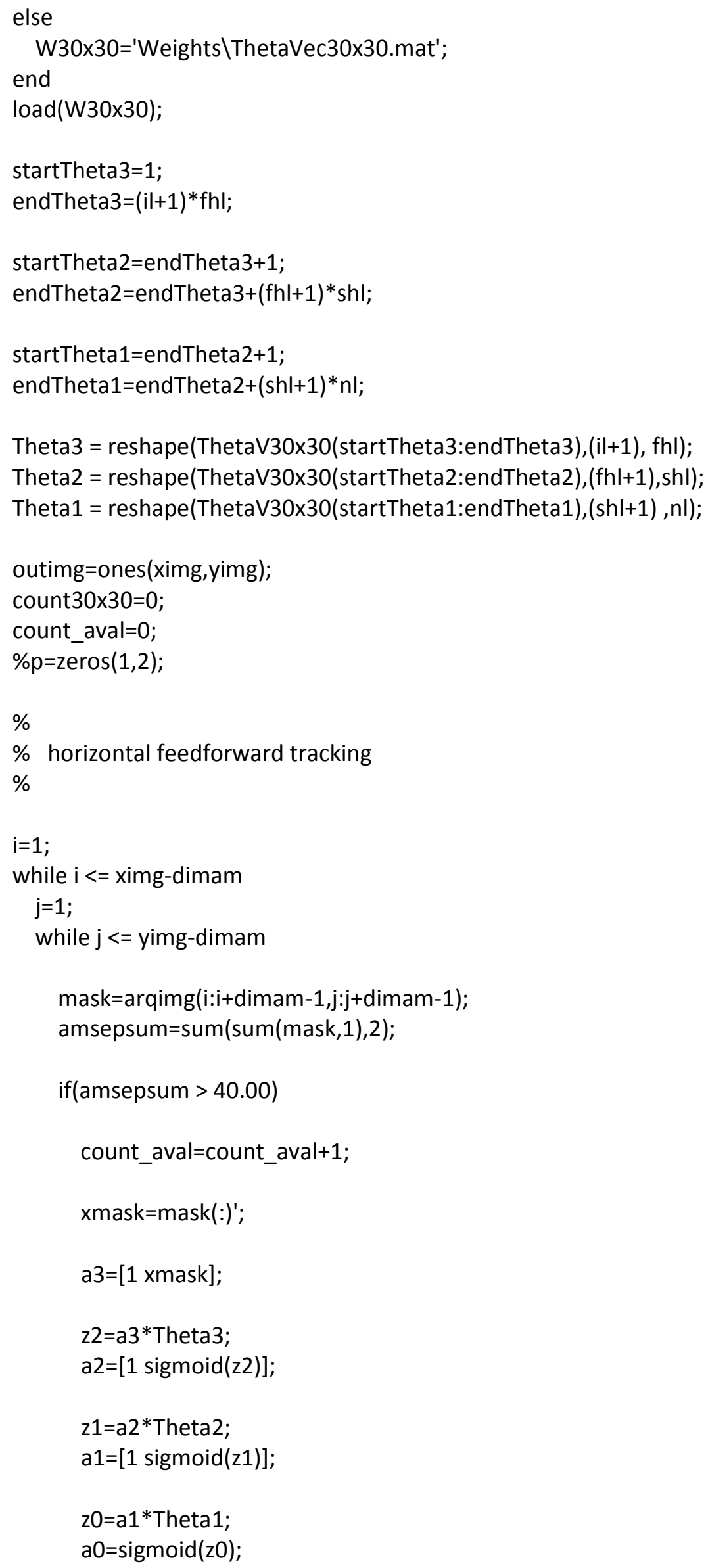


$\% \quad[\sim, p]=\max (\mathrm{a} 0,[], 2)$;

if $\mathrm{a} 0(1,1)>=0.999999 \& \& \mathrm{a} 0(1,2)<0.000001$

count $30 \times 30=$ count $30 \times 30+1$;

outimg(i:i+dimam-1,j:j+dimam-1)=...

arqimg(i:i+dimam-1,j:j+dimam-1);

[xc,yc,a_el,b_el,theta_el, , n_el]=rht_center(mask);

if(n_el $\sim=0)$

disp(['n_el = ',num2str(n_el)]);

for n_shape $=1:$ n_el

$\operatorname{disp}([' x i=$ ',num2str(i)]);

$\operatorname{disp}([' y j=$ ' ',num2str(j)]);

$\operatorname{disp}([' x c=$ ',num2str(xc(n_shape $))])$;

$\operatorname{disp}([$ 'yc = ',num2str(yc(n_shape) $)])$;

$\operatorname{disp}([$ 'a = ',num2str(a_el(n_shape))]);

disp(['b = ',num2str(b_el(n_shape))]);

$\operatorname{disp}([$ 'theta = ',num2str(theta_el(n_shape) $)])$;

frame_out=build_shape $\left(i, j, x c\left(n \_s h a p e\right), y c\left(n \_s h a p e\right), \ldots\right.$

a_el(n_shape),b_el(n_shape),theta_el(n_shape),...

ximg,yimg,dimam);

if frame_out $==0$

cleanel(i,j,xc(n_shape),yc(n_shape),...

a_el(n_shape),b_el(n_shape),...

theta_el(n_shape));

if icontv $30==1$

v30 $=(4 / 3) *$ pi*a_el(n_shape)...

*(b_el(n_shape $\left.)^{\wedge} 2\right)$;

sumv30=sumv30+v30;

end

end

end

end

end

end

$j=j+1$;

end

$\mathrm{i}=\mathrm{i}+1$;

end

if icontv30 $==0$

axes(handles.SampleAxes);

image(arqimg,'CDataMapping','scaled');

set(gcf,'colormap',gray);

axis image;

axis off;

disp(['n. resultados positivos =' num2str(count66x66)]);

disp(['n. de execuções da rede = ' num2str(count_aval)]);

imtool(outimg);

disp('press Enter to continue'); 


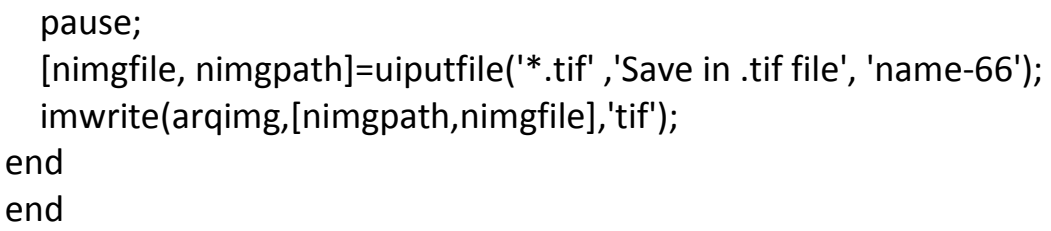

\section{maSamTool / Cost_2HL_30x30}

function [J, grad] = Cost_2HL_30x30(params,il,fhl,shl,nl, $x, y l, l a m b d a)$

\%COST30X30 Implements the neural network cost function for a two layer \%neural network which performs classification

$\%$ [J grad] $=$ Cost $30 \times 30$ (params, il,hl, nl, $\mathrm{x}, \mathrm{yl}$, lambda) computes the cost and

$\%$ gradient of the neural network. The parameters for the neural network

$\%$ are "unrolled" into the vector params and need to be converted back

$\%$ into the weight matrices.

$\%$

$\%$ The returned parameter grad should be a "unrolled" vector of the

$\%$ partial derivatives of the neural network.

$\%$

$\%$

$\%$ Reshape nn_params back into the parameters Theta1 and Theta2, the weight

$\%$ matrices for our 2 layer neural network

$\%$

$\%$ il .......... number of the input layer elements

$\% \mathrm{fhl}$.......... number of the first hidden layer elements

$\%$ shl .......... number of the second hidden layer elements

$\% \mathrm{nl}$.......... label numbers

$\% \times \quad$......... matrix with the input samples. Each sample corresponds

$\% \quad$ a one line of the matrix

$\%$ y .......... output

$\%$

$\%$ Theta1 ...... Weitghs for the second hidden layer

$\%$ Theta2 ...... Weights for the first hidden layer

$\%$ Theta3 ...... Weights for the input layer

$\%$

startTheta3 $=1$;

endTheta3=(il+1)*fhl;

startTheta $2=$ endTheta $3+1 ;$

endTheta $2=$ endTheta $3+(\mathrm{fhl}+1) *$ shl;

startTheta1=endTheta $2+1$

endTheta $1=$ endTheta $2+(\operatorname{shl}+1) * \mathrm{nl}$;

Theta3 = reshape (params(startTheta3:endTheta3),(il+1),fhl);

Theta2 $=$ reshape $($ params $($ startTheta2:endTheta2 $),($ fhl +1$)$, shl $)$;

Theta1 $=$ reshape $($ params $($ startTheta1:endTheta1),(shl+1), nl); 
\% Feedforward Neural Network with regularization

$\%$

$\%$ Setup some useful variables

$\% \mathrm{~m}$........... number of samples

$\%$

$m=\operatorname{size}(x, 1)$

$\%$

$\%$ Feedforward Neural Network

$\%$

$\mathrm{a} 3=[$ ones $(\mathrm{m}, 1) \mathrm{x}]$

$\mathrm{z} 2=\mathrm{a} 3 *$ Theta3;

$\mathrm{a} 2=[$ ones $(\mathrm{m}, 1) \operatorname{sigmoid}(\mathrm{z} 2)]$;

$\mathrm{z} 1=\mathrm{a} 2 *$ Theta2;

a1=[ones $(m, 1)$ sigmoid(z1)];

$\mathrm{z} 0=\mathrm{a} 1$ *Theta1;

$\mathrm{a} 0=\operatorname{sigmoid}(\mathrm{z} 0)$;

$\%$

$\%$ regularization term

$\%$

Theta3reg=Theta3(2:end,:);

Theta2reg=Theta2(2:end,:);

Theta1reg=Theta1(2:end,:);

$\%$

$\%$ Extracting the firs collumn of the Weigth matrix

$\%$

sqrTheta3 $=\left(\right.$ Theta3reg. ${ }^{*}$ Theta3reg);

sqrTheta $2=\left(\right.$ Theta2reg. ${ }^{*}$ Theta2reg);

sqrTheta $1=\left(\right.$ Theta1reg. ${ }^{*}$ Theta1reg);

sumTheta3=sum(sum(sqrTheta3,2));

sumTheta2=sum(sum(sqrTheta2,2));

sumTheta1=sum(sum(sqrTheta1,2));

regterm $=(\operatorname{lambda} /(2 * \mathrm{~m})) *($ sumTheta $3+$ sumTheta $2+$ sumTheta 1$)$;

$\%$

$\%$ regularized cost function

$\%$

$\mathrm{J}=\left((1 / \mathrm{m}) *\left(\operatorname{sum}\left(\operatorname{sum}\left(\left(-\mathrm{yl} .{ }^{*} \log (\mathrm{a} 0)-(1-\mathrm{yl}) \cdot{ }^{*} \log (1-\mathrm{a} 0)\right), 2\right)\right)\right)\right)+$ regterm; 


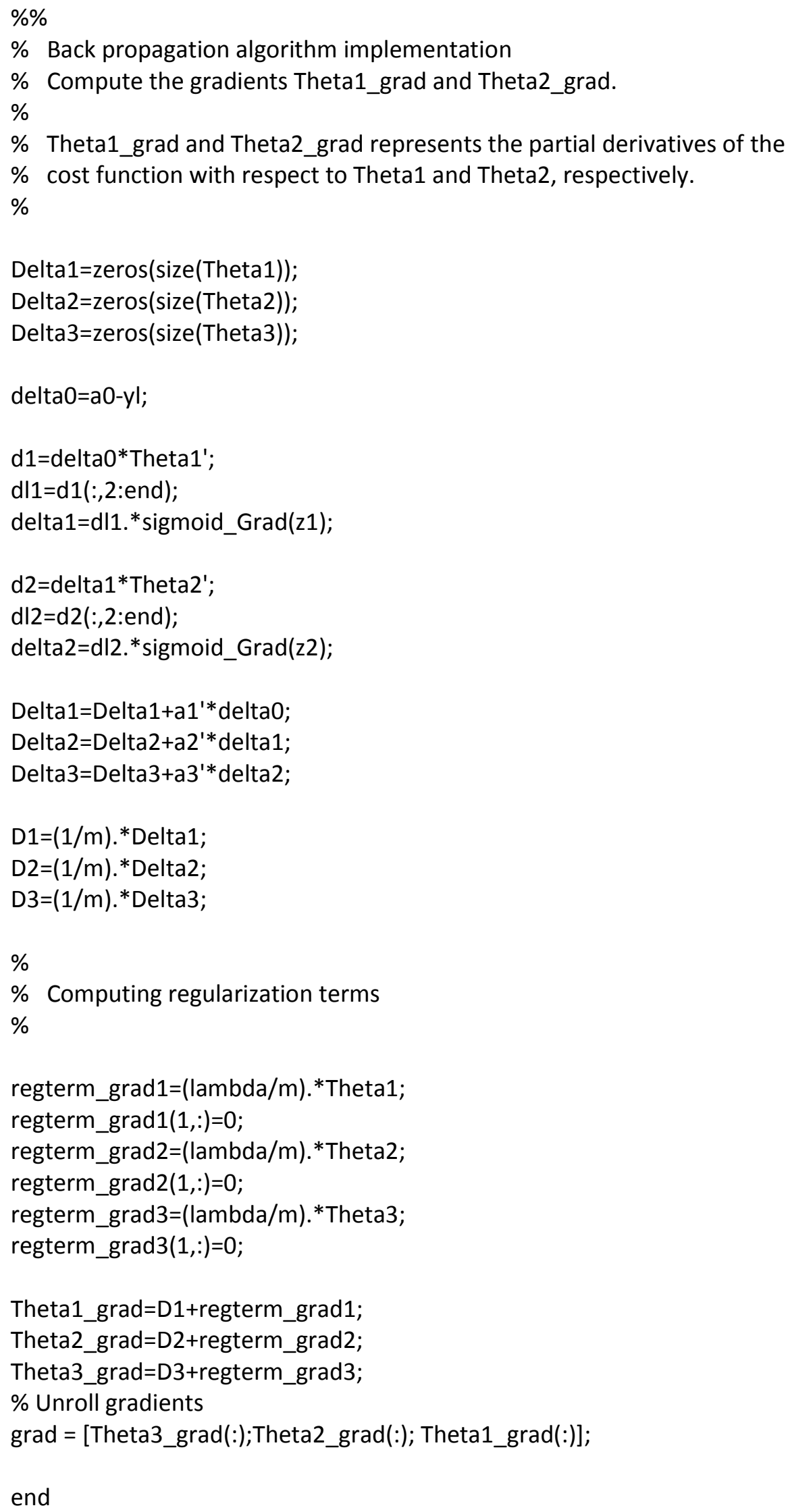




\section{maSamTool / rht_center}

function [x_c,y_c,a_ell,b_ell,theta_ell,flag, n_found] $=$ rht_center(f)

$[r, c]=\operatorname{size}(f)$;

$\mathrm{rc}=$ floor $($ hypot $(r, c) / 2)$;

$\%$

$\% \quad r$... number of the image rows

$\%$ c ... number of the image columns

$\%$ rc ... maximum value of the ellipse semi axes

$\%$

$\mathrm{gx}=\mathrm{zeros}(\mathrm{r}, \mathrm{c}) ; \%$ \%ok<NASGU>

$\mathrm{gy}=\mathrm{zeros}(\mathrm{r}, \mathrm{c}) ; \% \# \mathrm{ok}\langle\mathrm{NASGU}\rangle$

vote=zeros $(r, c)$;

vote_params=zeros $(r, c, 180)$;

max_vote_params $=$ zeros $(4,1)$;

$\operatorname{maxv}=0$;

max_vote=zeros $(4,1)$;

$\%$

$\%$ Voting acummulation matrices

$\%$

$\mathrm{xc}=$ zeros $(4,1)$;

$y c=z e r o s(4,1)$;

$x_{-} c=z e r o s(4,1)$;

y_c $=$ zeros $(4,1)$;

$\%$

$\%$ xc row ellipse center

$\%$ yc columm ellipse center

$\%$

a_el=zeros $(4,1)$;

b_el=zeros $(4,1)$;

theta_el=zeros $(4,1)$;

a_ell=zeros $(4,1)$;

b_ell=zeros $(4,1)$;

theta_ell=zeros $(4,1)$;

$\%$

$\%$ a_el ellipse semi major axis

$\%$ b_el ellipse semi minnor axis

$\%$ theta ellipse semi major axis angle relative to horizontal axis $\%$

A_el=zeros $(4,1)$;

B_el=zeros $(4,1)$; 
C_el=zeros $(4,1)$;

A_ell=zeros $(4,1)$;

B_ell=zeros $(4,1)$;

C_ell=zeros $(4,1)$;

$\%$

$\%$ A_el; B_el; C_el General ellipse equation coeficients

$\%$ A_ell;B_ell;C_ell selected general elipse equation coeficients

$\%$

a_pix=zeros $(4,1)$;

b_pix=zeros $(4,1)$;

c_pix=zeros $(4,1)$;

$\%$

$\%$ Gaussian filter application under $\mathrm{f}(\mathrm{r}, \mathrm{c})$ and derivatives computation

$\%$ gx ... row direction derivative

$\%$ gy ... columm direction derivative

$\%$

$\%$ flag ... control of the image tracking

$\% \quad$ flag $=0==>$ any ellipse was found (initial value)

$\% \quad$ flag $=1==>$ ellipse was found after tracking

$\% \quad$ flag $=2==>$ any ellipse was found after tracking

$\% \quad==>$ the image doesn't contain any

$\% \quad$ ellipse more

$\%$ pix_rate pixel rate regarding $n p$ and flag (threshold $>=0.25$ )

$\%$ n_found ... number of ellipses found

$\%$

flag $=0$;

$\mathrm{n}_{-}$found $=0$;

sig=stdev(f);

[gy,gx]=smoothGradient(f,sig);

border=edge(f,'canny');

while (flag $\sim=2$ )

$[\mathrm{rb}, \mathrm{cb}]=$ find(border);

$\mathrm{np}=\operatorname{size}(\mathrm{rb}, 1)$;

$\mathrm{zb}=[\mathrm{rb}, \mathrm{cb}]$;

$\% \operatorname{disp}([' n p=$ ',num2str(np)]);

$\%$ disp('Pause - press Enter to Continue $\gg>>~ ')$;

$\%$ pause;

$\%$

$\%$ sample_size ... size of the pixels sample of the border image

$\%$ it corresponds to $50 \%$ of the total (P1,P2) combinations

$\%$

sample_size $=$ floor $\left(0.6^{*}((\mathrm{np} *(\mathrm{np}-1)) / 2)\right)$; 


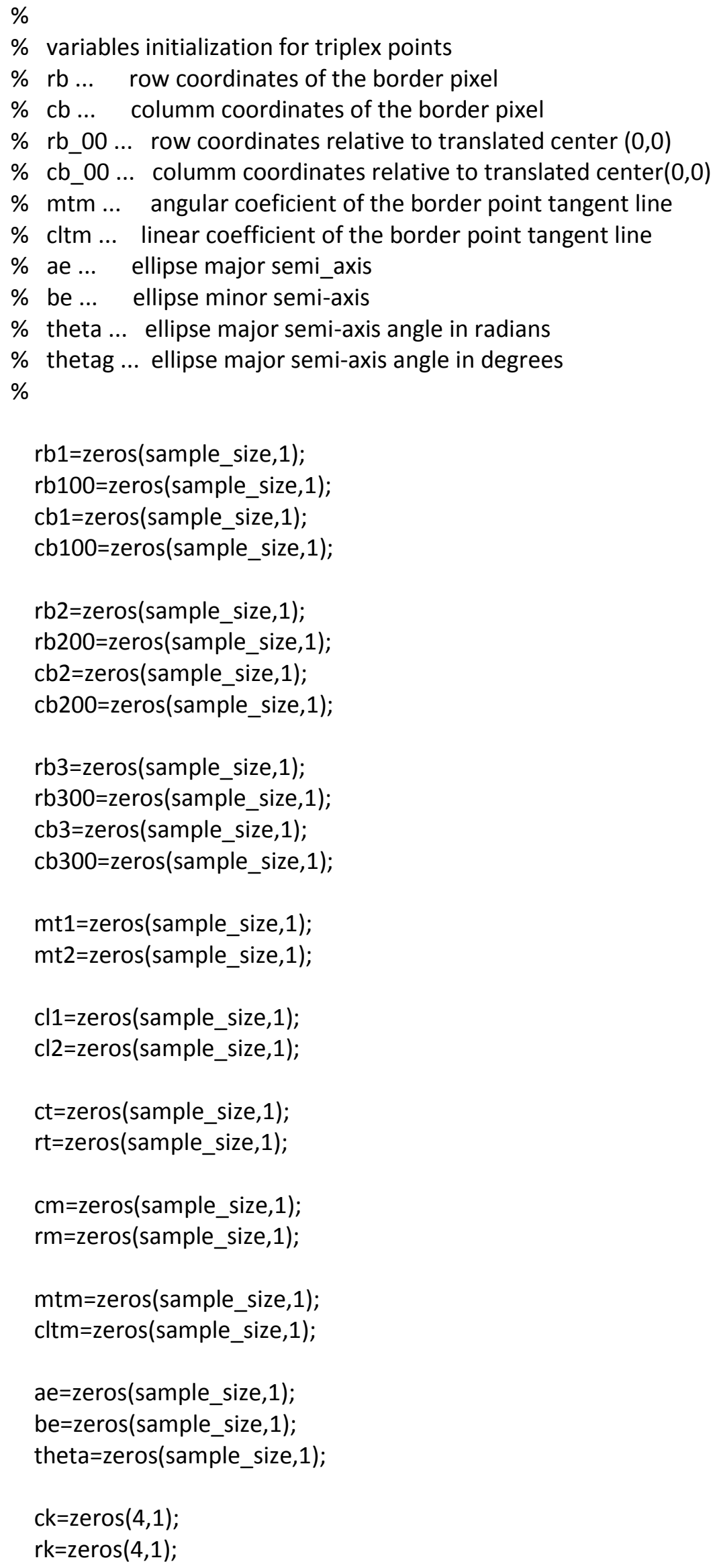


$\%$ triplex of border points $\mathrm{P} 1:(\mathrm{rb} 1, \mathrm{cb} 1), \mathrm{P} 2:(\mathrm{rb} 2, \mathrm{cb} 2)$ and $\mathrm{P} 3:(\mathrm{rb} 3, \mathrm{cb} 3)$

$\%$ sample_size combinations

$\%$

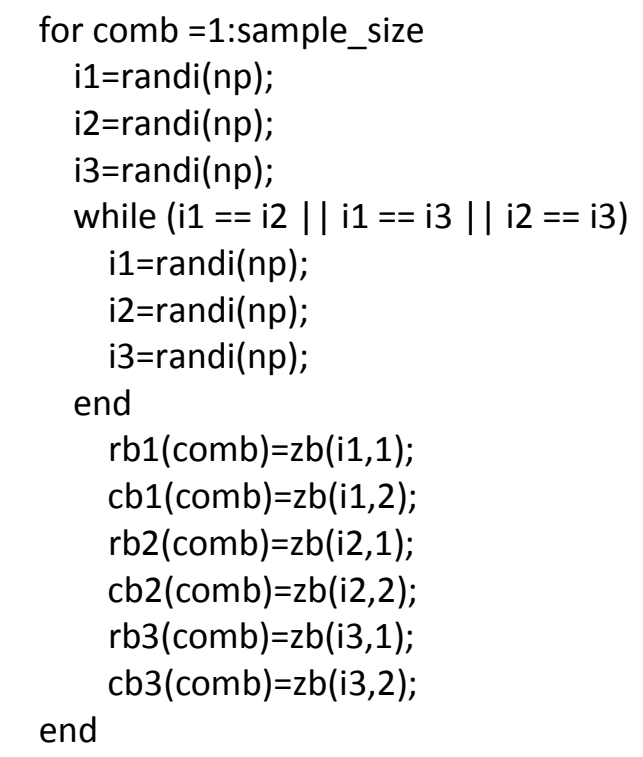

$\%$

$\%$ The center of the ellipse is at the line that passes through

$\%$ the tangents lines cross point (rt,ct) and the midpoints of the

$\%$ two sample points $(\mathrm{rm}, \mathrm{cm})$.

$\%$

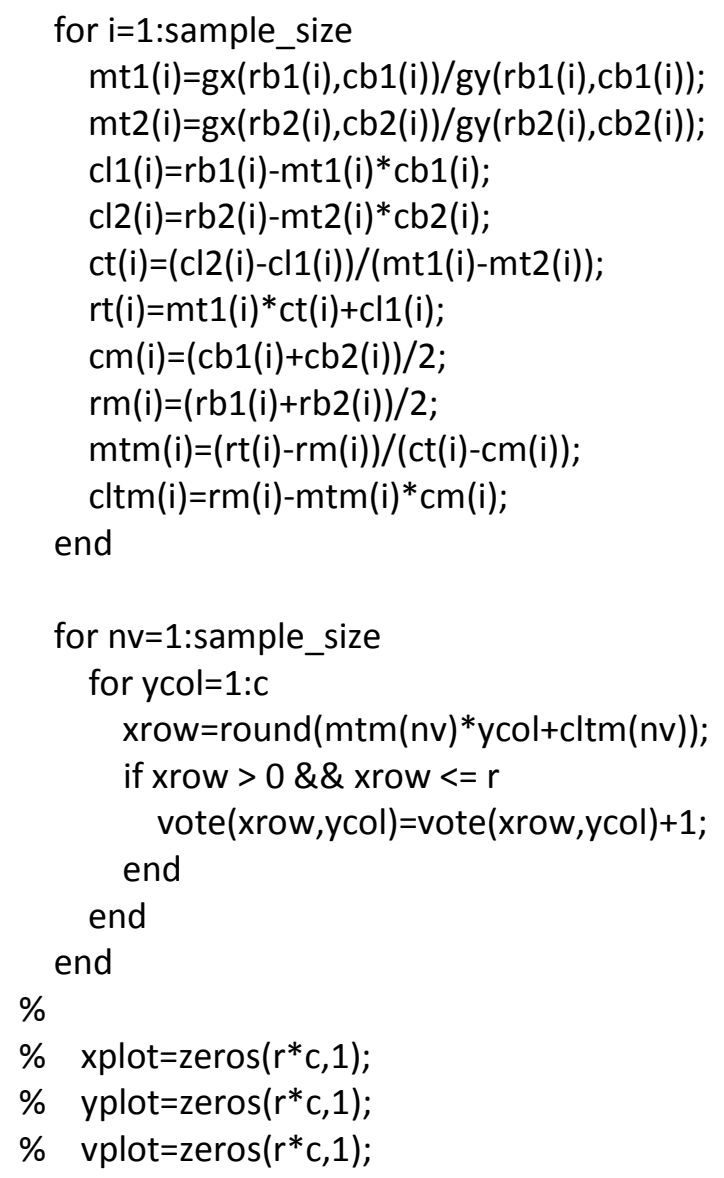




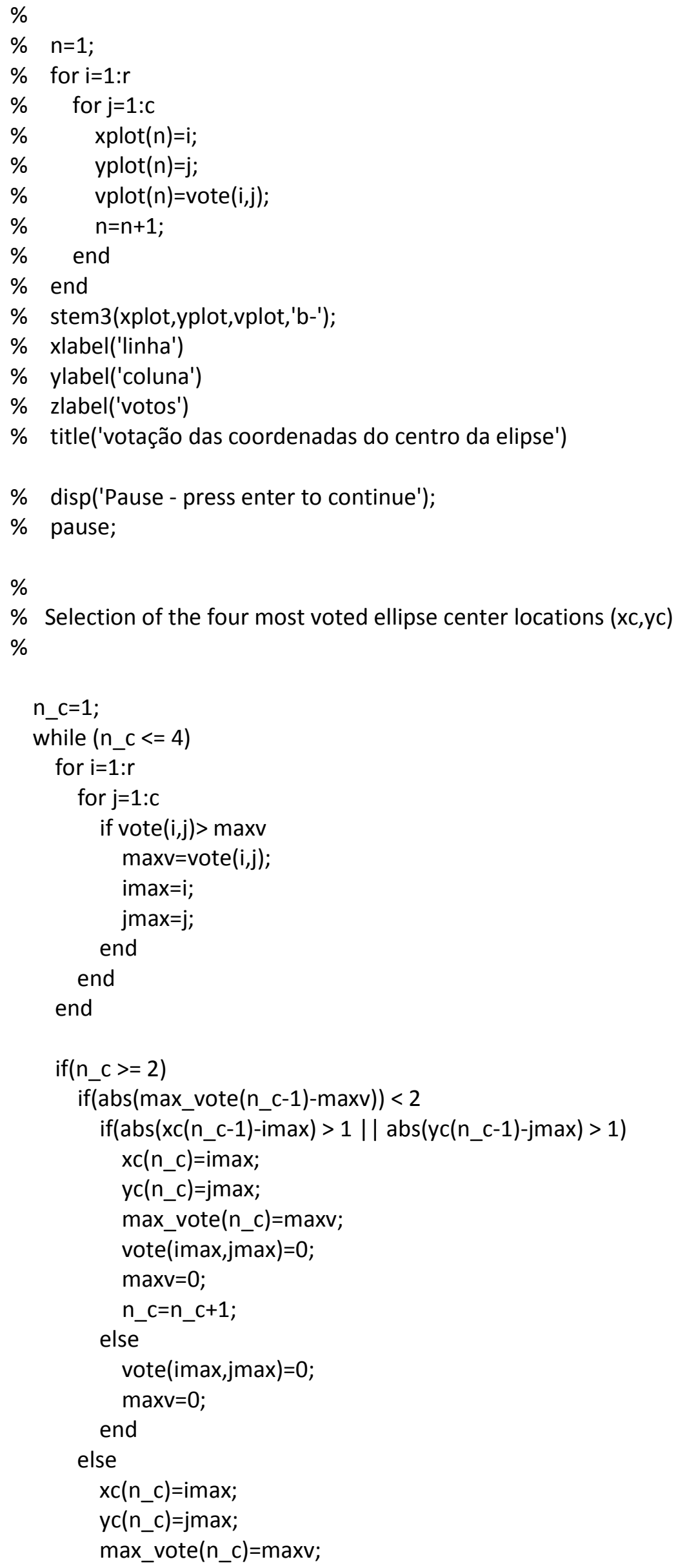




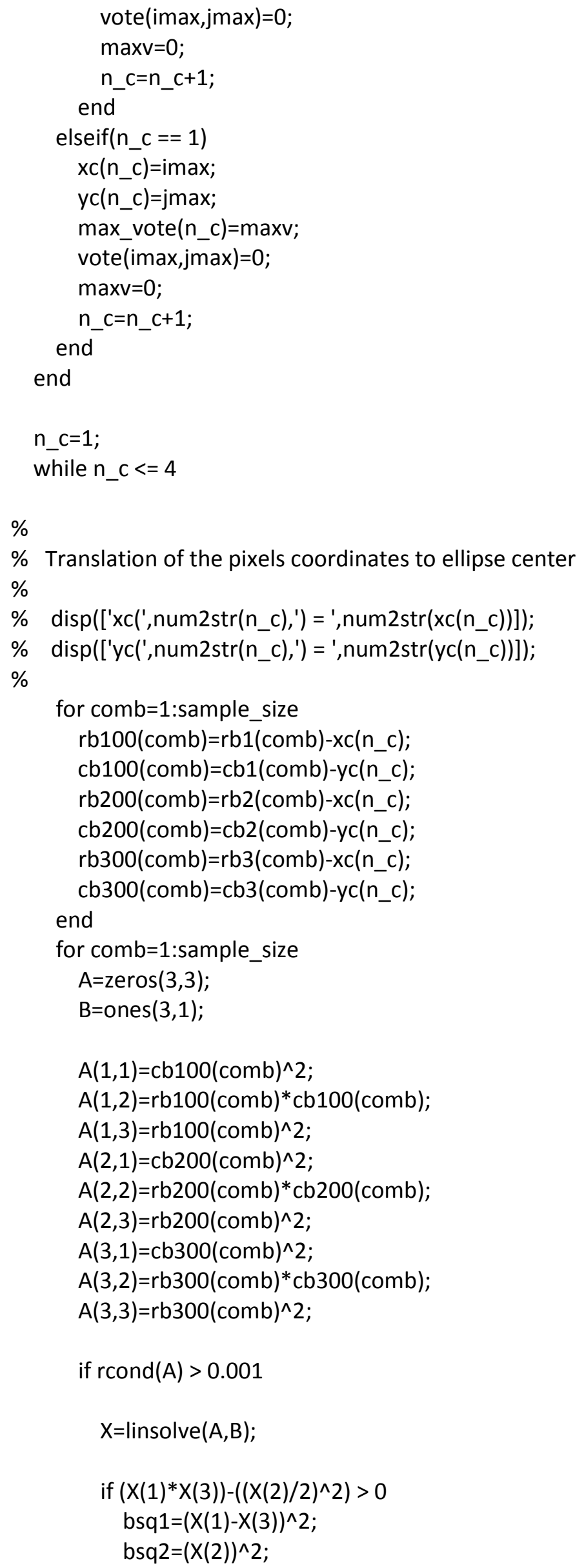




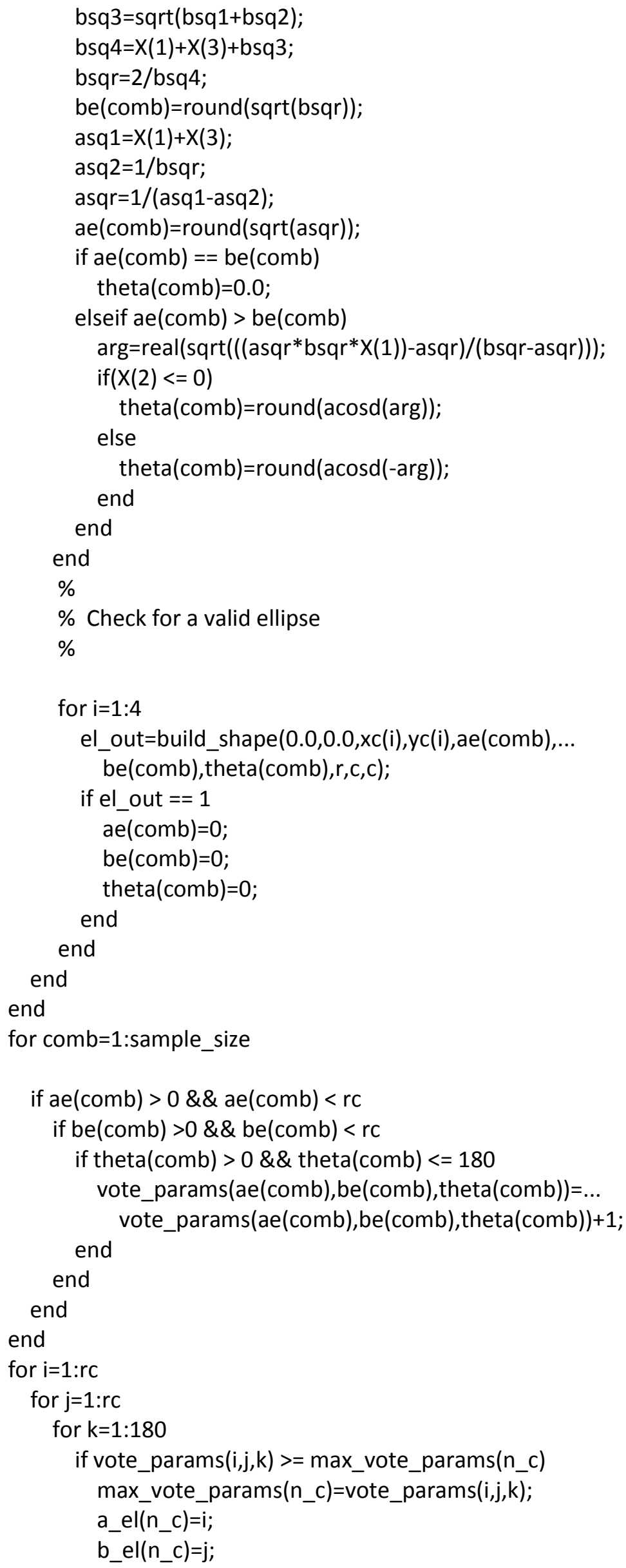




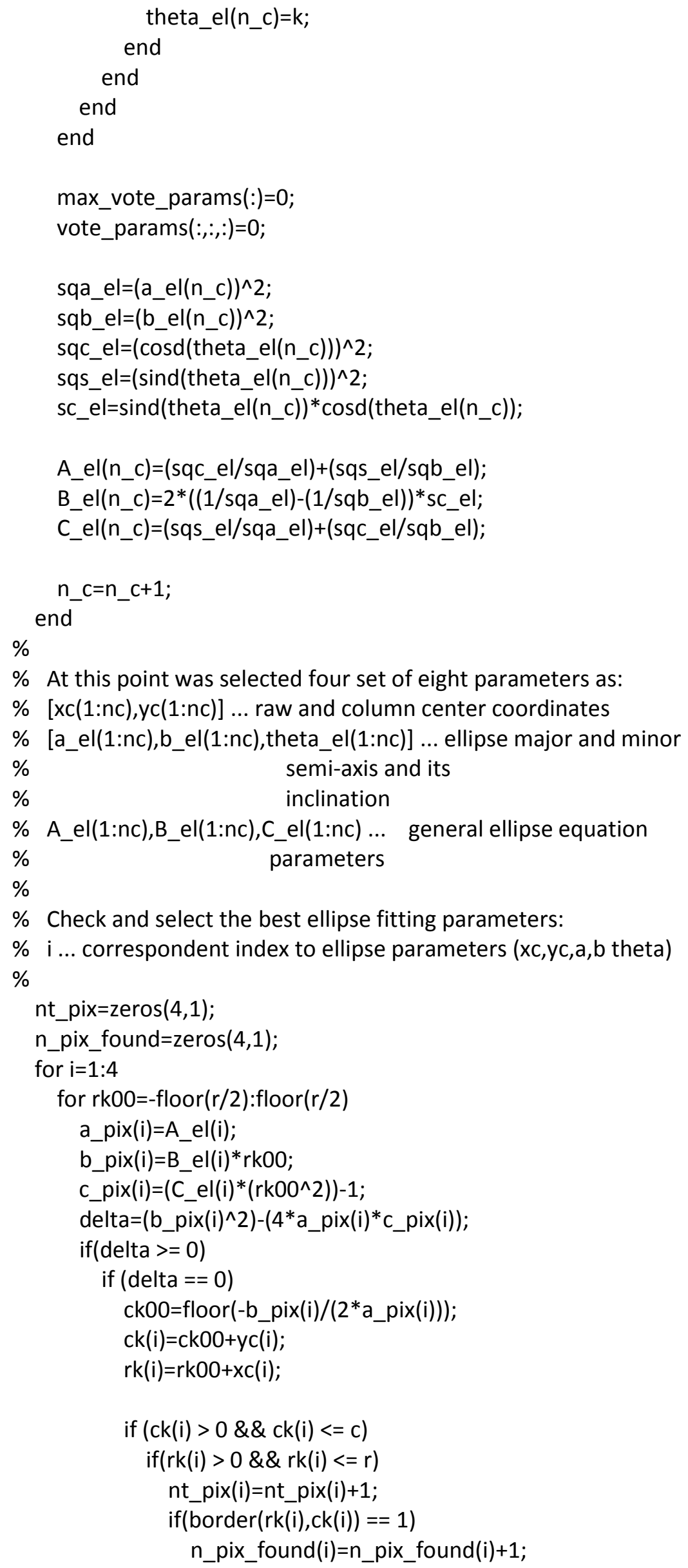




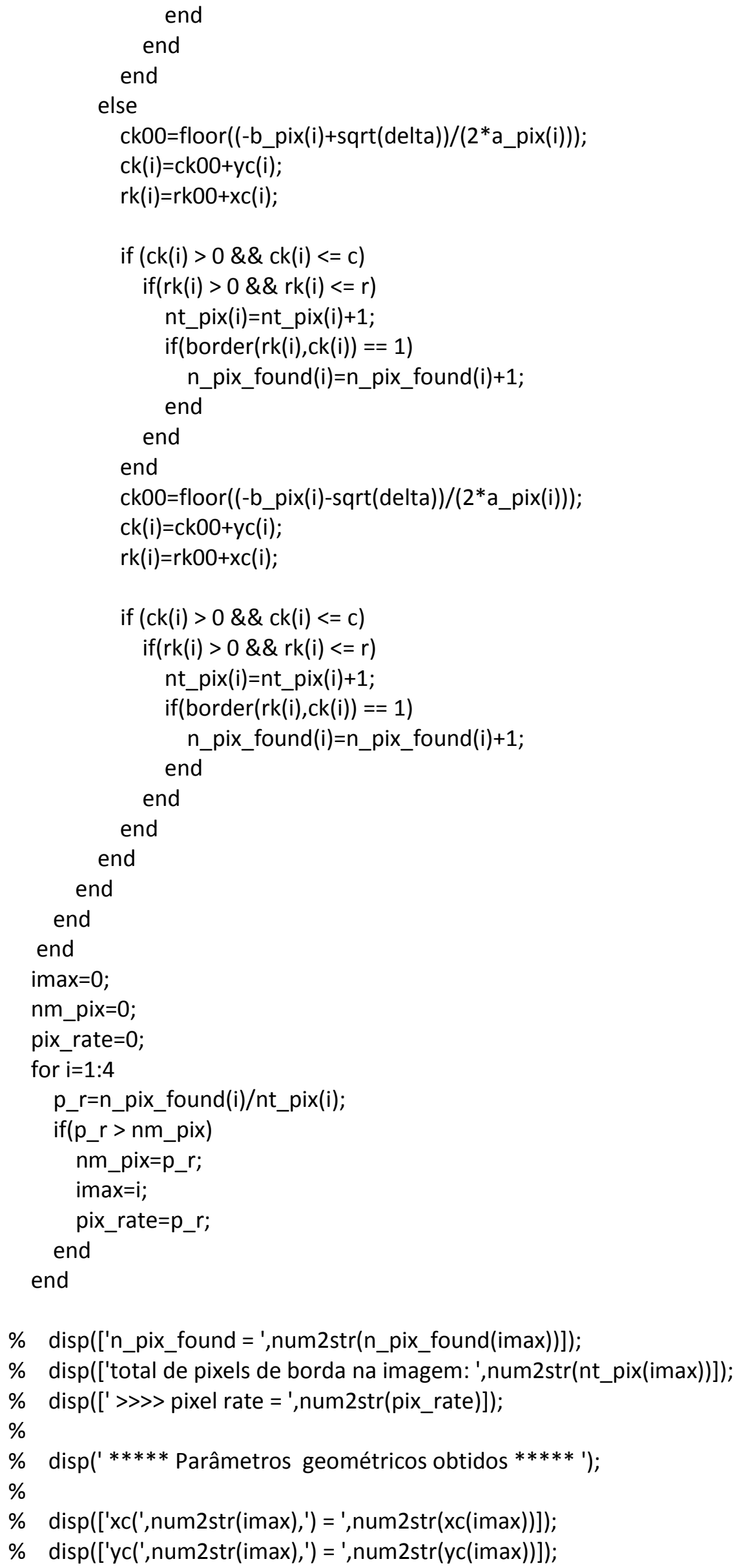


$\%$ disp(['a_el(',num2str(imax),') = ',num2str(a_el(imax))]);

$\%$ disp(['b_el(',num2str(imax),') = ',num2str(b_el(imax))]);

$\%$ disp(['theta_el(',num2str(imax),') = ',num2str(theta_el(imax))])

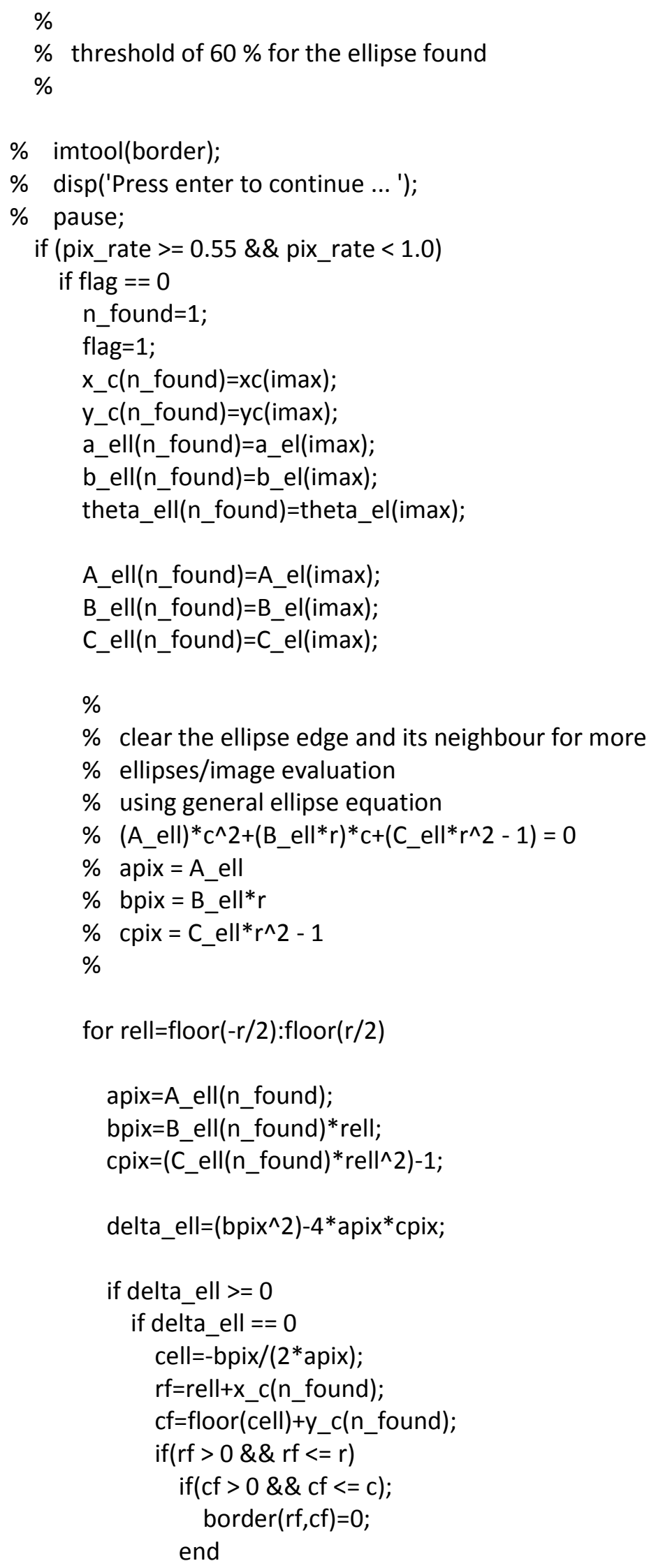




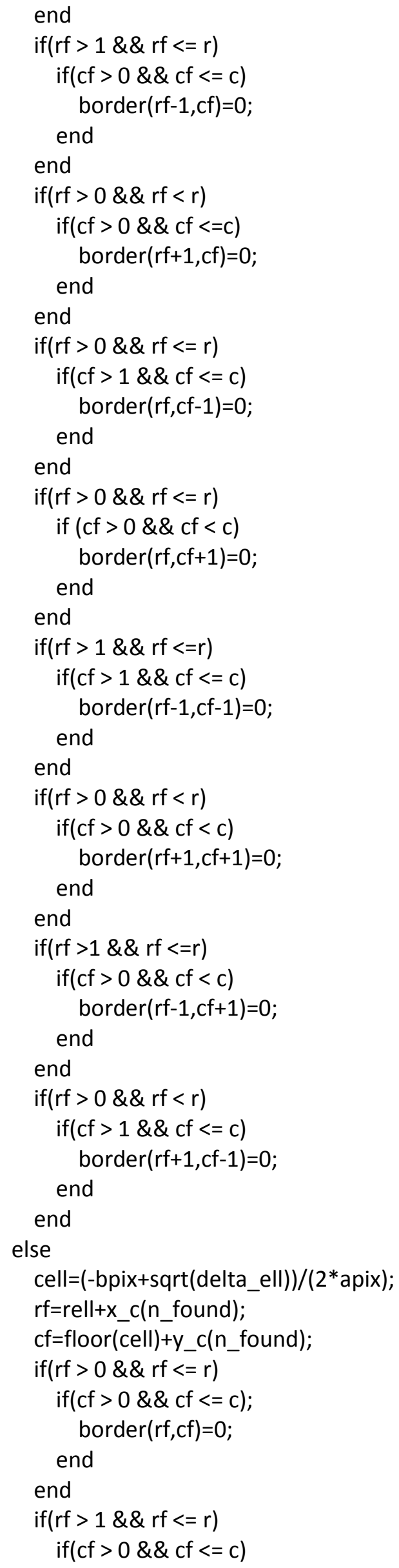




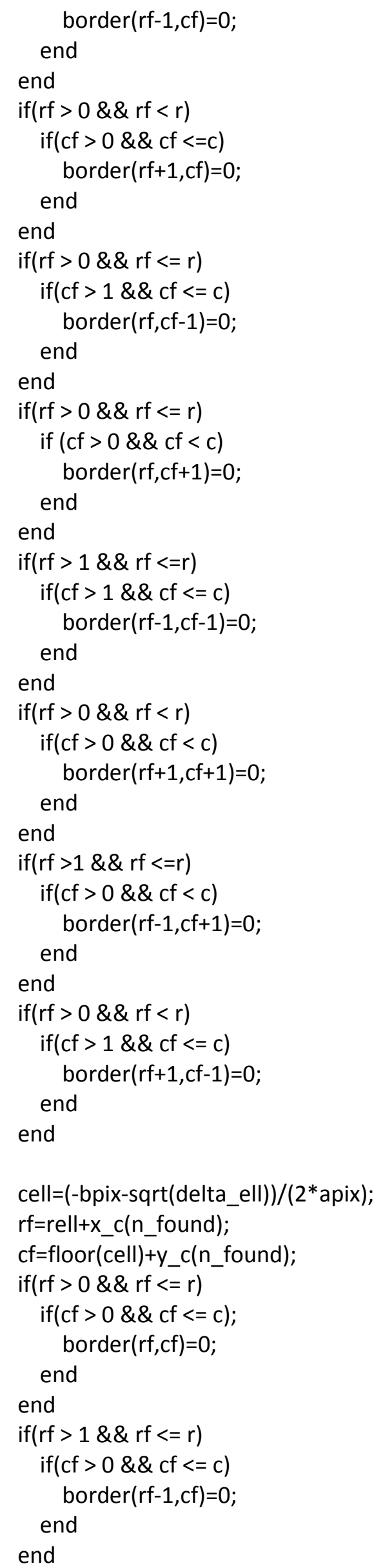




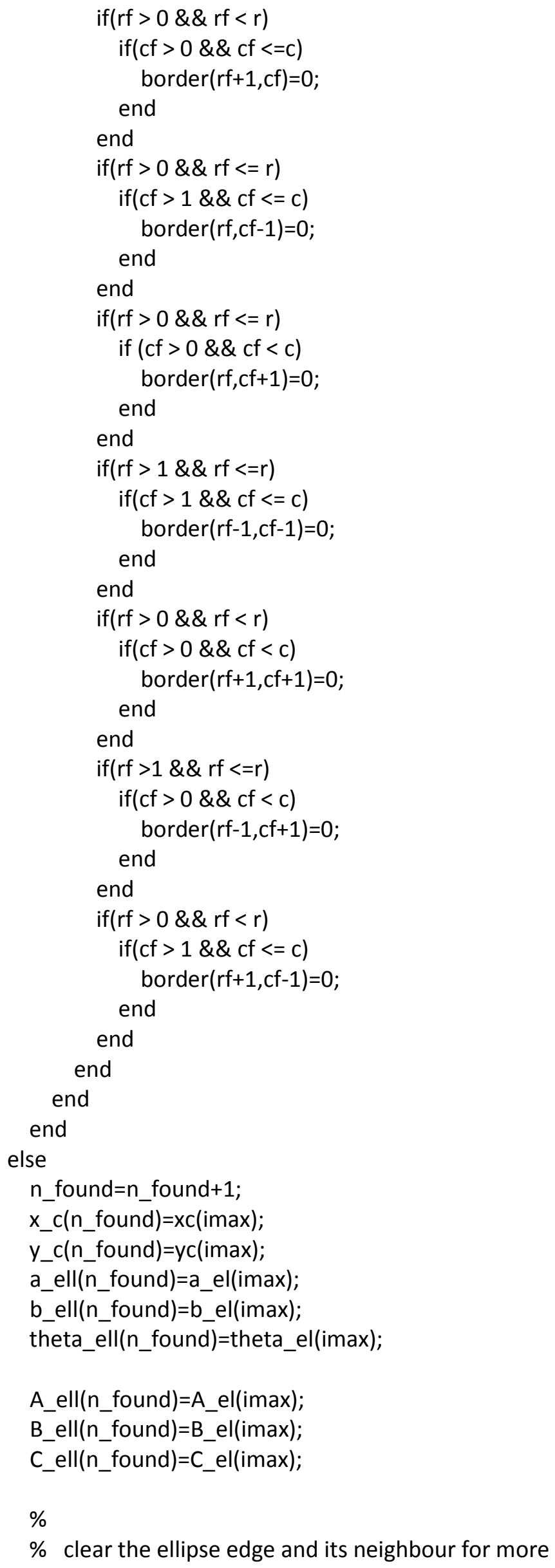




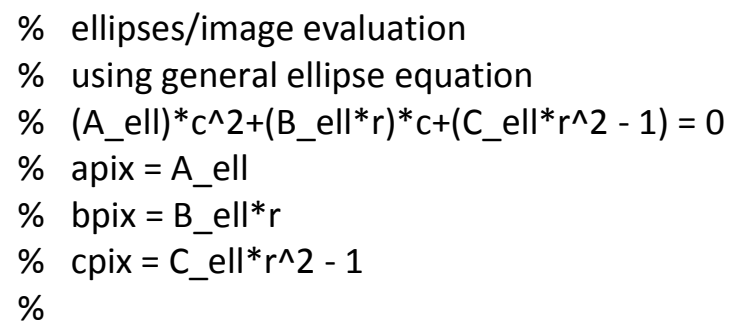

for rell=floor(-r/2):floor(r/2)

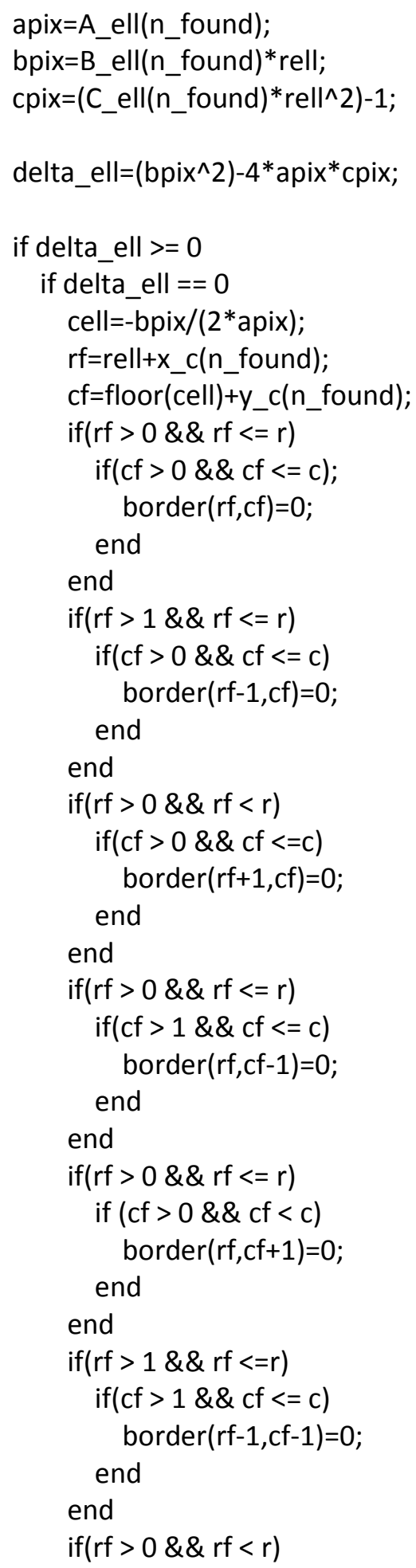




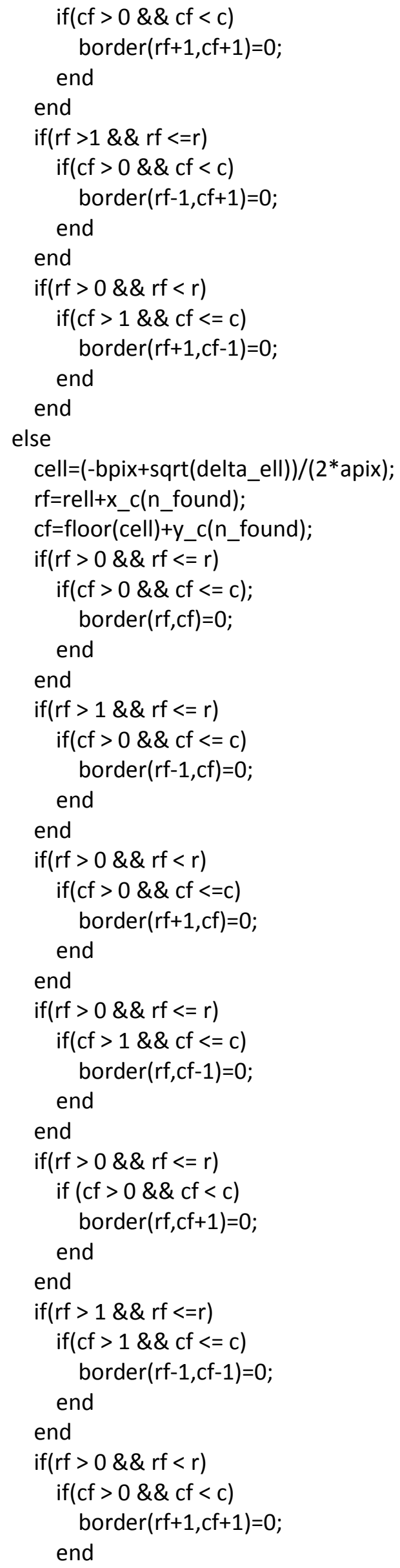




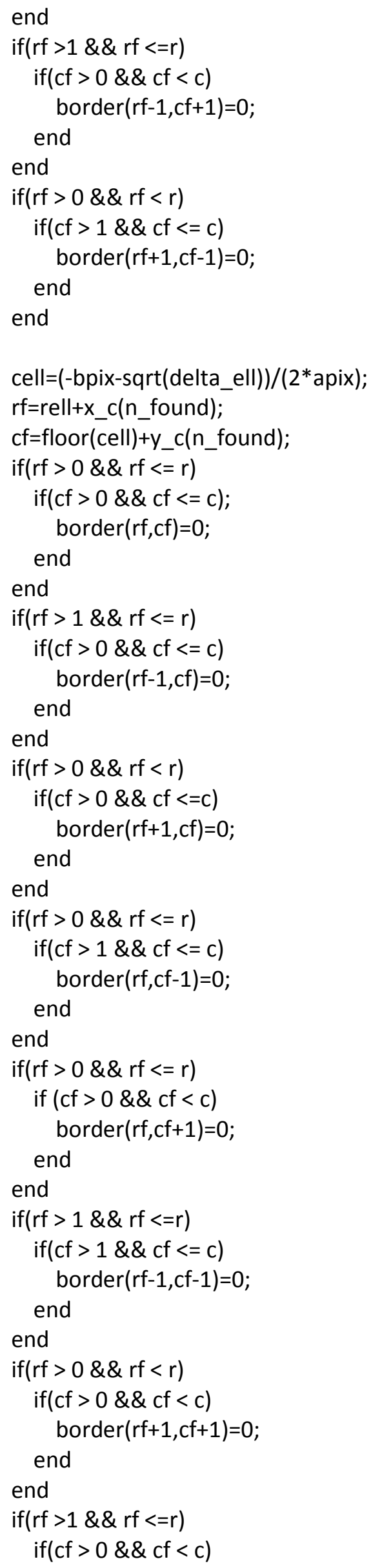




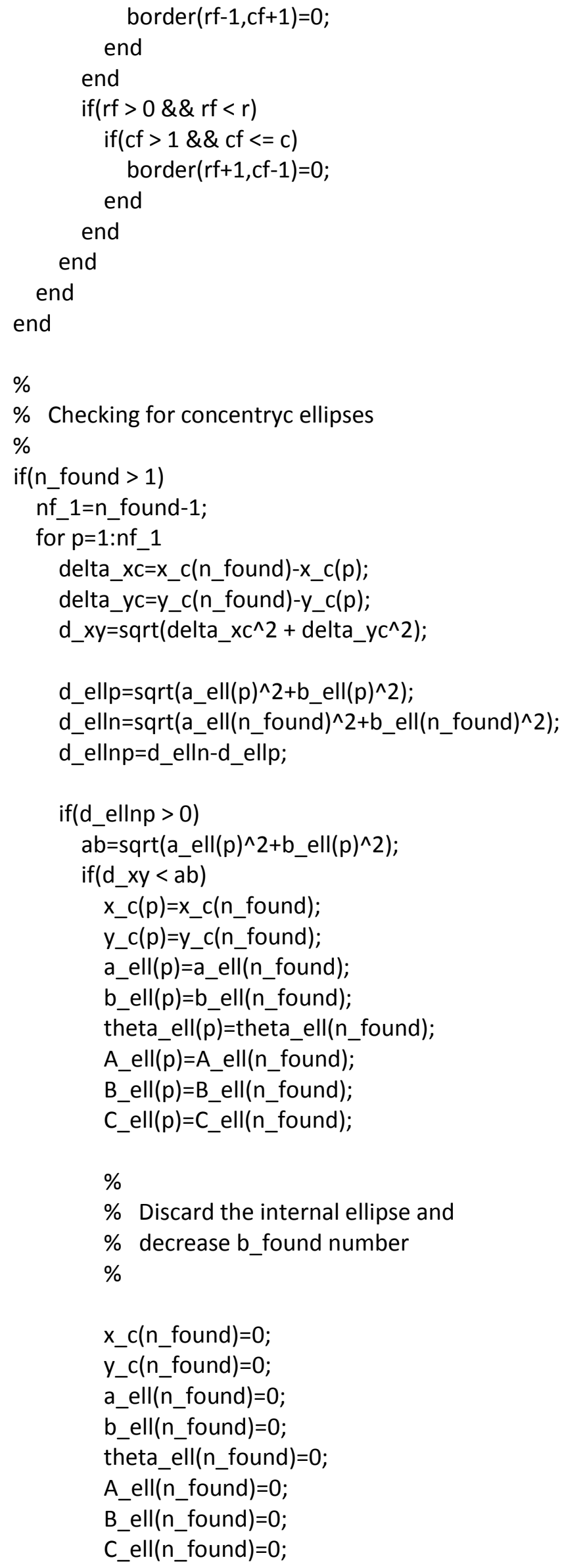




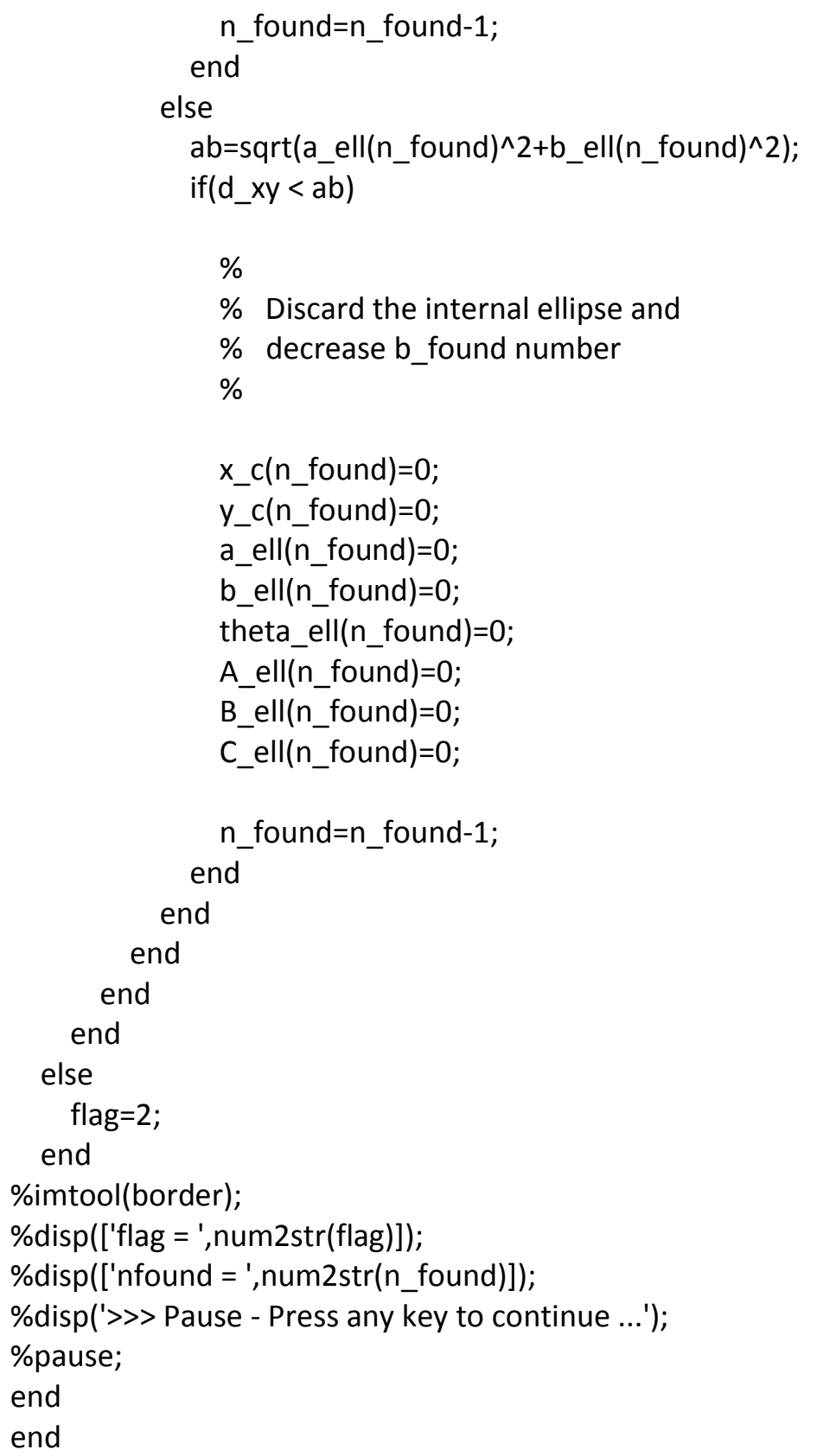

